Ighor Souza dos Santos

\title{
Projeto e Desenvolvimento de Sistema de Medição para Ensaios de Impulso de Perfuração em Isoladores
}

Dissertação de Mestrado

Dissertação apresentada como requisito parcial para obtenção do grau de Mestre pelo Programa de PósGraduação em Metrologia (Área de concentração: Metrologia para Qualidade e Inovação) da PUC-Rio.

Orientador: Prof. Carlos Roberto Hall Barbosa

Rio de Janeiro

Setembro de 2019 


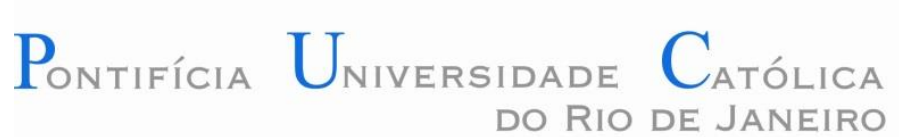

DO RIO DE JANEIRO

Ighor Souza dos Santos

\section{Projeto e Desenvolvimento de Sistema de Medição para Ensaios de Impulso de Perfuração em Isoladores}

Dissertação apresentada como requisito parcial para obtenção do grau de Mestre pelo Programa de PósGraduação em Metrologia (Área de concentração: Metrologia para Qualidade e Inovação) da PUC-Rio. Aprovada pela Comissão Examinadora abaixo.

Prof. Carlos Roberto Hall Barbosa

Orientador

Programa de Pós-graduação em Metrologia (PósMQI) Pontifícia Universidade Católica do Rio de Janeiro (PUC-Rio)

Prof. Hélio de Paiva Amorim Junior Centro de Pesquisas de Energia Elétrica - Cepel

Prof. José Franco Machado do Amaral Universidade do Estado do Rio de Janeiro

Prof. Jorge Luís Machado do Amaral Universidade do Estado do Rio de Janeiro

Rio de Janeiro, 12 de setembro de 2019 
Todos os direitos reservados. É proibida a reprodução total ou parcial do trabalho sem autorização da universidade, do autor e do orientador.

Ighor Souza dos Santos

Formado em Engenharia Elétrica pelo UniFOA, Centro Universitário de Volta Redonda, Volta Redonda, Brasil em 2016.

Ficha Catalográfica

Dos Santos, Ighor Souza

Projeto e Desenvolvimento de Sistema de Medição para Ensaios de Impulso de Perfuração em Isoladores / Ighor Souza dos Santos; Orientador: Carlos Roberto Hall Barbosa. - Rio de Janeiro: PUC, Programa de PósGraduação em Metrologia, 2019.

160 f.: il. ; $30 \mathrm{~cm}$

Dissertação (mestrado) - Pontifícia Universidade Católica do Rio de Janeiro, Programa de Pós-Graduação em Metrologia.

Inclui referências bibliográficas.

1. Metrologia - Dissertação.. 2. Ensaios elétricos. 3. Isoladores elétricos. 4. Ensaio de perfuração em isoladores. 5. Divisores de tensão. 6. Transformada de Wavelet. I. Barbosa, Carlos Roberto Hall. II. Pontifícia Universidade Católica do Rio de Janeiro. Centro Técnico Científico. Programa de Pós-Graduação em Metrologia. III. Título. 
A meus pais, Jorge Luis dos Santos e Elizabete Souza dos Santos. 


\section{Agradecimentos}

À PUC-Rio e ao Cepel, pelos auxílios concedidos, sem os quais este trabalho de mestrado não poderia ter sido realizado.

O presente trabalho foi realizado com apoio da Coordenação de Aperfeiçoamento de Pessoal de Nível Superior - Brasil (CAPES) - Código de Financiamento 001.

Ao meu orientador Prof. Dr. Carlos Roberto Hall Barbosa, pela orientação, paciência, oportunidade e todo conhecimento transmitido.

Aos meus amigos e companheiros de trabalho Luiz Carlos de Azevedo, Valdir Remilson Santos e Marcus Vinicius Barros Lopes que me motivaram e incentivaram nessa dissertação e em todo o trabalho desenvolvido no laboratório CA2, onde obtive um grande aprendizado profissionalmente e pessoalmente.

A Osmar José Fontes, responsável pelo Laboratório de Calibração CA1, por ter dado a oportunidade de me descobrir no vasto campo de conhecimento que é a Metrologia.

Ao pesquisador e amigo, Márcio Thelio Fernandes da Silva, por toda contribuição e auxílio neste trabalho. Pelo contínuo encorajamento e apoio para a conclusão deste trabalho.

Ao diretor de Laboratórios e Pesquisa Experimental (DL), Orsino Borges de Oliveira Filho, pelo grande apoio e conhecimento técnico transmitido.

Ao gerente de Departamento de Laboratório de Adrianópolis (DLA), Alberto José Salomon Junqueira por todo apoio institucional e pelo incentivo à pesquisa.

Aos colaboradores da oficina mecânica do Cepel, e também do Laboratório de Diagnóstico em Equipamentos e Instalações Elétricas (Labdig), pela excelência técnica e auxílio oferecido.

A todos que de forma direta ou indireta contribuíram para este trabalho. 


\section{Resumo}

Dos Santos, Ighor Souza; Barbosa, Carlos Roberto Hall (Orientador) Projeto e Desenvolvimento de Sistema de Medição para Ensaios de Impulso de Perfuração em Isoladores. Rio de Janeiro, 2019. 160p. Dissertação de Mestrado - Programa de Pós graduação em Metrologia (Área de concentração: Metrologia para Qualidade e Inovação), Pontifícia Universidade Católica do Rio de Janeiro.

O ensaio de impulso para perfuração de isoladores é um ensaio normalizado descrito na IEC 61211:2004 e é fundamental para verificar em laboratório a qualidade de isoladores de vidro ou porcelana utilizados no sistema elétrico de potência. A norma IEC 60060-2:2010 recomenda que a calibração dos Sistemas de Medição utilizados em ensaios para Perfuração de Isoladores (SMIP) deve ser realizada por comparação com um padrão. Contudo, embora o ensaio de perfuração seja normalizado, ainda não existem padrões para rastrear esse sistema de medição na maioria dos institutos de pesquisas em âmbito global. Quantificar a amplitude de um impulso de perfuração, com todas as garantias metrológicas, não é uma tarefa trivial, por se tratar de um sinal impulsivo com amplitude de centenas de kilovolts e durações da ordem de 200 ns. Além disso, divisores de tensão com alto desempenho dinâmico para essa aplicação especifica também não estão disponíveis comercialmente. Deste modo, o objetivo desta dissertação foi projetar e desenvolver um SMIP. O divisor de tensão, integrante do sistema de medição, foi construído a fim de garantir uma mínima indutância e um alto desempenho dinâmico. Também foi desenvolvido um filtro para a remoção de interferências eletromagnéticas baseado na transformada wavelet, integrado a um software que controla aquisição, condicionamento do sinal, determinação e análise dos parâmetros do impulso de perfuração. O desempenho do sistema de medição foi avaliado em baixa tensão e em alta tensão, bem como foi estimada sua incerteza de medição, sendo então capaz de atender às exigências normativas e metrológicas do Laboratório de Referência em medição do Cepel.

\section{Palavras-chave}

Metrologia; ensaios elétricos; isoladores elétricos; ensaio de perfuração em isoladores; divisores de tensão; transformada de wavelet. 


\section{Abstract}

Dos Santos, Ighor Souza; Barbosa, Carlos Roberto Hall (Advisor) Design and Development of Measurement System for Impulse Voltage Puncture Testing on Insulators. Rio de Janeiro, 2019. 160p. Dissertação de Mestrado - Programa de Pós graduação em Metrologia (Área de concentração: Metrologia para Qualidade e Inovação), Pontifícia Universidade Católica do Rio de Janeiro.

Impulse testing for puncture insulator is a standardized test described in IEC 61211:2004 and is essential for laboratory testing of the quality of glass or porcelain insulators used in the electrical power system. IEC 60060-2:2010 recommends that calibration of Measurement Systems used in Impulse Puncture Test on insulators (IPMS) should be performed by comparison against a standard. However, although the impulse puncture testing is standardized, there are still no standards for traceability of this measurement system at most research institutes globally. Quantifying the amplitude of an impulse puncture test, with all metrological guarantees, is not a trivial task, since it is an impulsive signal with amplitude of hundreds of kilovolts and durations of the order of 200 ns. In addition, high dynamic performance voltage dividers for this specific application are not commercially available either. Thus, the objective of this dissertation was to design and develop an IPMS. The voltage divider, which is part of the measuring system, is designed to ensure minimum inductance and high dynamic performance. A filter for electromagnetic interference removal based on the wavelet transform was also developed, integrated with software that controls acquisition, signal conditioning, determination and analysis of the impulse puncture testing parameters. The performance of the measuring system was evaluated at low voltage and high voltage, as well as its measurement uncertainty was estimated, being able to meet the normative and metrological requirements of the Cepel's Measurement Reference Laboratory.

\section{Keywords}

Metrology; electrical testing; electrical insulators; puncture testing on insulators; voltage dividers; wavelet transform. 


\section{Sumário}

1 Introdução 18

1.1. Contextualização 23

1.2. Motivação 24

1.3. Objetivos: geral e específicos 25

1.4. Estrutura da Dissertação 26

2 Ensaio de Perfuração sob Impulso em Isoladores 28

2.1. Sobretensões e formas de impulso padronizadas 29

2.1.1. Terminologia e definições básicas 29

2.1.2. Classificações das solicitações de tensão 31

2.1.3. Formas de onda normalizada das tensões 32

2.2. Isoladores de linhas aéreas 33

2.2.1. Classificação de isoladores 34

2.2.2. Classificação dos ensaios para isoladores 34

2.2.3. Material dos isoladores 35

2.2.4. Exemplo típico de um isolador de disco 36

2.2.5. Descargas disruptivas em isoladores de vidro ou cerâmica 36

2.3. Ensaio de perfuração sob impulso em isoladores de acordo com a norma IEC 61211

2.3.1. Arranjo de ensaio 40

2.3.2. Gerador de impulso $\quad 41$

2.3.3. Tensão de ensaio 44

2.3.4. Sistema de medição 45

2.4. Fatores relacionados ao sistema de medição 50

2.5. Cadeia de rastreabilidade para sistemas de medição 53

3 Divisor resistivo para ensaios de impulso de perfuração em isoladores 55

3.1. Projeto do divisor $\quad 55$

3.1.1. Características físicas $\quad 55$ 
3.1.2. Cálculos para determinação da impedância de alta tensão

3.1.3. Determinação da impedância de baixa tensão

3.2. Construção do resistor de alta tensão

3.3. Construção do resistor de baixa tensão

68

3.3.1. Análise das unidades secundárias

4 Processamento de sinais em ensaios de impulso de perfuração em isoladores

4.1. Descrição do problema

4.2. Very Fast Transients 77

4.2.1. Forma de onda experimental 77

4.2.2. Forma de onda simulada 78

4.3. Transformada Wavelet 79

4.4. Remoção do ruído do impulso de perfuração em isoladores por meio da análise wavelet multi-resolução 84

4.5. Validação, software e comparação em alta tensão 90

4.5.1. Seleção da wavelet mãe 90

4.5.2. Software desenvolvido para condicionamento do sinal 94

4.5.3. Comparação interlaboratorial em alta tensão 95

5 Sistema de medição para ensaios de impulso de perfuração em isoladores 100

5.1. Avaliação de desempenho do sistema de medição 100

5.1.1. Caracterização em baixa tensão 100

5.1.1.1. Medição dos componentes 101

5.1.1.2. Determinação do fator de escala em baixa tensão 103

5.1.2. Avaliação do desempenho dinâmico 104

5.1.3. Avaliação e análise da resposta em frequência 109

5.2. Calibração do sistema de medição para ensaios de impulso de perfuração em isoladores 116

5.2.1. Determinação do fator de escala 117

5.2.1.1. Cuidados na realização da medição de impulsos de perfuração 119

5.2.1.2. Verificação do nível de interferência 120 
5.2.2. Comparação em alta tensão para determinação do fator de escala 123

5.2.3. Avaliação da incerteza de medição 126

6 Discussão e conclusão 128

7 Referências bibliográficas 131

Anexo 1 - Artigo XXV SNPTEE SEMINÁRIO NACIONAL

DE PRODUÇÃO E TRANSMISSÃO DE ENERGIA ELÉTRICA

137

Anexo 2 - Artigo XIII Congresso Internacional de Metrologia Elétrica (SEMETRO)

Anexo 3 - Artigo Measurement - Journal of the International 


\section{Lista de figuras}

Figura 1: Forma de onda de impulso atmosférico pleno [9]. 29

Figura 2: Tensão de impulso atmosférico cortado na frente [9]. 30

Figura 3: Classes e formas das solicitações de tensão, conforme a norma IEC 60071-1.

Figura 4: Formas de onda normalizadas para os diferentes tipos de solicitações de tensão, conforme a norma IEC 60071-1. 32

Figura 5: Composição típica de um isolador de disco. 36

Figura 6: Descarga disruptiva e perfuração em uma unidade de isolador.37

Figura 7: Curva tensão x tempo para uma unidade de isolador [19]. $\quad 38$

Figura 8: Arranjo de ensaio para isoladores tipo disco. 41

Figura 9: Circuito equivalente de um gerador de impulso de um único estágio. [26]

Figura 10: Circuito do gerador de Marx de múltiplos estágios.

(a) Uma topologia possível. (b) Componentes ativos durante a carga.

(c) Componentes ativos durante a descarga.

Figura 11:Carregamento e descarga do gerador de impulso atmosférico.43 Figura 12: Geração do impulso de perfuração. (a) Circuito equivalente.

(b) Diagrama de potencial.

Figura 13: Impulso de perfuração aplicado, cortado pelo isolador na tensão de ensaio de acordo com a IEC 61211.

Figura 14: Relação entre a tensão de ensaio e $U_{50}$ de acordo com a norma IEC 61211:2004 [7].

Figura 15: Diferentes formas construtivas de divisores para diferentes aplicações em laboratórios de ensaios de alta tensão

Figura 16: Sistema de medição para impulso. a) Divisor resistivo de baixa impedância. b) cabo coaxial de medição. c) Registrador digital ou osciloscópio [30].

Figura 17: Exemplo de uma configuração recomendada de um arranjo de ensaio compacto incluindo objeto e divisor.

Figura 18: Circuito RC. (a) Circuito com degrau unitário $s(t)$ na entrada. 
(b) Saída da resposta ao degrau $g(t)$.

Figura 19: Efeito da largura de banda (tempo de resposta) na medição. 51

Figura 20: Resposta ao degrau com BW em $500 \mathrm{MHz}$ e em $20 \mathrm{MHz}$, respectivamente. 52

Figura 21: Parâmetros da resposta ao degrau com BW em $500 \mathrm{MHz} . \quad 53$

Figura 22: Parâmetros da resposta ao degrau com BW em 20 MHz. $\quad 53$

Figura 24: Tarugo de PVC. 56

Figura 25: Fio isolante de fibra óptica. 56

Figura 26: Fio resistivo. 56

Figura 27: Tubo termo retrátil. 57

Figura 28: Tubo de acrílico. $\quad 57$

Figura 29: Circuito de geração e medição apresentando cada componente do sistema. $\quad 60$

Figura 30:a)Atenuador resistivo. b) impedância de casamento. $\quad 60$

Figura 31: Método de enrolamento tipo Wenner [6]. 61

Figura 32: Non-Reactive Wenner Type Resistor. National Institute of

Standards and Technology Digital Collections, Gaithersburg, MD 20899.62

Figura 33: Construção da primeira camada da resistência de alta tensão.

62

Figura 34: Medição do resistor de alta tensão por ponte RLC e multímetro.

Figura 35: Curva de impedância e ângulo pela frequência da primeira camada do resistor de alta tensão.

Figura 36: Curva de resistência e indutância pela frequência da primeira camada do resistor de alta tensão.

Figura 37: Curva de impedância e ângulo pela frequência da segunda camada do resistor de alta tensão.

Figura 38: Curva de resistência e indutância pela frequência da segunda camada do resistor de alta tensão.

Figura 39: Curva de impedância e ângulo pela frequência da terceira camada do resistor de alta tensão.

Figura 40: Curva de resistência e indutância pela frequência da terceira camada do resistor de alta tensão. 
Figura 41: Curva de impedância e ângulo pela frequência da quarta camada do resistor de alta tensão.

Figura 42: Curva de resistência e indutância pela frequência da quarta camada do resistor de alta tensão.

Figura 43: Leitura da resistência e da indutância da primeira camada do resistor de alta tensão.

Figura 44: Leitura da resistência e da indutância da segunda camada do resistor de alta tensão.

Figura 45: Leitura da resistência e da indutância da terceira camada do resistor de alta tensão.

Figura 46: Estrutura da unidade secundaria do divisor composta por quatro camadas de enrolamento.

Figura 47: Valor ôhmico da unidade de baixa tensão do divisor. $\quad 69$

Figura 48: Resistor de fabricação industrial caddock.

Figura 49: Curva da indutância em função da frequência das unidades secundárias.

70

Figura 50: Componentes da montagem do divisor de alta tensão.

Figura 51: Configuração recomendada para análise do desempenho dinâmico do divisor de alta tensão.

Figura 52: Resposta ao degrau do resistor de baixa tensão com 1 camada.

Figura 53: Resposta ao degrau do resistor de baixa tensão com 2 camadas.

Figura 54: Resposta ao degrau do resistor de baixa tensão com 3 camadas.

Figura 55: Resposta ao degrau do resistor de baixa tensão com 4 camadas.

Figura 56: Resposta ao degrau do resistor de baixa tensão com o resistor caddock.

Figura 57: Curva da resistência em função da temperatura do resistor CADDOCK.

Figura 58: Curva da resistência em função da temperatura do fio resistivo ISAOHM. 
Figura 59: Impulso típico do ensaio de perfuração em isoladores.

Figura 60: Forma de onda típica de ensaios de impulso de perfuração.

a) No domínio do tempo e b) Sua decomposição no domínio da frequência.

Figura 61: Formas de onda simuladas como referência. a) Forma de onda teórica padrão. b) Forma de onda teórica simulada e ruído c) Forma de onda teórica simulada adicionada ao ruído e d) Forma de onda teórica simulada no domínio da frequência.

Figura 62: Exemplo da análise da transformada de Fourier.

Figura 63: Exemplo da transformada de Fourier de tempo curto.

Figura 64: Janelamento de uma STFT (Short-Time Fourier Transform). 81

Figura 65: Exemplo de um janelamento estreito.

82

Figura 66: Exemplo de um janelamento largo.

82

Figura 67: Exemplo de uma wavelet mãe $\psi(\mathrm{t})$, da família conhecida como "coiflet".

Figura 68: Processo de deslocamento da wavelet (shifting).

Figura 69: Análise do janelamento da transformada wavelet.

Figura 70: Processo de filtragem de um sinal considerando apenas um nível.

Figura 71: Diagrama de múltiplos níveis de decomposição.

Figura 72: Faixas de frequências correspondentes a cada componente de aproximação e detalhes de acordo com o nível de decomposição. 86 Figura 73: Espectro de frequências do sinal digitalizado referente a um ensaio de perfuração e limite superior de frequência do coeficiente de aproximação A1.

Figura 74: Distribuição de energia contida nos coeficientes de aproximação por nível para cada wavelet.

Figura 75: Coeficientes de aproximação a2, a5 e a7 da decomposição do sinal utilizando uma wavelet da família Daubechies.

Figura 76: Erro percentual no valor de crista entre a forma de onda padrão simulada ideal e a forma de onda obtida após o processo de filtragem para cada wavelet-mãe testada.

Figura 77: Formas de onda. a) corrompida pelo ruído, apresentada 
anteriormente na Figura 61c e, b) após o processo de filtragem pela wavelet mãe selecionada, juntamente com o sinal simulado ideal da Figura 61a.

Figura 78: Ruído removido pelo filtro. a) interferência adicionada ao sinal ideal. b) Ruído removido através da filtragem wavelet.

c) Diferença entre os sinais “a)" e "b)".

Figura 79: Comparação entre o sinal simulado ideal e o sinal após o processamento.

Figura 80: Diagrama de concepção do software RAPIT. 94

Figura 81: Interface com o usuário do software RAPIT. 95

Figura 82: Arranjo de ensaio no hall de alta tensão para comparação entre SMIP.

Figura 83: Instrumentos e software do Cepel e VTT utilizados na comparação.

Figura 84: Comparação entre os resultados medidos pelo SMIP do VTT-Mikes e Cepel.

Figura 85: Comparação entre resultados medidos pelos SMIP do VTT-Mikes e Cepel, após o processamento.

Figura 86: Diagrama elétrico do sistema de medição e sistema de aquisição de sinais.

Figura 87: Configuração da medição dos componentes a 4 fios.

Figura 88: Diagrama elétrico esquemático da medição a 4 fios.

Figura 89: Medição da unidade secundária $R_{2}$ mais cabo e atenuador. 103

Figura 90: Medição do sistema completo no laboratório de calibração. 103

Figura 91: Medição do atenuador resistivo no laboratório de calibração.104 Figura 92: Arranjo da avaliação do desempenho do divisor de tensão. 105 Figura 93: Resultado da resposta ao degrau do divisor de tensão. 106 Figura 94: Arranjo da avaliação do desempenho do atenuador resistivo.

Figura 95: Resultado da resposta ao degrau do atenuador resistivo. 107 Figura 96: Avaliação do desempenho do divisor de tensão na diagonal.107 Figura 97: Resposta ao degrau do divisor de tensão na diagonal. 108

Figura 98: Avaliação do desempenho do divisor de tensão na 
horizontal.

Figura 99: Resposta ao degrau do divisor de tensão na horizontal. 108

Figura 100: Transferência de tensão com toroide e na vertical. 110

Figura 101: Transferência de tensão com e sem toroide e na vertical. 110

Figura 102: Transferência de tensão com toroide e na diagonal.

Figura 103: Transferência de tensão com e sem toroide e na diagonal. 111

Figura 104: Transferência de tensão com toroide e na horizontal.

Figura 105: Transferência de tensão com e sem toroide e na horizontal.

Figura 106: Medição da impedância, com cabo e na posição vertical. 113

Figura 107: Medição da impedância, sem cabo e na posição vertical. 113

Figura 108: Medição da impedância, com cabo e na posição diagonal. 114

Figura 109: Medição da impedância, sem cabo e na posição diagonal. 114

Figura 110: Medição da impedância, com cabo e na posição horizontal.

Figura 111: Medição da impedância, sem cabo e na posição horizontal.

Figura 112: Diagrama simplificado para calibração de SMIP.

Figura 113: Arranjo para calibração de SMIP em alta tensão.

Figura 114: Gerador de impulso ajustado para IAP $(1,2 / 50 \mu \mathrm{s})$.

Figura 115: Resultado da primeira medição em alta tensão.

Figura 116: Blindagem extra realizada no cabo de medição.

Figura 117: Blindagem extra aterrada ao divisor e passando por duto subterrâneo.

Figura 118: Caixa de curto-circuito para a realização do ensaio de interferência.

Figura 119: Registro da interferência medida no osciloscópio.

Figura 120: Medição do impulso de perfuração após troca da unidade secundária.

Figura 121: Aplicação do impulso de perfuração no isolador sob ensaio.

Figura 122: Tela principal de análise do programa RAPIT.

Figura 123: Comunicação realizada entre o RAPIT e os osciloscópios. 124 


\section{Lista de tabelas}

Tabela 1: Resultados da comparação antes da remoção do ruído. $\quad 98$

Tabela 2: Resultados da comparação após o processo de filtragem. $\quad 99$

Tabela 3: Valores dos componentes resistivos medidos e fatores de escala.

Tabela 4: Fatores de escala determinados em baixa tensão em corrente contínua.

Tabela 5: Descrição de cada tipo de configuração de ensaio avaliada. 109 Tabela 6: Resultados obtidos por meio da resposta em frequência do sistema de medição.

Tabela 7: Resultados da determinação do FE em alta tensão.

Tabela 8: Resumo de diferentes métodos para determinação do FE.

Tabela 9: Cálculo da incerteza para a calibração do FE do SMIP em corrente contínua.

Tabela 10: Cálculo da incerteza para a calibração do FE do SMIP com impulso de perfuração em alta tensão. 


\section{Lista de abreviaturas e símbolos}

Cepel - $\quad$ - Centro de Pesquisas de Energia Elétrica

SIN - Sistema Interligado Nacional

CA1 - Laboratório de Calibração

CA2 - Laboratório de Referência em Medição de Alta Tensão

ABNT - Associação Brasileira de Normas Técnicas

NBR - Norma Brasileira

IEC - International Electrotechnical Commission

SM - Sistemas de Medição

CA - Corrente Alternada

CC - Corrente Contínua

EPE - Empresa de Pesquisa Energética

INM - $\quad$ Institutos Nacionais de Metrologia

CIGRÉ - Conseil international des grands réseaux électriques

$T_{\alpha} \quad$ - Tempo de resposta parcial

$U_{n} \quad$ - Tensão nominal de um sistema

$U_{s} \quad$ - Tensão máxima do sistema

RMS - Raiz do valor quadrático médio

IM - - Impulso de manobra

IAP - Impulso atmosférico pleno

$T_{1} \quad-\quad$ Tempo de frente

$\mathrm{O}_{1} \quad$ - Origem virtual

$T_{c} \quad$ - Tensão de impulso atmosférico cortado

$T_{p} \quad$ - Tempo até a crista

$T_{2} \quad$ - Tempo ate a cauda

$f$ - Frequência 


\begin{tabular}{|c|c|c|}
\hline VFT & - & Very Fast Transient \\
\hline UV & - & Ultravioleta \\
\hline $\mathrm{NCI}$ & - & Non Ceramic Insulator \\
\hline EPR & - & Etileno-Propileno \\
\hline EPDM & - & Etileno-Propileno-Dieno \\
\hline IPT & - & Impulse Puncture Test \\
\hline$U_{50}$ & - & Tensão com $50 \%$ de probabilidade de descarga \\
\hline SMA & - & Sistema de Medição Aprovado \\
\hline$k$ & - & Fator de abrangência \\
\hline$G(t)$ & - & Resposta ao degrau de um sistema de medição \\
\hline$G(s)$ & - & Função de transferência da resposta ao degrau \\
\hline$\tau$ & - & Constante de tempo \\
\hline$T_{a}$ & - & Tempo de subida da resposta ao degrau \\
\hline BW & - & Bandwidth (largura de banda) \\
\hline$T_{N}$ & - & Tempo de resposta experimental \\
\hline$T_{R E}$ & - & Tempo de resposta residual \\
\hline$t_{s}$ & - & Tempo de estabilização \\
\hline$T_{0}$ & - & Tempo de distorção inicial \\
\hline SI & - & Sistema Internacional de Unidades \\
\hline BIPM & - & Bureau international des poids et mesures \\
\hline $\mathrm{PVC}$ & - & Policloreto de vinila \\
\hline$R_{T}$ & - & Resistência total \\
\hline FE & - & Fator de Escala \\
\hline$Z_{c}$ & - & Impedância de casamento \\
\hline NIST & - & National Institute of Standards and Technology \\
\hline STERAL & - & Step Response Analysis \\
\hline SMIP & - & Sistema de Medição de Impulso de Perfuração \\
\hline FFT & - & Transformada rápida de Fourier \\
\hline DFT & - & Transformada discreta de Fourier \\
\hline$\omega$ & - & Frequência angular \\
\hline
\end{tabular}




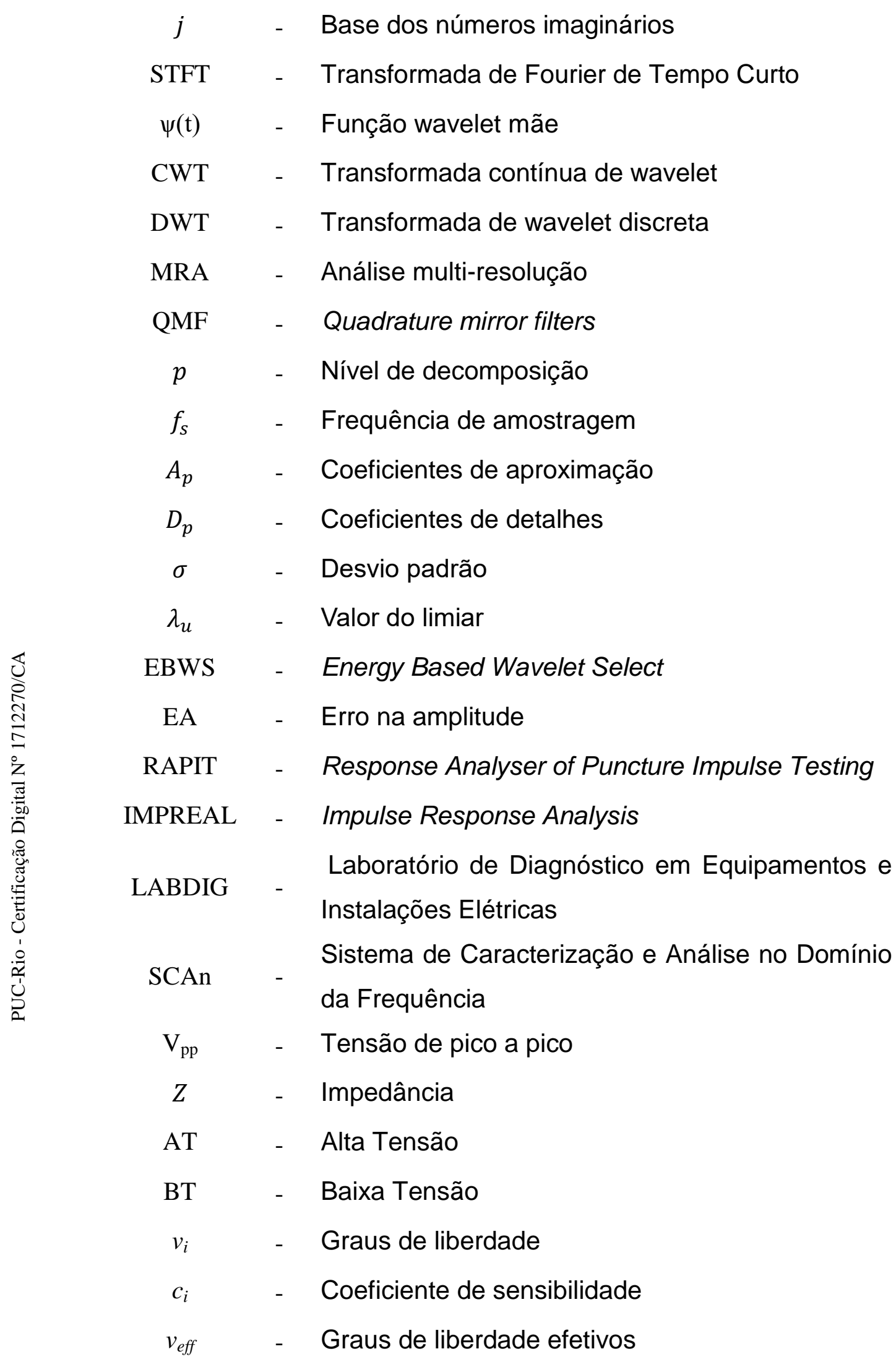




\section{Introdução}

O Centro de Pesquisa de Energia Elétrica (Cepel) completou 45 anos em 2019 e está diretamente relacionado ao setor elétrico brasileiro, realizando pesquisas estratégicas e essenciais para o setor em diversas áreas da engenharia e em especial na engenharia elétrica, para ensaios de equipamentos de baixa, média, alta tensão e ultra alta tensão, sendo uma referência em pesquisas, calibração e ensaios em alta tensão no Brasil e na América do Sul. Evoluiu durante anos neste segmento, graças ao seu empenho e competência em criar soluções tecnológicas específicas para atender às peculiaridades do Sistema Interligado Nacional (SIN) que engloba o parque gerador nacional, com predominância de usinas hidrelétricas, e da malha de transmissão que, para suprir as necessidades de um país com dimensões continentais, exige esforços e competências em relação à manutenção, segurança e confiabilidade desta rede. Além dos diferentes ensaios realizados para pesquisas em diversas áreas da energia elétrica, o Cepel é conhecido também como referência quando o assunto é calibração de instrumentos e sistemas de medição. Os laboratórios de calibração do Cepel, CA1 e CA2, situados na unidade Adrianópolis, dispõem de capacidade técnica e infraestrutura para atuar na calibração de instrumentos e sistemas de medição utilizados em ensaios de alta tensão para corrente alternada (CA) e corrente contínua (CC), impulso atmosférico pleno (IAP), cortado (IAC) e impulso de manobra (IM) [1, 2].

Um campo da metrologia que vem merecendo uma maior atenção e novas pesquisas é o associado às técnicas de medição em ensaios de alta tensão, mas a grande maioria de laboratórios de pesquisa/ensaios em equipamentos para alta tensão no Brasil não possuem padrões e tampouco são acreditados de acordo com a norma ABNT NBR IEC 17025:2017 [3]. Atualmente existem poucos laboratórios acreditados para calibração de Sistemas de Medição (SM) utilizados em ensaios com alta tensão CA, CC e só um acreditado, no país, para impulsos atmosféricos de tensão, que é o laboratório CA2 do Cepel. 
A construção de novas linhas de transmissão é necessária e fundamental para o suprimento de energia aos grandes centros consumidores, cuja demanda tem crescimento anual em torno de $5 \%$ [4], segundo a Empresa de Pesquisa Energética (EPE). Um dos equipamentos de maior importância em linhas aéreas para transmissão em alta tensão, seja em CA ou CC, é o isolador, que pode ser construído por materiais do tipo vidro temperado, porcelana ou polimérico. A importância dos isoladores está associada diretamente à confiabilidade no suprimento de energia, e uma importante ferramenta para verificar o desempenho de isoladores em condições de uso em laboratório é o ensaio de perfuração de isoladores, como descrito na norma IEC 61211:2004 - "Insulators of ceramic material or glass for overhead lines with a nominal voltage greater than $1000 \mathrm{~V}-$ Impulse puncture testing in air" [5].

Alguns Institutos Nacionais de Metrologia (INM) e Centros de pesquisas nacionais e estrangeiros estão realizando atividades no Grupo de trabalho D1.60 do Cigré ${ }^{1}$ denominado "Traceable measurement techniques for very fast transients", com o objetivo de definir metodologias e procedimentos para calibração e rastreabilidade desses SM. Sem rastreabilidade, é um desafio avaliar e garantir a reprodutibilidade dos resultados dos ensaios com outros laboratórios de alta tensão, algo que é extremamente recomendado para um centro de pesquisas como o Cepel, que possui um laboratório de referência em medição e necessita de rastreabilidade em seus sistemas de medição.

Esse fato é de suma importância não só científica, pois o país carece de padrões e rastreabilidade em alguns ensaios em alta tensão, especificamente aqueles associados à perfuração de isoladores. Sem padrões e rastreabilidade a indústria nacional de fabricantes de isoladores não pode garantir a confiabilidade $\mathrm{e}$ qualidade dos isoladores para esse ensaio em especial, fatores que podem influenciar negativamente na competitividade desses produtos no mercado nacional e internacional e aumentar o risco para o suprimento de energia elétrica à sociedade.

${ }^{1}$ O Conselho Internacional de Grandes Sistemas Elétricos (Conseil International des Grands Réseaux Électriques, CIGRÉ) é uma organização global no campo da eletricidade de alta tensão. Foi fundada na França em 1921, e sua secretaria-geral está em Paris. Ele lida com os aspectos técnicos e económicos de redes, mas também com os aspectos ambientais e de regulamentação. 


\section{1.}

\section{Contextualização}

A realização de ensaios em alta tensão necessita de precisão nos parâmetros medidos para que as especificações das normas possam ser cumpridas de fato. Em geral, para tensões superiores a $1000 \mathrm{~V}$, não se consegue realizar uma medição diretamente, sendo necessário algum dispositivo de conversão para diminuir a tensão a um nível que se consiga medir por meio de instrumentos convencionais. Além disso, divisores de tensão são dispositivos amplamente utilizados em laboratórios de alta tensão, por possuírem algumas vantagens como bom desempenho dinâmico, versatilidade, serem práticos e, se bem construídos, apresentarem baixa incerteza de medição.

Pesquisas e considerações sobre particularidades no desempenho de um sistema de medição para impulsos de perfuração, especialmente para características de desempenho dinâmico dos divisores de tensão, são realizadas há décadas [6]. Estudos recentes realizados no Cepel confirmam que o parâmetro de tempo de resposta parcial $T_{\alpha}$ é um dos principais requisitos para adequação desses divisores de tensão e que a calibração de sistemas de medição para impulsos de perfuração por comparação é tecnicamente viável para fins de rastreabilidade [7]. A construção de um padrão para o ensaio de perfuração de isoladores é de grande importância, visto que hoje não existe um padrão em nível nacional. A construção desse padrão deve obedecer aos requisitos descritos na norma IEC 61211:2004 [4], que são requisitos especiais para avaliação de divisores utilizados em ensaios de perfuração de isoladores, sendo que o fator de escala do divisor deve possuir uma incerteza $\leq 2 \%$, um tempo de resposta parcial $\leq 3 \mathrm{~ns}$ e um tempo de resposta experimental $\leq 5$ ns. A incerteza na amplitude da tensão para o sistema completo de medição (Divisor/cabo/casador/digitalizador) deve ser $\leq 5 \%$. Vale ressaltar que esse impulso tem uma característica muito especial, e se difere em muito das características de um impulso atmosférico pleno, pois sua transição entre o zero e seu valor máximo da tensão pode chegar a $600 \mathrm{kV}$ e ocorre aproximadamente em um intervalo de tempo entre $100 \mathrm{~ns}$ e $200 \mathrm{~ns}$.

Em função das características do ensaio de perfuração, é comum surgirem interferências de alta frequência sobrepostas ao sinal de impulso. Assim, além de 
um excelente desempenho dinâmico do divisor de tensão, como requerido pela norma IEC 61211:2004 [4], também deve fazer parte do sistema de medição um filtro digital, projetado com técnicas de processamento de sinais específicas, para o condicionamento do sinal e redução dessas interferências de altas frequências que podem vir a comprometer os resultados e a análise do isolador sob ensaio.

\section{2. \\ Motivação}

Devido à carência de informações referentes a ensaios de impulso de perfuração em isoladores elétricos de alta tensão realizados em laboratório, e que envolvem geração e medição de impulsos de tensão de frente muito rápida, se tornou um desafio muito grande possuir o conhecimento necessário das técnicas de medição específicas para este ensaio. Assim, a motivação para essa pesquisa de mestrado está em contribuir com o suprimento de parte dessa necessidade de informações.

Os resultados desta dissertação poderão trazer diversos benefícios para as partes interessadas, como garantir uma maior confiabilidade na isolação do sistema elétrico, prover as condições técnicas de garantir a rastreabilidade desse ensaio no país e reduzir os riscos de fornecimento de energia, visto que a utilização de isoladores é fundamental para o sistema elétrico de potência, sendo que o desempenho do isolador pode comprometer todo o fornecimento e a proteção do sistema elétrico. Também será possível proporcionar suporte à compatibilidade entre diferentes laboratórios de ensaio, possibilitando medições com maior qualidade por meio dos serviços de calibração, proporcionando também uma maior garantia na qualidade dos resultados dos ensaios. Finalmente, poderá ser uma contribuição para a próxima revisão da norma IEC 61211:2004 [4], além de permitir possíveis intercomparações dos laboratórios do Cepel com outros laboratórios internacionais. 


\section{3.}

\section{Objetivos: geral e específicos}

O objetivo geral desta dissertação é desenvolver um sistema de medição para impulsos de perfuração em isoladores, que seja rastreável metrologicamente e atenda aos requisitos técnicos estabelecidos na norma IEC 612111:2004 [4].

Para atingir este objetivo geral, definem-se os seguintes objetivos específicos:

- Identificar e analisar estudos empíricos sobre ensaios de perfuração em isoladores, que considerem os requisitos da norma IEC 61211:2004 [4].

- Definir os requisitos de projeto e parâmetros de desempenho que deverão ser considerados na construção de um padrão rastreável de medição de impulsos de tensão até $600 \mathrm{kV}$ para ensaios de perfuração de isoladores.

- Projetar e construir um divisor de tensão resistivo de baixa impedância e mínima indutância, para ensaios de impulsos de tensão até $600 \mathrm{kV}$ em perfuração de isoladores com base em requisitos técnicos de projeto específicos.

- Realizar as medições de resistência, indutância, resposta em frequência e avaliar o seu desempenho dinâmico. O divisor de tensão será parte de um SM completo, composto ainda por um cabo de transmissão do sinal, atenuadores, casadores de impedância e um digitalizador.

- Desenvolver um software em LabVIEW para a aquisição, condicionamento do sinal medido, análise e avaliação dos parâmetros de ensaio, que também fará parte do sistema de medição.

- Realizar uma calibração em alta tensão do sistema de medição desenvolvido para a determinação do seu fator de escala e realizar a sua estimativa de incerteza. 


\section{4. \\ Estrutura da Dissertação}

Esta dissertação de mestrado está estruturada com base nos seguintes 6 capítulos, que abordam toda a sistemática e desafios encontrados na metrologia envolvendo sistemas de medição para impulsos de perfuração em isoladores, suprindo as lacunas da literatura científica, contribuindo para aspectos de segurança do sistema elétrico de potência, a operadores do sistema elétrico e à comunidade científica por meio das investigações, informações e dados obtidos ao longo de toda a pesquisa.

Este Capítulo 1 contém Introdução, contexto, motivação, objetivo, e estrutura da dissertação.

No Capítulo 2 é abordado o ensaio de perfuração de isoladores de forma geral e de acordo com a norma IEC 61211:2004 [4], assim como também são apresentados os requisitos do ensaio, características e aspectos construtivos dos isoladores. Também são descritos os requisitos que os sistemas de medição devem possuir para a realização deste ensaio.

No Capítulo 3 são apresentados o projeto e os aspectos construtivos do divisor de tensão resistivo de baixa impedância e mínima indutância para ensaios de perfuração em isoladores sob impulso, metodologias utilizadas e também a caracterização do divisor em baixa tensão. Uma avaliação do comportamento dinâmico do conjunto divisor/atenuador pela resposta ao degrau unitário e cálculo do parâmetro $T_{\alpha}$ também é apresentada neste capitulo.

No Capítulo 4 são abordados conceitos sobre processamento de sinais aplicados a ensaios de perfuração em isoladores sob impulso e é descrito o procedimento para desenvolvimento do filtro utilizando a transformada de wavelet, apresentando a teoria envolvida no processo de análise do sinal, além da validação do filtro e métodos de seleção da wavelet mãe.

No Capítulo 5 é descrito o sistema de medição completo para ensaios de impulso de perfuração, e é realizada a avaliação em alta tensão para determinar o fator de escala e verificar a linearidade do sistema de medição em alta tensão, composto pelo divisor, cabo, atenuador e digitalizador, em conjunto com o software. Também são apresentados o procedimento e cálculo da incerteza do sistema de medição. 
Por último, no Capítulo 6 são relatadas as conclusões, discussões e trabalhos futuros.

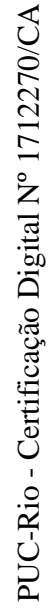




\section{2 \\ Ensaio de Perfuração sob Impulso em Isoladores}

Isoladores em linhas de transmissão sofrem frequentes solicitações por esforço excessivo causado pela própria tensão nominal do sistema, sobretensões de baixa frequência e sobretensões transitórias. Para uma operação confiável do sistema de transmissão, os isoladores instalados devem ser capazes de resistir a essas solicitações, que podem se manifestar de todas as formas, ou seja, elétricas, mecânicas, térmicas e ambientais. No caso de uma sobretensão, o isolador pode sofrer uma descarga disruptiva (flash-over) com a obrigação adicional de suportar a descarga parcialmente ou totalmente, de modo a garantir a continuidade do fornecimento de energia. Por esse motivo, os sistemas de transmissão são projetados com certa tolerância a falhas levando em consideração a economia e a segurança.

Dessa forma, o tipo e a qualidade dos isoladores desempenham um papel de grande importância para o sistema elétrico de potência. Se o isolador não for resistente o suficiente a sobretensões ou flash-overs parciais/plenos, ele possivelmente será perfurado e também ocorrerá um curto-circuito entre as partes aterradas e ativas por meio de um canal ionizante através do material de isolamento. Isso pode resultar em uma interrupção do sistema de transmissão se houver apenas um isolador entre a linha e a terra. E, no caso de uma cadeia de isoladores, a perfuração de uma ou mais unidades resultaria na diminuição da resistência de isolamento total. Este é o motivo pelo qual unidades de isoladores individuais são substituídas em intervalos regulares na cadeia de isoladores de linhas de transmissão [8].

Antes de prosseguir neste capítulo, é importante conhecer alguns termos e definições relativas a sobretensões e formas de onda de impulso padronizadas $[9,10]$. 


\section{1.}

\section{Sobretensões e formas de impulso padronizadas}

\subsection{1.}

\section{Terminologia e definições básicas}

- Tensão nominal de um sistema $\boldsymbol{U}_{\boldsymbol{n}}$ : valor de tensão aproximada usada para designar ou identificar algum sistema.

- Tensão máxima do sistema $\boldsymbol{U}_{\boldsymbol{s}}$ : máximo valor de tensão de operação fasefase (valor RMS) que ocorre, sob condições normais de operação, em qualquer hora e em qualquer ponto do sistema.

- Sobretensão: qualquer tensão:

- Entre fase e terra, cujo valor de crista exceda o valor de crista deduzido da tensão máxima do equipamento dividido por $\sqrt{3}$.

- Entre fases, cujo valor de crista seja maior que a amplitude da tensão máxima do sistema.

- Tensão de impulso: tensão transitória aperiódica intencionalmente aplicada, que usualmente cresce rapidamente a um valor de crista e depois decai mais lentamente até zero.

- Tensão de impulso de manobra (IM): tensão de impulso com um tempo de frente de $20 \mu$ s ou mais.

- Tensão de impulso atmosférico: tensão de impulso com tempo de frente menor que $20 \mu \mathrm{s}$.

- Tensão de impulso atmosférico pleno (IAP): tensão de impulso atmosférico que não é interrompido por uma descarga disruptiva, como mostra a Figura 1.

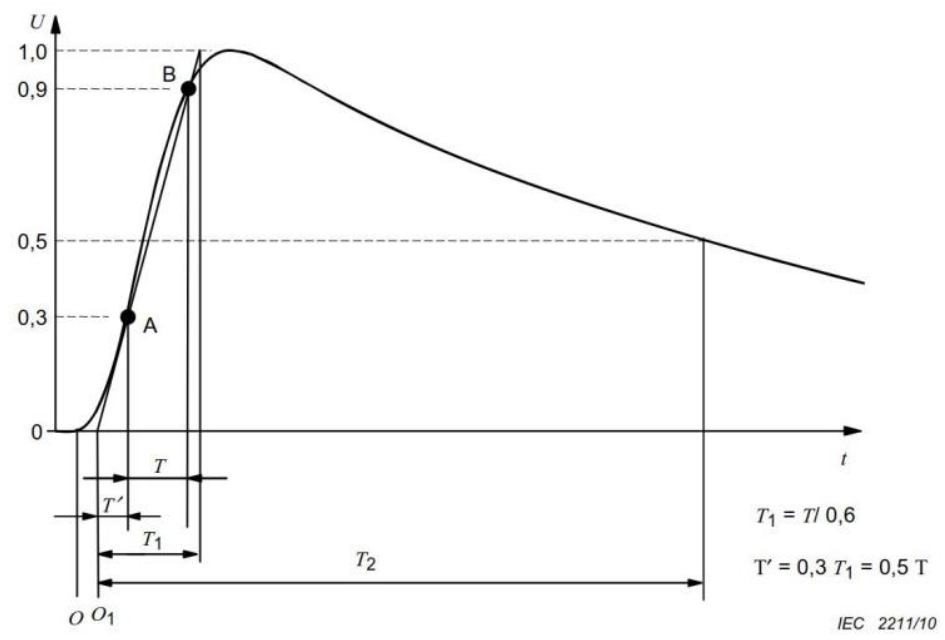

Figura 1: Forma de onda de impulso atmosférico pleno [9]. 
- Tempo de frente $\boldsymbol{T}_{\mathbf{1}}$ : parâmetro virtual definido como 1/0,6 vezes o intervalo de tempo $\boldsymbol{T}$ entre os instantes correspondentes a $30 \%$ e $90 \%$ do valor de crista na curva da tensão do ensaio, como visto na figura 1 .

- Origem virtual $\mathbf{0}_{\mathbf{1}}$ : Instante que precede de $0,3 T_{1}$ o instante correspondente ao ponto A da curva da tensão da figura 1.

- Tempo até o meio valor $\boldsymbol{T}_{2}$ : parâmetro virtual definido como o intervalo entre a origem virtual, $\mathbf{0}_{\mathbf{1}}$, e o instante no qual a curva de tensão de ensaio decresceu até $50 \%$ do valor de crista da tensão de ensaio.

- Tensão de impulso atmosférico cortado (IAC): tensão de impulso atmosférico durante a qual uma descarga disruptiva causa um rápido colapso de tensão, praticamente ao valor zero, como mostrado na Figura 2.

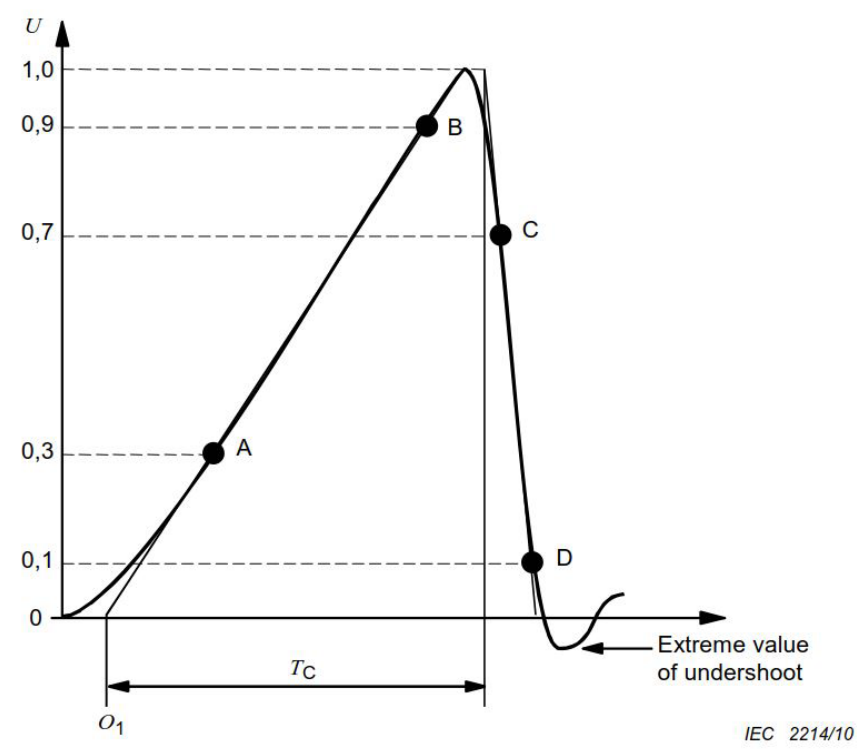

Figura 2: Tensão de impulso atmosférico cortado na frente [9].

- Instante de corte: instante em que a extrapolação da linha entre os pontos de $70 \%$ e $10 \%$ sobre o colapso de tensão cruza o nível de tensão imediatamente antes do colapso.

- Tempo de corte $\boldsymbol{T}_{\mathbf{c}}$ : intervalo de tempo entre a origem virtual, $\mathbf{O}_{\mathbf{1}}$, e o instante de corte, como visto na figura 2. 


\subsection{2.}

\section{Classificações das solicitações de tensão}

As solicitações de tensão e sobretensões, de acordo com a forma de onda e a duração, são divididas nas classes e subclasses a seguir:

- Baixa frequência (frequência fundamental): tensão senoidal de duração relativamente longa, dividida nas duas subclasses a seguir:

- Contínua: tensão senoidal de frequência fundamental $(50 \mathrm{~Hz}$ ou $60 \mathrm{~Hz}$ ), considerada como tendo valor eficaz constante, continuamente aplicada a qualquer par de terminais de uma configuração de isolação.

○ Temporária: sobretensão de baixa frequência (entre $10 \mathrm{~Hz}$ e $500 \mathrm{~Hz}$ ) de duração relativamente curta em relação à subclasse anterior.

- Transitória: sobretensão de curta duração, de alguns milissegundos ou menos, oscilatória ou não oscilatória, tipicamente amortecida, dividida nas seguintes subclasses:

○ Frente lenta: uma sobretensão transitória, que é normalmente unidirecional, com tempo até o valor de crista $20 \boldsymbol{\mu s}<\boldsymbol{T}_{\mathbf{p}}<$ $\mathbf{5 0 0 0} \boldsymbol{\mu s}$, e tempo até a cauda $\boldsymbol{T}_{\mathbf{2}} \leq \mathbf{2 0} \mathbf{~ m s}$.

- Frente rápida: uma sobretensão transitória, que é normalmente unidirecional, com tempo até o valor de crista $\mathbf{0 , 1} \boldsymbol{\mu} \mathbf{s}<\boldsymbol{T}_{\mathbf{p}}<\mathbf{2 0} \boldsymbol{\mu S}$, e tempo até a cauda $\boldsymbol{T}_{\mathbf{2}} \leq \mathbf{3 0 0} \boldsymbol{\mu s}$.

- Frente muito rápida: uma sobretensão transitória, que é normalmente unidirecional, com tempo até o valor de crista $\boldsymbol{T}_{\mathrm{f}} \leq \mathbf{0 , 1} \boldsymbol{\mu} \mathbf{s}$, e com oscilações sobrepostas de frequência $30 \mathbf{~ k H z}<\boldsymbol{f}<\mathbf{1 0 0} \mathbf{~ M H z}$. Também pode ser chamada de Very Fast Transient (VFT).

A Figura 3, adaptada da norma IEC 60071-1, ilustra estas formas de onda.

\begin{tabular}{|c|c|c|c|c|c|}
\hline Classe & \multicolumn{2}{|c|}{ Baixa frequência } & \multicolumn{3}{|c|}{ Transitório } \\
\hline & Contínua & Temporária & Frente lenta & Frente rápida & Frente muito rápida \\
\hline $\begin{array}{c}\text { Forma de } \\
\text { onda das } \\
\text { tensões ou } \\
\text { sobretensões }\end{array}$ & $\begin{array}{l}\text { VVV } \\
-\quad T_{t}\end{array}$ & $\underset{t}{\|} T_{t}$ & $\stackrel{T_{p}}{T_{2}}$ & $\stackrel{T_{1}}{\longrightarrow}$ & $\prod_{\rightarrow 1 / f_{1}}^{T} \eta_{1 / f_{2}} N^{N}$ \\
\hline $\begin{array}{c}\text { Faixa de } \\
\text { forma de onda } \\
\text { das tensões } \\
\text { ou } \\
\text { sobretensões }\end{array}$ & $\begin{array}{c}f=50 \mathrm{~Hz} \text { or } \\
60 \mathrm{~Hz} \\
T_{\mathrm{t}} \geq 3600 \mathrm{~s}\end{array}$ & $\begin{array}{c}10 \mathrm{~Hz}<f< \\
500 \mathrm{~Hz} \\
0,02 \mathrm{~s} \leq T_{\mathrm{t}} \leq \\
3600 \mathrm{~s}\end{array}$ & $\begin{array}{c}20 \mu \mathrm{s}<T_{\mathrm{p}} \leq \\
5000 \mu \mathrm{s} \\
T_{2} \leq 20 \mathrm{~ms}\end{array}$ & $\begin{array}{c}0,1 \mu \mathrm{s}<T_{1} \leq \\
20 \mu \mathrm{s} \\
T_{2} \leq 300 \mu \mathrm{s}\end{array}$ & $\begin{array}{c}T_{\mathrm{f}} \leq 100 \mathrm{~ns} \\
0,3 \mathrm{MHz}<f_{1}< \\
100 \mathrm{MHz} \\
30 \mathrm{kHz}<f_{2}< \\
300 \mathrm{kHz}\end{array}$ \\
\hline
\end{tabular}

Figura 3: Classes e formas das solicitações de tensão, conforme a norma 
Algumas fontes destas sobretensões, conforme [11], são:

- Fontes de sobretensões temporárias: Falha de aterramento, desconexão de carga, ressonância e ferro-ressonância e falta de fase ou conexão assimétrica.

- Fontes de sobretensões de frente lenta: Conexões de carga na rede, falhas e manobras, aplicação de tensão e corrente na desconexão da carga.

- Fontes de sobretensões de frente rápida: Descargas atmosféricas diretas nas linhasou em componentes das linhas aterradas, e tensões induzidas por descargas atmosféricas próximas.

- Fontes de sobretensões de frente muito rápida: Interrupção de arco elétrico, operações de manobra e troca de motores e transformadores com curtas conexões para comutadoras e certas condições de descargas atmosféricas.

\subsection{3.}

\section{Formas de onda normalizada das tensões}

Os ensaios normalizados de tensão suportável são os ensaios de dielétrico realizados em condições específicas para garantir, com confiança adequada, que a isolação atenda a uma tensão suportável nominal normalizada. São exemplos: os ensaios de tensão de frequência fundamental de curta duração, os ensaios de impulso de manobra e de impulso atmosférico. Assim, é necessário utilizar formas de onda normalizadas em tais ensaios, conforme indicado na Figura 4, também adaptada da norma IEC 60071-1.

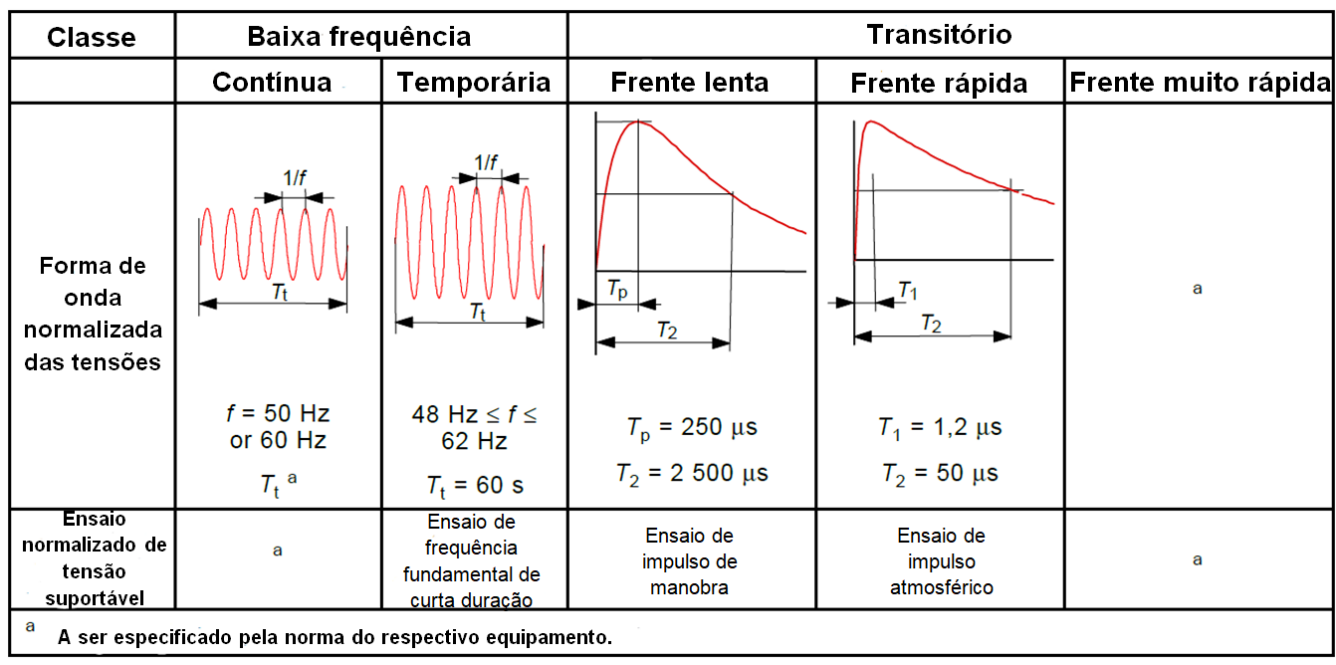

Figura 4: Formas de onda normalizadas para os diferentes tipos de solicitações de tensão, conforme a norma IEC 60071-1. 
Observa-se na figura 4 que não existe uma forma de onda padronizada para sobretensões/transientes de frente muito rápida. Este é um dos motivos pelos quais os ensaios de impulso de perfuração em isoladores de vidro ou cerâmica vêm encontrando bastante divergência nos métodos de medição e calibração de equipamentos.

\section{2.}

\section{Isoladores de linhas aéreas}

As linhas elétricas aéreas são linhas de distribuição ou transmissão com ou sem condutores de proteção. Linhas de transmissão de alta tensão são usadas para transportar energia elétrica para regiões mais distantes, devido à menor quantidade de perdas que ocorrem pela corrente ser mais baixa nessas linhas. Já as linhas de distribuição são usadas para distribuir a mesma energia transmitida para cidades e indústrias, reduzindo-a com grande eficiência para uma tensão mais baixa através de subestações. Os isoladores de linhas aéreas são usados nesses sistemas, juntamente com isoladores de subestações, para garantir o funcionamento adequado do sistema elétrico de potência sob todas as condições.

Toda rede elétrica utiliza isoladores, seja em nível de transmissão ou de distribuição. As principais funções que um isolador desempenha em linhas elétricas são [12]:

- Isolar a linha da torre aterrada, atuando como um suporte de isolamento não condutor entre as partes vivas e mantendo um espaço de ar (gap) nas tensões de operação;

- Resistir às sobretensões elétricas;

- Manter a resistência mecânica do sistema de transmissão suportando as forças resultantes causadas pelo peso do arqueamento do condutor e condições climáticas, como vento, neve, etc.; e

- Executar todas as funções acima, sendo imune a efeitos ambientais, como calor, frio, radiação UV, poluição, etc.

A confiabilidade do sistema elétrico de potência é amplamente dependente da qualidade e integridade do próprio sistema de isolamento. Por exemplo, se o sistema de isolamento falhar, em nível de rede nacional, uma grande área poderá 
perder energia elétrica por um longo período de tempo. Dessa mesma forma, a falha de um sistema de isolamento pode criar problemas complexos em que o sistema elétrico seria movido a um estado de instabilidade e as grandes usinas geradoras perderiam o sincronismo e seriam desligadas do sistema.

\subsection{1.}

\section{Classificação de isoladores}

A classificação dos níveis de tensão é padronizada e definida pela norma IEC 60038:2009 [13] como: sistemas de baixa tensão (até $1 \mathrm{kV}$ ), sistemas de média tensão ( $1 \mathrm{kV}$ até $35 \mathrm{kV})$, sistemas de alta tensão $(35 \mathrm{kV}$ até $230 \mathrm{kV})$ e sistemas de extra alta tensão (acima de $245 \mathrm{kV}$ ). A classificação de ultra-alta tensão é atribuída a tensões acima de $800 \mathrm{kV}$. Cada nível de tensão exige um nível de isolamento adequado, com o aumento da tensão implicando diretamente no aumento do tamanho do isolamento, em termos da distância entre a linha e a torre, para evitar "flash-overs" nos isoladores. Os isoladores de linhas aéreas são classificados em quatro tipos, conforme a norma IEC 60383-1:1993 [14]:

- Isoladores de pino;

- Isoladores-pilar;

- Isoladores para tração de linhas aéreas; e

- Isoladores de cadeia para linhas aéreas.

Os isoladores do tipo de cadeia para linhas aéreas são divididos em duas classes, de acordo com duas dimensões de projeto:

- Classe A: Isolador cuja menor distância de perfuração, ou seja, a menor distância do material isolante onde ocorre a perfuração, é igual ou maior que a metade da distância de descarga a seco. Um bom exemplo é o isolador-bastão com engates metálicos externos; e

- Classe B: Isolador cuja menor distância de perfuração é inferior à metade da distância de descarga a seco. Um bom exemplo é o isolador de disco.

\subsection{2.}

\section{Classificação dos ensaios para isoladores}

Os ensaios são divididos em três grupos, conforme apresentado a seguir: 
- Ensaios de tipo: São ensaios realizados pelo fabricante e possuem como objetivo a verificação das principais características de um isolador, que dependam principalmente da sua forma e tamanho. Geralmente, quando se trata de um novo projeto ou um novo processo de fabricação do isolador, os ensaios de tipo devem ser realizados uma única vez, em um pequeno número de unidades. Devem ser repetidos somente se o projeto ou processo de fabricação forem alterados.

- Ensaios de rotina: São ensaios realizados pelo fabricante em todos os isoladores. Destinam-se a eliminar isoladores defeituosos e devem ser realizados durante a fabricação, sobre cada um dos isoladores produzidos.

- Ensaios de recebimento: São ensaios que possuem como objetivo verificar as características de um isolador sujeitas a variar com a qualidade do processo de fabricação e com a qualidade dos materiais empregados. Os ensaios de recebimento são utilizados como ensaios de aceitação de uma amostra de isoladores obtidos aleatoriamente de um lote que tenha atendido às exigências dos ensaios de rotina.

\subsection{3. \\ Material dos isoladores}

Os materiais utilizados para a fabricação dos isoladores, conforme a norma IEC 60383-1:1993 [14], são:

- Porcelana, que deve ser produzida pelo processo plástico ou líquido, impermeável, livre de trincas, rebarbas ou inclusões de materiais estranhos, e deve ser recoberta com uma camada de esmalte liso vitrificado, nas cores marrom ou cinza. Outras cores podem ser utilizadas, mediante acordo prévio comercial entre as partes interessadas;

- Vidro recozido, cujas tensões mecânicas internas tenham sido aliviadas por meio de tratamento térmico; ou

- Vidro temperado, que tenha sido submetido a tratamento térmico para a indução de tensões mecânicas internas controladas.

Atualmente, um novo material também está sendo usado em grande escala, chamado NCI (Non Ceramic Insulator). É composto principalmente de borracha de silicone ou Etileno-Propileno (EPR)/Etileno-Propileno-Dieno (EPDM). O 
motivo para usar este material em vez do vidro ou cerâmica é o fato de os NCIs apresentarem menor peso e maior resistência à tração. Os NCIs são também mais fáceis para manipulação. Além disso, um fator muito importante no isolador é o desempenho hidrofóbico, que é muito melhor nos NCIs, permitindo a operação de forma mais eficiente em ambientes contaminados ou poluídos [15].

\subsection{4.}

\section{Exemplo típico de um isolador de disco}

Os isoladores de disco são um dos isoladores de classe B. Seu formato deve permitir uma melhor distribuição de potencial ao longo do seu corpo, anulando valores de gradiente que possam causar estresses excessivos tanto no material dielétrico quanto nas ferragens [16]. Esse tipo de isolador foi utilizado durante os ensaios experimentais desta dissertação e apresenta um formato e composição típicos mostrados na Figura 5.

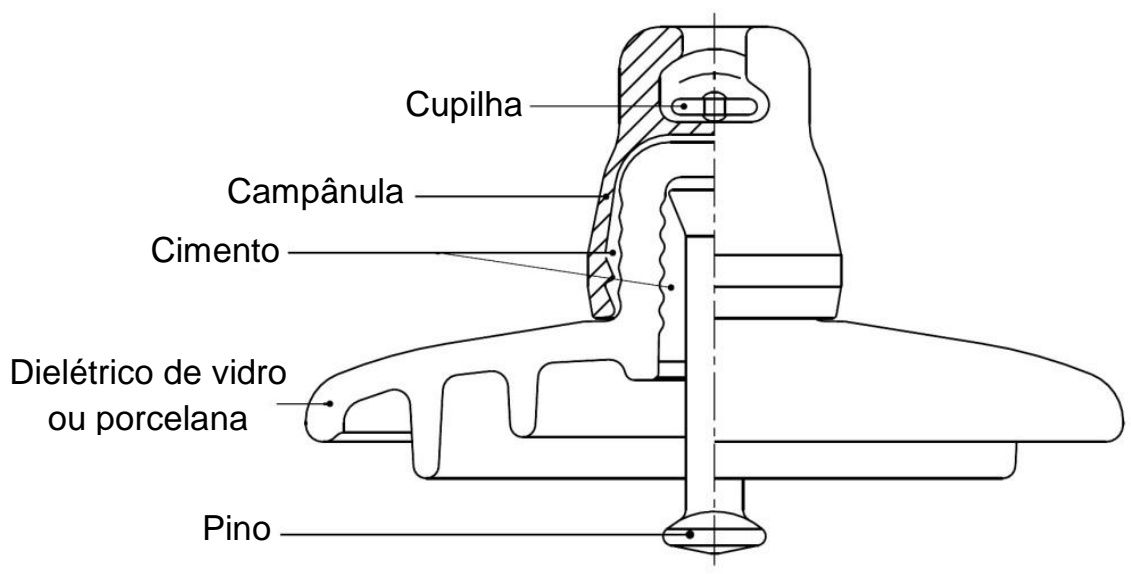

Figura 5: Composição típica de um isolador de disco.

\subsection{5.}

\section{Descargas disruptivas em isoladores de vidro ou cerâmica}

Descargas disruptivas, de forma geral, podem ser definidas como a manifestação da perda de rigidez dielétrica de um isolador devido a um valor elevado de tensão elétrica. Este fenômeno é aquele no qual a tensão elétrica do isolador causa uma falha que inclui o colapso de tensão e a passagem abrupta de corrente elétrica. Em meios sólidos, isso causa uma perda permanente de resistência e rigidez dielétrica e, em líquidos ou gases, pode ser causada apenas 
uma perda temporária. Quando uma descarga disruptiva ocorre entre dois eletrodos em um gás ou líquido, ou ainda sobre uma superfície sólida no ar, é chamada de flashover. Se a descarga ocorrer através de um isolamento sólido, é chamada de perfuração [17].

As descargas disruptivas em isoladores podem aparecer de duas formas [18]:

- Na parte externa do isolador, onde o material isolante é o ar e a superfície do isolador está sujeita a tensões elétricas como discargas disruptivas do isolador. O arco elétrico criado, que é devido a uma falha do aterramento, gera grandes tensões térmicas e elétricas. Estas tensões deterioram o isolador, logo os isoladores são projetados levando estes fatores em consideração.

- Na parte interna do isolador, quando o colapso ocorre no material isolante interno do isolador. O isolamento interno é submetido a sobretensões, que são limitadas pelas descargas disruptivas geradas na parte externa do isolador. Com isso, o isolador é perfurado se não houver descarga disruptiva na parte externa. A Figura 6 apresenta essas duas situações.
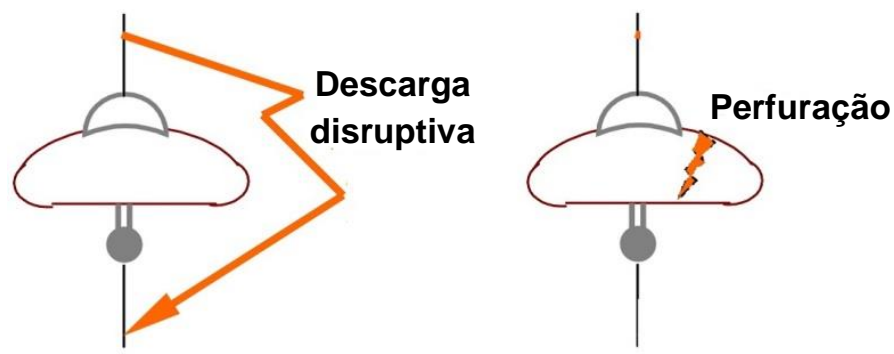

Figura 6: Descarga disruptiva e perfuração em uma unidade de isolador.

Ou seja, quanto mais íngreme o impulso for e maior a amplitude, mais a descarga tende a perfurar o isolador, saindo da zona em que ocorre a descarga disruptiva externa, no ar [19]. Existem duas maneiras de evitar a perfuração, nesse caso: aumentar a espessura do isolamento ou utilizar materiais isolantes melhores, aumentando a suportabilidade do objeto isolador para este tipo de fenômeno. Com isso, se o isolador for dimensionado corretamente, projetado com materiais de boa qualidade, será rara a ocorrência de uma perfuração e o desempenho do isolador será satisfatório sob este aspecto. A Figura 7 exemplifica esta explanação. 


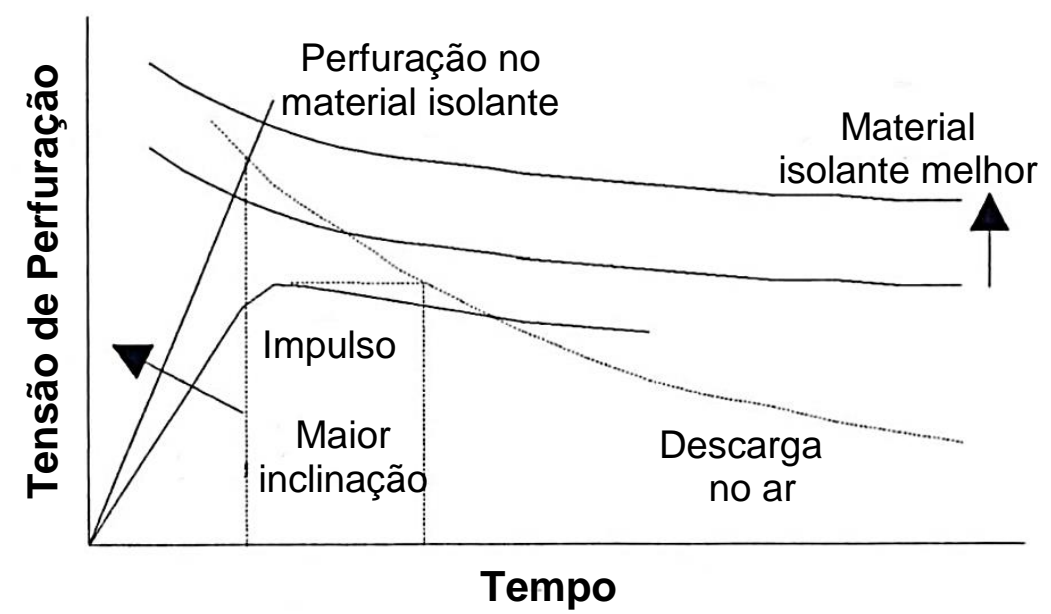

Figura 7: Curva tensão $x$ tempo para uma unidade de isolador [19].

Logo, se for aplicado um impulso de tensão com a frente muito rápida, com maior inclinação, a curva de tensão atingirá a curva que representa o isolamento sólido antes de atingir a curva de isolamento no ar.

\section{3. Ensaio de perfuração sob impulso em isoladores de acordo com a norma IEC 61211}

Para evitar os cenários discutidos nos tópicos anteriores, os isoladores são projetados de acordo com requisitos específicos. Alguns tipos de isoladores foram apresentados no item 2.2, sendo que cada um deles precisa ser projetado e fabricado satisfazendo pré-requisitos econômicos e de qualidade. Existem diferentes tipos de ensaios padronizados para auxiliar na concepção, fabricação e compra, assim como para garantir a qualidade dos isoladores. $\mathrm{O}$ ensaio de perfuração sob impulso (Impulse Puncture Test - IPT) em isoladores é um dos diversos ensaios padronizados que garantem a qualidade dos isoladores. Isoladores classe A, conforme a norma IEC 60383-1:1993 [14], não são perfuráveis devido ao longo trajeto de perfuração através do material sólido do isolador. Assim, este ensaio é destinado a isoladores de vidro ou cerâmica de classe B (isoladores de disco, bastão, pilar e outros tipos similares de isoladores) que possuem um caminho mais curto de perfuração através do material sólido do isolador do que pelo ar (flash-over). Já os isoladores NCIs possuem diferentes 
definições para este cenário, porém esta dissertação trata apenas de isoladores de cerâmica e de vidro, para os quais se aplica a norma citada.

O ensaio de perfuração sob impulso é realizado em isoladores, de linhas aéreas, de vidro ou cerâmica, conforme a norma IEC 61211:2004 [5], a fim de garantir que eles sejam capazes de resistir a tensões de frente rápidas e sobretensões de frente muito rápida (VFT) com uma tolerância de erro/perfuração. Logo, se um isolador se mantiver íntegro neste ensaio, é provável que ele não perfure quando for submetido a transientes de alta tensão, resultando em um flashover externo no ar sobre o corpo do isolador. Contudo, o isolador pode ser perfurado por tensões graduais ao longo do tempo combinadas com uma sobretensão repentina. Estas tensões podem ser térmicas, elétricas ou mecânicas, juntamente com o simples processo de envelhecimento.

A principal tensão elétrica é causada por sobretensões de frente muito rápida e sobretensões de frente rápida como, por exemplo, o impulso atmosférico e, portanto, deve ser simulada em laboratório por meio de um ensaio representativo das condições de operação. Em 1994, pela primeira vez, uma diretriz apropriada para conduzir este ensaio foi concebida e finalizada em um relatório intitulado Type 2 IEC Report 1211, por Martti Aro, como resultado de seus anos de pesquisa [20]. Este relatório mais tarde se transformou na norma IEC 61211:2004 [5].

Qualquer ensaio deve representar as condições reais de operação do sistema às quais o equipamento relevante será exposto. Além disso, o ensaio deve apresentar reprodutibilidade, repetibilidade e seletividade. Antes de existir o ensaio de perfuração sob impulso conforme a norma IEC 61211:2004 [5], a suportabilidade da resistência dos isoladores em relação a sobretensões era largamente avaliada usando um ensaio de frequência industrial em óleo de acordo com a norma IEC 60383-1:1993 [14], que os fabricantes de isoladores consideravam suficiente [21]. No entanto, uma pesquisa [22] mostrou que este ensaio não é reprodutível, seletivo ou viável e que também não representa as condições reais de operação. Para contornar este problema, ensaios de perfuração sob impulso de alta tensão em isoladores em óleo foram estudados [23], mas também não deram resultados produtivos, pois eram confusos, sem uma boa interpretação [24, 25]. Comparado com os demais tipos de ensaio, o ensaio de perfuração sob impulso em isoladores no ar representa as condições reais de 
operação devido ao impulso de tensão no ar representar as condições reais das solicitações.

A norma IEC 61211:2004 [5] recomenda o ensaio de perfuração como um ensaio de recebimento. Entretanto, como a suportabilidade à perfuração dos isoladores é dependente tanto do projeto quanto da qualidade da fabricação, é necessário um procedimento para ensaio de tipo e de recebimento. A norma define o número de isoladores a serem ensaiados. Se for um ensaio de tipo, serão cinco isoladores. Já o ensaio de recebimento é realizado conforme a norma IEC 603831:1993 [14], ou seja, o ensaio de perfuração, que pode ser executado em amostras retiradas do mesmo lote.

A norma IEC 61211:2004 [5] é focada em como ensaiar isoladores de cerâmica ou vidro aplicando impulsos de frente íngreme, definindo alguns arranjos básicos de configuração de ensaio para vários tipos de isoladores, requisitos de ensaio e procedimentos, especificações do ensaio e critérios de aceitação. Como os ensaios experimentais desta dissertação foram realizados utilizando isoladores de disco, grande parte das discussões foram feitas com base em isoladores de Classe B.

\subsection{1. \\ Arranjo de ensaio}

O arranjo de ensaio depende do tipo de isolador e de seu vínculo metálico, quando existir.

O condutor de aterramento entre o isolador e o divisor deve ser uma chapa ou placa metálica. $\mathrm{O}$ isolador de disco deve ser montado com a campânula para baixo, sobre o aterramento. A distância da chapa de aterramento ao dielétrico do isolador deve ser a menor possível, mas suficiente para evitar descargas disruptivas diretamente na placa. No lado do pino, um engate esférico com a dimensão aproximada da campânula do isolador deve ser utilizado para proteger a área crítica existente ao nível da cimentação em torno do pino. O divisor de tensão e o gerador de impulso devem ser conectados no topo desse engate esférico, conforme é apresentado na Figura 8. 


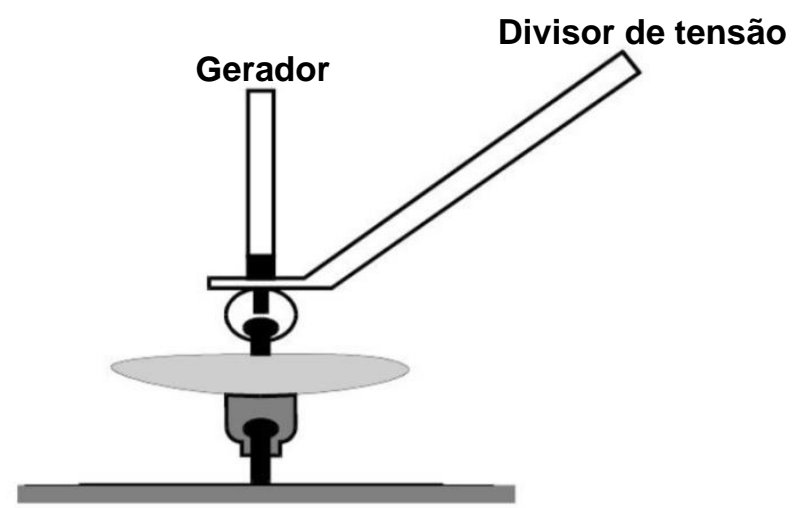

Figura 8: Arranjo de ensaio para isoladores tipo disco.

\subsection{2.}

\section{Gerador de impulso}

Para um único estágio, o esquemático do circuito de geração de impulso é mostrado na Figura 9. O capacitor $C_{S}$ é carregado e, em seguida, descarregado em $C_{B}, R_{D}$ e $R_{E}$, criando um impulso através de $C_{B}$.

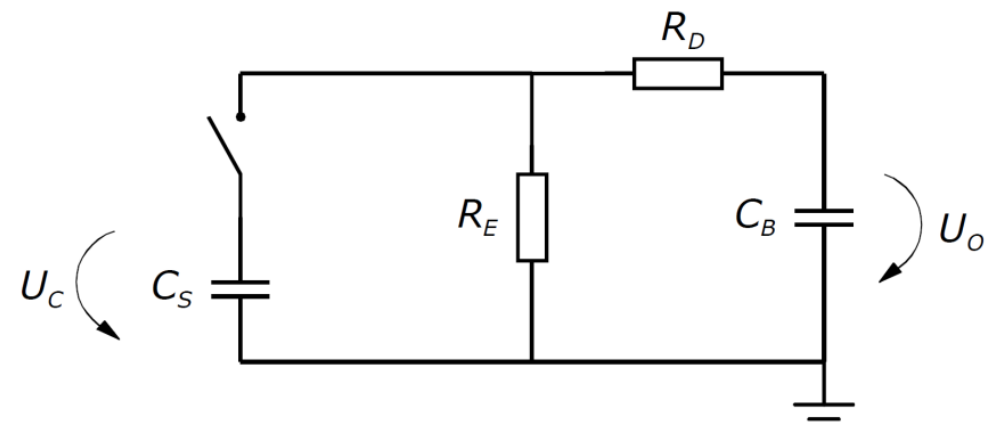

Figura 9: Circuito equivalente de um gerador de impulso de um único estágio. [26]

A onda de saída é uma curva exponencial dupla, cuja forma depende do ajuste dos valores dos componentes. Com uma escolha apropriada dos valores dos componentes, o circuito produz um impulso padrão atmosférico ou de manobra.

No entanto, para solicitações de tensões mais altas, esse circuito de um estágio não é viável, sendo necessário utilizar múltiplos estágios e sendo denominado gerador de Marx, o qual pode ser facilmente usado para tensões muito altas. Este circuito é apresentado na Figura 10. 
a)

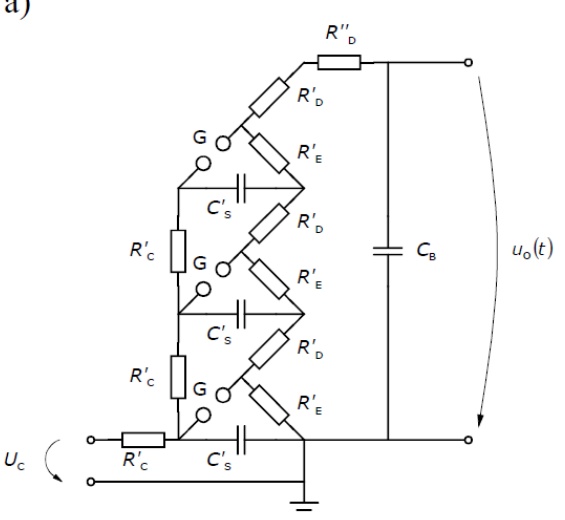

$$
\begin{aligned}
& C_{\mathrm{S}}=\frac{C_{\mathrm{S}}^{\prime}}{n} \\
& R_{\mathrm{D}}=n R_{\mathrm{D}}^{\prime}+R_{\mathrm{D}}^{\prime \prime} \\
& R_{\mathrm{E}} \approx n R_{\mathrm{E}}^{\prime} \\
& G: \text { sphere gap }
\end{aligned}
$$

b)

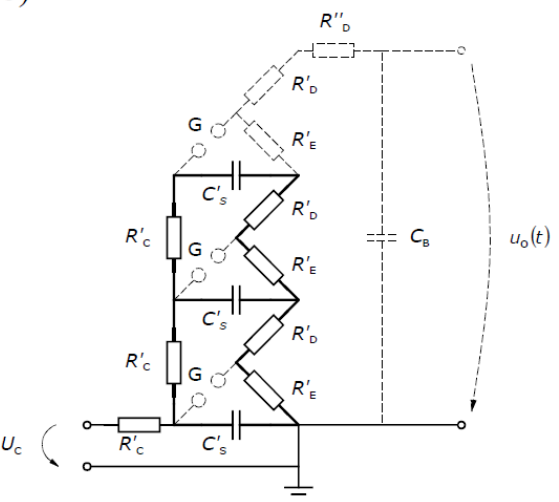

c)

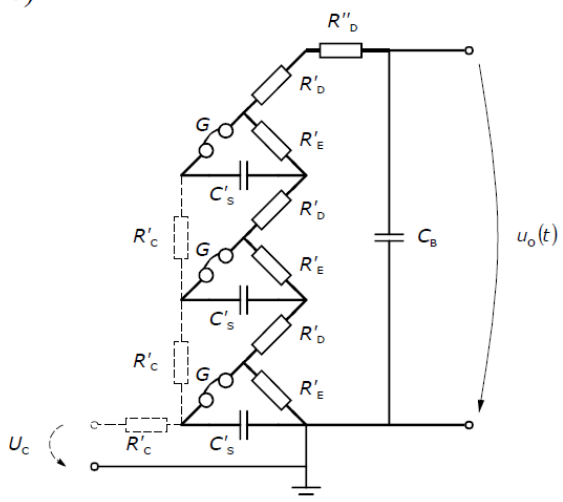

Figura 10: Circuito do gerador de Marx de múltiplos estágios. (a) Uma topologia possível. (b) Componentes ativos durante a carga. (c) Componentes ativos durante a descarga.

O circuito é formado por resistores de frente (série) responsáveis pelo tempo de subida $T_{1}$, resistores de cauda (paralelo) responsáveis pelo tempo de descida $T_{2}$ e por esferas centelhadoras (gaps) que possuem a função de colocar os estágios do gerador em paralelo ou em série, de modo que o carregamento ocorra em paralelo e a descarga em série no circuito, obtendo-se um somatório das tensões das esferas no objeto sob ensaio.

Os capacitores $C_{S}{ }^{\prime}$ são carregados através dos resistores de carga $R_{C}{ }^{\prime}$, que possuem alto valor ôhmico, já que sua função é limitar a corrente de carga dos capacitores do gerador de impulso. Em seguida, o gap inferior é disparado usando uma vela de ignição. Isso faz com que todos os outros gaps disparem.

Assim, todos os centelhadores são conectados em série e, por sua vez, um impulso atmosférico de alta tensão é gerado e descarregado na rede de saída. Os valores de $R_{D}{ }^{\prime}$ e $R_{E}{ }^{\prime}$ controlam o tempo de frente e de cauda da onda, respectivamente [26]. Outra forma de visualizar o processo de carregamento e descarga do gerador de impulso é apresentada na Figura 11. 


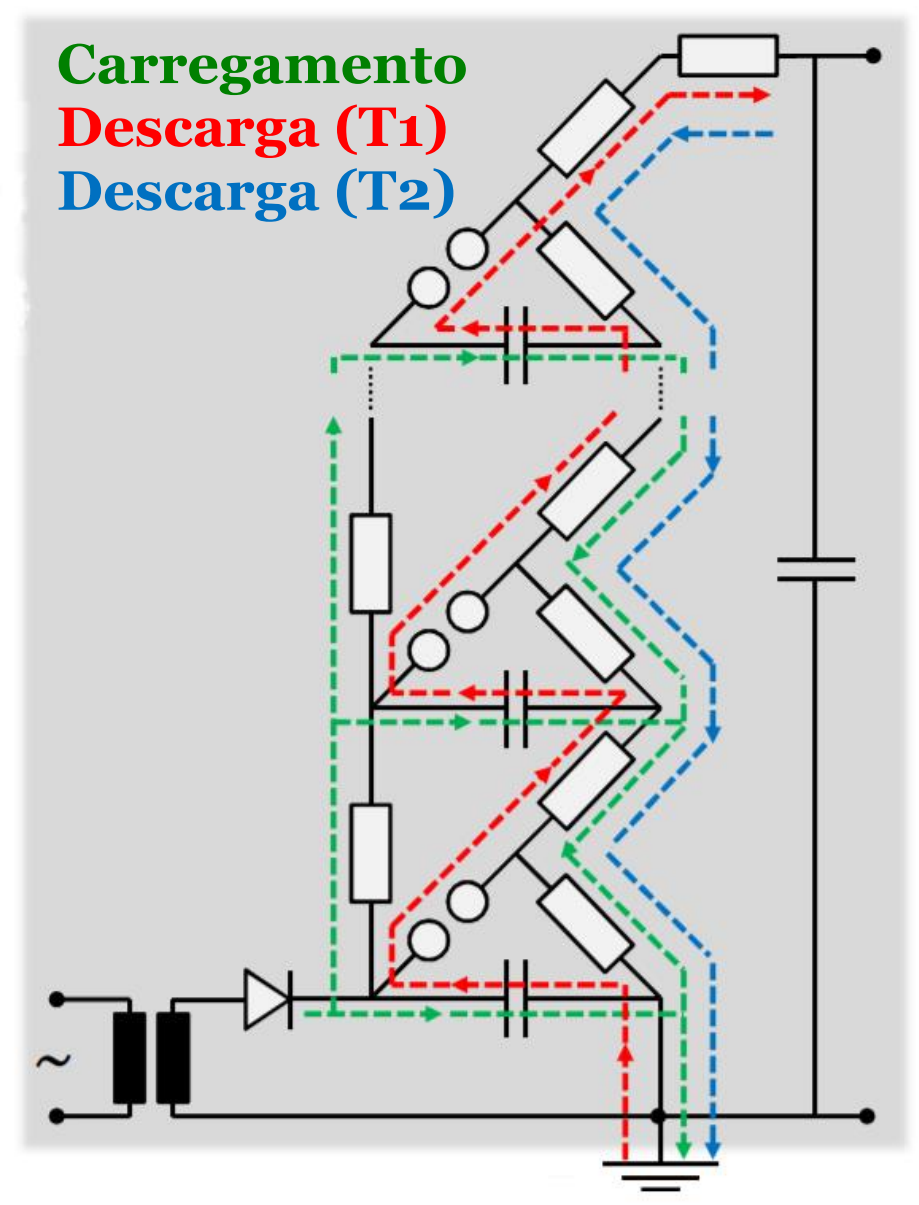

Figura 11: Carregamento e descarga do gerador de impulso atmosférico.

Qualquer gerador de impulso atmosférico com tensão de no mínimo $1000 \mathrm{kV}$ é suficiente para a geração de impulsos de frente íngreme para o ensaio, segundo a norma IEC 61211:2004 [5], porém deve-se observar a capacitância do gerador de impulso, que é um parâmetro importante para a forma de onda de impulso. Em vários casos, inclusive no ensaio de isoladores unitários de dimensões normalizadas, uma tensão de circuito aberto de $500 \mathrm{kV}$ a $600 \mathrm{kV}$ é suficiente. Um gap adicional em série com o isolador sob ensaio é necessário para facilitar a geração de altas tensões de ensaio. Geradores compactos e sistemas de ensaio automáticos podem auxiliar o ensaio.

O gap em série é acionado e um pico súbito de tensão aparece no objeto de ensaio, que é o isolador, sendo este impulso então cortado pelo flash-over, ou descarga disruptiva. Este pico é, na verdade, uma sobretensão de frente muito rápida, conhecida também como VFT (Very fast transient) [27]. Um esquema conceitual do circuito de geração é apresentado na Figura 12. 
(a)

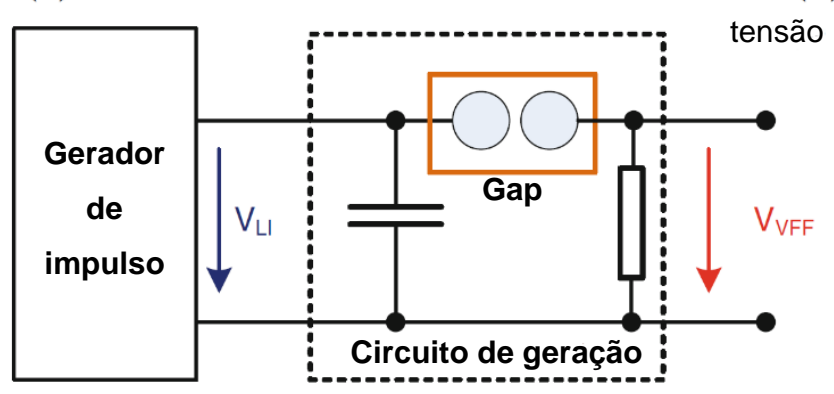

(b)

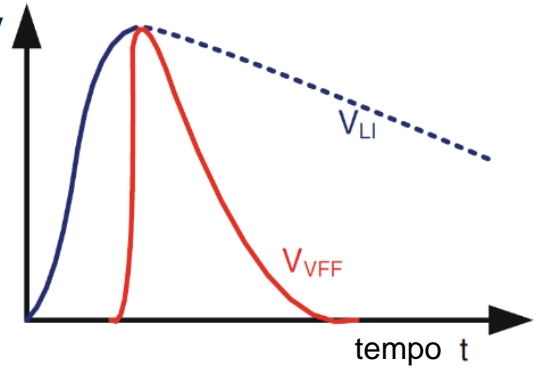

Figura 12: Geração do impulso de perfuração. (a) Circuito equivalente. (b) Diagrama de potencial.

A figura 12 mostra um gap, um resistor e um capacitor como parte do circuito de geração do VFT, no entanto, um simples gap também pode cumprir a tarefa, como está descrito na norma IEC 61211:2004 [5].

\subsection{3.}

\section{Tensão de ensaio}

A tensão de ensaio, segundo a norma IEC 61211:2004 [5], é definida como a amplitude real do pico determinado pela descarga disruptiva do impulso de tensão aplicado. Exceto em relação ao valor de pico, nesta norma não há outras exigências para a forma de onda do impulso de perfuração. A frente rápida e íngreme do impulso é, na verdade, gerada por causa da descarga disruptiva, como apresenta a Figura 13. A tensão de carga varia até que um valor de pico seja atingido no ponto em que ocorre a descarga disruptiva.

Já no que se refere ao valor da tensão de ensaio pretendida, ele deve ser especificado pelo produto normalizado, ou pelo fabricante, ou pelo contrato entre o fabricante e o comprador. E se não for esses casos, então é um múltiplo de $U_{50}$, que é o valor médio da tensão de impulso atmosférico que define uma probabilidade de $50 \%$ de ocorrer descarga em uma cadeia de isoladores reduzida e normalizada. Para o caso de isoladores de disco a tensão de ensaio é 2,8 x $U_{50}$.

Os valores em pu para as tensões de ensaio foram prescritos na norma IEC 61211:2004 [5], tendo em vista que eles se mantiveram comparáveis ao requisito anterior de $2500 \mathrm{kV} / \mu \mathrm{s}$ quando o critério de interesse era a inclinação, e não o valor de pico. 


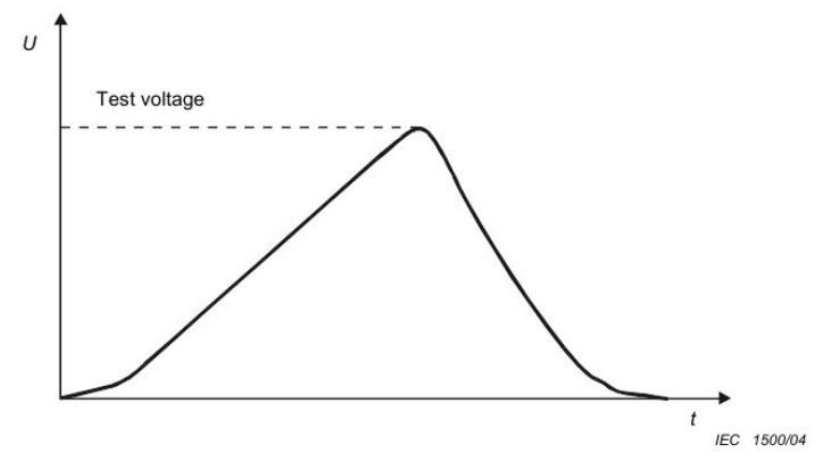

Figura 13: Impulso de perfuração aplicado, cortado pelo isolador na tensão de ensaio de acordo com a IEC 61211:2004 [5].

Uma relação gráfica entre o valor da tensão de ensaio e $U_{50}$ é apresentada na Figura 14, destacando que o impulso de perfuração é muito mais rápido e apresenta uma maior inclinação em comparação ao impulso atmosférico pleno.

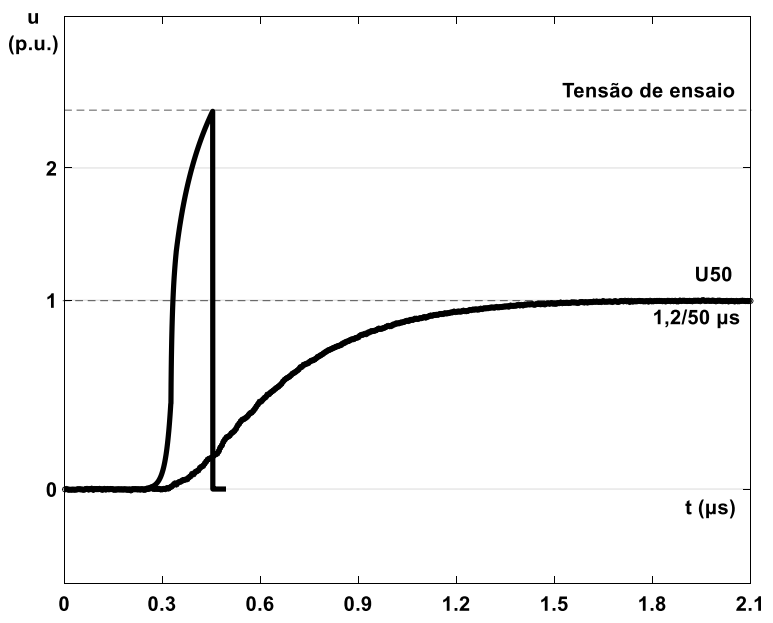

Figura 14: Relação entre a tensão de ensaio e $U_{50}$ de acordo com a norma IEC 61211:2004 [7].

\subsection{4.}

\section{Sistema de medição}

Segundo a norma IEC 60060-2:2010 [28], um sistema de medição é um conjunto de dispositivos que são adequados para a realização de uma medição de alta tensão. Também compõe um sistema de medição um programa computacional, utilizado para se obter ou calcular os resultados da medição. Um sistema de medição normalmente inclui: 
- Dispositivo de conversão: Um dispositivo que tem a capacidade de converter a grandeza de entrada (tensão e os parâmetros de tempo relevantes) em uma grandeza que esteja na faixa de entrada do instrumento de medição (baixa tensão ou corrente), mantendo sua forma, parâmetros de tempo e componentes de frequência até uma certa precisão, garantindo assim ao instrumento uma réplica do mensurando. Na maioria das vezes o dispositivo de conversão, transdutor, é um simples divisor de tensão que possui um braço de alta tensão e um braço de baixa tensão. A tensão de entrada é aplicada ao braço de alta tensão enquanto a saída é gerada no braço de baixa tensão. Existem muitos outros tipos de dispositivos de conversão, como impedância de conversão de tensão, transformador, sonda de campo elétrico, etc. O dispositivo de medição, ou divisor, reduz a grandeza de entrada por um determinado fator chamado fator de escala. Podem ser aplicados tanto em corrente contínua (CC) quanto em corrente alternada (CA), dependendo de sua especificação.

- Sistema de transmissão: Um conjunto de dispositivos que transmite a saída do dispositivo de conversão para o sistema de medição, ou seja, a entrada do instrumento. Na maior parte das vezes é um simples cabo coaxial ou triaxial, juntamente com a sua impedância. O cabo geralmente é caracterizado pela sua impedância. Atenuadores opcionais também podem estar presentes, diminuindo ainda mais a tensão para a entrada do instrumento de medição. A presença de atenuadores também é levada em conta para a determinação do fator de escala. Em algumas aplicações, também são usados sistemas de transmissão do tipo óptico, usando um conjunto transmissor-receptor com um cabo óptico.

- Instrumento de medição: Dispositivo (registrador digital ou osciloscópio) que mede, exibe e calcula todos os parâmetros relevantes da tensão de entrada. Depois de obter a tensão do sistema de transmissão, o instrumento multiplica este valor pelo fator de escala pré-definido no sistema. Na maioria dos casos, ele possui um software embarcado para cálculos, que também faz parte do sistema de medição como um todo. O software do instrumento calcula parâmetros como, por exemplo, tempo de frente, tempo de corte, entre outros, conforme as normas aplicáveis. 
Os braços de alta e baixa tensão dos divisores de tensão, na verdade, consistem em vários componentes que podem ser capacitores ou resistores, ou ambos, em vários arranjos em série, resultando conjuntamente em duas impedâncias principais, uma de alto valor e outra de baixo valor. Deve-se notar que divisores de tensão de vários tipos construtivos são usados para a medição de diferentes formas de onda utilizadas em ensaios com altas tensões, como é mostrado na Figura 15 [29].

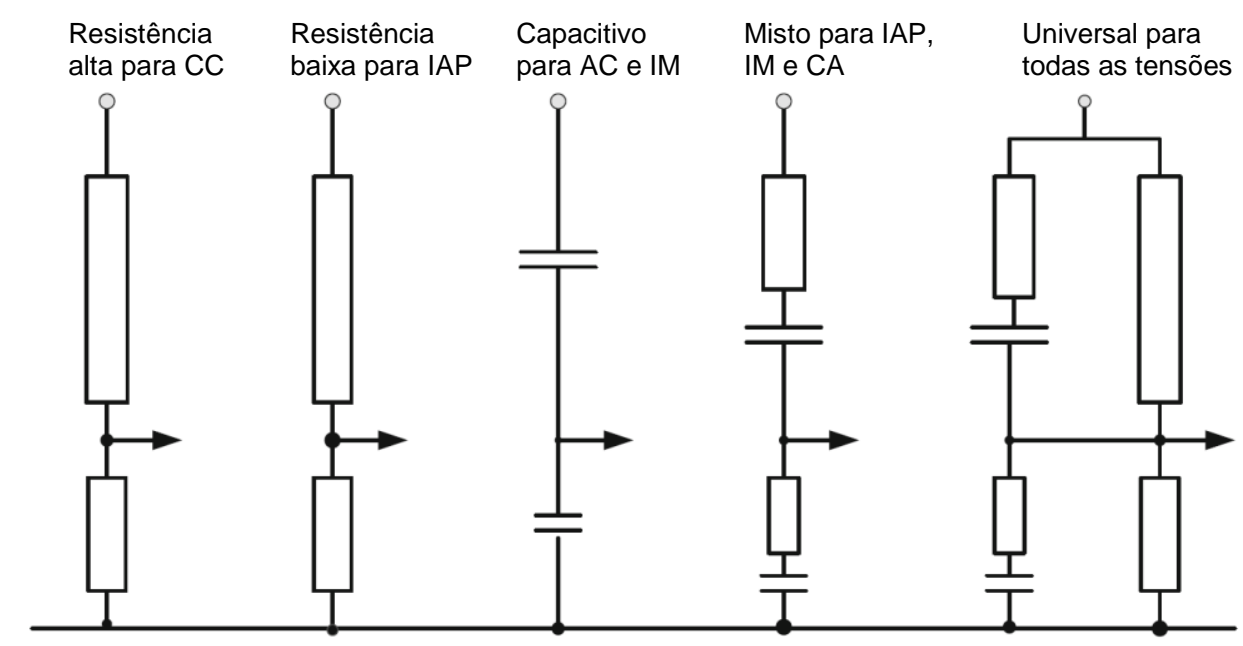

Figura 15: Diferentes formas construtivas de divisores para diferentes aplicações em laboratórios de ensaios de alta tensão

Um sistema com um divisor de tensão puramente resistivo é mostrado na Figura 16 para elucidar os conceitos.

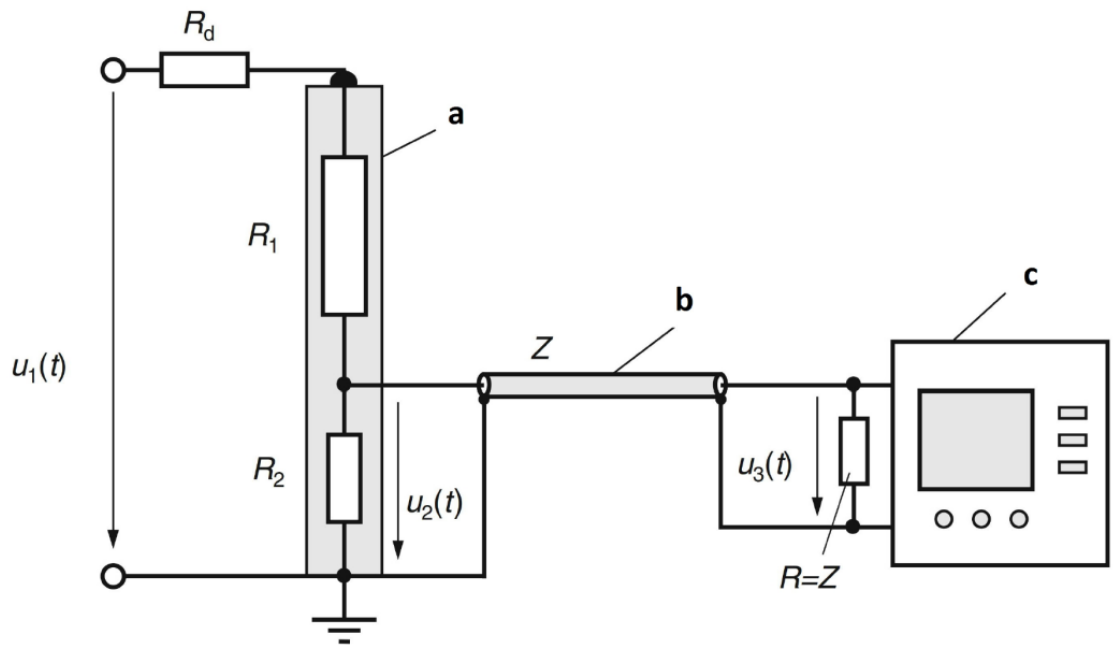

Figura 16: Sistema de medição para impulso. a) Divisor resistivo de baixa impedância. b) cabo coaxial de medição. c) Registrador digital ou osciloscópio [30]. 
A Figura 16, no entanto, não mostra as várias capacitâncias do sistema, por exemplo, do braço de alta tensão para a terra e do braço de baixa tensão para a terra, que estão inerentemente presentes em todos os divisores. Devido a essas capacitâncias parasitas, até mesmo um divisor resistivo funciona como um circuito RC ou um filtro passa-baixa. Juntamente com essas capacitâncias, indutâncias parasitas e capacitâncias parasitas também contribuem para influenciar o desempenho dinâmico do sistema como um todo. Assim, cada divisor resistivo, como qualquer circuito RC ou RLC, possui propriedades relacionadas a sua resposta ao degrau, que define a qualidade do seu desempenho e limite de aplicação. A aplicação do SM para impulsos inclui parâmetros como tempo de subida, largura de banda, tempo de resposta, tempo de estabilização e overshoot. Essas definições de parâmetros de desempenho do sistema de medição, por meio da resposta ao degrau e outras condições operacionais, são fornecidas na norma IEC 60060-2:2010 [28].

Além disso, todo sistema de medição de alta tensão é caracterizado pelas condições operacionais sob as quais o sistema opera dentro dos limites da incerteza, que incluem: fator de escala atribuído, tensão nominal de operação, faixa de medição do sistema, tempo de operação e tipo da forma de onda de entrada (por exemplo, um impulso atmosférico pleno), taxa de aplicações e condições ambientais. Osciloscópios digitais geralmente são classificados por sua resposta em frequência [30]. O fator de escala atribuído a um sistema completo inclui os respectivos fatores de escala de todo o sistema, ou seja, o divisor, o cabo, os atenuadores e o instrumento. $\mathrm{O}$ fator de escala deve ser calibrado para que a medição seja rastreável a um padrão. A calibração é influenciada por duas principais condições. A primeira é que o fator de escala deve ser calculado incluindo o comportamento dinâmico do sistema. A segunda é que a incerteza em toda a medição deve ser aproximada ou estimada com uma precisão adequada. Quando estas condições são atendidas, tendo em vista as tolerâncias da norma IEC 60060-2:2010 [28], o sistema torna-se um sistema de medição aprovado (SMA) e pode ser usado em laboratórios de ensaios para equipamentos de alta tensão.

A norma IEC 61211:2004 [5] define algumas especificações de desempenho para sistemas de medição que devem ser usados em ensaios de perfuração sob impulso em isoladores. Essas especificações são fornecidas para obter a incerteza necessária na medição. São elas: 
- A relação do divisor deve ser conhecida com uma incerteza $\leq 2 \%$ (para $k=2)$.

- A incerteza total do sistema de medição deve ser $\leq 5 \%$ (para $k=2$ ). Além disso, o sistema deve ser calibrado/aprovado de acordo com os requisitos da norma IEC 60060-2:2010 [28].

- O instrumento de medição, osciloscópio ou digitalizador deve satisfazer aos requisitos da norma IEC 61083-1:2001 [31]. O tempo de subida (0$100 \%$ ) deve ser $\leq 12$ ns, e uma taxa de amostragem mínima de 500 MHz e possuir resolução vertical $\geq 8$ bits.

- Sistema de medição sem instrumentos:

- Para resposta oscilante: tempo de resposta parcial $\left(T_{\alpha}\right)$ deve ser $\leq$ 3 ns.

- Para resposta monotônica: tempo de resposta $T$ deve ser $\leq 5$ ns.

Estas condições devem ser atendidas com relação ao sistema de medição que deve ser usado no ensaio de perfuração sob impulso em isoladores. Uma configuração recomendada para o circuito de medição é dada na norma IEC 61211:2004 [5], como apresentado na Figura 17. No entanto, esta é uma representação muito vaga, pois nenhum parâmetro, como a distância entre o divisor e o isolador, é definido, e esse fator pode afetar os resultados como foi visto em [7].

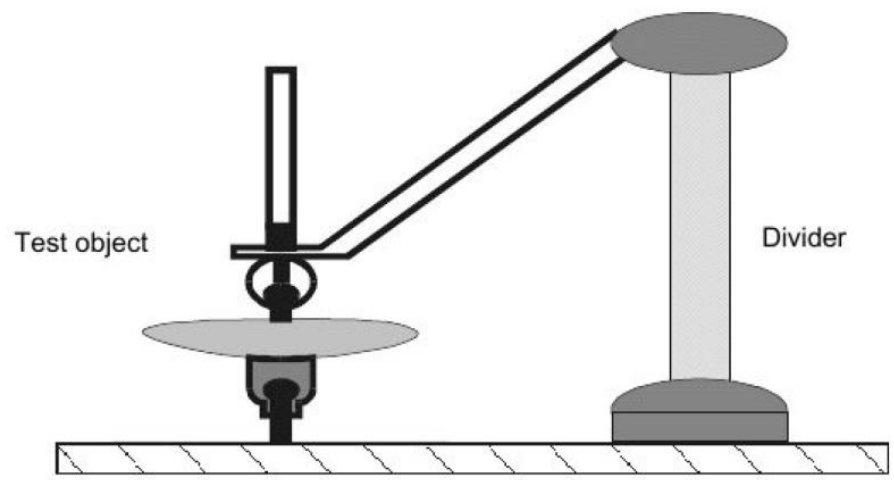

IEC $1502 / 04$

Figura 17: Exemplo de uma configuração recomendada de um arranjo de ensaio compacto incluindo objeto e divisor [5]. 


\section{4. Fatores relacionados ao sistema de medição}

O sistema de medição foi discutido em detalhes no item 2.3.4. É importante considerar alguns fatores antes do projeto de um sistema de medição. Espera-se que todos os divisores de impulso sejam rápidos, tenham um tempo de estabilização curto e suportabilidade para altas tensões. Porém, os ensaios de perfuração sob impulso em isoladores empregam impulsos de alta tensão de curta duração com tempos de frente variando em torno de $100 \mathrm{~ns}$, portanto, sua medição é muito difícil em comparação aos impulsos atmosféricos padronizados, ou seja, impulsos de alta tensão de 1,2/50 $\mu \mathrm{s}$ e, portanto, tais tensões são medidas com uma incerteza muito menor [8]. Mas, ainda assim, não é trivial obter boa precisão (ou uma incerteza total de $5 \%$ ). A comparação interlaboratorial realizada em [32] mostra que a maioria dos laboratórios vinha medindo impulsos de curta duração com divisores simples e de tamanho não recomendado. Devido a estes erros serem bastante elevados, qualquer tentativa de corrigi-los utilizando o tempo de resposta foi em vão. Divisores compactos com tempo de resposta rápido são recomendados para tais medições para evitar assim a influência das indutâncias e capacitâncias parasitas [33].

Considerando a função de transferência da resposta ao degrau unitário $G(s)$ de um circuito RC, tem-se

$$
G(s)=\frac{1}{s(1+R C s)} .
$$

Com isso, para um circuito RC, a constante de tempo $\tau=R C$ ou o tempo de subida da resposta ao degrau $\left(T_{a}\right)$ determinam a velocidade da resposta, ou seja, quanto menor, mais rápido, conforme é visualizado na Figura 18.

(a)

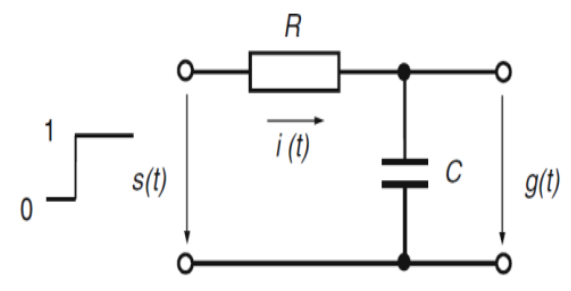

(b)

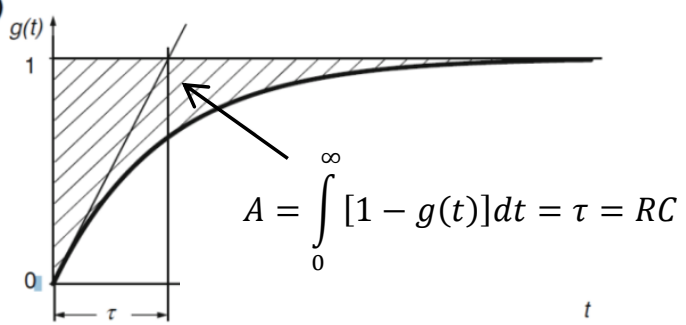

Figura 18: Circuito RC. (a) Circuito com degrau unitário $s(t)$ na entrada. (b) Saída da resposta ao degrau $g(t)$. 
A equação (2) é válida neste caso, sendo $T_{\alpha}$ o tempo de subida (rise time) calculado a partir da resposta ao degrau, ou seja, o tempo entre $10 \%$ e $90 \%$ do valor de crista da resposta ao degrau.

$$
T_{\alpha} \approx 2,2 R C=2,2 \tau
$$

Se $3 \mathrm{~ns}$ for assumido como valor de $\tau$ como requisito para o sistema de medição sem o instrumento, descrito em 2.3.4, então conforme a equação (2) $T_{\alpha}=$ 6,6 ns. Simplificando, esse valor pode ser assumido como 6 ns. Em instrumentos de medição, o tempo máximo de subida que pode ser medido com razoável precisão de amplitude está diretamente relacionado à largura de banda de $-3 \mathrm{~dB}$ do instrumento. Usando a equação (3), considerando o fator de 0,35 sendo válido para sistemas sem overshoot na resposta transiente [34], o requisito de largura de banda para o sistema é de aproximadamente $60 \mathrm{MHz}$, já se fosse considerada a presença de overshoot o fator seria 0,45 e a largura de banda do sistema de aproximadamente $70 \mathrm{MHz}$.

$$
\text { Bandwidth }=\frac{0,35 \ldots 0,45}{T_{a}}
$$

Assim, o tempo de resposta, o tempo de subida e a constante de tempo $\tau$ para um circuito RC de primeira ordem podem estar relacionados entre si quanto ao requisito de largura de banda do sistema de medição. Um impulso em formato triangular foi disparado em um circuito RLC na Figura 19.

(a)

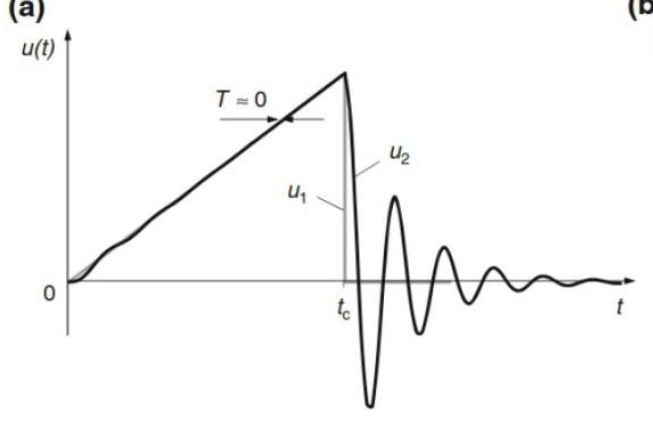

(b)

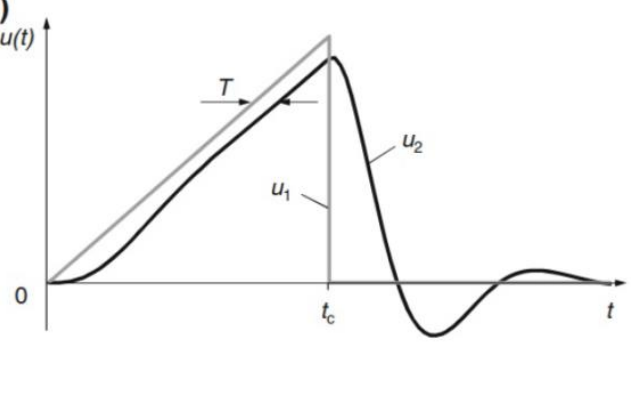

Figura 19: Efeito da largura de banda (tempo de resposta) na medição.

$T$ é o tempo de resposta determinado a partir da resposta ao degrau do circuito. Com um valor de $T$ maior que zero, um erro do valor de crista está 
sempre presente. Quando $T$ se aproxima de zero, o erro do valor de crista diminui enquanto as oscilações são sobrepostas na frente e, portanto, a determinação do tempo de frente com precisão fica comprometida. A largura de banda menor do que a especificada leva a grandes erros do valor de crista, conforme calculado para uma resposta não oscilante para um circuito RC da Figura 18 [30]. Como a maioria das respostas ao degrau de um sistema de medição para impulso são oscilantes, faz sentido a recomendação da IEC 61211:2004 [5] em sugerir um sistema de medição com osciloscópio com largura de banda $>100 \mathrm{MHz}$.

Na Figura 20, é apresentada a medição de uma resposta ao degrau de um atenuador misto para exemplificar a influência da largura de banda, bandwidth (BW), do osciloscópio na prática.

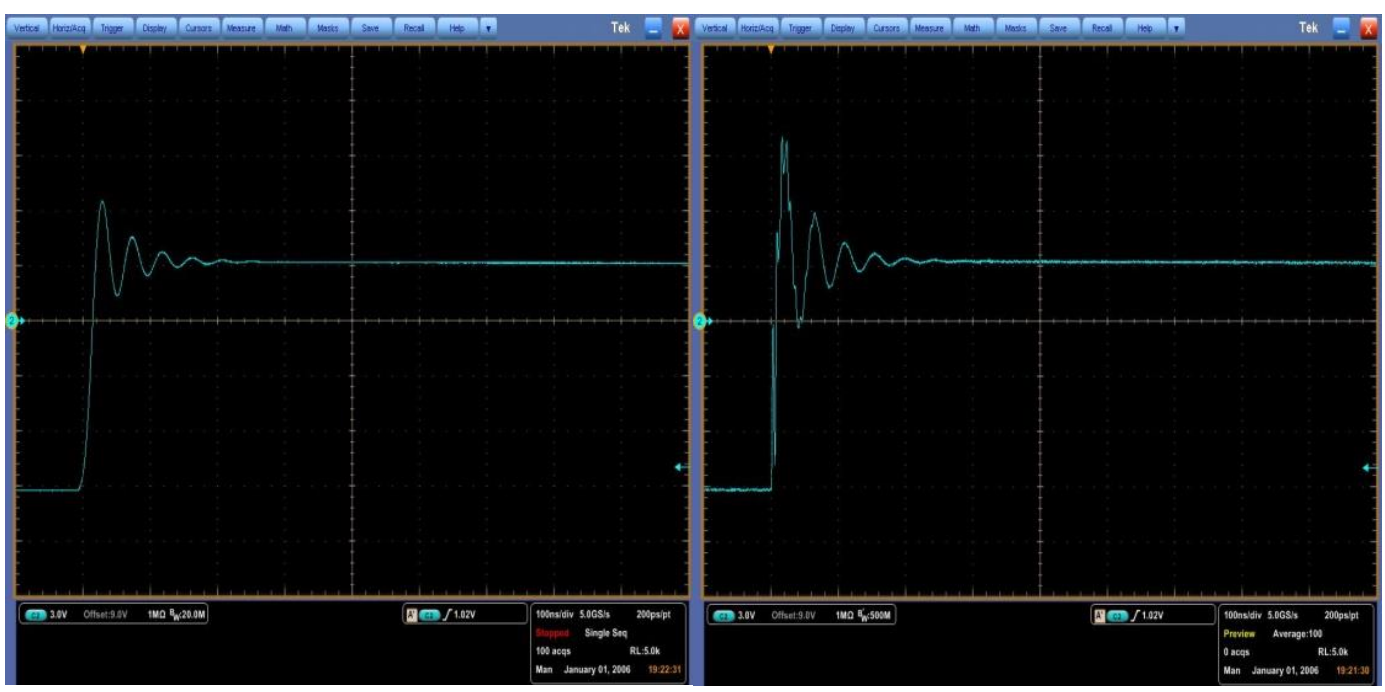

Figura 20: Resposta ao degrau com BW em 500 MHz e em 20 MHz, respectivamente.

Observa-se que, quando se limita a largura de banda, atenua-se bastante o sinal e deixa-se de observar certas características, o que influencia no cálculo dos parâmetros da resposta ao degrau, conforme mostrado na Figura 21 e na Figura 22. 


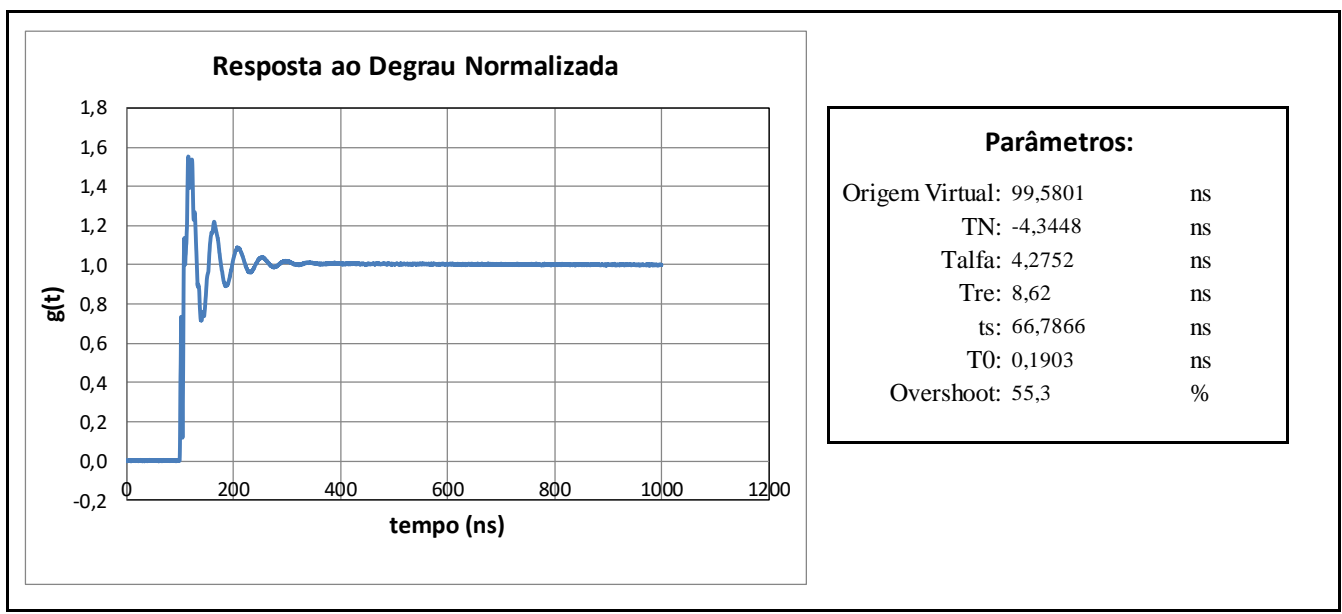

Figura 21: Parâmetros da resposta ao degrau com BW em 500 MHz.
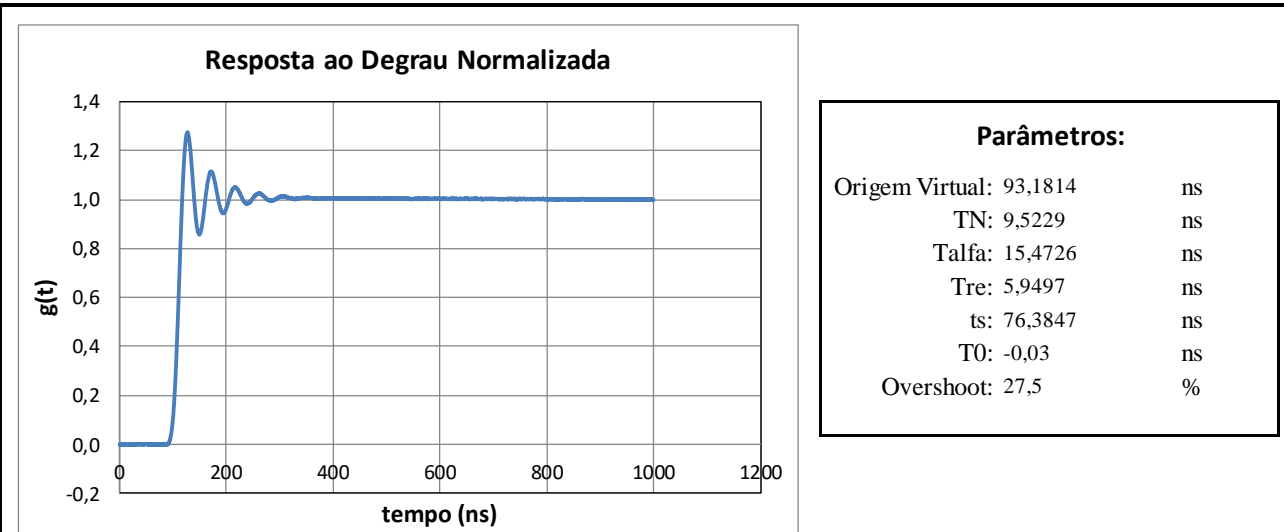

Figura 22: Parâmetros da resposta ao degrau com BW em 20 MHz.

\section{5.}

\section{Cadeia de rastreabilidade para sistemas de medição}

A necessidade de rastreabilidade dos equipamentos ou do setor industrial resulta que, para garantir a precisão dos instrumentos de medição, é essencial que eles sejam calibrados periodicamente utilizando padrões mais precisos, em laboratórios de calibração [35]. A rastreabilidade metrológica requer uma hierarquia de calibração estabelecida, conforme Figura 23. 
HIERARQUIA DO SISTEMA METROLÓGICO

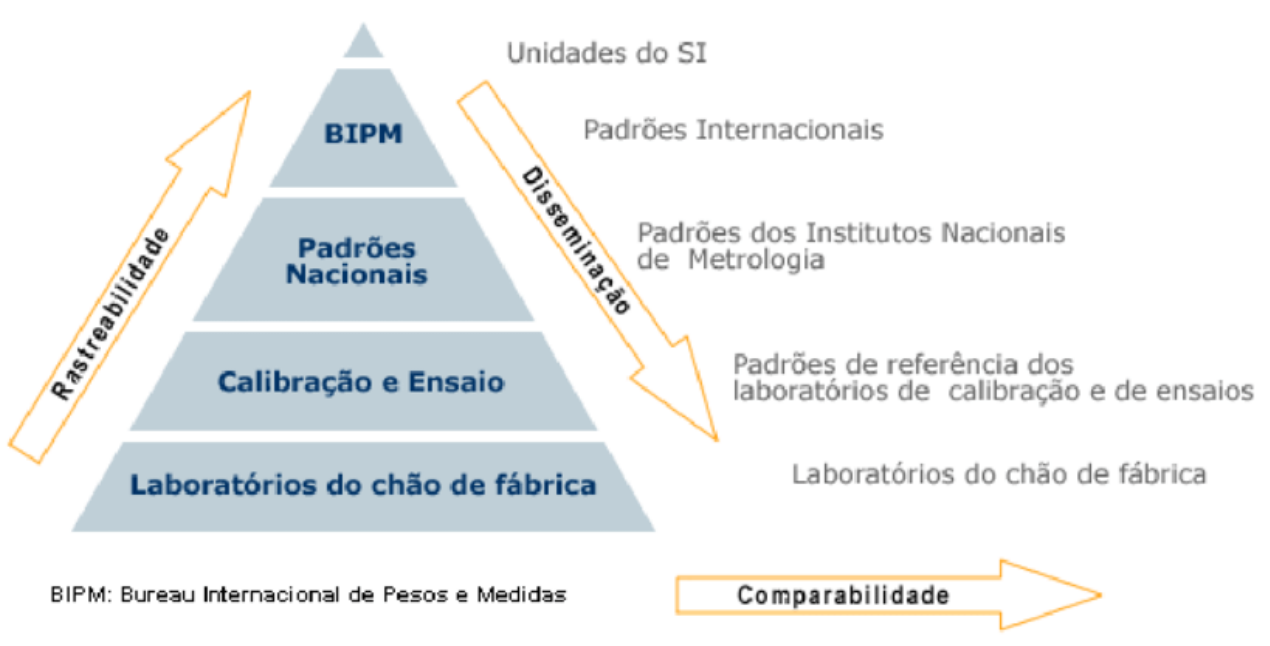

Figura 23: Hierarquia do sistema metrológico.

Segundo a norma ISO/IEC 17025:2017 [36], todo equipamento utilizado em ensaios ou calibrações, incluindo equipamentos para medição auxiliares, que tenham efeito significativo sobre a exatidão ou validade do resultado do ensaio, calibração ou amostragem, deve ser calibrado antes de entrar em serviço.

Porém, no caso do ensaio de perfuração sob impulso em isoladores, não existe ainda uma metodologia definida na IEC 61211:2004 [5] para a calibração do sistema de medição, e o mesmo também não possui rastreabilidade, por não haver um padrão nacional ou internacional para essa forma de onda específica.

O que está sendo realizado atualmente para garantir reprodutibilidade e qualidade em nível internacional é uma comparação interlaboratorial entre institutos nacionais de metrologia e/ou Centros de pesquisas, coordenada por um grupo de pesquisas do CIGRÉ chamado Working Group D1.60: Traceable measurement techniques for very fast transients, no qual o Cepel tem contribuído com vários trabalhos sobre o tema. Com isso, existe bastante diversificação nos métodos utilizados na medição do impulso de perfuração entre os laboratórios, ainda mais em relação aos divisores de tensão. Por mais que todos os divisores sigam o mesmo requisito de desempenho dinâmico proposto pela norma e sejam compactos, existem diferentes aspectos construtivos que estão envolvidos em um projeto de um divisor de tensão juntamente com a sua caracterização, o que será abordado no capítulo a seguir. 


\section{3}

Divisor resistivo para ensaios de impulso de perfuração em isoladores

Este capítulo apresenta a construção, caracterização e avaliação de um divisor de alta tensão resistivo de mínima indutância para ser aplicado a ensaios de perfuração em isoladores. O divisor foi construído com fios resistivos e utilizando técnicas para minimizar o efeito indutivo, e projetado com o objetivo de realizar medições de impulsos de alta tensão com frente muito rápida, como é o caso de impulsos medidos em ensaios de perfuração em isoladores, de até $600 \mathrm{kV}$; e com características de incerteza de medição até $2 \%$, conforme estabelecido pela norma IEC 61211:2004 [5]. Os ensaios para verificar o desempenho dinâmico do divisor, como o ensaio normalizado de comportamento dinâmico e avaliações de resposta em frequência, foram realizados e os resultados também são apresentados aqui.

\section{1. Projeto do divisor}

Para o projeto do divisor resistivo, os cálculos foram efetuados para uma tensão máxima suportável de $600 \mathrm{kV}$. Para garantir um bom desempenho do divisor de alta tensão do tipo resistivo para impulsos rápidos na faixa de centenas de nanosegundos, a construção deve ter uma impedância de $3 \mathrm{k} \Omega$ ou menos, já que divisores resistivos para medição de impulsos atmosféricos, com duração de dezenas de microssegundos, devem possuir impedâncias entre $3 \mathrm{k} \Omega$ a $15 \mathrm{k} \Omega$ [37].

\subsection{1.}

\section{Características físicas}

Utilizar resistores resistivos é o melhor método para medir impulsos rápidos de tensão devido a suas eficientes características de desempenho. Para a construção do divisor foram utilizados os seguintes materiais, apresentados da Figura 24 à Figura 28. 
- Um tarugo de PVC, possuindo as seguintes dimensões: diâmetro interno de $11 \mathrm{~mm}$, comprimento de rosca de $30 \mathrm{~mm}$ e comprimento de $880 \mathrm{~mm}$.

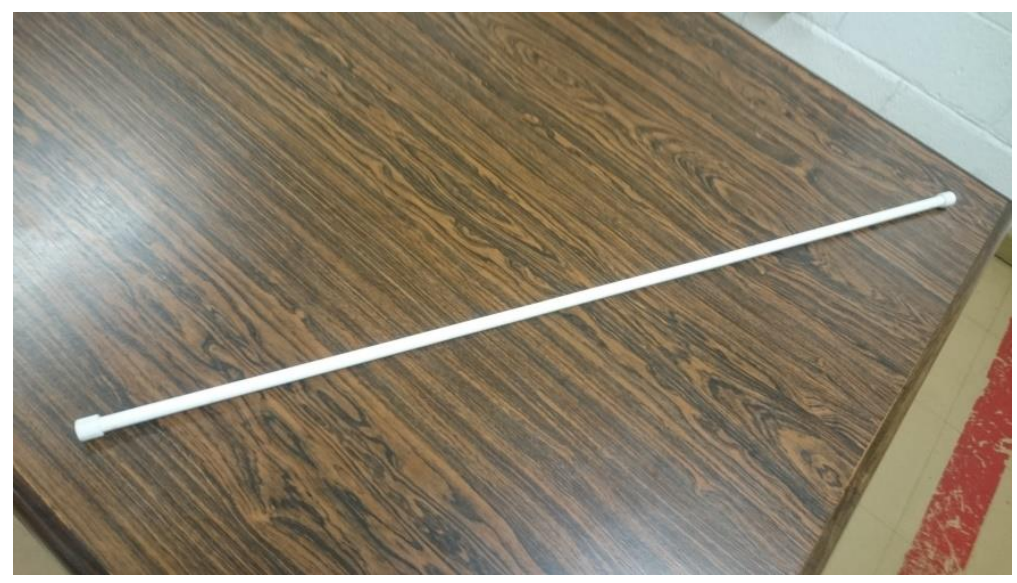

Figura 24: Tarugo de PVC.

- Fibra óptica, com diâmetro de aproximadamente $1 \mathrm{~mm}$, servindo como núcleo auxiliar do divisor.

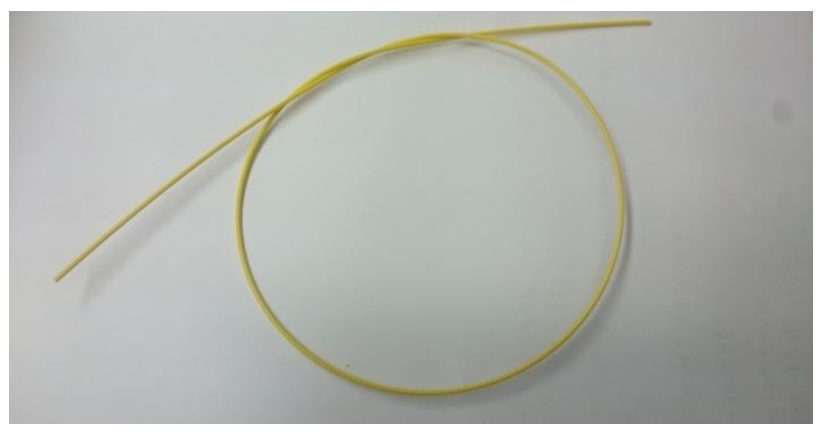

Figura 25: Fio isolante de fibra óptica.

- Fio resistivo possuindo as seguintes especificações: diâmetro de $0,18 \mathrm{~mm}$ e $52,15 \Omega / \mathrm{m}$. Composição NiCr20AlSi.

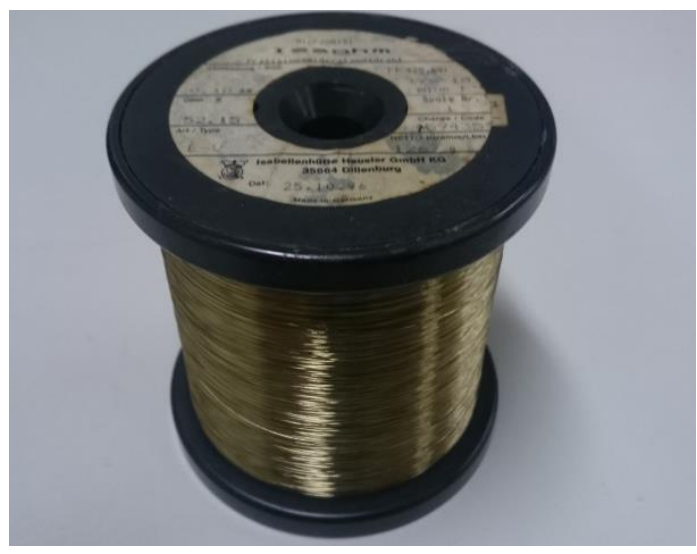

Figura 26: Fio resistivo. 
- Tubo termo retrátil 2:1.

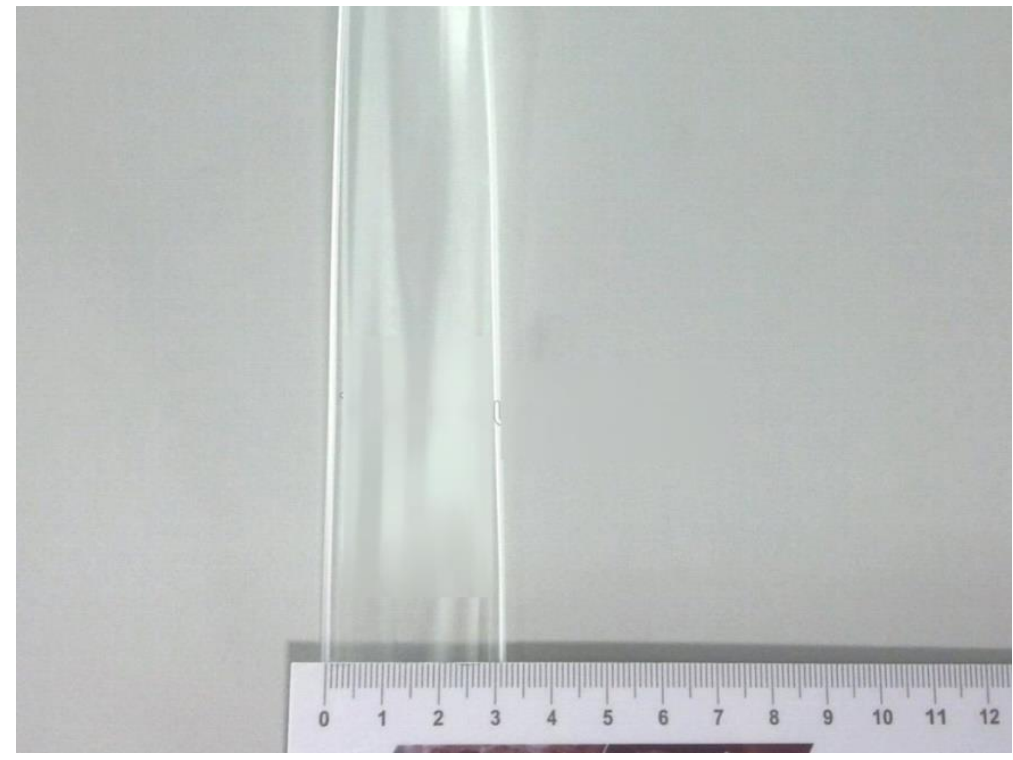

Figura 27: Tubo termo retrátil.

- Tubo de acrílico $80 \mathrm{~mm}$ x $70 \mathrm{~mm}$ x $1000 \mathrm{~mm}$.

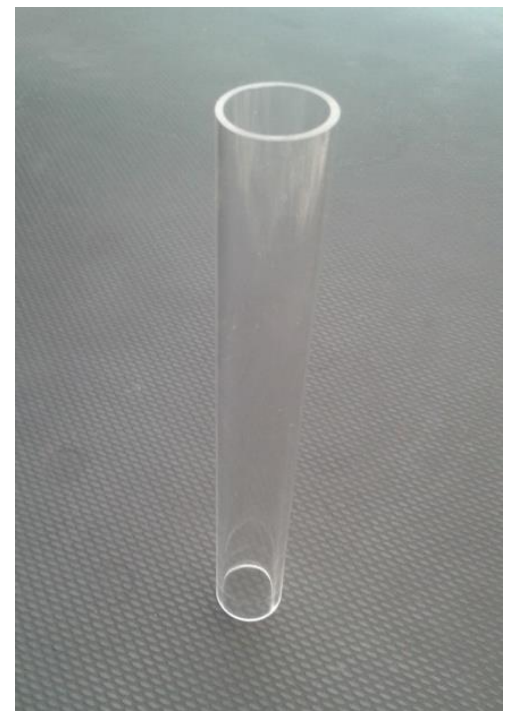

Figura 28: Tubo de acrílico.

\subsection{2.}

\section{Cálculos para determinação da impedância de alta tensão}

Primeiramente foi determinado o comprimento do tubo PVC, que define a distância entre o condutor de alta tensão e a estrutura aterrada. Quanto maior é o valor do impulso de tensão aplicado, maior será a altura do divisor de tensão 
empregado. Podem-se admitir as seguintes distâncias entre o condutor de alta tensão e o terra, segundo [29]:

- 2 a 2,5 m/MV para impulsos atmosféricos; ou

- Igual ou maior que $4 \mathrm{~m} / \mathrm{MV}$ para impulsos de manobra.

Considerando $600 \mathrm{kV}$ aplicados e a menor relação para a aplicação de medição de impulso atmosférico, que seria $2 \mathrm{~m} / \mathrm{MV}$, a distância obtida é $1,2 \mathrm{~m}$. Como esta regra é proporcional à energia armazenada em cada duração de impulso, o impulso de perfuração em isoladores exige uma menor energia armazenada comparado aos outros impulsos, considerando sua duração 6 vezes menor que o valor de tempo de frente $T_{1}$ do impulso atmosférico. Com isso, a relação m/MV pode ser menor para impulsos de perfuração em isoladores.

O número de espiras pode ser calculado por

$$
N \text { o de espiras }=\frac{\text { comprimento do tarugo-comprimento da rosca }}{\text { diametro do fio }}
$$

Considerando o comprimento do tarugo $880 \mathrm{~mm}$ e o comprimento da rosca $30 \mathrm{~mm}$, o comprimento útil para enrolar o fio resistivo de $0,18 \mathrm{~mm}$ de diâmetro é de $850 \mathrm{~mm}$. Logo,

$$
\text { № de espiras }=\frac{880 \mathrm{~mm}-30 \mathrm{~mm}}{0,18 \mathrm{~mm}} \cong 4722 \text { espiras }
$$

Considerando o diâmetro do tarugo de $11 \mathrm{~mm}$ acrescentado do diâmetro da fibra óptica de $1 \mathrm{~mm}$, tem-se um raio de $6 \mathrm{~mm}$.

Para calcular o comprimento do fio resistivo primeiro usa-se a equação para definir o comprimento de cada espira por camada

$$
\text { Comprimento da espira }{ }_{1 \text { o camada }}=2 \pi\left(r_{\text {tubo }}+d_{\text {fio }}\right) \cong 0,0388 \mathrm{~m}
$$

Levando em consideração o aumento do diâmetro em cada camada, em função da adição do núcleo auxiliar, tem-se

$$
\begin{aligned}
& \text { Comprimento da espira }_{2^{\circ} \text { camada }}=2 \pi\left(r_{\text {tubo }}+2 d_{\text {fio }}\right) \cong 0,0399 \mathrm{~m} \\
& \text { Comprimento da espira }_{3^{\circ} \text { camada }}=2 \pi\left(r_{\text {tubo }}+3 d_{\text {fio }}\right) \cong 0,0399 \mathrm{~m} \\
& \text { Comprimento da espira }_{4^{\circ} \text { camada }}=2 \pi\left(r_{\text {tubo }}+4 d_{\text {fio }}\right) \cong 0,0399 \mathrm{~m}
\end{aligned}
$$


Logo, o comprimento do fio resistivo, por camada, será

$$
\begin{aligned}
& \text { Comp.do fio }_{1{ }_{1} \text { camada }=N^{\mathrm{o}}} \text { de espiras } \times \text { Comp }_{\text {da espira }} \cong 183,36 m \text { (10) }
\end{aligned}
$$

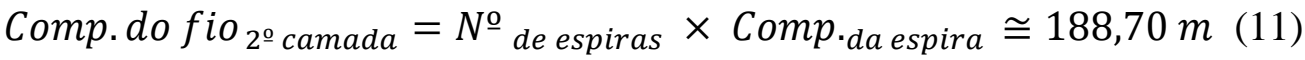

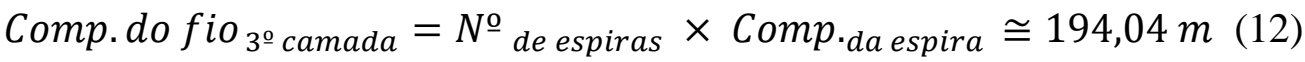

$$
\begin{aligned}
& \text { Comp.do fio }_{4}{ }_{\text {camada }}=N^{\mathrm{o}} \text { de espiras } \times \text { Comp }_{\text {da }} \text { espira } \cong 199,38 \mathrm{~m} \text { (13) }
\end{aligned}
$$

Então, a resistência por camada será

$$
\begin{aligned}
& R T_{1{ }^{\text {o }} \text { camada }}=\text { Comprimento }_{\text {fio }} \times R_{\text {fio }} \cong 9562,4 \Omega
\end{aligned}
$$

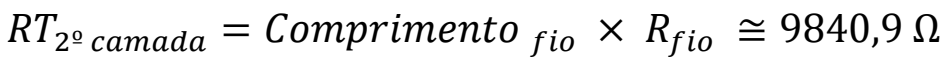

$$
\begin{aligned}
& R T_{3_{\text {o }} \text { camada }}=\text { Comprimento }_{\text {fio }} \times R_{\text {fio }} \cong 10119,4 \Omega \\
& R T_{4^{\circ} \text { camada }}=\text { Comprimento }_{\text {fio }} \times R_{\text {fio }} \cong 10398,0 \Omega
\end{aligned}
$$

Obtém-se então o valor da resistência equivalente, a partir de

$$
\begin{gathered}
\frac{1}{R_{e q}}=\frac{1}{R T_{1^{\circ} \text { camada }}}+\frac{1}{R T_{2^{\circ} \text { camada }}}+\frac{1}{R T_{3^{\circ} \text { camada }}}+\frac{1}{R T_{4^{\circ} \text { camada }}} \\
R_{e q}=2492,6 \Omega
\end{gathered}
$$

Este valor de impedância satisfaz o comentário no item 1.1, sendo um pouco menor que $3 \mathrm{k} \Omega$.

\subsection{3.}

\section{Determinação da impedância de baixa tensão}

Tendo em vista o valor de resistência ôhmica da unidade de alta tensão, para se determinar a impedância de baixa tensão deve ser levada em conta a tensão máxima direcionada na instrumentação e sala de controle.

Considerando o valor de tensão de entrada do divisor $V_{1}=600 \mathrm{kV}$ e $V_{2}=$ $600 \mathrm{~V}, \mathrm{FE}$ desejado $\approx 1000: 1$. E utilizando o FE calculado pelo $V_{1}$ e $V_{2}$ e fixando o valor do resistor de alta tensão $R_{1}=2492,6 \Omega$ (resistor com 4 camadas), é obtido o valor ôhmico do resistor de baixa tensão por meio de

$$
F E=\frac{R_{1}}{R_{2}}+1
$$

Sendo $R_{1}=2492,6 \Omega$ e FE $=1000$, tem-se

$$
R_{2}=2,495 \Omega
$$


A transmissão do sinal é feita através de um cabo de $50 \Omega$ e 7,5 m, juntamente com uma resistência de casamento $R_{o}=50 \Omega$ e impedância do instrumento $R_{\text {in }}=Z_{\text {osc }}=1 \mathrm{M} \Omega$.

A impedância do atenuador foi definida em $Z_{1}=47 \Omega$ e $Z_{2}=3 \Omega$, mantendo o casamento de impedâncias do circuito. A Figura 29 apresenta o circuito do sistema de medição utilizando um osciloscópio como registrador digital.

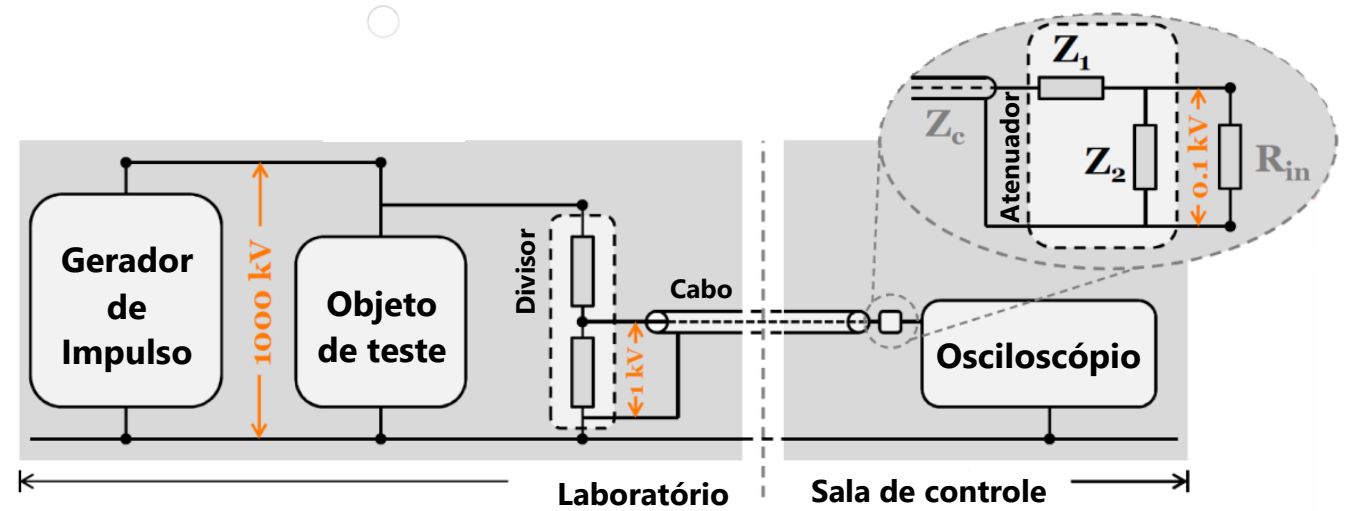

Figura 29: Circuito de geração e medição apresentando cada componente do sistema.

A impedância de casamento $Z_{c}$ está correlacionada à transferência máxima de potência do circuito e deve ser igual ao conjugado da impedância do cabo. Se o circuito não estiver com o casamento realizado corretamente, poderá refletir uma parte do sinal emitido, uma vez que, à medida que a frequência aumenta, as componentes indutivas e capacitivas podem influenciar consideravelmente. Não havendo o casamento de impedâncias, uma fração desse sinal retorna à fonte de origem e nela é dissipada, causando consequentemente erros significativos de medição. Logo, para minimizar esses erros, o cabo de medição deve ser sempre casado na extremidade onde será efetuada a medição [38,39]. A Figura 30 mostra o atenuador resistivo utilizado e a impedância de $50 \Omega$ que serve de acoplamento adicional na entrada do osciloscópio.

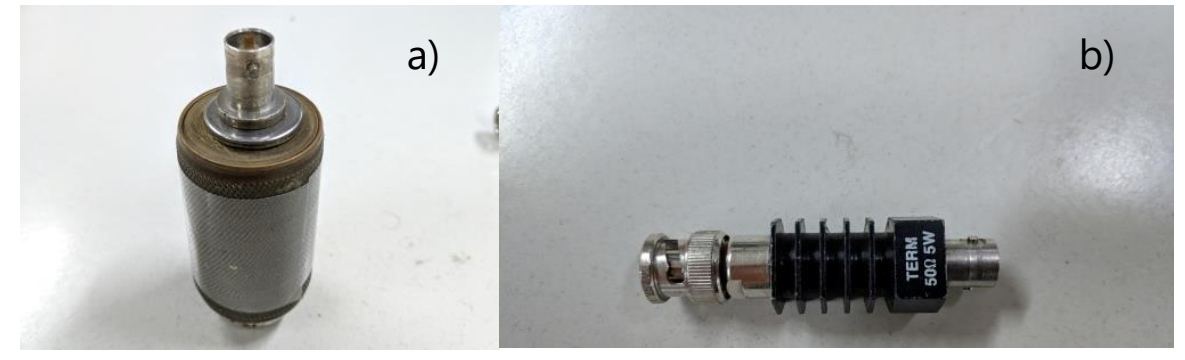

Figura 30:a)Atenuador resistivo. b) impedância de casamento. 


\section{2.}

\section{Construção do resistor de alta tensão}

A técnica utilizada na construção do divisor de alta tensão foi baseada no método de enrolamento tipo Wenner, que consiste em enrolar um fio condutor em um núcleo principal com um núcleo auxiliar em paralelo. O núcleo principal utilizado foi o tarugo de PVC, já o núcleo auxiliar utilizado foi a fibra óptica. O enrolamento do fio condutor neste método nunca chega a completar uma volta completa, apenas indo e retornando no mesmo caminho no sentido oposto à outra espira através do núcleo auxiliar, conforme a Figura 31. Este tipo de enrolamento implica alguns desafios, visto que ele só é possível ser executado manualmente, construído de forma artesanal. O objetivo de utilizar este tipo construtivo é minimizar os efeitos da indutância, já que ao formar o fluxo magnético nas bobinas ambas se anularão. A minimização do efeito indutivo tem em vista o bom desempenho dinâmico do divisor de tensão para a aplicação em medição de impulsos de tensão. Com cada camada de enrolamento adicional, observa-se que as indutâncias sofrem uma atenuação e, consequentemente, o comportamento dinâmico do divisor tende ser cada vez mais linear e estável à medida que a frequência é elevada [40].
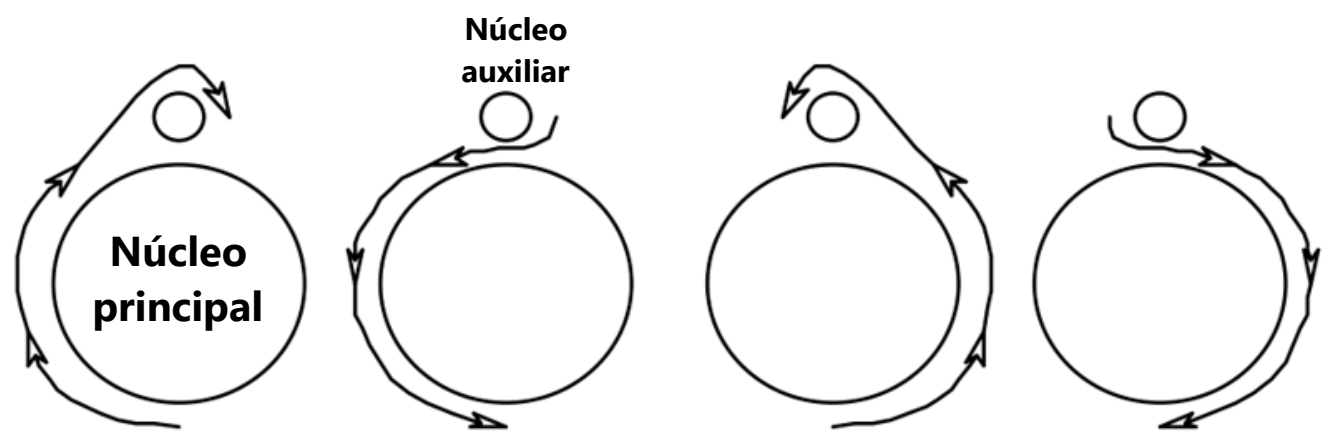

Figura 31: Método de enrolamento tipo Wenner [6].

O método de enrolamento tipo Wenner foi proposto por Frank Wenner, físico americano, por volta de 1930, com o mesmo objetivo de manter a indutância muito baixa em aplicações de alta frequência. O protótipo da década de 30 se encontra atualmente no museu do NIST (National Institute of Standards and Technology), conforme a Figura 32. 


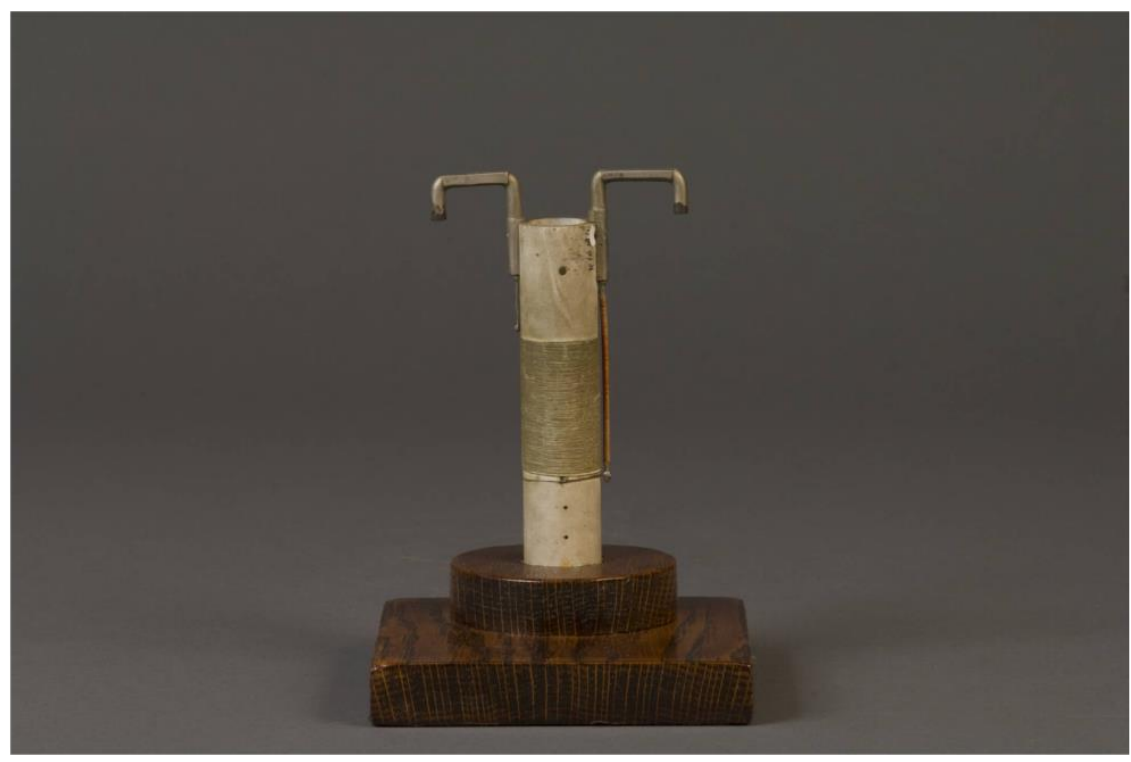

Figura 32: Non-Reactive Wenner Type Resistor. National Institute of Standards and Technology Digital Collections, Gaithersburg, MD 20899.

Foi determinada a construção de 4 camadas de enrolamentos sobrepostos no total, com o objetivo de dividir a intensidade da corrente elétrica que irá circular pelo divisor de alta tensão, e consequentemente atenuar o efeito da indutância no divisor. Este conceito também foi usado na confecção do resistor de baixa tensão do divisor.

A confecção da primeira camada é apresentada na Figura 33 a seguir.

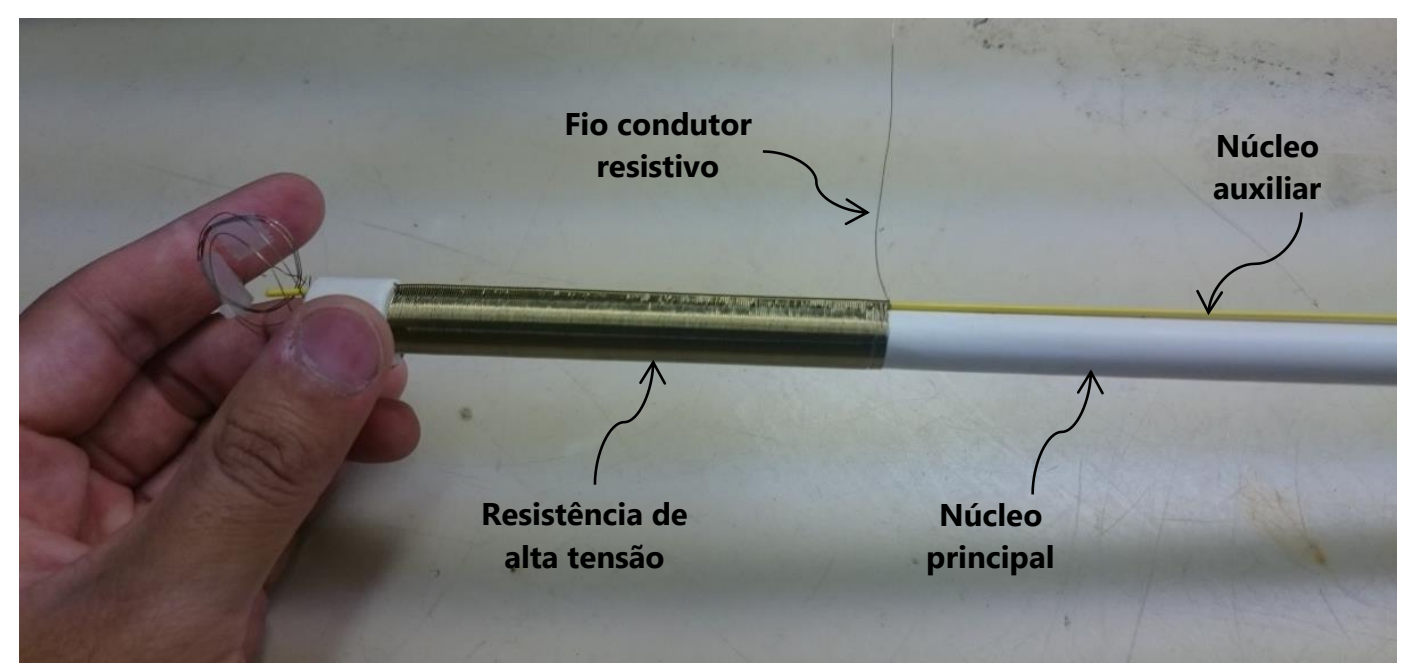

Figura 33: Construção da primeira camada da resistência de alta tensão.

Após o término de cada camada foi realizada uma avaliação parcial do comportamento dinâmico por meio de uma ponte RLC realizando a varredura em uma determinada faixa de frequência. $\mathrm{O}$ instrumento de precisão utilizado foi o 
Quadtech LCR 7600, que possui uma faixa de frequência de $10 \mathrm{~Hz}$ a $2 \mathrm{MHz}$, e também foi utilizado um multímetro digital de precisão Fluke 8,5 dígitos para medir a resistência CC, conforme a Figura 34.

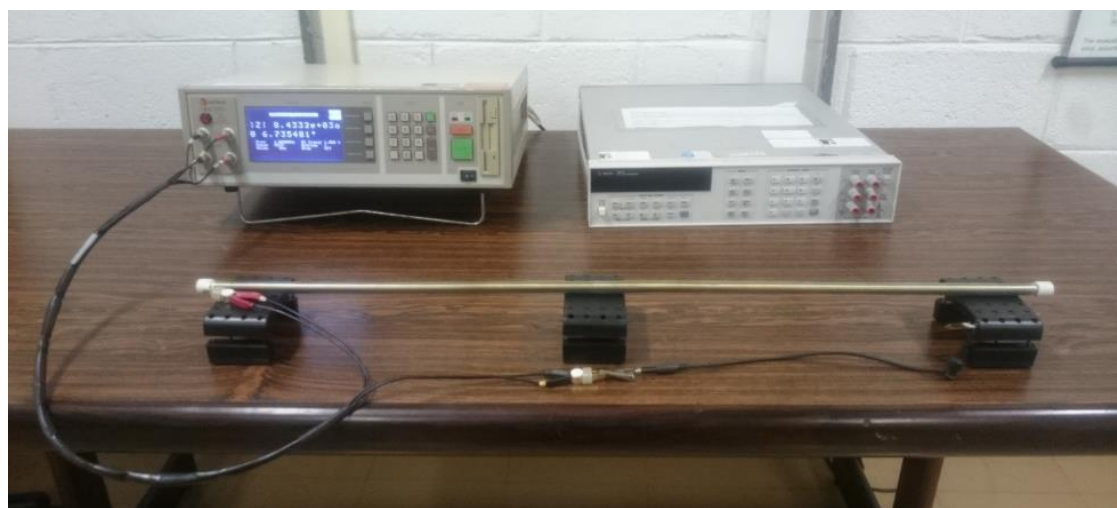

Figura 34: Medição do resistor de alta tensão por ponte RLC e multímetro.

Os parâmetros medidos nesta verificação foram resistência, ângulo da impedância, faixa de frequência e indutância. É possível perceber que, a cada camada sobreposta, ocorre uma associação em paralelo a fim de se obter a resistência equivalente do resistor de alta tensão.

Os gráficos da Figura 35 à Figura 42 mostram as curvas da impedância, ângulo da impedância, resistência e indutância em função da frequência, à medida em que se aumenta o número de camadas.
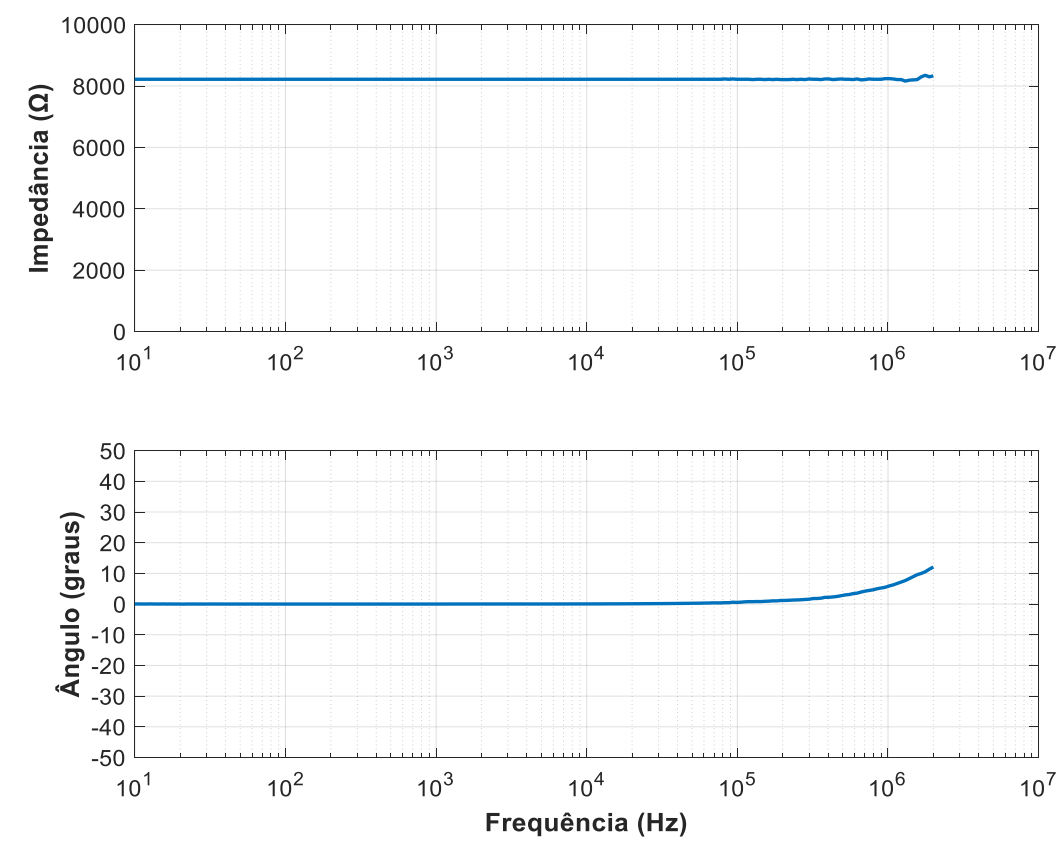

Figura 35: Curva de impedância e ângulo pela frequência da primeira camada do resistor de alta tensão. 

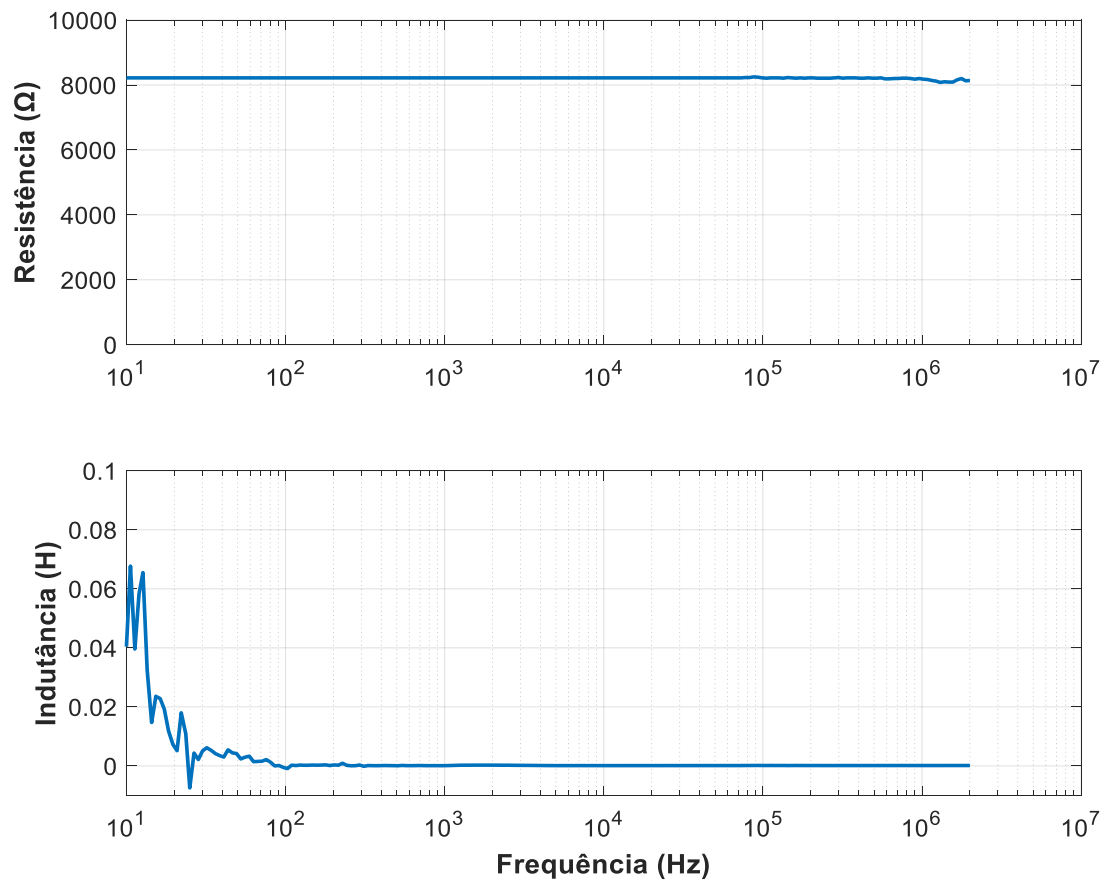

Figura 36: Curva de resistência e indutância pela frequência da primeira camada do resistor de alta tensão.
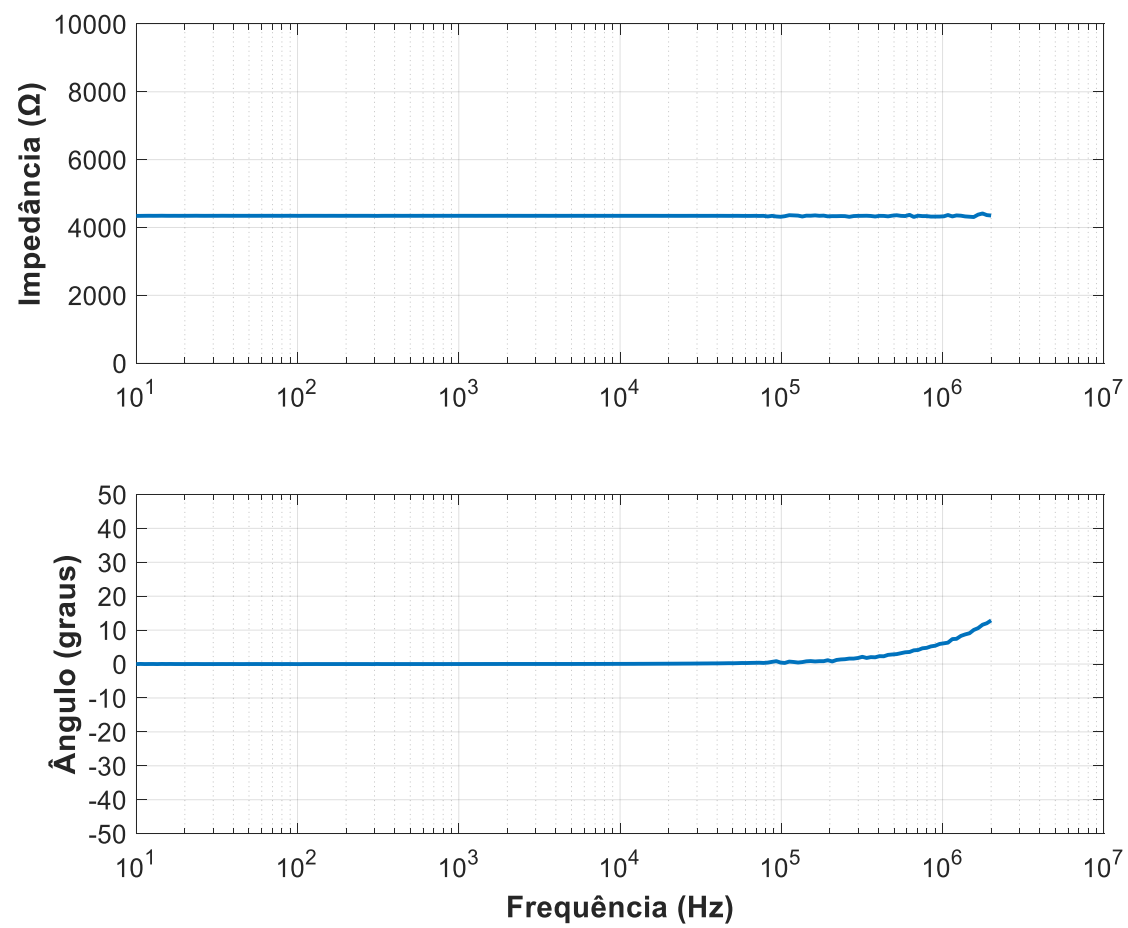

Figura 37: Curva de impedância e ângulo pela frequência do resistor de alta tensão com duas camadas. 

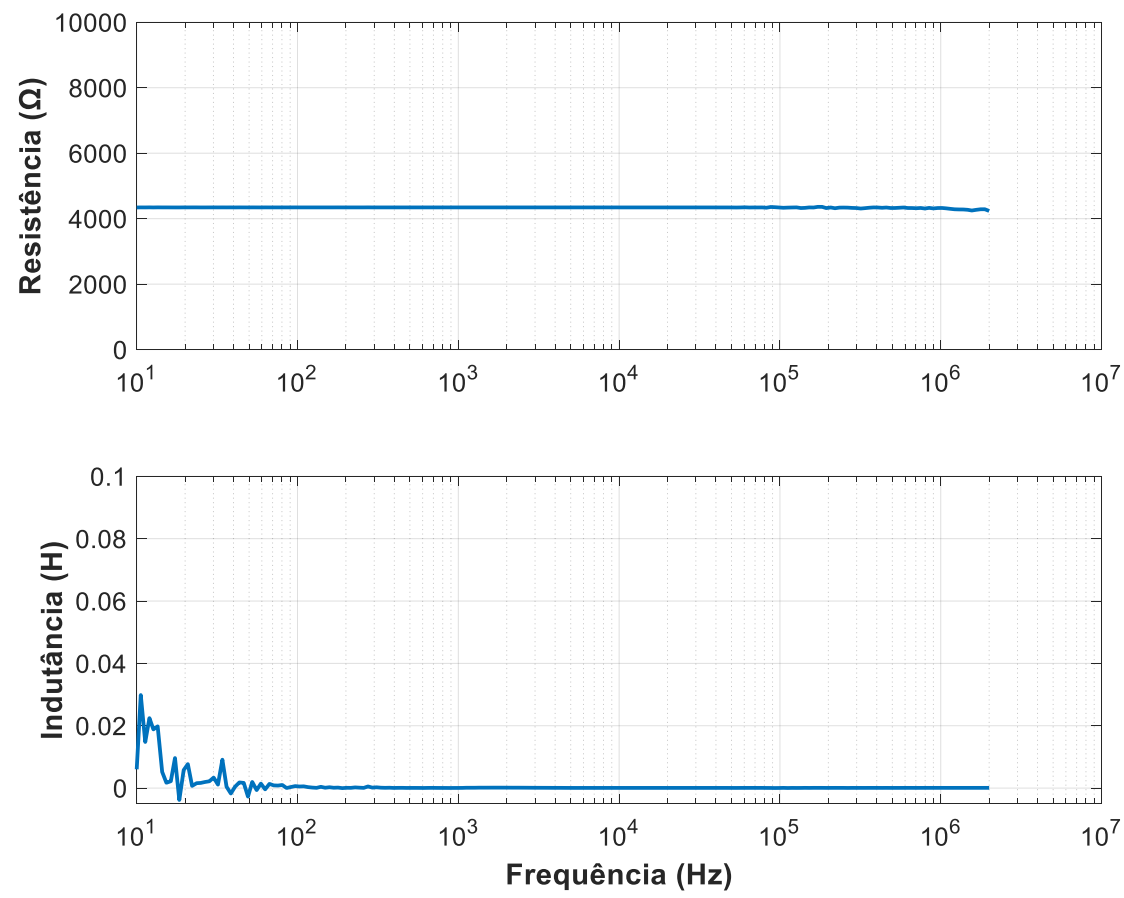

Figura 38: Curva de resistência e indutância pela frequência do resistor de alta tensão com duas camadas.
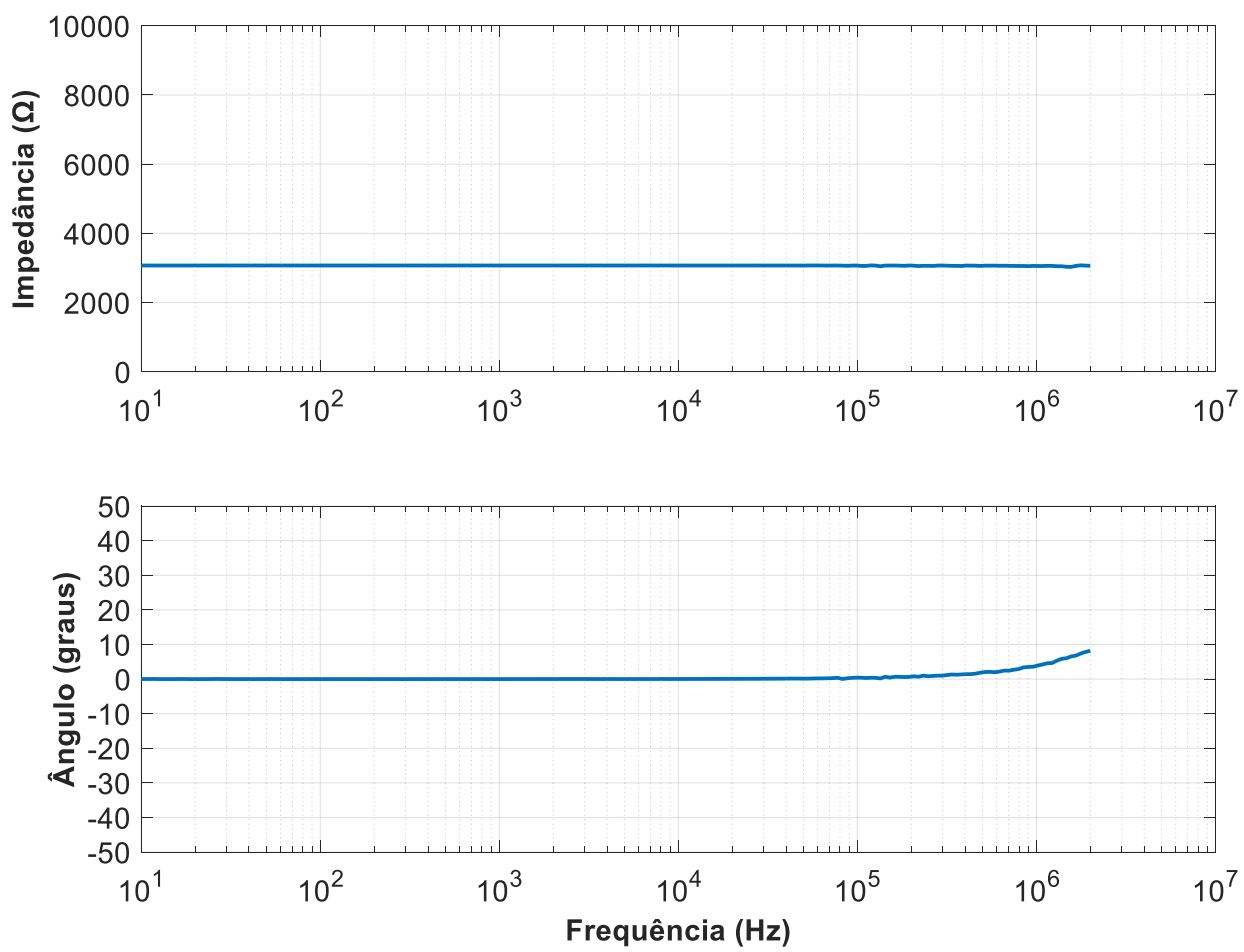

Figura 39: Curva de impedância e ângulo pela frequência do resistor de alta tensão com três camadas. 

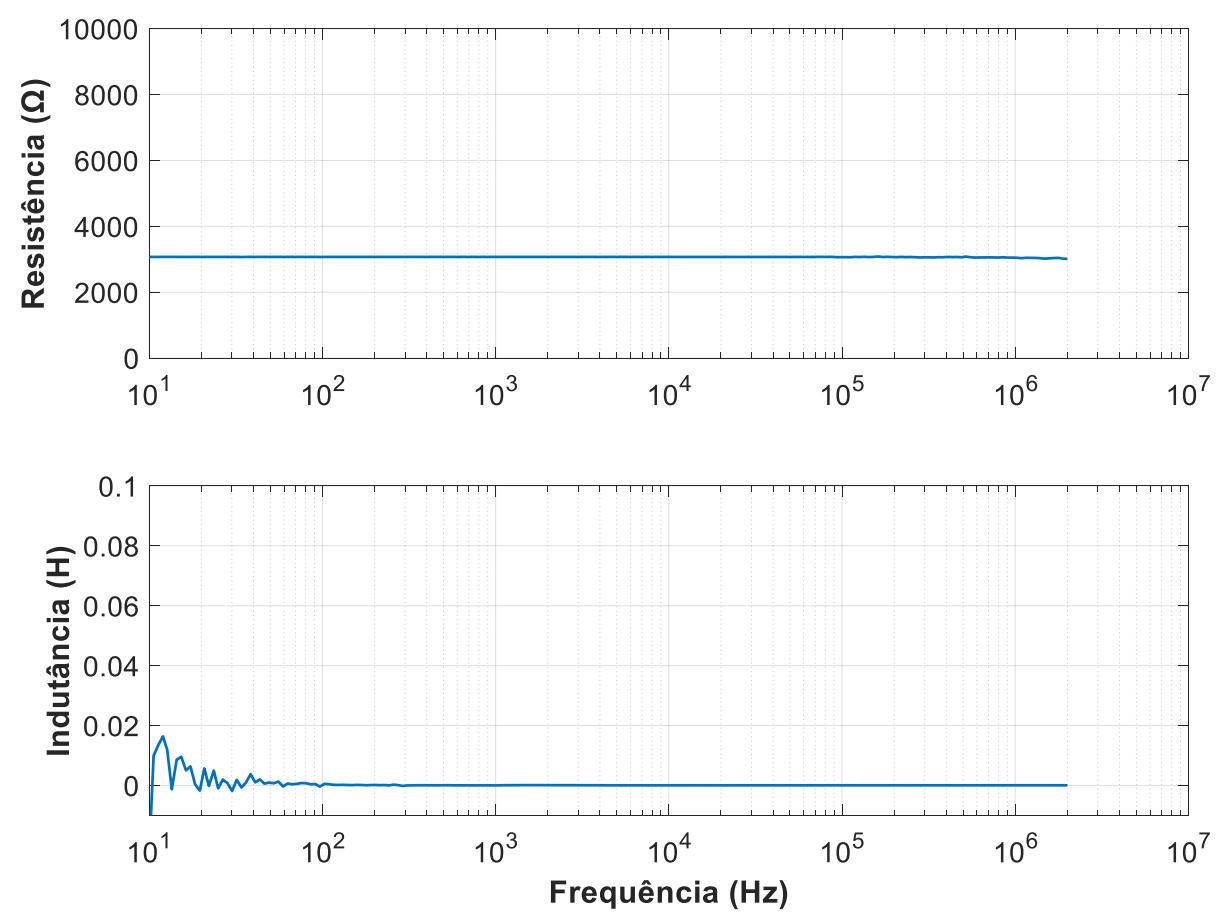

Figura 40: Curva de resistência e indutância pela frequência do resistor de alta tensão com três camadas.
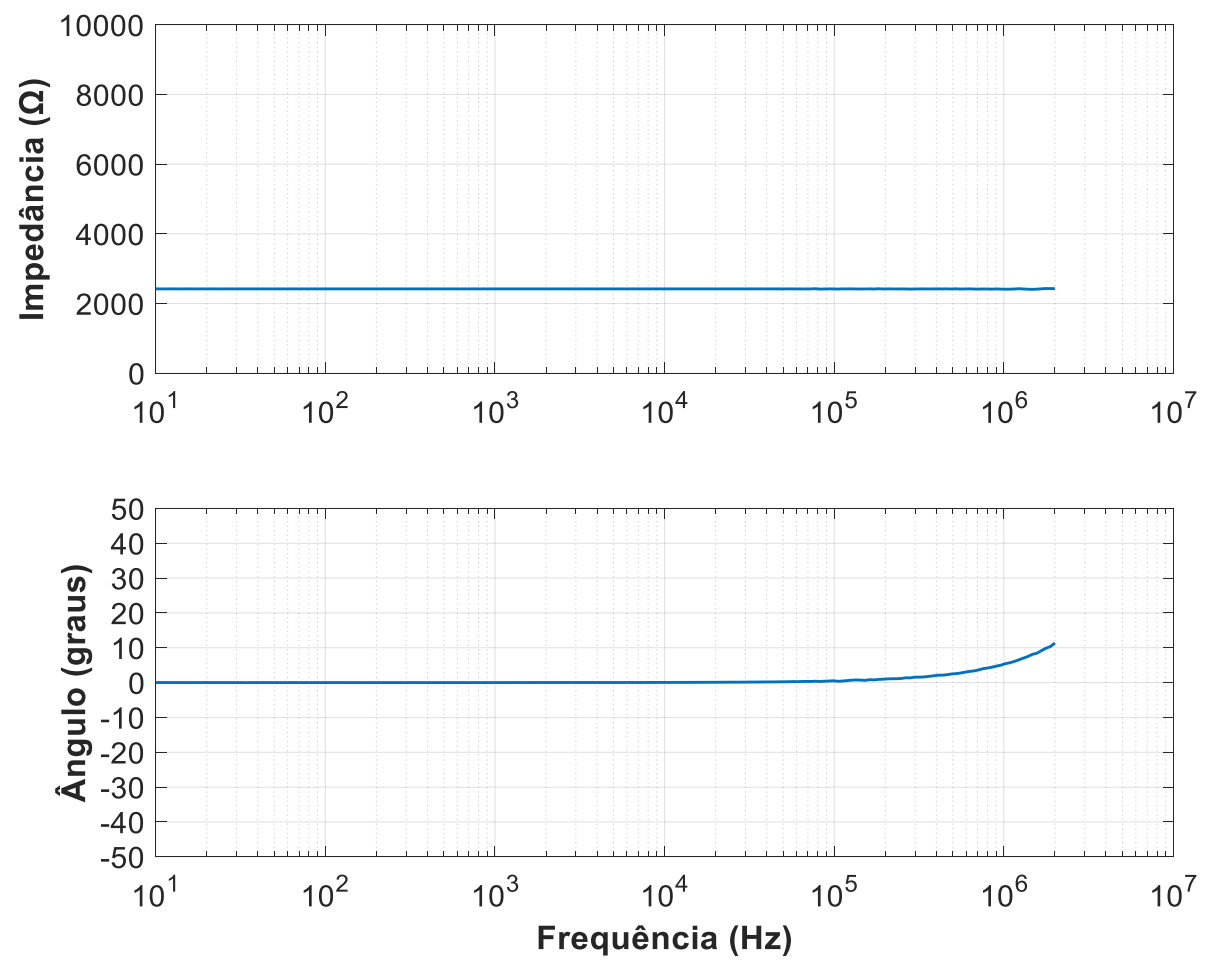

Figura 41: Curva de impedância e ângulo pela frequência do resistor de alta tensão com quatro camadas. 

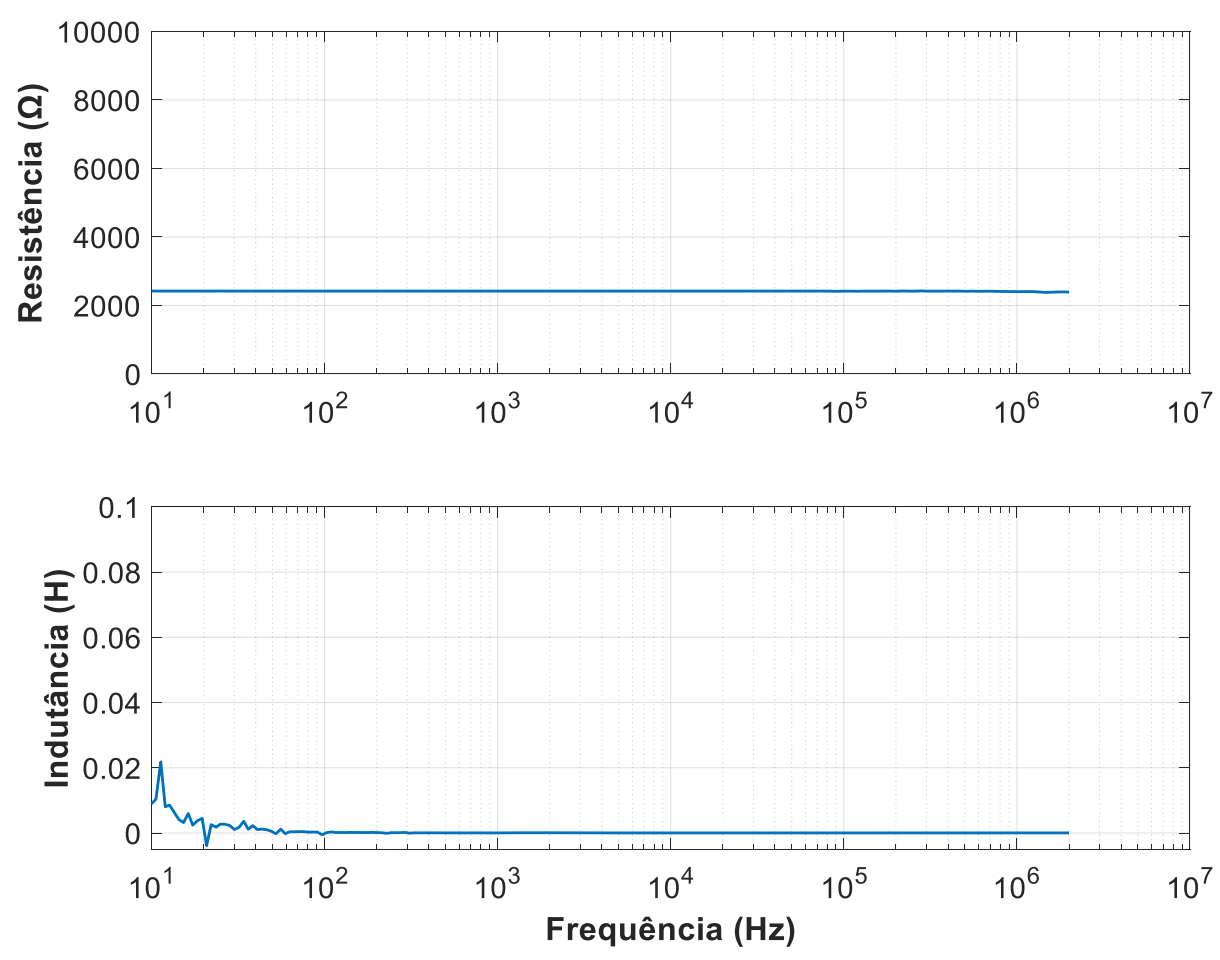

Figura 42: Curva de resistência e indutância pela frequência do resistor de alta tensão com quatro camadas.

As variações nas medições da indutância em baixa frequência são relativamente pequenas e desconsideradas visto que o sistema não opera bem nesta faixa de frequência e que também ocorre uma atenuação proporcional ao número de camadas.

Para poder apresentar melhor os resultados da resistência, e em especial a variação da indutância à medida que aumenta o número de camadas, foi realizada a medição destes parâmetros, mostrados nas Figura 43 a Figura 45. A variação da frequência se deve ao ajuste automático do instrumento.

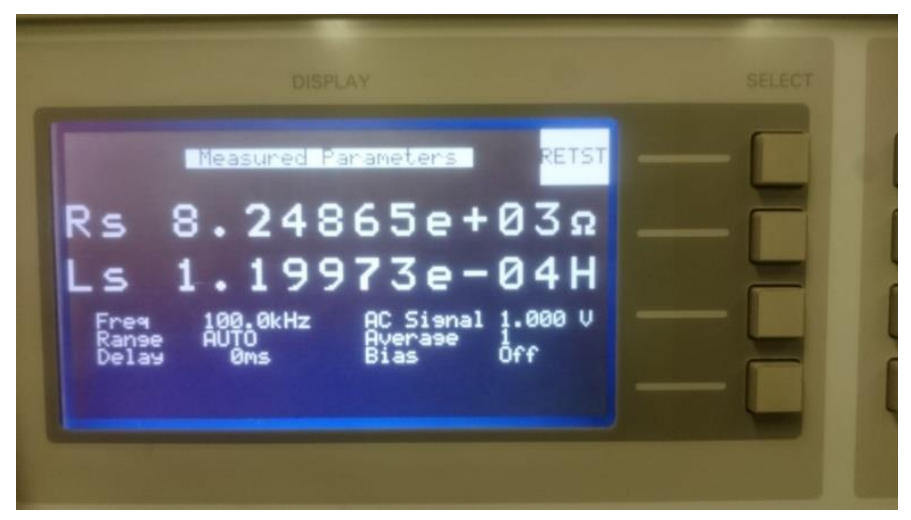

Figura 43: Leitura da resistência e da indutância da primeira camada do resistor de alta tensão. 


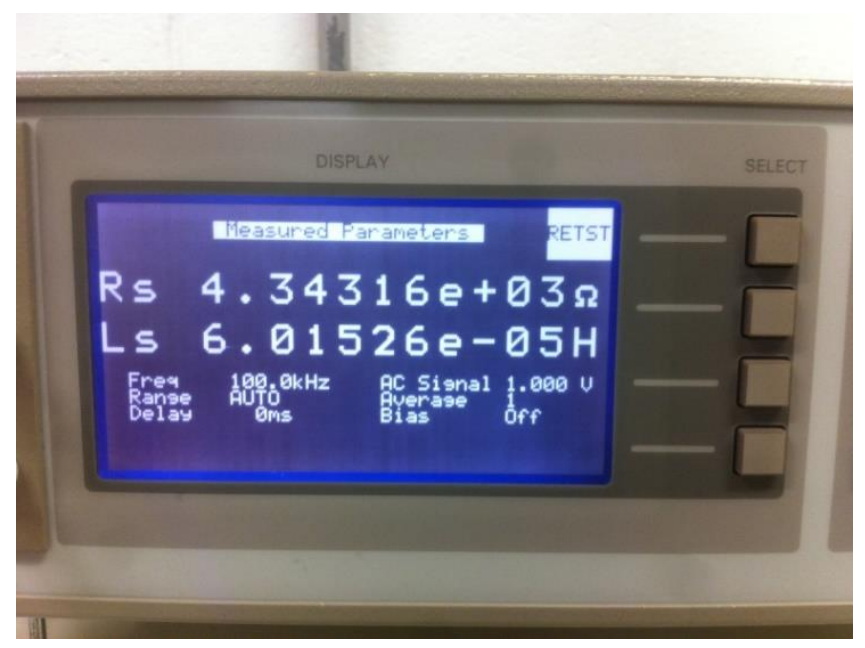

Figura 44: Leitura da resistência e da indutância da segunda camada do resistor de alta tensão.

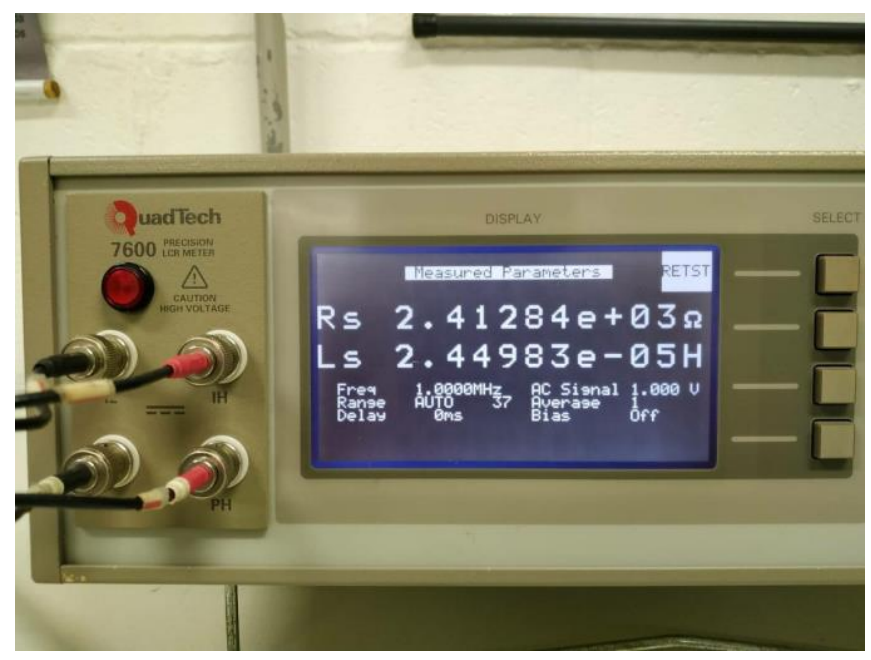

Figura 45: Leitura da resistência e da indutância da quarta camada do resistor de alta tensão.

\section{3.}

\section{Construção do resistor de baixa tensão}

A princípio, a construção da unidade secundária do divisor, composta pelo resistor de baixa tensão, foi desenvolvida através da carcaça de um shunt de medição, enrolando o fio condutor da própria estrutura, como é apresentado na Figura 46. Como no caso do resistor de alta tensão, foram realizadas 4 camadas de enrolamento tipo Wenner. 


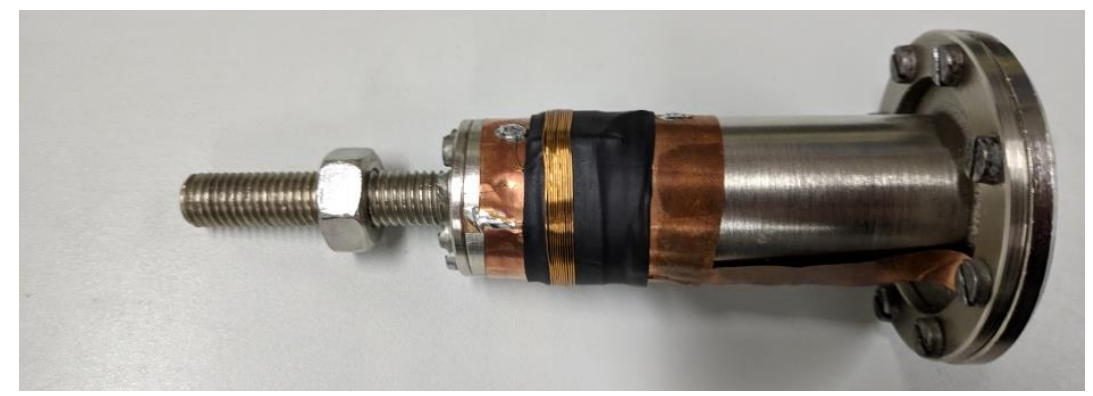

Figura 46: Estrutura da unidade secundária do divisor composta por quatro camadas de enrolamento.

O mesmo apresentou um valor de resistência de $2,416 \Omega$, como apresenta a Figura 47.

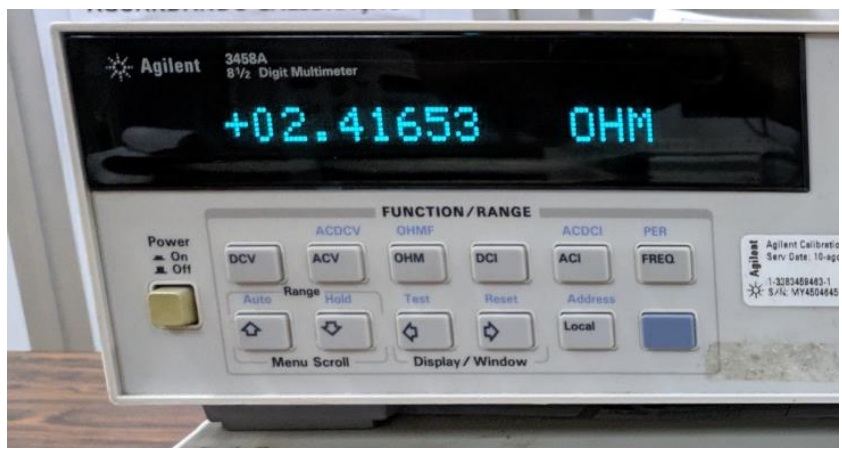

Figura 47: Valor ôhmico da unidade de baixa tensão do divisor.

Para uma verificação do desempenho de múltiplas camadas aplicadas também no resistor de baixa tensão foi construída outra unidade secundária, com o mesmo material, porém utilizando resistores de precisão de fabricação industrial da CADDOCK, como o mostrado na Figura 48.

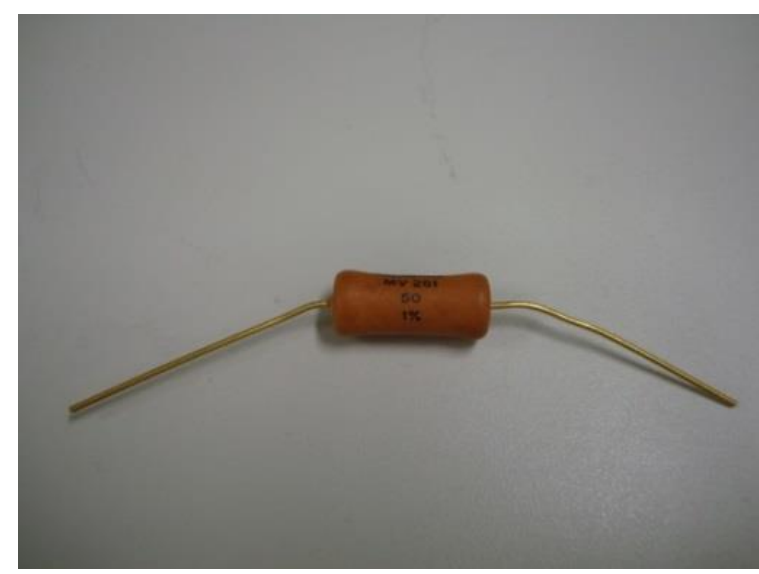

Figura 48: Resistor de fabricação industrial CADDOCK. 
Foram utilizados 4 resistores de $10 \Omega$ e $1 \%$ de tolerância, para obter um resultado próximo ao calculado e ao enrolado artesanalmente. Uma primeira verificação, que tem como objetivo definir e comparar os valores de indutância entre as duas opções apresentadas, é apresentada na Figura 49.
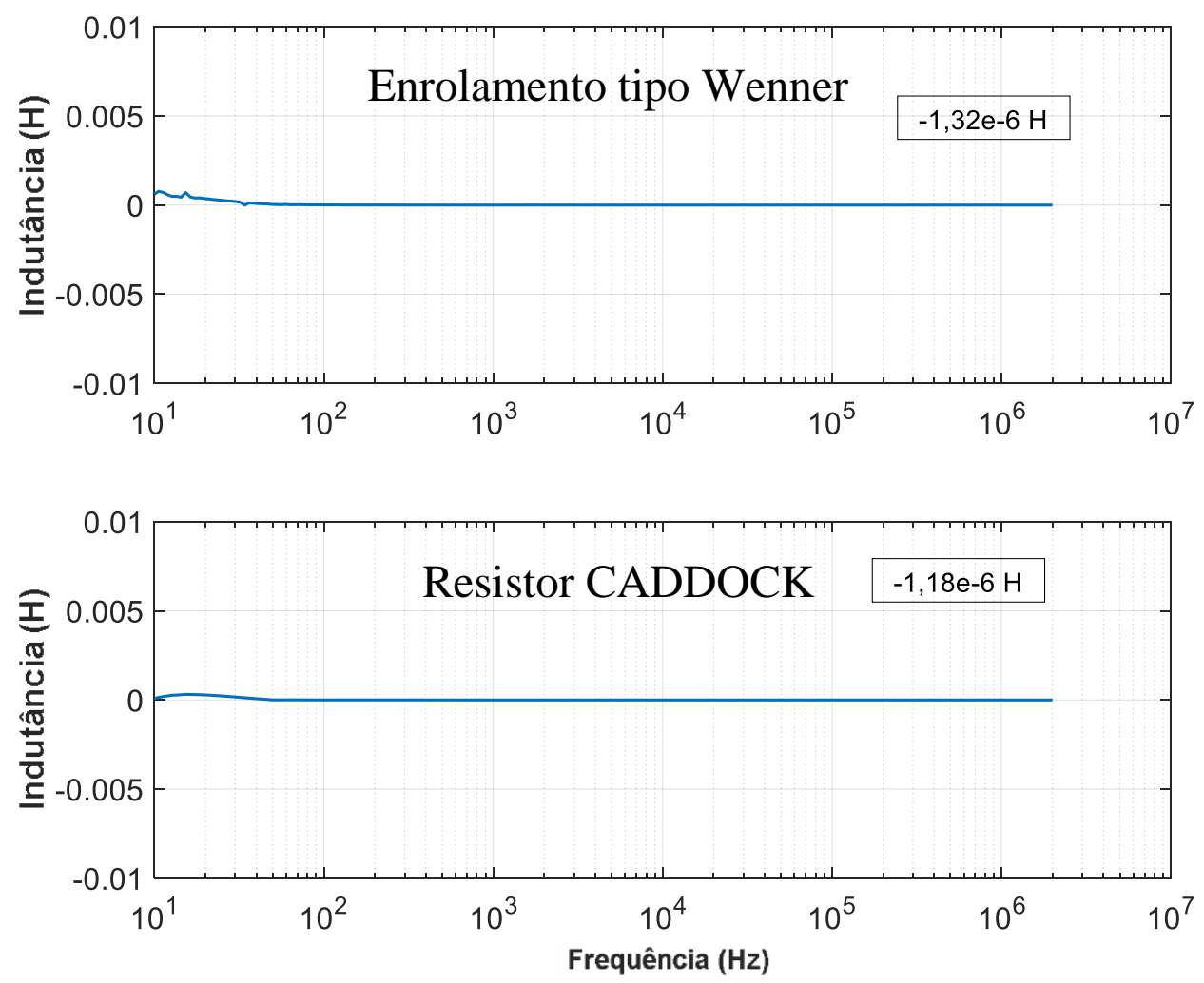

Figura 49: Curva da indutância em função da frequência das unidades secundárias.

\subsection{1.}

\section{Análise das unidades secundárias}

Após ter definido as duas unidades secundárias que serão utilizadas nesta análise comparativa, e também de posse de todos os componentes do divisor, conforme Figura 50, pôde-se efetuar a montagem do divisor de alta tensão e a montagem do arranjo para avaliação do desempenho dinâmico do divisor, como é visualizado na Figura 51. 


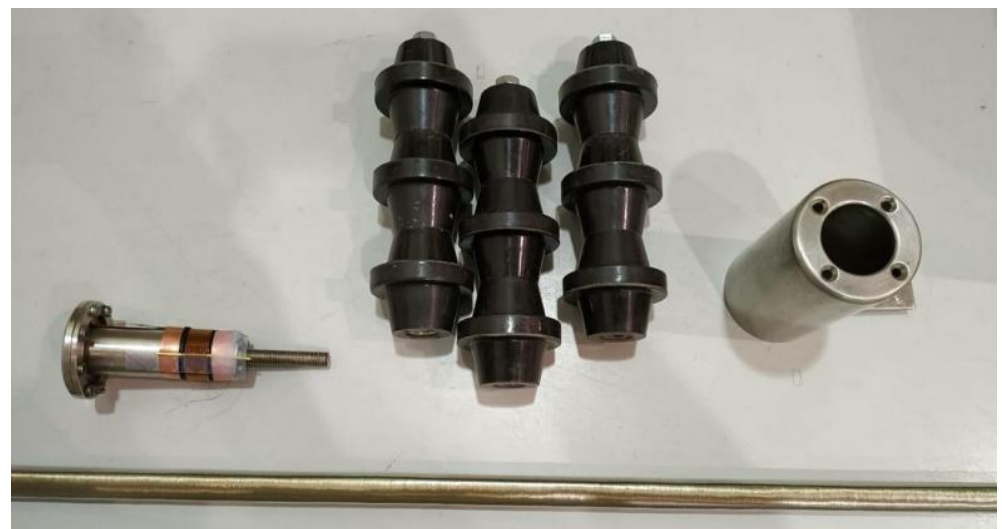

Figura 50: Componentes da montagem do divisor de alta tensão.

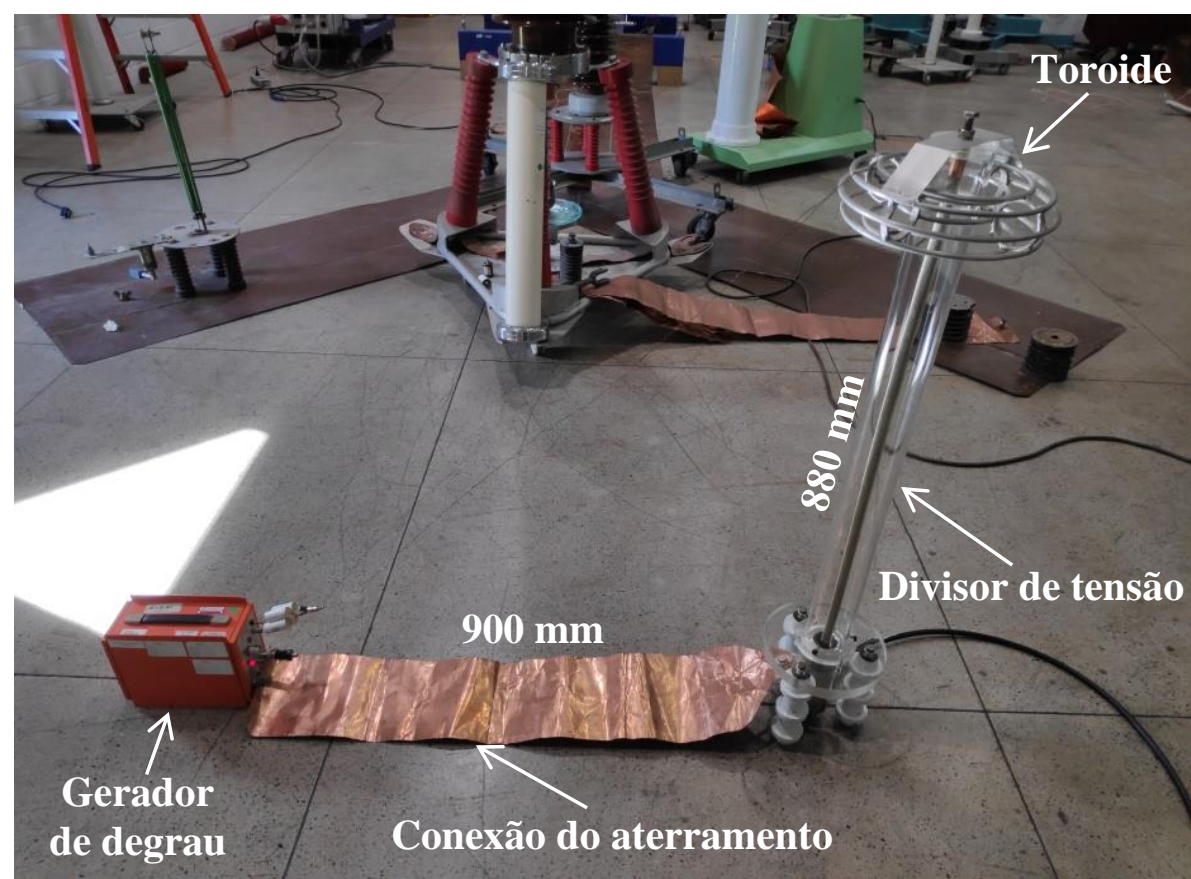

Figura 51: Configuração recomendada para análise do desempenho dinâmico do divisor de alta tensão.

A avaliação do desempenho dinâmico foi realizada pela análise da resposta ao degrau. Um gerador de degrau com tensão $\cong 90 \mathrm{~V}$ de crista e com tempos de subida com ordem de 4 ns foi posicionado no lugar do isolador sob ensaio. Um osciloscópio com largura de banda plena de $1 \mathrm{GHz}$ foi utilizado para aquisição e o processamento do sinal foi feito pelo software STERAL, programa computacional para cálculo e análise de parâmetros da resposta ao degrau [41,42]. São apresentadas, da Figura 52 à Figura 56, as respostas ao degrau das 4 camadas do resistor construído artesanalmente e do resistor da caddock. 


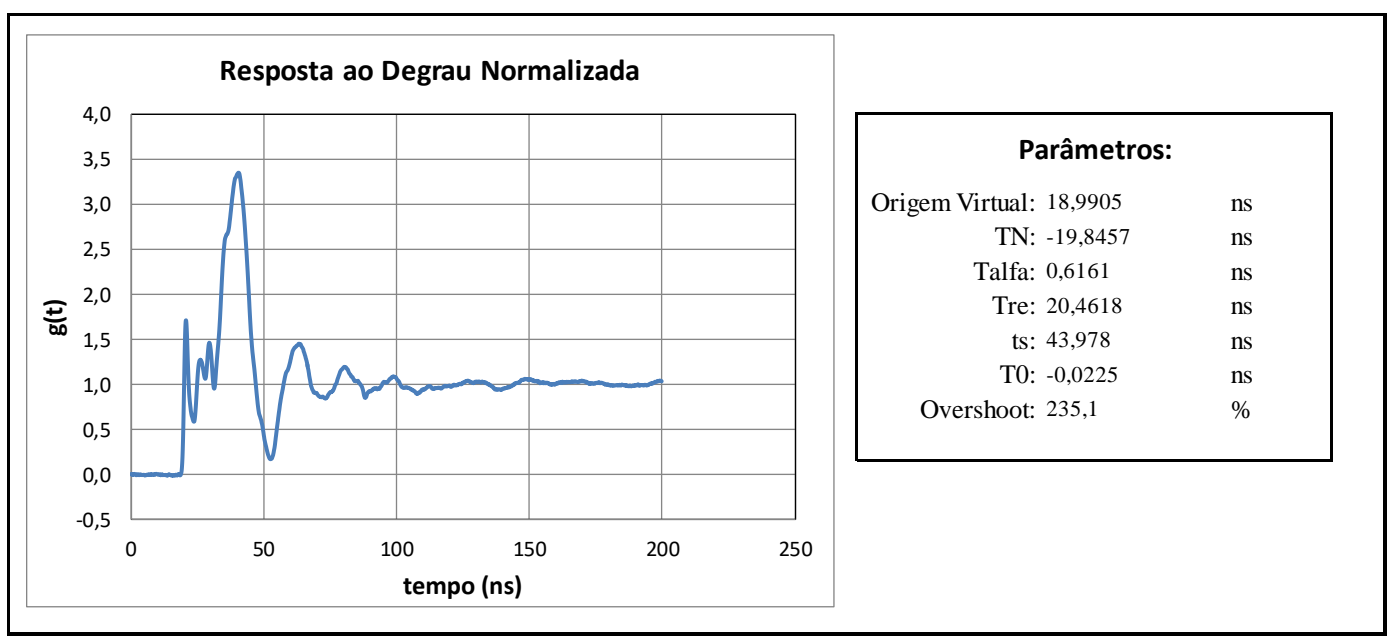

Figura 52: Resposta ao degrau do resistor de baixa tensão com 1 camada.

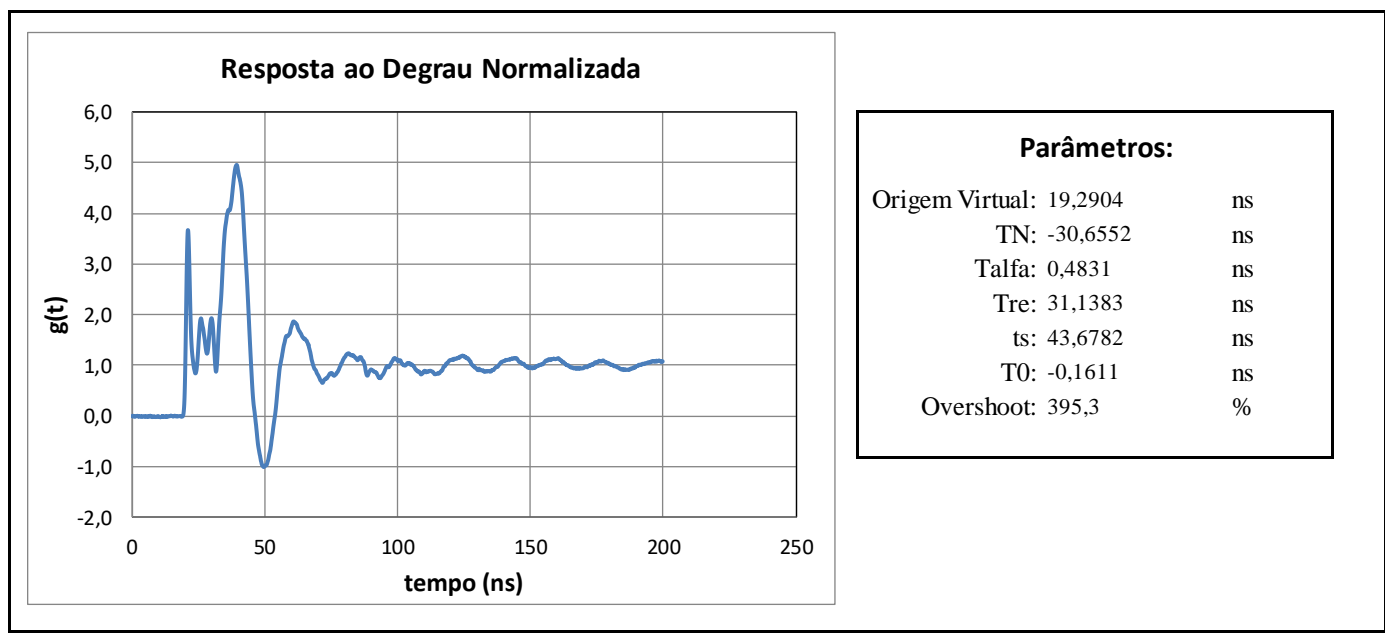

Figura 53: Resposta ao degrau do resistor de baixa tensão com 2 camadas.

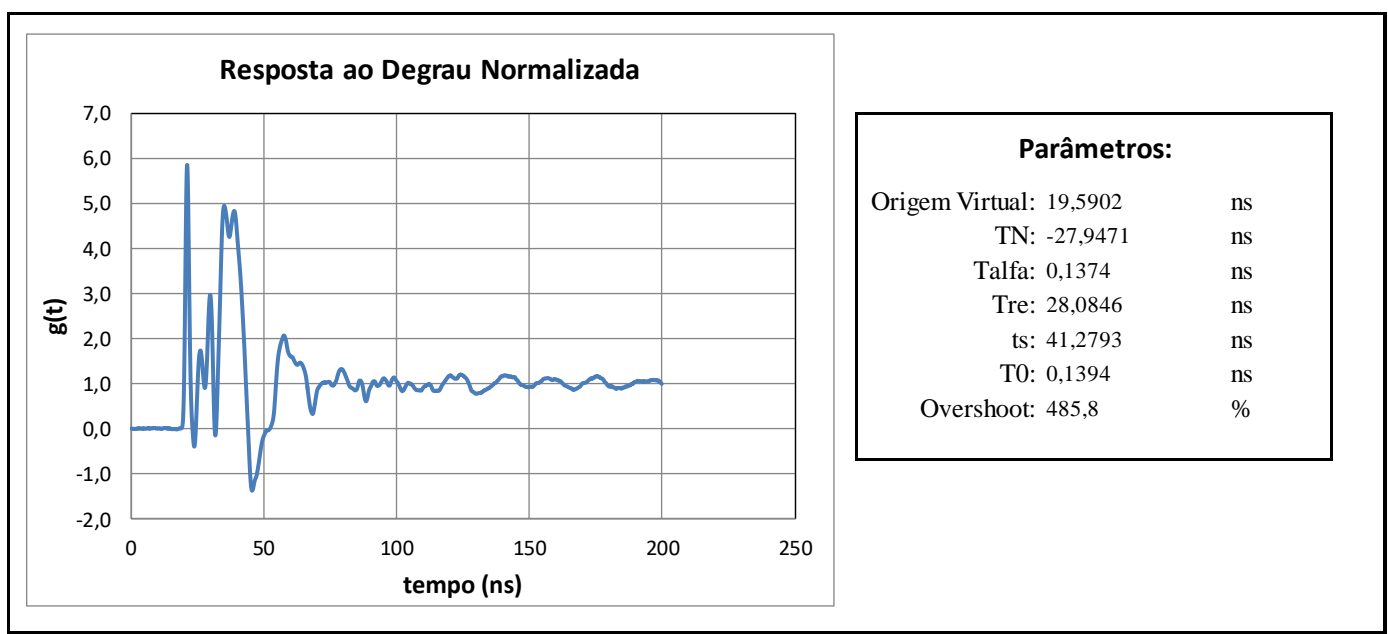

Figura 54: Resposta ao degrau do resistor de baixa tensão com 3 camadas. 


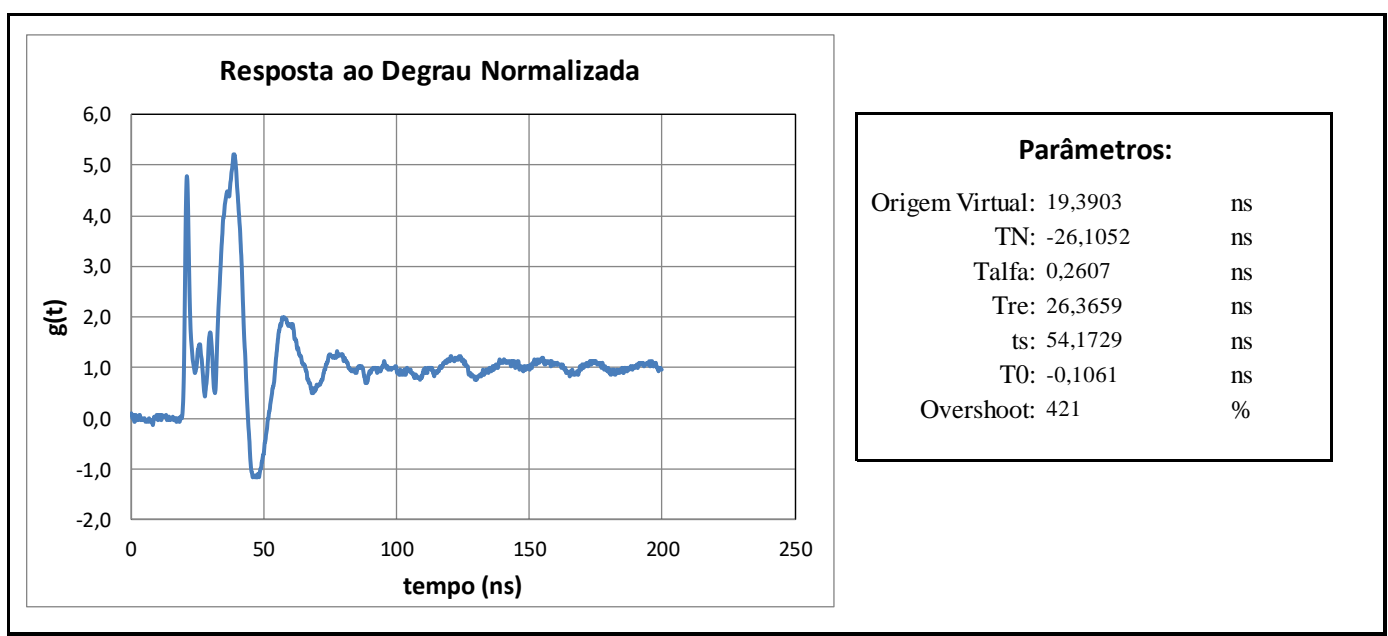

Figura 55: Resposta ao degrau do resistor de baixa tensão com 4 camadas.

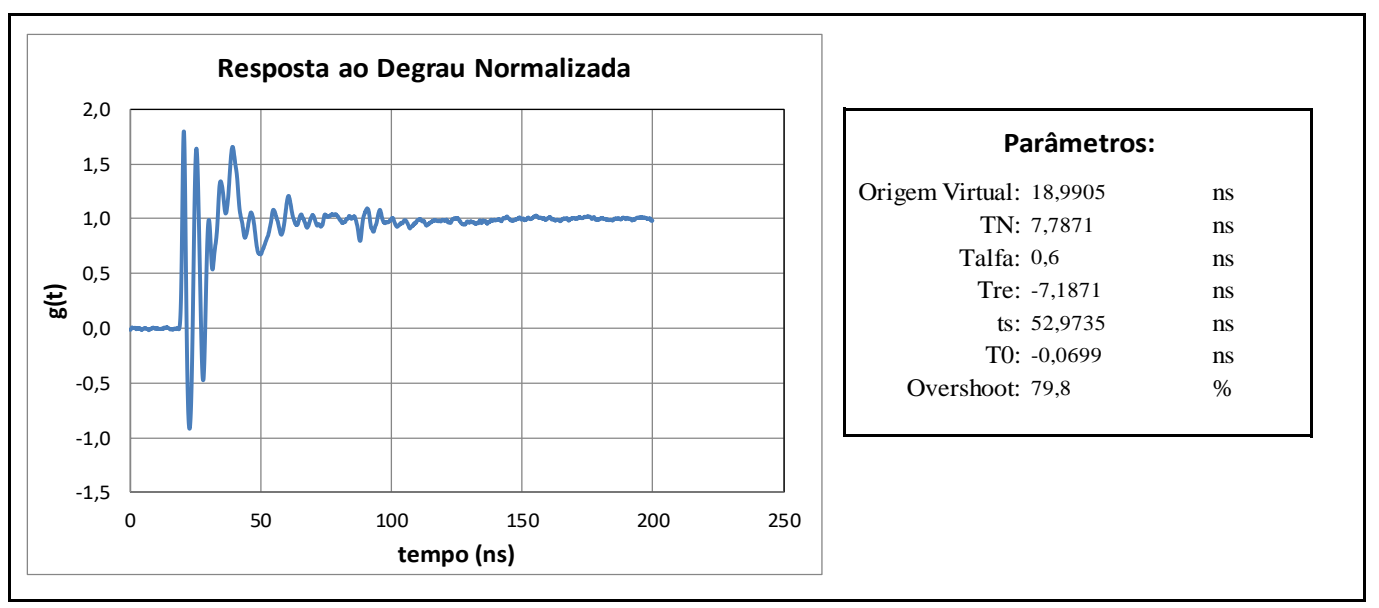

Figura 56: Resposta ao degrau do resistor de baixa tensão com o resistor CADDOCK.

Conclui-se que, à medida que aumenta o número de camadas com método de enrolamento Wenner, a indutância do resistor diminui, assim como é visto na unidade de alta tensão, e consequentemente nota-se nos resultados acima que a redução do parâmetro $T_{\alpha}$ é proporcional ao número de camadas em paralelo. Além disso, o projeto da unidade de baixa tensão utilizando resistores de alto desempenho possui um desempenho equivalente ao resistor com somente uma camada. Logo, foi preferível utilizar a unidade enrolada pelo método manual, por apresentar o melhor desempenho, projetado de acordo com as necessidades do divisor.

Vale ressaltar que o resistor Caddock comparado também é de aplicação em sistemas que requerem alta precisão e um bom desempenho, além de possuir um baixo nível de indutância. Ambos os resistores foram avaliados nas mesmas 
condições ambientais. As figuras 57 e 58 apresentam os gráficos de resistência em função da temperatura $[43,44]$.

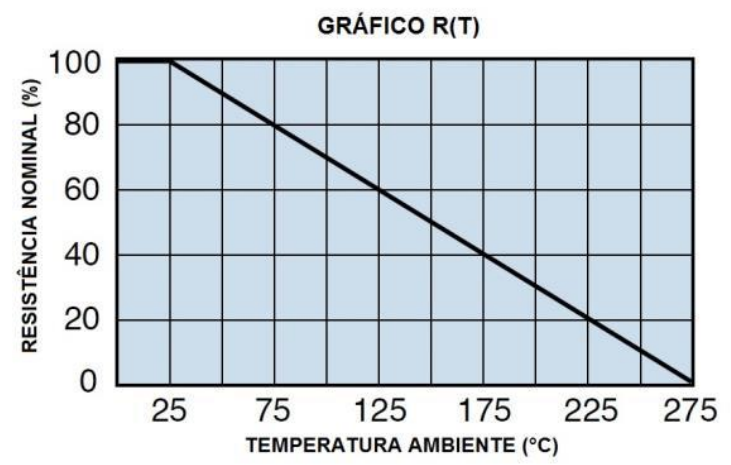

Figura 57: Curva da resistência em função da temperatura do resistor CADDOCK.

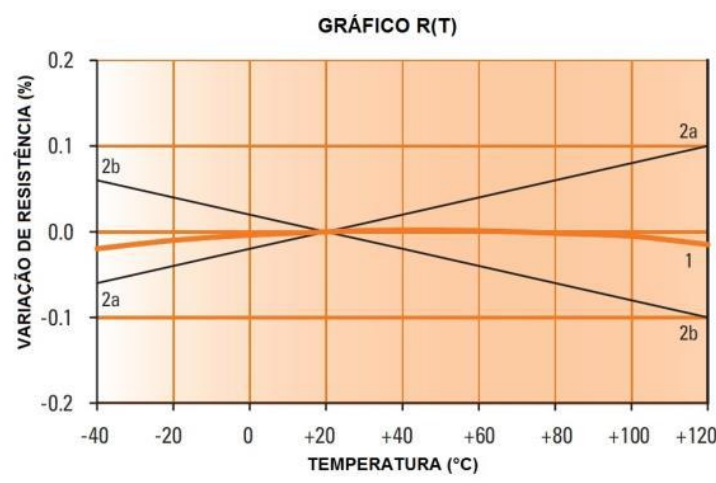

Figura 58: Curva da resistência em função da temperatura do fio resistivo ISAOHM.

Considerando a verificação destes aspectos construtivos, o divisor de tensão se mostrou adequado para a medição de impulsos de ensaios de perfuração em isoladores. A construção do divisor com 4 camadas diminuiu consideravelmente o efeito indutivo e manteve o divisor linear. Porém, somente o divisor de tensão estar apto não significa que a medição ocorrerá de forma correta e satisfatória. $\mathrm{O}$ sistema de medição completo necessita estar de acordo com a norma IEC 61211:2004 [5] e também são necessários cuidados específicos para este tipo de ensaio, referentes à mitigação de interferências propícias às condições de ensaio, assuntos que terão continuidade no próximo capítulo. 


\section{4 \\ Processamento de sinais em ensaios de impulso de perfuração em isoladores}

Este capítulo descreve uma abordagem de processamento de sinais provenientes de ensaios em laboratórios com impulsos de alta tensão para perfuração em isoladores utilizando análise multi-resolução baseada na transformada de wavelet. São apresentados resultados qualitativos e quantitativos para diferentes tipos de wavelets estudadas, assim como o melhor desempenho obtido pelo filtro. Para esse ensaio também foi desenvolvido um software para tratamento e análise do sinal. São apresentados também resultados, com a utilização do filtro, para uma comparação interlaboratorial pioneira entre sistemas de medição utilizados em ensaios para perfuração em isoladores.

\section{1. Descrição do problema}

Os impulsos de tensão utilizados em ensaios de perfuração em isoladores são fundamentais para verificar, em laboratório, a qualidade do projeto, da fabricação e dos materiais utilizados em isoladores de vidro ou porcelana para linhas de transmissão e distribuição de energia [45].

A confiabilidade dos resultados deste ensaio é dependente da incerteza na medição dos parâmetros dos impulsos de tensão utilizados, que têm como característica uma frente de onda muito íngreme, com tempo de frente de $100 \mathrm{~ns}$ a 200 ns e valores de crista na ordem de centenas de kilovolts. Porém, em função das características da geração do ensaio de perfuração, é comum se observarem interferências de alta frequência sobrepostas ao sinal de impulso, conforme apresenta a Figura 59. Os impulsos de tensão utilizados nos ensaios de perfuração de isoladores são quantificados por meio da digitalização das formas de onda, que podem ser distorcidas em relação à forma de onda real aplicada, dependendo do desempenho dinâmico do sistema de medição e de fatores externos, devido à contribuição de diferentes fontes de interferência eletromagnética. Com isso, um 
grande desafio é garantir a rastreabilidade metrológica dos sistemas de medição utilizados para que se possam obter resultados comparáveis a outros laboratórios de ensaios em alta tensão.

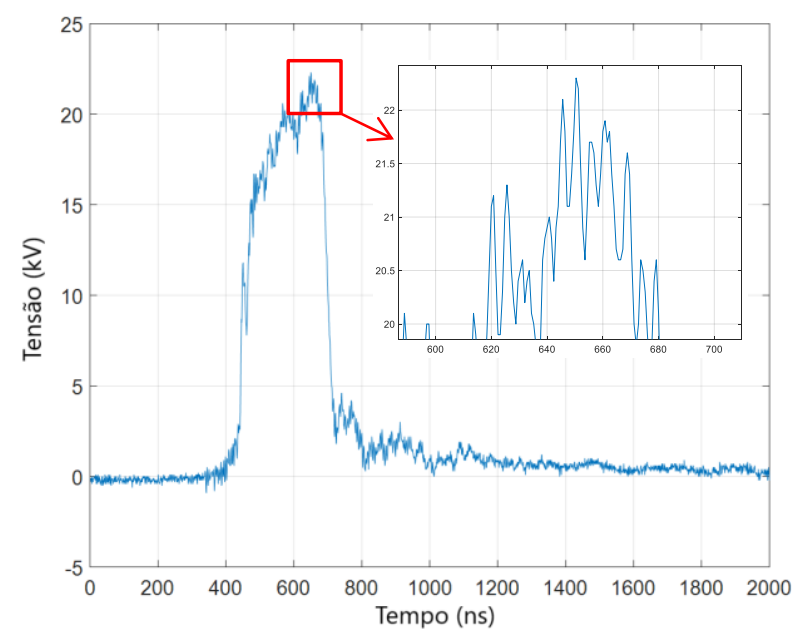

Figura 59: Impulso típico do ensaio de perfuração em isoladores.

Neste caso, para que o sistema de medição possua um desempenho dinâmico adequado e de acordo com os requisitos da norma IEC 61211:2004 [5], é necessário desenvolver um filtro que seja capaz de minimizar os efeitos de interferências eletromagnéticas nos sinais de impulso de tensão. O conceito para esse desenvolvimento está baseado no processamento digital com foco na localização do sinal no tempo e na duração das interferências. Isto é de grande importância em situações mais críticas e complexas como impulsos de perfuração em isoladores. Com isso, o processamento do sinal a ser utilizado deve levar em conta as informações do sinal tanto no domínio do tempo quanto no domínio da frequência.

Alguns trabalhos anteriores já investigaram a remoção de ruídos típicos em ensaios em alta tensão nos impulsos atmosféricos e impulsos atmosféricos cortados na frente [46-48], utilizando análise multi-resolução baseada na transformada de wavelet, que é uma poderosa ferramenta de processamento de sinais. Considerando que o impulso de perfuração em isoladores é cerca de 10 vezes mais rápido que os impulsos atmosféricos convencionais investigados nos trabalhos anteriores, foram necessários novos estudos e desenvolvimentos baseados na transformada de wavelet como ferramenta para remoção destes ruídos para esta aplicação específica. 
O próximo item descreve as formas de onda do tipo Very Fast Transients (VFT), apresentando dados experimentais e simulações computacionais dos mesmos. Em seguida, apresenta-se uma breve introdução à teoria da transformada de wavelet e uma descrição detalhada do método de análise multi-resolução.

\section{2.}

Very Fast Transients

Very Fast Transient (VFT) voltages são impulsos de tensão normalmente unidirecionais com tempo até a crista $\leq 0,1 \mu \mathrm{s}$, com ou sem oscilações sobrepostas na faixa de frequência entre $30 \mathrm{kHz}$ e $100 \mathrm{kHz}$ [49]. Embora o ensaio de perfuração seja normalizado, ainda não existem, na maioria dos Institutos Nacionais de Metrologia (INM), padrões para rastrear os sistemas de medição utilizados.

Com isso, vem a necessidade de se utilizarem técnicas de medição específicas para garantir a rastreabilidade dos sistemas de medição para ensaios de perfuração em isoladores.

Assim como não existe um padrão para calibração em alta tensão de um Sistema de Medição de Impulso de Perfuração (SMIP), também não existe uma forma de onda padronizada de acordo com a norma IEC 60071-1:2006 [50] para este tipo de impulso, classificado como Very Fast Transient (VFT), e se caracterizando apenas como um impulso com uma determinada duração e com componentes significativas em uma faixa de frequência.

\subsection{1.}

\section{Forma de onda experimental}

A Figura 60 apresenta o impulso típico de um ensaio real de perfuração em isoladores no laboratório de alta tensão do Cepel. O principal parâmetro que caracteriza esta forma de onda é o valor de crista, que é extremamente corrompido pela interferência eletromagnética que afeta a medição, apresentando assim uma incerteza de medição muito elevada. Na figura também é apresentada a caracterização deste sinal no domínio da frequência. 

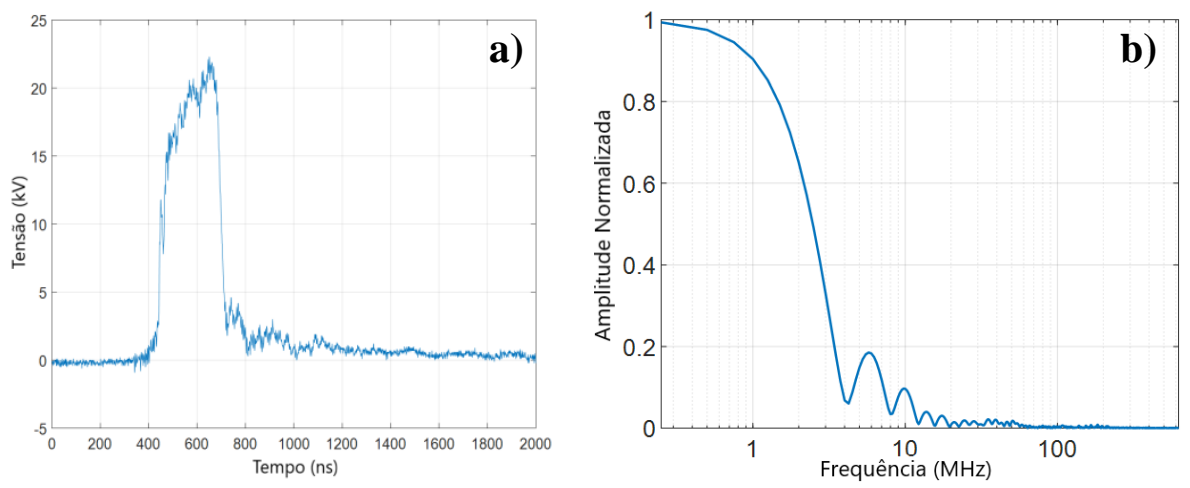

Figura 60: Forma de onda típica de ensaios de impulso de perfuração. a) No domínio do tempo e b) Sua decomposição no domínio da frequência.

A faixa de frequências de interesse situa-se abaixo de $20 \mathrm{MHz}$. Oscilações referentes ao circuito de ensaio raramente possuem frequências acima de $500 \mathrm{kHz}$, e assim a interferência eletromagnética costuma ser caracterizada em frequências acima de $500 \mathrm{kHz}$ até no máximo $10 \mathrm{MHz}$, sendo que o ruído dos digitalizadores utilizados nas configurações de medições em alta tensão possui claramente frequências acima de $10 \mathrm{MHz}$ [51].

\subsection{2.}

\section{Forma de onda simulada}

Com o objetivo de representar, para fins de referência, um impulso típico do ensaio de perfuração de isoladores, foi utilizada uma forma de onda exponencial com amplitude unitária e aproximadamente 200 ns de duração. Estes parâmetros levaram a uma inclinação de $2500 \mathrm{kV} / \mu \mathrm{s}$, o que remete ao especificado na versão anterior da norma IEC 61211:2004 [5], mas que é uma inclinação válida pra esta análise.

Após a simulação da forma de onda exponencial, foi medido empiricamente o ruído a ser adicionado ao sinal simulado, por meio do ensaio de interferência descrito na norma IEC 60060-2:2010 [28], segundo a qual, para se realizar o ensaio, é preciso desconectar a ligação entre o sistema de medição e o sistema de transmissão, mantê-los na posição atual e curto-circuitar os seus terminais, assim gerando uma condição de interferência na entrada do sistema por meio do impulso aplicado em alta tensão.

O sinal exponencial simulado utilizado como referência, com e sem a adição do ruído, é apresentado na Figura 61. 

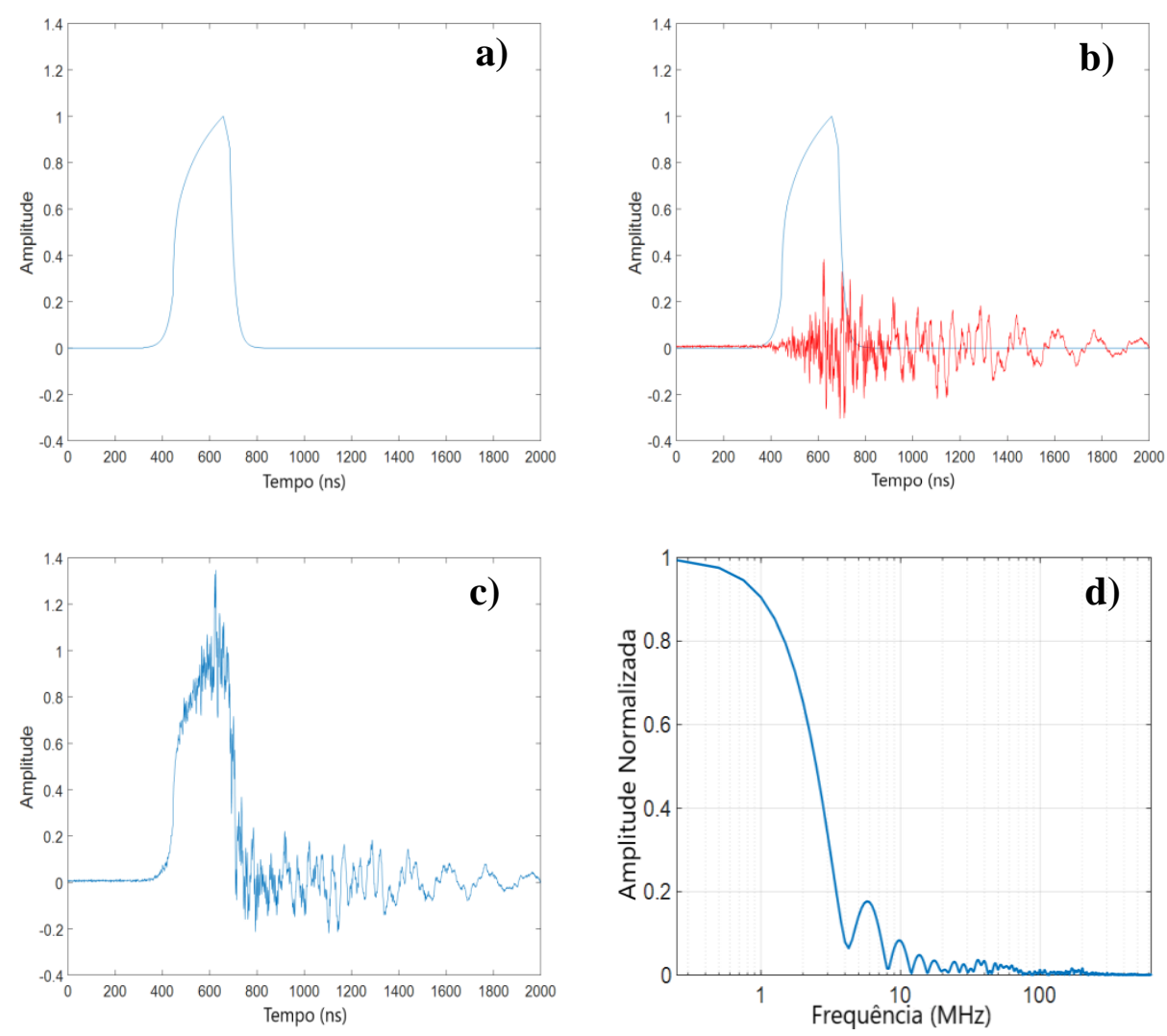

Figura 61: Formas de onda simuladas como referência. a) Forma de onda teórica padrão. b) Forma de onda teórica simulada e ruído c) Forma de onda teórica simulada adicionada ao ruído e d) Forma de onda teórica simulada no domínio da frequência.

É possível constatar, comparando a Figura 61c com a Figura 60a e a Figura 61d com a Figura 60b, que a simulação de impulso de perfuração obtida assemelha-se qualitativa e quantitativamente ao sinal experimental, tanto no domínio do tempo quanto da frequência. Pode-se então, para fins de desenvolvimento dos algoritmos de filtragem, considerar o sinal da Figura 61a como o sinal ideal de referência, partindo do sinal corrompido pelo ruído da Figura 61c.

\section{3.}

\section{Transformada Wavelet}

A transformada wavelet é uma poderosa ferramenta de processamento de sinais utilizada para análise de sinais na frequência e no tempo. É considerado o 
melhor método para análise de sinais não estacionários, que são boa parte dos sinais relacionados a fenômenos físicos.

A transformada de wavelet surgiu com as limitações encontradas em outras ferramentas de processamento de sinais, como é o caso da Transformada rápida de Fourier (FFT), que é um algoritmo eficiente com o objetivo de calcular a Transformada Discreta de Fourier (DFT), mas que não analisa informações relacionadas ao posicionamento temporal dos sinais, não sendo assim adequada para sinais não estacionários, por não representar de maneira eficiente mudanças bruscas nas características espectrais. Também não localiza os componentes de frequência ao longo do tempo, conforme a Figura 62, que é algo essencial para uma análise de um impulso de perfuração em isoladores. A razão para isso é que a Transformada de Fourier representa os sinais temporais como uma soma de ondas senoidais, que não estão localizadas no tempo ou no espaço e que oscilam infinitamente.
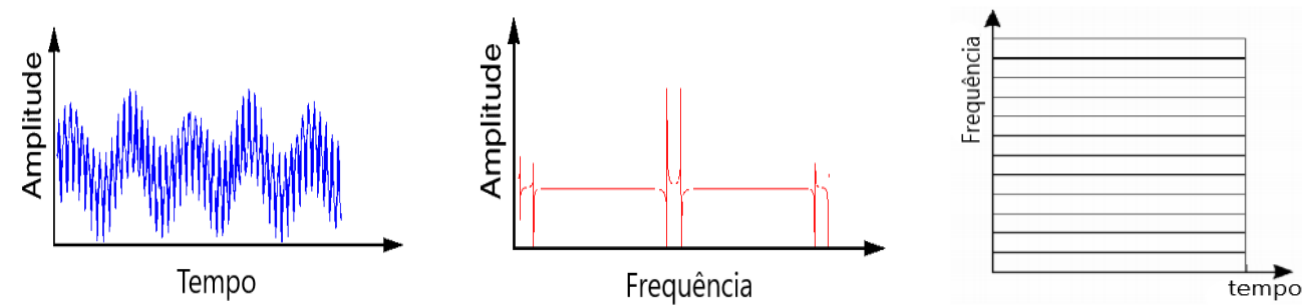

Figura 62: Exemplo da análise da transformada de Fourier.

Sendo assim, a transformada de Fourier de uma sequência discreta $x[n]$, que possua amostras espaçadas uniformemente de um sinal $x(t)$ contínuo no tempo de $-\infty$ a $+\infty$, é dada por (1)

$$
X\left(e^{j \omega}\right)=\sum_{n=-\infty}^{\infty} x[n] e^{-j \omega n}
$$

$\mathrm{Na}$ análise de um impulso de perfuração em isoladores não é possível determinar a forma deste via FFT e sua localização não pode ser obtida. Além disso, o impulso de perfuração de isoladores é de natureza transiente, irregular e não periódica, o que dificulta o seu processamento por meio de Fourier.

Quando for preciso localizar no tempo a componente espectral, para determinar como a componente de frequência do sinal varia em função do tempo, será necessário uma representação tempo-frequência [52]. Uma primeira solução para atender a essas necessidades é a Transformada de Fourier de Tempo Curto (STFT). Quando se deseja obter informações sobre a frequência de um sinal em 
torno de um certo local no tempo pode-se aplicar a STFT, que mapeia o sinal em uma função de duas dimensões, que são o tempo $\tau$ e a frequência $\omega[53,54]$, conforme ilustra a Figura 63.

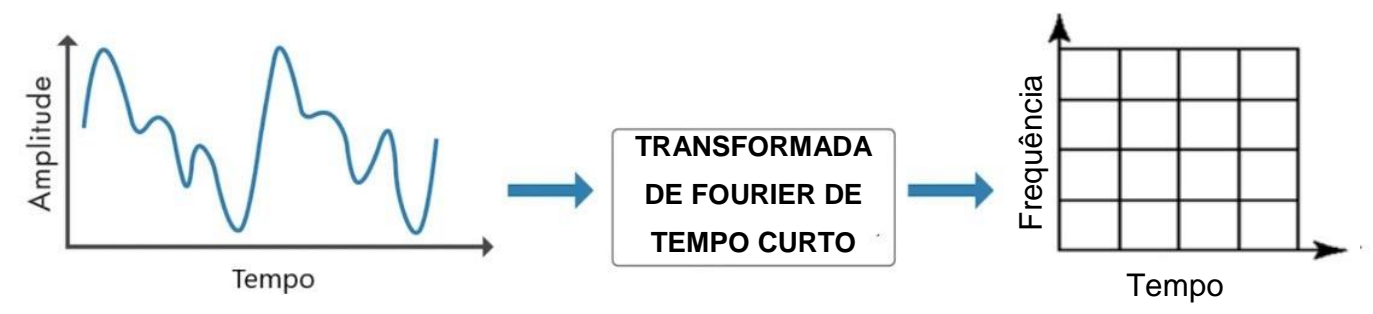

Figura 63: Exemplo da transformada de Fourier de tempo curto.

O objetivo da STFT é calcular a FFT de um sinal $x(t)$ multiplicado por uma função de janelamento $\omega(t-\tau)$, isolando o sinal em torno de $t=\tau$ antes de calcular a FFT. Logo, para cada valor de $\tau$, é encontrado o espectro de $x(t)$ em torno de $t=\tau$, conforme

$$
\operatorname{STFT}(\tau, \omega)=\int_{-\infty}^{+\infty} x(t) \omega(t-\tau) e^{-j \omega n} d t .
$$

Embora a STFT mapeie o sinal na frequência e no tempo, ela apresenta informações com uma resolução fixa, uma vez que a função $\omega(t)$ tem que ser fixa. Assim, não se pode definir quais frequências existem em quais intervalos de tempo, consequentemente não se podendo definir um tamanho ideal de janela, já que uma janela pequena resulta em pouca informação do sinal, resolução em frequência ruim e também muito processamento e com uma janela grande aumenta o erro ao considerar o sinal ser estacionário e possuir uma resolução no tempo ruim como se pode visualizar na Figura 64. Nas Figura 65 e Figura 66 estão apresentados exemplos para janelamento estreito e largo, respectivamente.

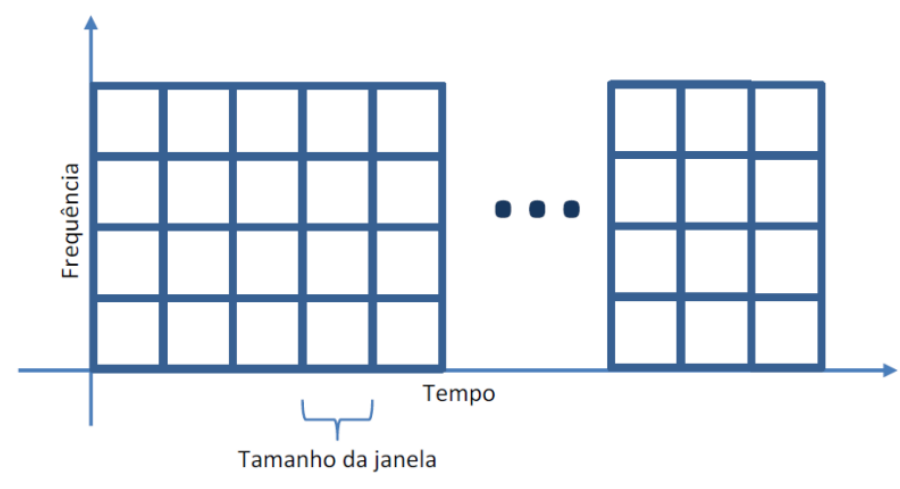

Figura 64: Janelamento de uma STFT (Short-Time Fourier Transform).

Dessa forma, para o tratamento de sinais de impulso de perfuração em isoladores, necessita-se de maior resolução no tempo para sinais de alta frequência 
com curta duração, assim como maior resolução na frequência para sinais de baixa frequência com longa duração [55].
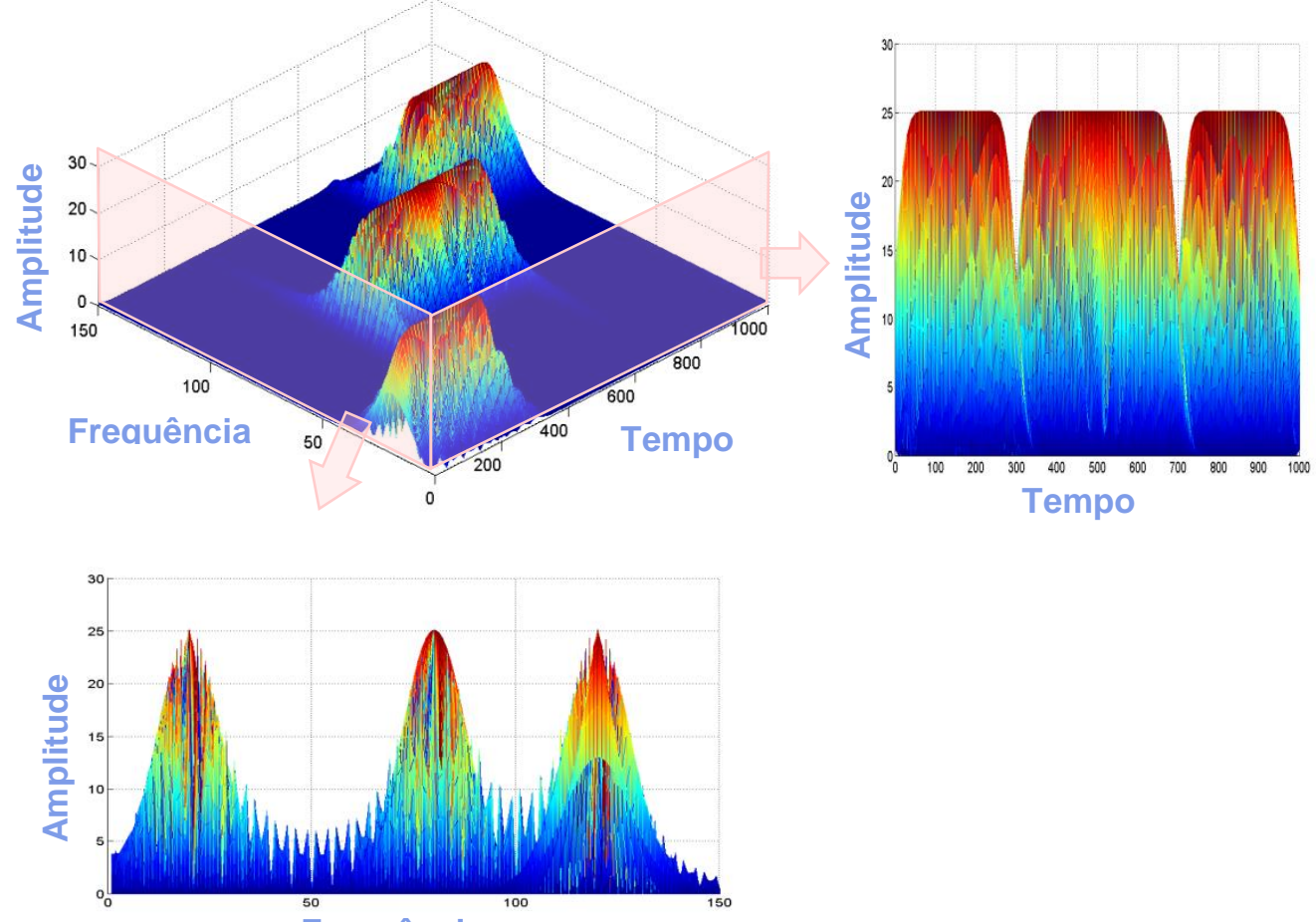

Frequência

Figura 65: Exemplo de um janelamento estreito.
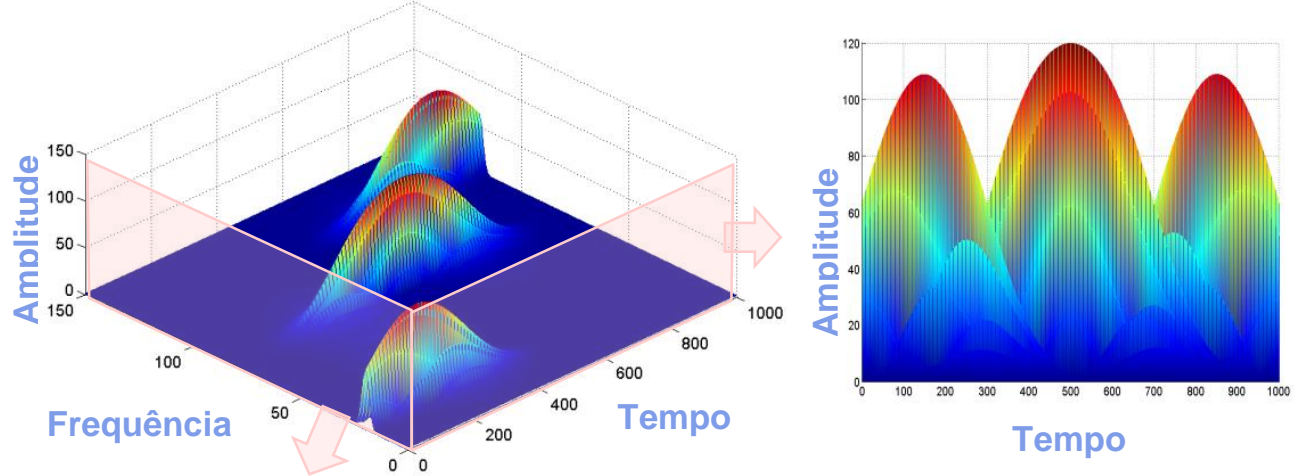

Tempo

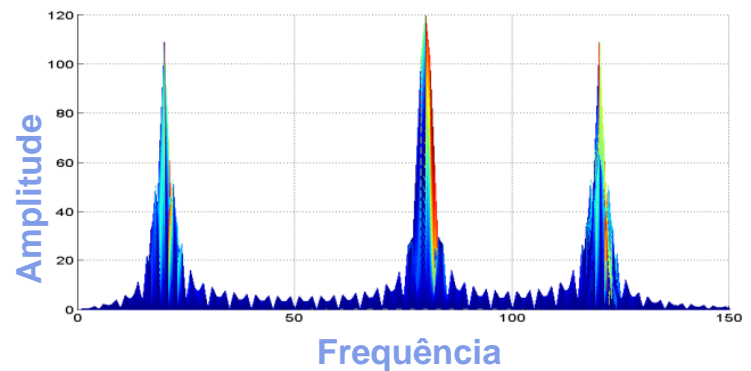

Figura 66: Exemplo de um janelamento largo. 
Assim, é necessária uma transformada que possua diferentes tamanhos de janela, para poder superar estas limitações da STFT e se adequar às características do sinal a ser estudado. A transformada de wavelet atende a esta necessidade.

Em contraposição à transformada de Fourier, que se baseia em funções com suporte infinito (senoides), a transformada de wavelet baseia-se em funções $\psi(t)$ com suporte finito, chamadas wavelets-mãe, como por exemplo a mostrada na Figura 67 [56].

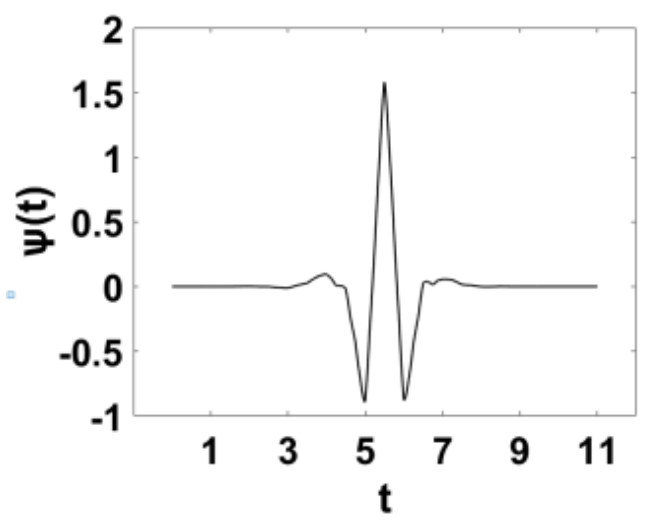

Figura 67: Exemplo de uma wavelet mãe $\psi(t)$, da família conhecida como "coiflet".

De forma similar ao escalonamento de frequência utilizada na transformada de Fourier, a transformada Wavelet emprega escalonamentos da wavelet-mãe, e também deslocamentos temporais.

As duas principais transformadas na análise wavelet são as transformadas wavelet contínuas e discretas. Essas transformadas se diferem basicamente em como as wavelets são escalonadas e deslocadas.

A transformada contínua de wavelet (CWT) de $x(t)$, que divide o sinal em versões deslocadas e escaladas de uma wavelet-mãe $\psi(\mathrm{t})$ [56], é definida por

$$
\operatorname{CWT}(a, b)=\frac{1}{\sqrt{|a|}} \int_{-\infty}^{+\infty} x(t) \Psi^{*}\left(\frac{t-b}{a}\right) d t,
$$

onde $a$ e $b$ são parâmetros de escala e translação, respectivamente, e o símbolo * significa o conjugado complexo.

A transformada de wavelet discreta (DWT) é expressa por

$$
D W T(j, k)=2^{-j / 2} \int_{-\infty}^{+\infty} x(t) \Psi^{*}\left(2^{-j} t-k\right) d t,
$$

onde $j$ e $k$ são versões discretas de $a$ e $b$, respectivamente. 
Finalmente, no caso de sequências discretas (como ocorre no processamento de sinais digitalizados), define-se a transformada discreta como

$$
T W D(j, k)=2^{-j / 2} \sum_{n=0}^{N-1} x[n] \Psi^{*}\left(2^{-j} n-k\right) .
$$

Com esses dois parâmetros $j$ e $k$ podem-se analisar os dois conceitos importantes da transformada de wavelet. O parâmetro de escala $j$, também podendo ser chamado de dimensionamento, refere-se ao processo de alongamento ou encolhimento do sinal no tempo.

Já o parâmetro de translação $k$ refere-se ao deslocamento da wavelet ao longo de todo o sinal de interesse, conforme a Figura 68.

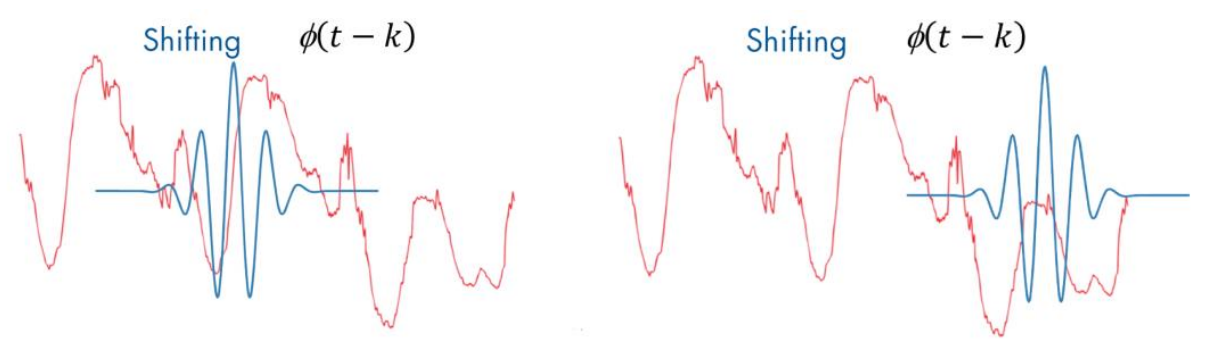

Figura 68: Processo de deslocamento da wavelet (shifting).

Assim, ainda de forma similar à transformada de Fourier, um sinal arbitrário $x(t)$ ou $x[n]$ pode ser escrito como a composição de funções de base (waveletmãe) deslocadas e escalonadas. Contudo, diferentemente de Fourier, a transformada de Wavelet permite observar diferentes aspectos do sinal e seu comportamento não estacionário, conforme ilustrado na Figura 69.

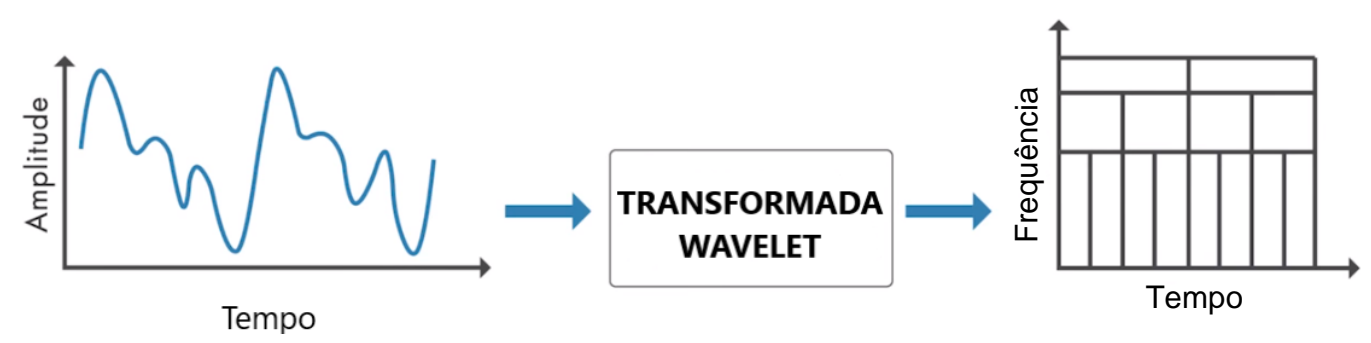

Figura 69: Análise do janelamento da transformada wavelet.

\section{4. Remoção do ruído do impulso de perfuração em isoladores por meio da análise wavelet multi-resolução}

Existe um algoritmo eficiente para executar a Transformada de Wavelet Discreta, chamado de análise multi-resolução (MRA), introduzido por Mallat [57] em 1988. A MRA substitui a TWD que é usada na transformação de sinais no 
domínio do tempo, digitalizados durante um ensaio de impulso, no domínio da transformada de wavelet. Na prática, a técnica de análise multi-resolução (MRA) baseia-se na filtragem de um sinal por meio de filtros passa baixa e passa alta cujos coeficientes são diretamente relacionados à wavelet-mãe, fornecendo representações do sinal final em relação aos coeficientes de funções wavelet e funções de escala.

Considerando a transformada de wavelet, é comum a utilização dos termos aproximações e detalhes. As aproximações são escalas altas, ou seja, as componentes de baixa frequência do sinal. Já os detalhes são as escalas mais baixas, que representam as componentes de alta frequência do sinal. O processo simplificado de filtragem é mostrado na Figura 70.

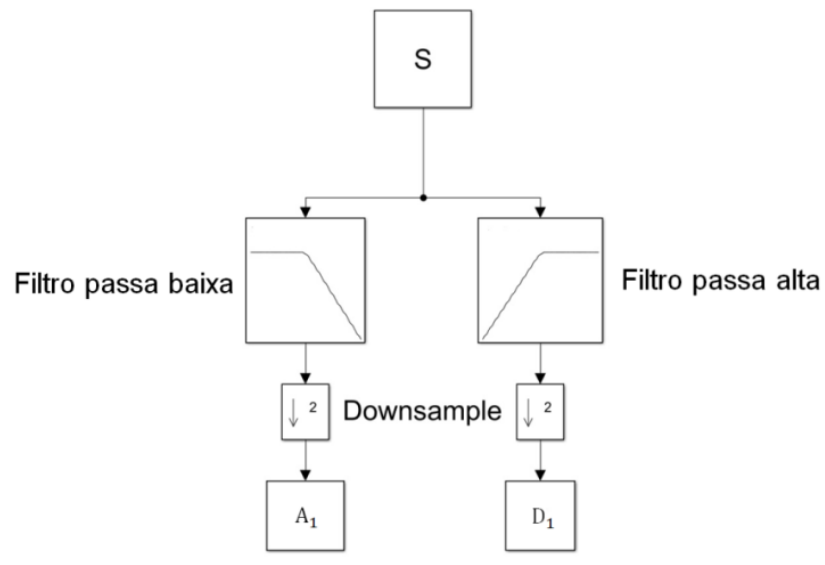

Figura 70: Processo de filtragem de um sinal considerando apenas um nível.

Neste processo o sinal $\mathrm{S}$ é aplicado a dois filtros em paralelo complementares, do tipo passa baixa e passa alta, chamados de quadrature mirror filters (QMF). Um operador de subamostragem, downsample, é utilizado para diminuir o número de amostras, pois sem este operador ter-se-ia duas vezes mais amostras em relação aos dados iniciais. Subamostrar um sinal $x(n)$ por um fator igual a 2 significa reduzir sua taxa de amostragem em 2 vezes, descartando metade das amostras. Se o sinal S possuir um número de amostras igual a 2000, os coeficientes de aproximação $\left(A_{1}\right)$ e os coeficientes de detalhes $\left(D_{1}\right)$ possuirão 1000 amostras, cada um, totalizando o número de amostras do sinal original. Com esta primeira decomposição, a informação de alta frequência se concentra nos coeficientes de detalhes, incluindo tipicamente boa parte do ruído que se deseja remover, e as informações de baixa frequência se concentram nos coeficientes de aproximação. 
Repetindo o processo de decomposição do sinal, atuando sempre nos componentes de aproximação subsequentes, obtêm-se sub-bandas. A partir da decomposição em sub-bandas da wavelet obtém-se a arvore de decomposição, conforme mostrado na Figura 71, até o nível 3.

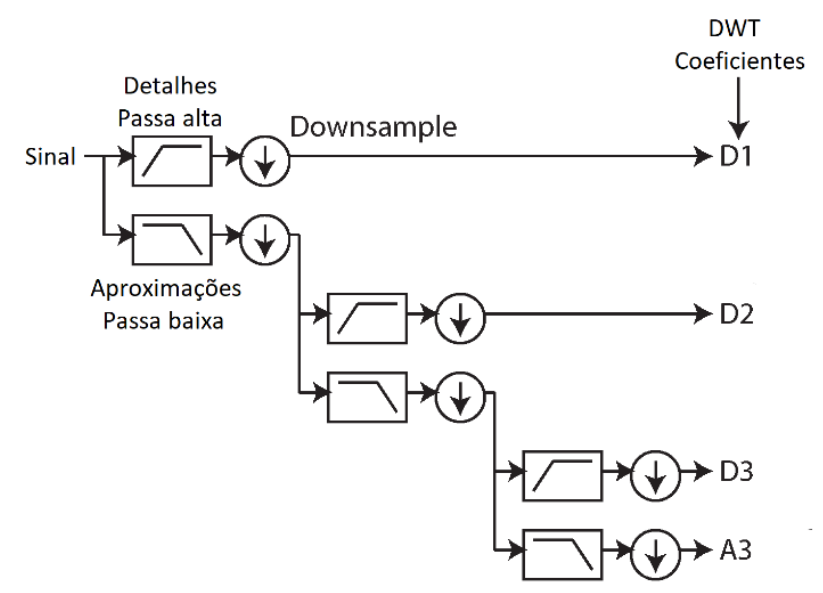

Figura 71: Diagrama de múltiplos níveis de decomposição.

Os níveis de decomposição da DWT determinam as faixas de frequências que podem ser observadas em cada componente de aproximação e detalhes. A Figura 72 apresenta esquematicamente a divisão das faixas de frequência para a decomposição até o nível $p=3$ ilustrado na Figura 71.

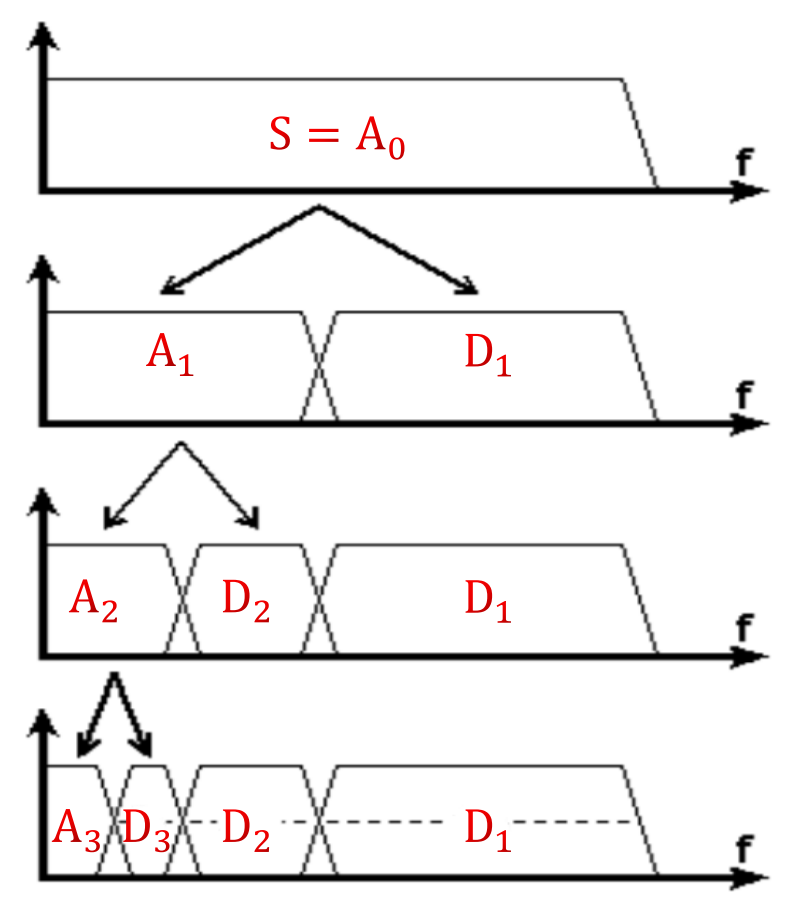

Figura 72: Faixas de frequências correspondentes a cada componente de aproximação e detalhes de acordo com o nível de decomposição. 
Considera-se que a frequência máxima do sinal original corresponde à aproximação de nível 0 ilustrada na Figura 72, que é a frequência de Nyquist, igual à metade da frequência de amostragem $f_{s}$ utilizada no processo de digitalização. A decomposição pelo algoritmo piramidal de Mallat até o nível $p$ gera 1 (um) conjunto de coeficientes de aproximação $A_{p}$ e $p$ conjuntos de coeficientes de detalhes, $D_{1}, D_{2}, \ldots, D_{p}$. Uma forma de se definir o nível de decomposição ideal é estimar a frequência máxima desejada dos coeficientes de aproximação de acordo com [58]

$$
p=\text { floor }\left(\frac{\log \left(\frac{f_{S}}{f_{\text {max }, \text { approx }}}\right)}{\log (2)}-1\right) .
$$

Assim, a maior frequência que pode ser observada nos coeficientes de aproximação $A_{p}$ para um determinado nível de decomposição $p$ e frequência de amostragem $f_{s}$ é expressa por

$$
f_{\text {max }}, A_{p}=\frac{f_{s}}{2^{p+1}} .
$$

$\mathrm{Na}$ verdade, não existe um método determinístico específico para escolher o nível ótimo de decomposição no sinal, devendo-se em princípio testar exaustivamente todas as decomposições para observar as diferenças, pois o nível necessário depende do que se pretende obter após a decomposição. Contudo, em uma aplicação de remoção de ruído, como é o caso desta dissertação, pode-se escolher o nível de decomposição com base no conhecimento do espectro de frequências típico do sinal a ser processado.

Considerando a frequência de amostragem de $1,25 \mathrm{GHz}$ e o nível de decomposição $p=5$, a frequência máxima do componente de aproximação $A_{5}$ é 19,5 MHz, como indicado na Figura 73 juntamente com o espectro de um sinal de impulso de perfuração anteriormente mostrado na Figura 60.

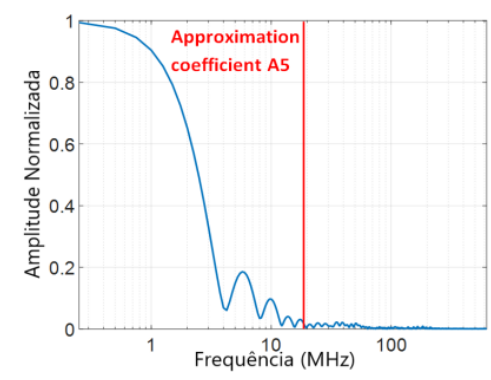

Figura 73: Espectro de frequências do sinal digitalizado referente a um ensaio de perfuração e limite superior de frequência do coeficiente de aproximação $A_{1}$. 
Pode-se notar que este nível de decomposição parece adequado para o tipo de sinal e frequência de amostragem utilizada, preservando o conteúdo de interesse nas baixas frequências do sinal.

O emprego da transformada wavelet para remoção de ruído baseia-se no conceito de que a energia de um sinal de interesse frequentemente se concentra em poucos coeficientes no domínio wavelet, enquanto a energia do ruído se espalha ao longo de todos os coeficientes no domínio wavelet. Desta forma, definir um limiar de energia mínima tenderá a manter os coeficientes de maior energia que representam o sinal de interesse. Assim, o processo de remoção de ruído por wavelets consiste nos seguintes passos.

- Utilizando o algoritmo piramidal de Mallat, decompor o sinal até um determinado nível $p$.

- Preservar integralmente o componente de aproximação $A_{p}$.

- Definir um limiar de ruído que será utilizado sobre os coeficientes de detalhes $D_{1}, D_{2}, \ldots, D_{p}$.

- Eliminar (zerar) os coeficientes de detalhes que estejam abaixo do limiar pré-definido.

Esta etapa de determinação do limiar (threshold) é importante, pois uma escolha inadequada pode resultar em perda significativa do sinal. Embora não haja uma regra única para se determinar o nível de threshold, é bastante comum o uso de alguns estimadores estatísticos para este fim, como os métodos apresentados em [59-61].

A utilização de um limiar menos conservativo pode preservar sinais de impulso cujos coeficientes estejam muito próximos ao limiar do ruído. Nesta dissertação foi escolhido o método do limiar universal [62], que utiliza um estimador fixo do nível de ruído dado por

$$
\lambda_{u}=\sigma \sqrt{2 \log (N)},
$$

onde $N$ é o tamanho da amostra (2500) e $\sigma$ é o desvio padrão do nível de ruído que, caso não seja conhecido, pode ser estimado por meio dos coeficientes wavelet de menor escala $\left(D_{p}\right)$. No caso, $\sigma$ foi estimado com base no ruído apresentado na Figura 61b, como 0,0675. O valor do limiar $\lambda_{u}$ obtido foi de 0,1759 . 
Após várias simulações com diversas wavelets mãe disponíveis no Matlab, que nesse caso foram 36, comprovou-se que o valor ótimo de $p$, referente ao nível de decomposição, deve ser selecionado em 5. De fato, percebe-se que um baixo nível de decomposição ( 2 ou 3 , ou até mesmo 4) do sinal pelo método de decomposição por wavelet não é suficiente para reduzir o nível de ruído presente. Já para valores acima de 5, nota-se uma grande perda das características do sinal.

Para embasar esta observação, há um método de seleção de nível chamado EBWS - Energy Based Wavelet Select [63], sendo uma seleção baseada na distribuição de energia entre os coeficientes das sub-bandas de composição para cada nível $(j=1,2, \ldots, p)$. A equação para a energia percentual na banda de aproximação é definida por

$$
E_{a, p}=\frac{\sum_{k}\left(a_{p, k)}{ }^{2}\right.}{\sum_{k}\left(a_{p, k}\right)^{2}+\sum_{j=1}^{p} \sum_{k}\left(d_{j, k}\right)^{2}},
$$

onde $a$ e $d$ são, respectivamente, os vetores dos coeficientes de aproximação e detalhes para cada nível $(j=1,2, \ldots, p)$.

Para cada nível é feita uma decomposição do sinal para cada função wavelet disponível, e o nível que possuir o coeficiente de aproximação $a$ com o maior percentual de energia será o nível ótimo. O método se baseia no fato de que, quando os coeficientes de detalhes $d$ sofrem atenuação no processo de limiarização, o sinal filtrado perde energia e sofre distorções bruscas. Com isso, escolhendo o nível ótimo de decomposição e aproximação com maior porcentagem de energia, o sinal perderá menos energia e terá uma menor distorção na sua forma de onda quando os coeficientes de detalhes $d$ sofrerem o processo de limiarização.

A Figura 74 apresenta o percentual de energia dos coeficientes de aproximação para cada nível $(p=1, \ldots, 12)$ para as 36 wavelets disponíveis avaliadas.

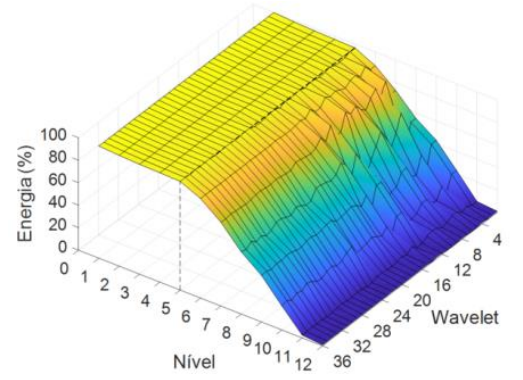

Figura 74: Distribuição de energia contida nos coeficientes de aproximação por nível para cada wavelet. 
Percebe-se na Figura 74 que, independentemente da wavelet-mãe escolhida, o nível $p=5$ é o que representa o maior percentual de energia nos coeficientes de aproximação, que no caso é o $A_{5}$.

Finalmente, são apresentados na Figura 75 os componentes de aproximação $A_{2}, A_{5}$ e $A_{7}$, utilizando como exemplo a wavelet mãe Daubechies, podendo-se perceber crescente perda das características do sinal para um nível $p$ maior que 5 .
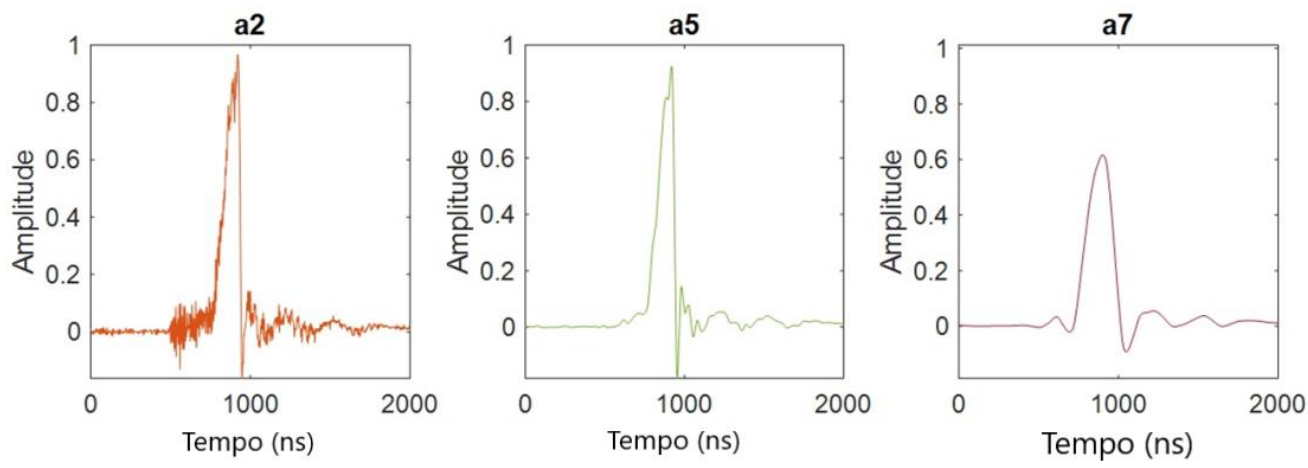

Figura 75: Coeficientes de aproximação a2, a5 e a7 da decomposição do sinal utilizando uma wavelet da família Daubechies.

\section{5. Validação, software e comparação em alta tensão}

Para tornar prática a utilização de um filtro em medições realizadas em laboratório, foi desenvolvido um software específico, baseado nos conceitos para o filtro apresentados anteriormente e na wavelet mãe selecionada a seguir. O filtro também foi testado em alta tensão em uma comparação interlaboratorial internacional, sendo mais uma forma de validação do mesmo.

\subsection{1.}

\section{Seleção da wavelet mãe}

Como descrito anteriormente, o principal parâmetro de interesse a ser estimado durante o ensaio de perfuração em isoladores é o valor de crista. Assim, a escolha da wavelet mãe a ser utilizada foi feita com base na análise do erro na estimativa deste valor.

O erro na amplitude, como sendo um critério proposto por [64-66], fornece uma medida da variação percentual entre o valor de crista $V_{1}$ da forma de onda 
padrão simulada ideal da Figura 61a e o valor de crista $V_{2}$ da forma de onda resultante do processo de filtragem por wavelet do sinal corrompido por ruído conforme a Figura 61c, ou seja, é expresso por

$$
E A=\frac{V_{1}-V_{2}}{V_{1}} \times 100 \%
$$

Considerando as formas de onda ideal e corrompida pelo ruído, sem filtragem, obtém-se um erro na amplitude de $34 \%$. Os valores dos erros de amplitude após filtragem, para todas as 36 wavelets testadas, são apresentados na Figura 76.

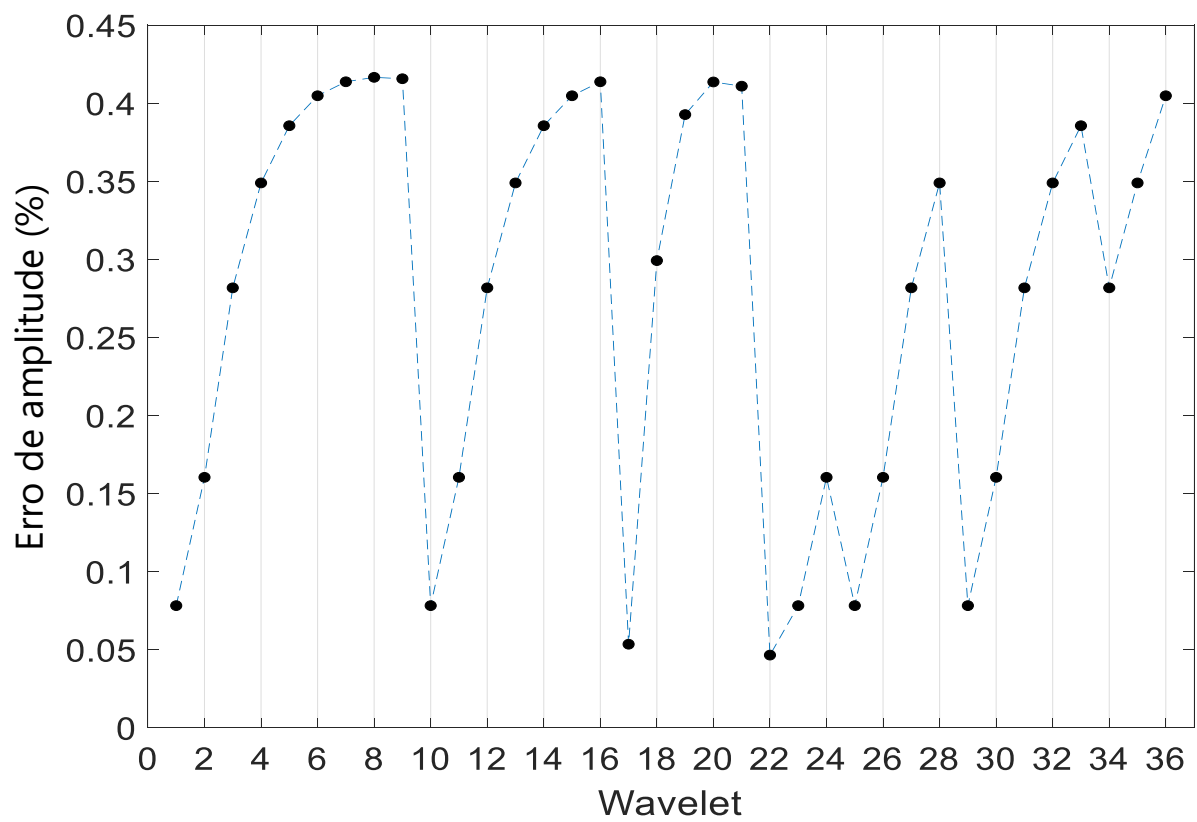

Figura 76: Erro percentual no valor de crista entre a forma de onda padrão simulada ideal e a forma de onda obtida após o processo de filtragem para cada wavelet-mãe testada.

Após esta análise foi verificado que a wavelet número 22, da família Biorthogonal 1.1, obteve o menor erro de amplitude com valor de aproximadamente $0,05 \%$.

O resultado qualitativo da utilização deste filtro é apresentado na Figura 77. Pode-se notar, na Figura 77b, uma boa similaridade entre o sinal simulado ideal e o sinal filtrado, com a principal diferença sendo observada a partir de $700 \mathrm{~ns}$, com uma componente de baixa frequência que não foi removida na filtragem. 

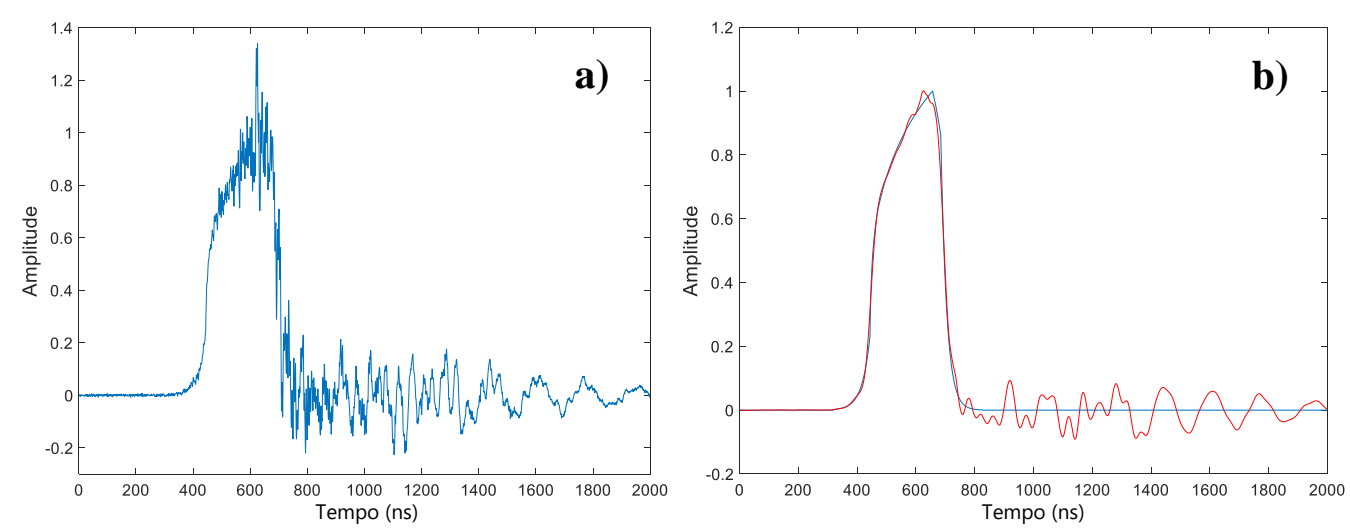

Figura 77: Formas de onda. a) corrompida pelo ruído, apresentada anteriormente na Figura 61c e, b) após o processo de filtragem pela wavelet mãe selecionada, juntamente com o sinal simulado ideal da Figura 61 .

Esta interferência, visualizada após o corte e com frequência fundamental em torno de $6 \mathrm{MHz}$, é inerente ao circuito de ensaio que envolve geração e medição deste tipo de impulso e aparece constantemente nas medições em alta tensão. Ou seja, a diferença observada é devida na verdade à não modelagem de tal interferência do sinal simulado da Figura 61a, e não a uma deficiência do processo de filtragem por wavelet. Uma verificação do aterramento e instalações no laboratório onde ocorreram esses eventos é necessária para identificar a possível fonte de tais interferências.

A Figura 78 apresenta o ruído que foi adicionado ao sinal ideal (Figura 61b) e o ruído removido pelo filtro baseado em wavelets, obtido pela subtração do sinal filtrado (Figura 77b) do sinal corrompido pelo ruído (Figura 77a), podendo-se notar sua grande similaridade. Apresenta-se também a subtração entre dois sinais de ruído, que mostra o resíduo de ruído não removido, correspondendo ao sinal de baixa frequência anteriormente descrito. 

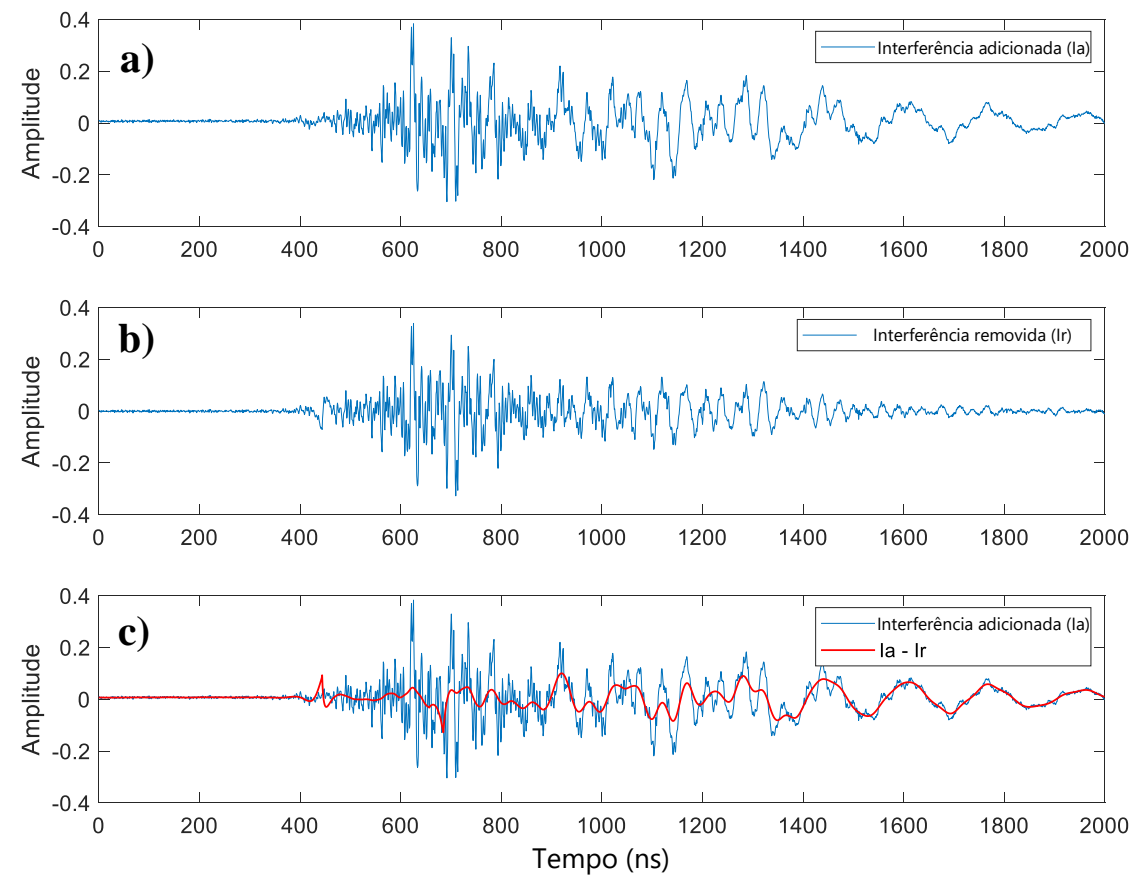

Figura 78: Ruído removido pelo filtro. a) interferência adicionada ao sinal ideal. b) Ruído removido através da filtragem wavelet. c) Diferença entre os sinais "a)" e "b)".

O resultado da comparação do impulso com a referência simulada no domínio da frequência é apresentado na Figura 79
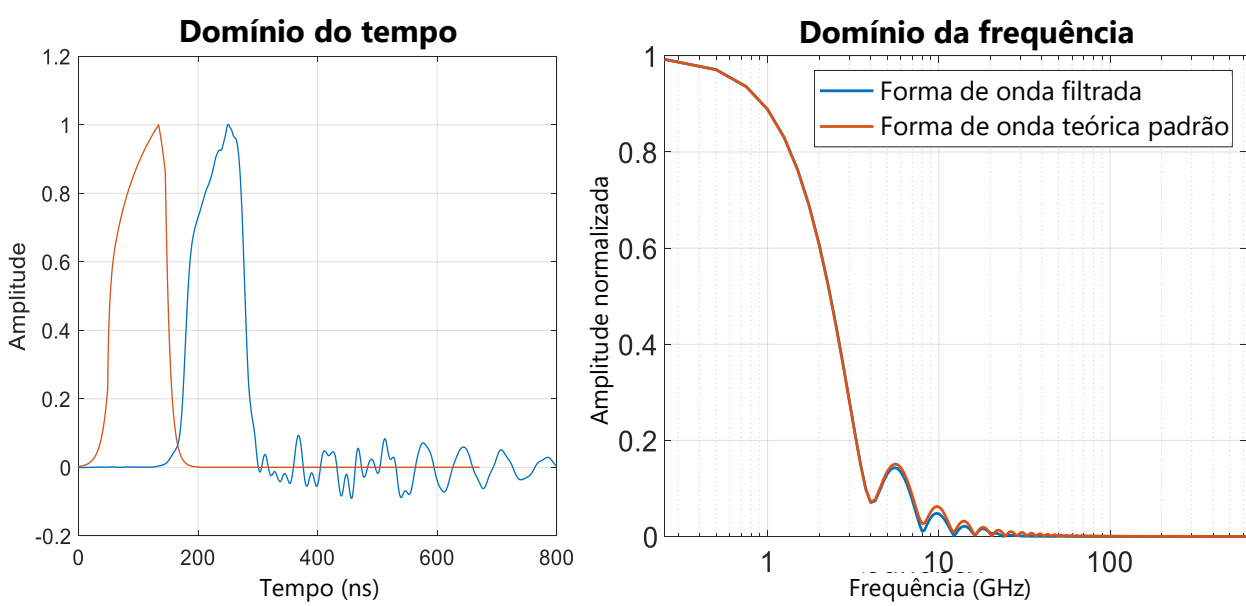

Figura 79: Comparação entre o sinal simulado ideal e o sinal após o processamento. 


\subsection{2.}

\section{Software desenvolvido para condicionamento do sinal}

Para tornar prática a utilização do filtro em medições realizadas em laboratório, foi desenvolvido em LabVIEW um software específico denominado RAPIT (Response Analyser of Puncture Impulse Testing), baseado nos conceitos para o filtro wavelet apresentados anteriormente.

A ideia base de arquitetura do software foi aproveitar os módulos desenvolvidos para aquisição dos osciloscópios Tektronix das famílias 5000 e 7000 presentes no programa STERAL, desenvolvido pelo Cepel em parceria com a PUC-Rio, mais a ideia de análise de parâmetros de impulso que faz parte do programa IMPREAL. O diagrama da Figura 80 apresenta a ideia da concepção do software.

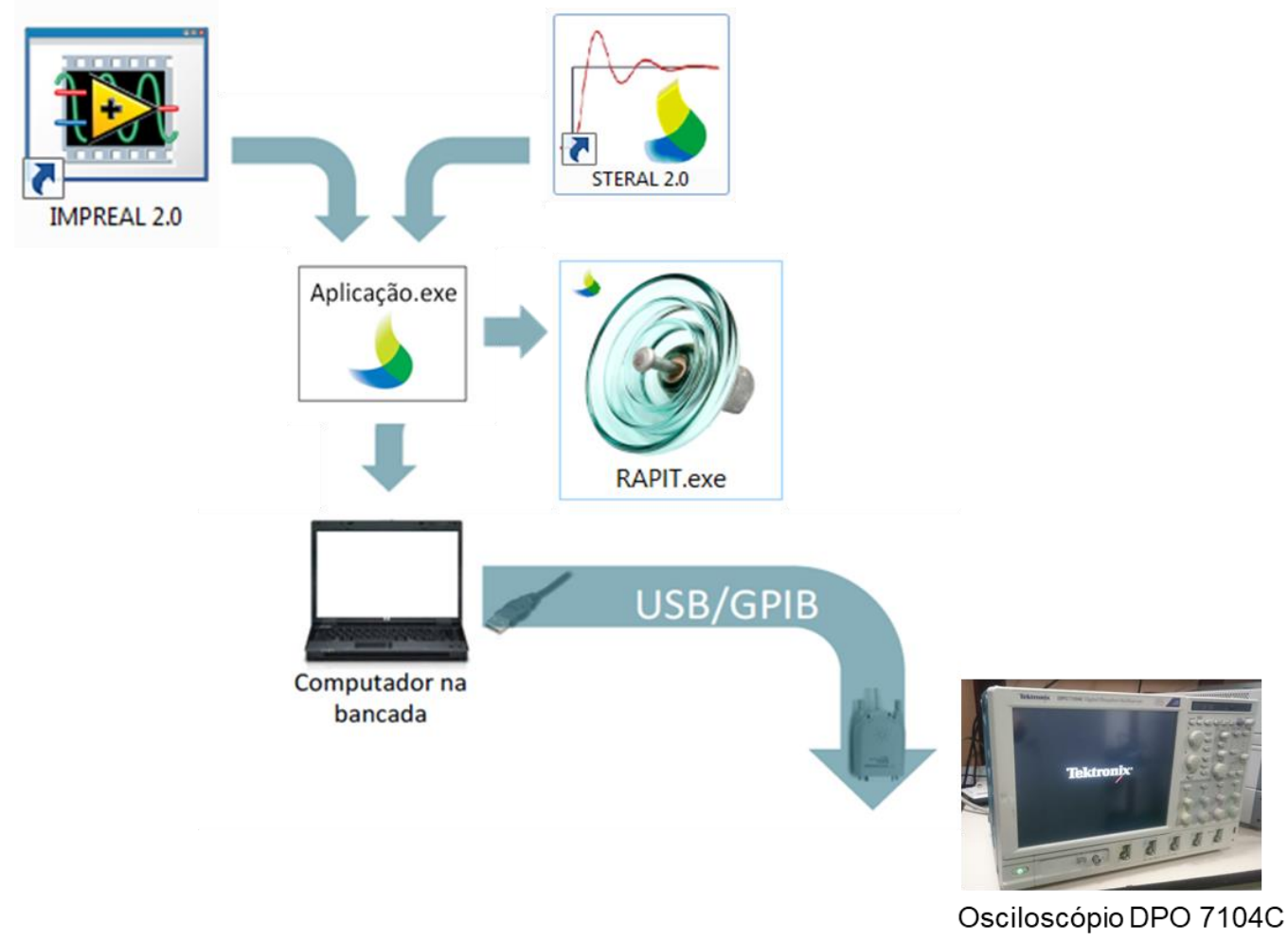

Figura 80: Diagrama de concepção do software RAPIT.

O software desenvolvido para a aquisição e condicionamento do sinal tem por objetivo garantir uma maior confiabilidade na medição do valor de pico do impulso de perfuração e minimizar o efeito de interferências comumente presentes no sinal a ser medido neste tipo de ensaio. $\mathrm{O}$ resultado experimental visualizado pelo software desenvolvido é apresentado na Figura 81. 


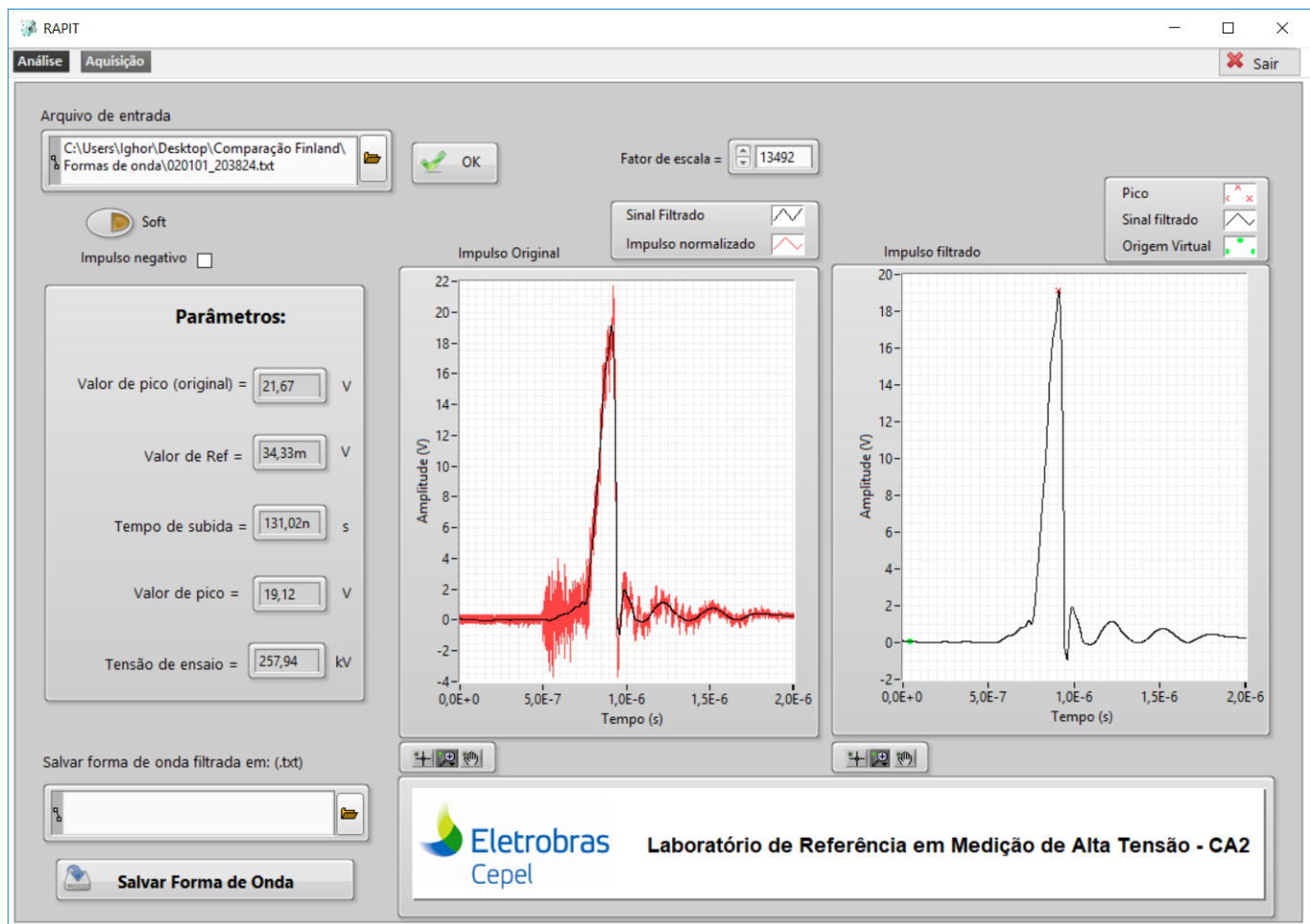

Figura 81: Interface com o usuário do software RAPIT.

O software foi desenvolvido para a aquisição, processamento e análise de formas de onda de impulso de perfuração em isoladores, permitindo estimar os seguintes parâmetros: valor de crista do sinal de impulso original; valor de referência, calculado para se obter o valor de nível zero do impulso; valor de crista após a remoção do ruído; e tempo de subida (rise time), definido como o intervalo de tempo decorrido entre $10 \%$ e $90 \%$ do valor de crista na curva da tensão de ensaio filtrado, além da tensão de ensaio, que é o valor de crista filtrado multiplicado pelo fator de escala do sistema de medição.

Além de uma garantia da confiabilidade da medição, removendo praticamente toda a interferência de alta frequência no sinal de impulso, podem-se observar excelentes resultados, como é o caso da comparação interlaboratorial entre os SMIP do Technical Research Centre of Finland (VTT Mikes) e Cepel, apresentada no item a seguir.

\subsection{3.}

\section{Comparação interlaboratorial em alta tensão}

Outra forma de validação do programa e filtro desenvolvido e utilizado para os ensaios de perfuração em isoladores foi utilizar o software para compor o 
sistema de medição utilizado em uma comparação interlaboratorial feita pelo Cepel e VTT-Mikes. Esta foi uma comparação entre sistemas de medição para impulso de perfuração, que está associada à atividade de pesquisa do Cigré Working Group D1.60: Traceable measurement techniques for very fast transients. A comparação foi realizada conforme o arranjo apresentado na Figura 82 e instrumentos de medição da Figura 83.

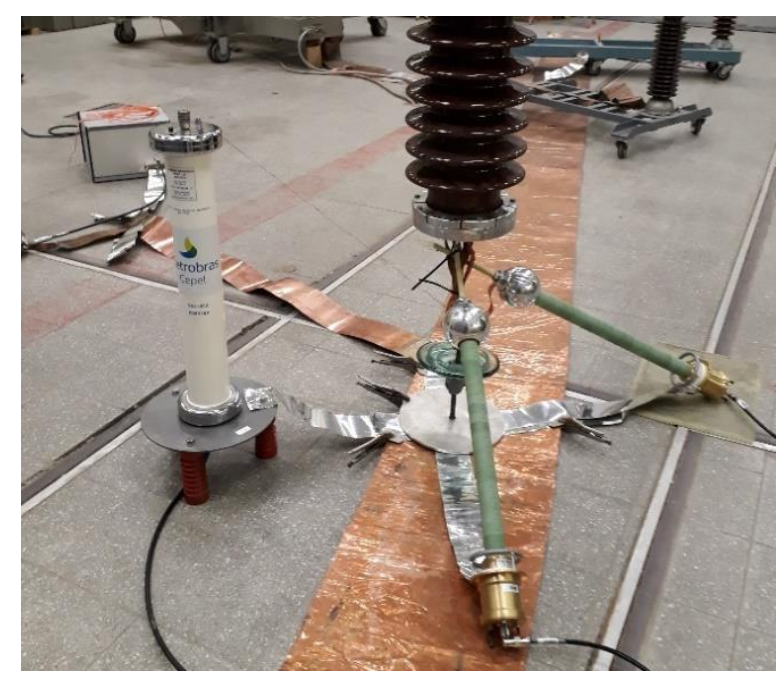

Figura 82: Arranjo de ensaio no hall de alta tensão para comparação entre SMIP.

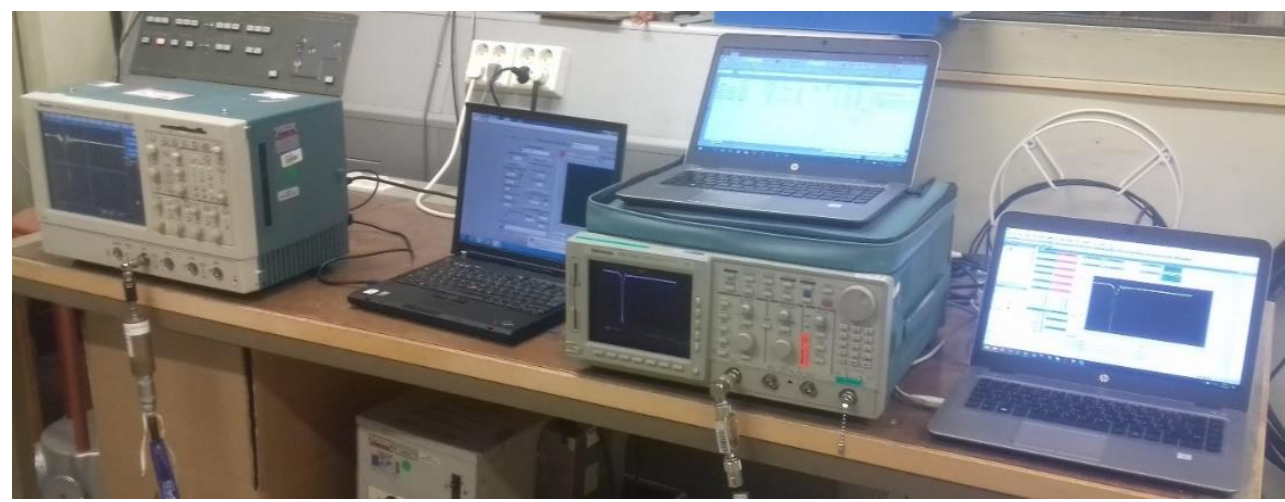

Figura 83: Instrumentos e software do Cepel e VTT utilizados na comparação.

Nesta comparação o sistema de medição utilizado pelo Cepel foi composto por um divisor de tensão do tipo resistivo de baixa impedância, um sistema de transmissão do sinal, atenuador resistivo, casador de impedâncias e um osciloscópio digital, de 8 bits e com largura de banda de $1,25 \mathrm{GHz}$, em conjunto com o software RAPIT. 
No arranjo compacto de ensaio para a comparação o divisor do VTT-Mikes foi utilizado em posição diagonal conectado diretamente ao isolador de vidro sob ensaio, enquanto o divisor do Cepel foi colocado na posição vertical conectado ao isolador através de um condutor de alta tensão. Outro divisor com características similares ao do VTT também foi utilizado na comparação de SMIP. O arranjo de ensaio mostrado na Figura 82 está de acordo com as recomendações da IEC 61211:2004. A comparação das duas formas de ondas medidas é apresentada na Figura 84.

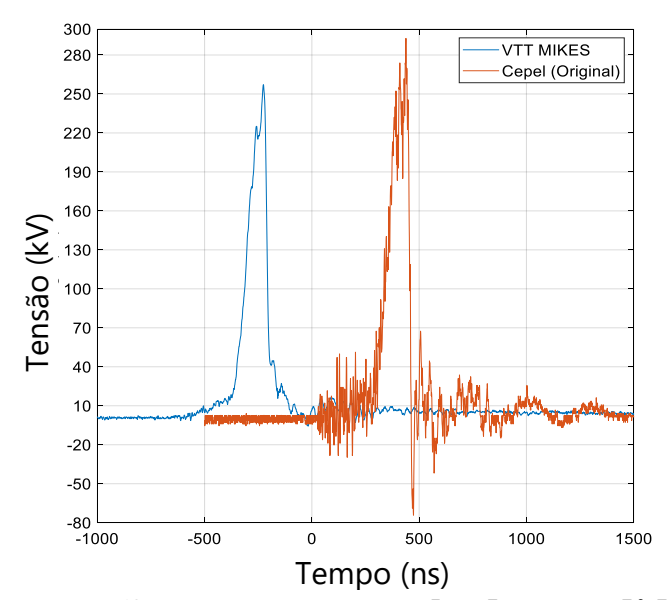

Figura 84: Comparação entre os resultados medidos pelo SMIP do VTT-Mikes e Cepel.

O resultado do processamento pelo filtro, utilizando o software RAPIT, do sinal medido pelo sistema de medição de 1mpuıso de perfuração juntamente com o sinal pelo sistema de medição do VTT-Mikes, é apresentado na Figura 85. A forma de onda filtrada pelo software obteve uma maior correlação em termos de amplitude e forma de onda com o sinal medido pelo sistema de medição do VTTMikes.

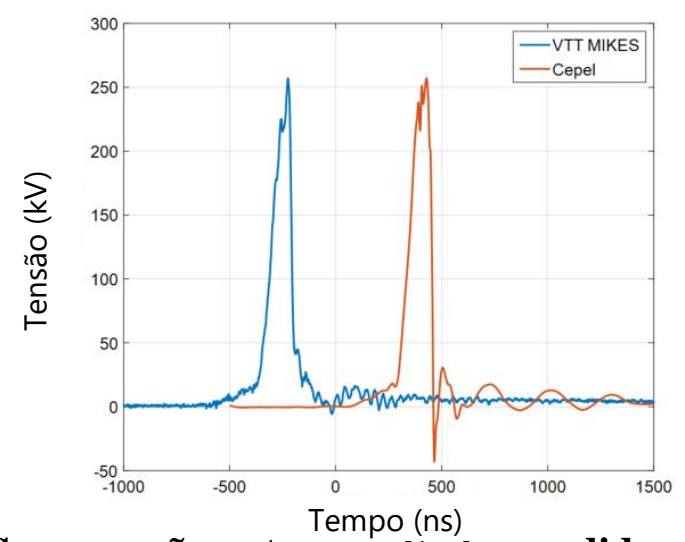

Figura 85: Comparação entre resultados medidos pelos SMIP do VTTMikes e Cepel, após o processamento. 
Embora os dois sistemas de medição utilizem osciloscópios com 8 bits de resolução vertical, os modelos são diferentes, possibilitando diferentes taxas de amostragem. Nesse caso as características principais utilizadas nos ensaios foram, para o osciloscópio do VTT-Mikes, uma frequência de amostragem de 1,0 GHz e banda de passagem de $0,5 \mathrm{GHz}$, enquanto que para o do Cepel foi selecionada $1,25 \mathrm{GHz}$ de frequência de amostragem e $1 \mathrm{GHz}$ de banda de passagem. É importante também destacar que o VTT-Mikes também utilizou técnicas de processamentos de sinais em seu SMIP, cujos detalhes não foram divulgados.

Na Tabela 1 e na Tabela 2 estão apresentados os resultados da comparação interlaboratorial entre VTT-Mikes e Cepel, considerando 10 aplicações em cada polaridade para o arranjo de ensaio mostrado na Figura 82. São apresentados o desempenho do SMIP, incluindo o software RAPIT com e sem filtro. Nesse sentido observa-se uma redução significativa do erro médio entre os dois SMIP, assim como o desvio padrão máximo de $2 \%$.

Tabela 1: Resultados da comparação antes da remoção do ruído.

\begin{tabular}{|c|c|c|c|c|}
\hline $\begin{array}{c}\text { Referênci } \\
\text { a VTT } \\
(\mathbf{k V})\end{array}$ & $\begin{array}{c}\text { CEPEL } \\
\mathbf{( k V )}\end{array}$ & Erro & Média & $\begin{array}{c}\text { Desvio } \\
\text { Padrão }\end{array}$ \\
\hline 260,936 & 291,437 & $11,70 \%$ & & \\
252,665 & 292,786 & $15,90 \%$ & & \\
262,415 & 298,183 & $13,60 \%$ & & \\
259,069 & 292,786 & $13,00 \%$ & & \\
257,435 & 307,627 & $19,50 \%$ & $13 \%$ & $3 \%$ \\
256,983 & 291,437 & $13,40 \%$ & & \\
259,445 & 279,293 & $7,70 \%$ & & \\
264,369 & 299,532 & $13,30 \%$ & & \\
266,051 & 302,230 & $13,60 \%$ & & \\
263,471 & 292,786 & $11,10 \%$ & & \\
$-268,338$ & $-303,580$ & $13,10 \%$ & & \\
$-271,300$ & $-303,580$ & $11,90 \%$ & & \\
$-265,264$ & $-286,040$ & $7,80 \%$ & & \\
$-273,851$ & $-298,183$ & $8,90 \%$ & & \\
$-270,739$ & $-298,183$ & $4,20 \%$ & \multirow{2}{*}{$12 \%$} & $5 \%$ \\
$-272,709$ & $-281,992$ & $19,20 \%$ & & \\
$-271,823$ & $-325,168$ & $13,20 \%$ & & \\
$-269,876$ & $-307,627$ & $21,50 \%$ & & \\
$-272,825$ & $-298,183$ & $9,30 \%$ & & \\
$-271,852$ & $-310,326$ & $14,20 \%$ & & \\
\hline
\end{tabular}


Tabela 2: Resultados da comparação após o processo de filtragem.

\begin{tabular}{|c|c|c|c|c|}
\hline $\begin{array}{c}\text { Referência } \\
\text { VTT (kV) }\end{array}$ & $\begin{array}{c}\text { CEPEL } \\
\text { (kV) }\end{array}$ & Erro & Média & $\begin{array}{c}\text { Desvio } \\
\text { Padrão }\end{array}$ \\
\hline 260,936 & 270,253 & $3,6 \%$ & & \\
252,665 & 256,626 & $1,6 \%$ & & \\
262,415 & 257,436 & $-1,9 \%$ & & \\
259,069 & 256,356 & $-1,0 \%$ & & \\
257,435 & 263,912 & $2,5 \%$ & $-0,4 \%$ & $2,0 \%$ \\
256,983 & 254,197 & $-1,1 \%$ & & \\
259,445 & 256,221 & $-1,2 \%$ & & \\
264,369 & 260,134 & $-1,6 \%$ & & \\
266,051 & 260,269 & $-2,2 \%$ & & \\
263,471 & 257,031 & $-2,4 \%$ & & \\
\hline$-268,338$ & $-266,206$ & $-0,8 \%$ & & \\
$-271,300$ & $-271,468$ & $0,1 \%$ & & \\
$-265,264$ & 268,499 & $1,2 \%$ & & \\
$-273,851$ & $-274,976$ & $0,4 \%$ & & \\
$-270,739$ & $-271,738$ & $0,4 \%$ & $0,2 \%$ & $0,7 \%$ \\
$-272,709$ & $-272,277$ & $-0,2 \%$ & & \\
$-271,823$ & $-270,388$ & $-0,5 \%$ & & \\
$-269,876$ & $-272,007$ & $0,8 \%$ & & \\
$-272,825$ & $-276,325$ & $1,3 \%$ & & \\
$-271,852$ & $-269,440$ & $-0,9 \%$ & & \\
\hline \multicolumn{7}{|l}{}
\end{tabular}

O erro médio entre as amplitudes dos sistemas de medição para impulso de perfuração do VTT-Mikes e do Cepel sem aplicar o filtro foi de aproximadamente $13 \%$. Com o filtro observa-se uma redução significativa desse erro para abaixo de 0,5\%. Com base nos resultados da comparação interlaboratorial entre Cepel e VTT-Mikes, pôde-se comprovar a confiabilidade dos resultados do sistema de medição utilizado pelo Cepel, composto pelo divisor de tensão, sistema de transmissão do sinal, atenuador, casador de impedância e o registrador digital com o software RAPIT. Desta forma, todo o sistema de medição do Cepel, incluindo o software RAPIT, está rastreado a padrões de um Instituto Nacional de Metrologia do exterior (VTT, Finlândia) e de acordo com os requisitos da IEC 61211:2004, o que contribui para garantir a confiabilidade dos resultados de ensaios de perfuração realizados no Cepel e no Brasil.

Comprovada a eficácia do software RAPIT desenvolvido, foi então adicionado no sistema de medição para impulso de perfuração, projetado e desenvolvido pelo Cepel neste trabalho, para a realização da calibração por comparação em alta tensão apresentada no capítulo a seguir. 


\section{5 \\ Sistema de medição para ensaios de impulso de perfuração em isoladores}

Este capítulo apresenta a caracterização, avaliação e calibração do novo sistema de medição do Cepel para impulso de perfuração em isoladores, baseado no divisor resistivo descrito no Capítulo 3. Foi realizada uma caracterização em baixa tensão dos componentes individuais para determinar o fator de escala em baixa tensão em corrente contínua, considerando o sistema de medição completo. A seguir, foi realizada a avaliação do desempenho dinâmico por meio da análise da resposta ao degrau e da resposta em frequência. Comparações em alta tensão também foram realizadas para a determinação do fator de escala do sistema de medição e sua incerteza foi comparada com os limites normativos.

\section{1.}

\section{Avaliação de desempenho do sistema de medição}

A avaliação consiste na caracterização de todos componentes que integram o sistema de medição, principalmente em relação ao desempenho dinâmico e fator de escala do sistema de medição completo, com o objetivo de comprovar a adequação do sistema de medição de impulso de perfuração do Cepel para ensaios de perfuração em isoladores.

\subsection{1.}

\section{Caracterização em baixa tensão}

O sistema de medição de impulso de perfuração do Cepel é composto por um divisor de tensão resistivo com resistores de alta e baixa tensão construídos artesanalmente com o objetivo de minimizar a indutância, conforme descrito no Capítulo 3, por um sistema de transmissão do sinal através de cabo triaxial que contém dupla blindagem, atenuador resistivo também de indutância reduzida, casador de impedância e por um sistema de aquisição e processamento de sinais, conforme ilustrado na Figura 86. 

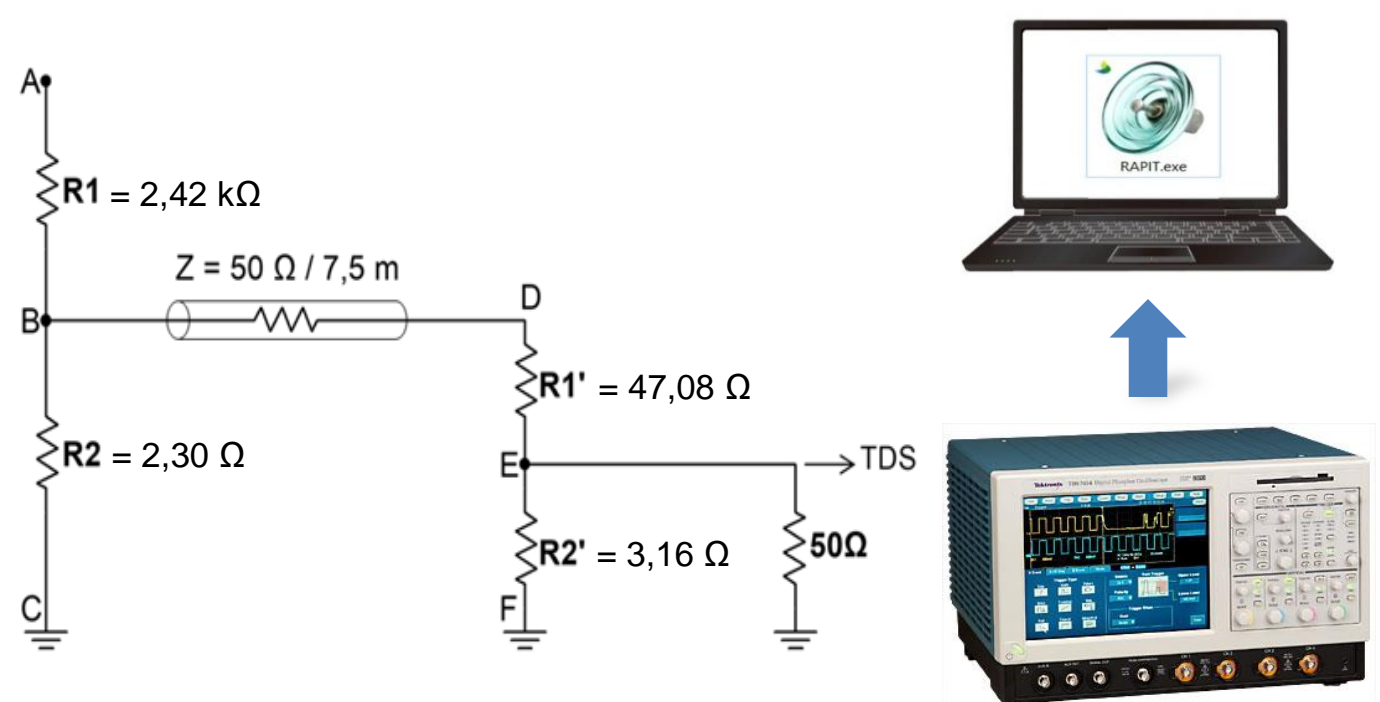

Figura 86: Diagrama elétrico do sistema de medição e sistema de aquisição de sinais.

\subsubsection{1.}

\section{Medição dos componentes}

A caracterização foi realizada pela medição em baixa tensão dos componentes individuais e pela determinação do fator de escala em baixa tensão em corrente contínua, conforme apresentado na Figura 87.

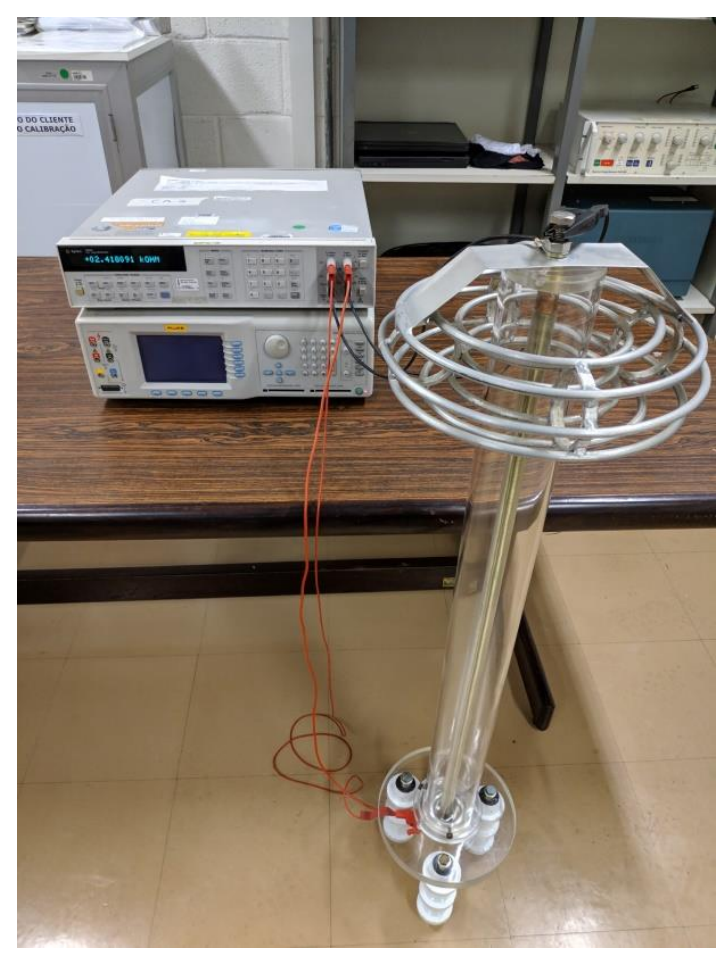

Figura 87: Configuração da medição dos componentes a 4 fios. 
As resistências dos resistores das unidades de alta e baixa tensão do divisor de tensão e do atenuador foram medidas pelo método a quatro terminais, no qual são desprezadas as resistências dos fios condutores conforme mostra a Figura 88.

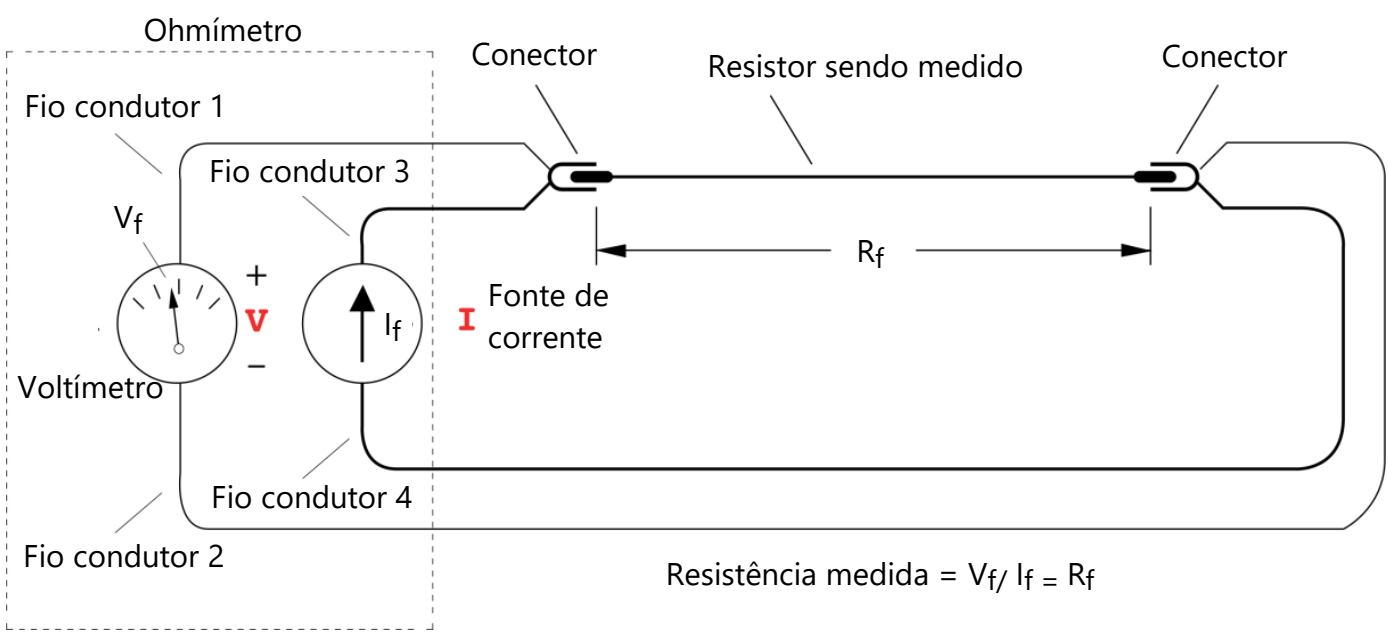

Figura 88: Diagrama elétrico esquemático da medição a 4 fios.

$\mathrm{Na}$ Tabela 3 encontram-se os resultados da medição utilizando um multímetro digital de alta resolução, 8,5 dígitos, bem como o fator de escala (FE) calculado a partir destes resultados, de acordo com as equações a seguir

$$
\begin{gathered}
\text { Fator de escala }=F E=\frac{V_{\text {entrada }}}{V_{\text {saída }}} \\
F E=\frac{R_{1}+R_{2}}{R_{2}}=\frac{R_{1}}{R_{2}}+1 \\
F E_{\text {Divisor de tensão }}=\frac{R_{1}}{R_{2}}+1 \\
F E_{\text {Atenuador }}=\frac{R_{1}}{R_{2}}+1 \\
F E_{S M I P}=F E_{\text {Divisor de tensão }} \times F E_{\text {Atenuador }}
\end{gathered}
$$

\begin{tabular}{|c|c|c|c|}
\hline Descrição & $\mathbf{R}(\mathbf{\Omega})$ & Fator de escala FE & Adimensional \\
\hline $\mathrm{R}_{1}=\mathrm{R}_{\mathrm{AB}}$ & 2418,9 & \multirow{2}{*}{ Divisor de tensão } & \multirow{2}{*}{1050,6} \\
\hline $\mathrm{R}_{2}$ sem cabo $=\mathrm{R}_{\mathrm{BC}}$ & 2,4165 & & \\
\hline $\mathrm{R}_{2}$ com cabo $+\mathrm{R}_{\mathrm{o}}=\mathrm{R}_{\mathrm{BC}}$ & 2,3045 & \multirow{2}{*}{ Atenuador } & \multirow{2}{*}{15,916} \\
\hline $\mathrm{R}_{1}^{\prime}=\mathrm{R}_{\mathrm{DE}}$ & 47,084 & & \\
\hline $\mathrm{R}_{2}^{\prime}=\mathrm{R}_{\mathrm{EF}}$ & 3,1566 & \multirow{2}{*}{ SMIP } & \multirow{2}{*}{16722} \\
\hline $\mathrm{R}_{\mathrm{o}}=\mathrm{R}_{\mathrm{DF}}$ & 50,262 & & \\
\hline
\end{tabular}

Tabela 3: Valores dos componentes resistivos medidos e fatores de escala. 
Vale ressaltar que para calcular o FE do divisor e do sistema completo foram consideradas as medições com o cabo conectado, para representar de fato o sistema utilizado em alta tensão. A Figura 89 a seguir apresenta a medição da unidade secundária com o cabo conectado.

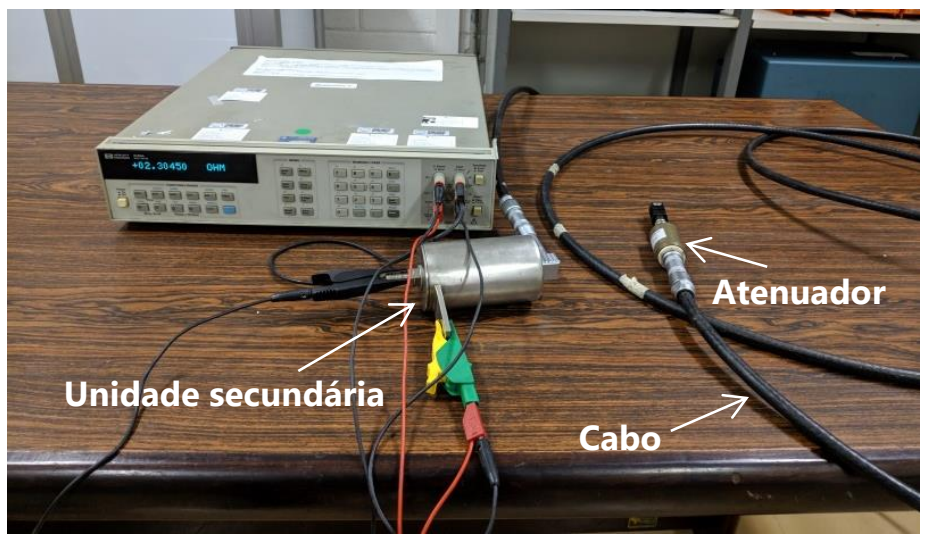

Figura 89: Medição da unidade secundária $\mathbf{R}_{2}$ mais cabo e atenuador.

\subsubsection{2.}

\section{Determinação do fator de escala em baixa tensão}

Os fatores de escala também foram determinados individualmente, em baixa tensão, levando em consideração o divisor de tensão, o atenuador e o sistema de medição completo. Foi utilizado um calibrador Fluke 5720A para gerar a tensão do ensaio, e adotado o valor verdadeiro do instrumento, que é usado para calibrar outros instrumentos no laboratório de calibração do Cepel acreditado pela RBC (Rede Brasileira de Calibração), conforme apresenta a Figura 90 e Figura 91. Após isso, foi utilizado um multímetro de alta resolução, 8,5 dígitos, para medir o sinal.

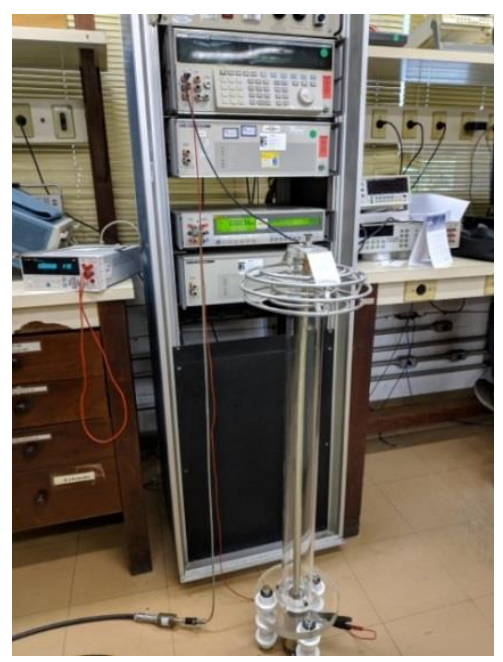

Figura 90: Medição do sistema completo no laboratório de calibração. 


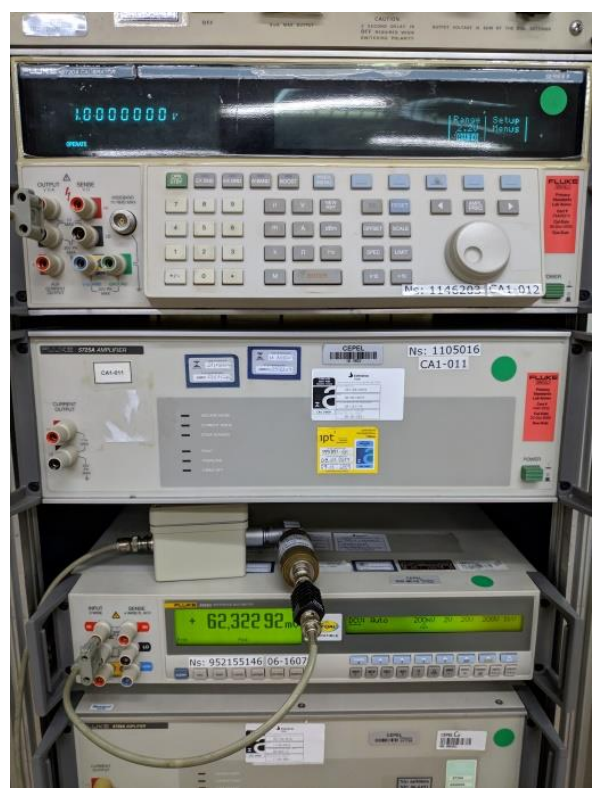

Figura 91: Medição do atenuador resistivo no laboratório de calibração.

São apresentados na Tabela 4 os fatores de escala obtidos utilizando esta metodologia.

Tabela 4: Fatores de escala determinados em baixa tensão em corrente contínua.

\begin{tabular}{|c|c|c|c|c|c|c|c|c|}
\hline \multicolumn{3}{|c|}{ Divisor de tensão } & \multicolumn{3}{|c|}{ Atenuador } & \multicolumn{3}{|c|}{ SMIP } \\
\hline $\mathrm{V}_{1}(\mathrm{~V})$ & $\mathrm{V}_{2}(\mathrm{mV})$ & $\mathrm{FE}\left(\mathrm{V}_{1} / \mathrm{V}_{2}\right)$ & $\mathrm{V}_{1}(\mathrm{~V})$ & $\mathrm{V}_{2}(\mathrm{mV})$ & $\mathrm{FE}\left(\mathrm{V}_{1} / \mathrm{V}_{2}\right)$ & $\mathrm{V}_{1}(\mathrm{~V})$ & $\mathrm{V}_{2}(\mathrm{mV})$ & $\mathrm{FE}\left(\mathrm{V}_{1} / \mathrm{V}_{2}\right)$ \\
\hline \multirow{10}{*}{29,98798} & 28,16110 & 1064,87 & \multirow{10}{*}{0,99958} & 62,31954 & 16,040 & \multirow{10}{*}{29,98799} & 1,75509 & 17086 \\
\hline & 28,16020 & 1064,91 & & 62,32331 & 16,039 & & 1,75505 & 17087 \\
\hline & 28,16018 & 1064,91 & & 62,32371 & 16,039 & & 1,75509 & 17086 \\
\hline & 28,16022 & 1064,91 & & 62,32292 & 16,038 & & 1,75510 & 17086 \\
\hline & 28,16024 & 1064,90 & & 62,32433 & 16,038 & & 1,75502 & 17087 \\
\hline & 28,16020 & 1064,91 & & 62,32440 & 16,038 & & 1,75501 & 17087 \\
\hline & 28,16005 & 1064,91 & & 62,32566 & 16,038 & & 1,75595 & 17078 \\
\hline & 28,16037 & 1064,90 & & 62,32589 & 16,038 & & 1,75503 & 17087 \\
\hline & 28,16036 & 1064,90 & & 62,32560 & 16,038 & & 1,75508 & 17086 \\
\hline & 28,16019 & 1064,91 & & 62,32553 & 16,038 & & 1,75501 & 17087 \\
\hline \multicolumn{2}{|c|}{ Média } & 1064,902 & \multicolumn{2}{|c|}{ Média } & 16,038 & \multicolumn{2}{|c|}{ Média } & 17086 \\
\hline
\end{tabular}

\subsection{2.}

\section{Avaliação do desempenho dinâmico}

Após a caracterização do sistema de medição, este foi avaliado em relação ao seu desempenho dinâmico para impulsos de perfuração, considerando que um 
sistema para este tipo de aplicação deve possuir desempenho dinâmico compatível com o impulso muito rápido que será medido.

A avaliação do desempenho dinâmico foi realizada pela análise da resposta ao degrau. Um gerador de degrau com tensão $\cong 90 \mathrm{~V}$ de crista e com tempos de subida com ordem de 4 ns foi posicionado no lugar do isolador sob ensaio. Um osciloscópio com largura de banda plena de $1 \mathrm{GHz}$ foi utilizado para aquisição e o processamento do sinal foi feito pelo software STERAL, programa computacional para cálculo e análise de parâmetros da resposta ao degrau. Estão apresentados na Figura 92 e na Figura 93 o arranjo de medição e sua respectiva resposta ao degrau. O tempo de resposta parcial é um dos requisitos específicos previstos na IEC 61211:2004 [5] para sistemas de medição para impulso de perfuração. Porém, por apresentar um comportamento dinâmico, outros parâmetros podem influenciar no parâmetro principal.

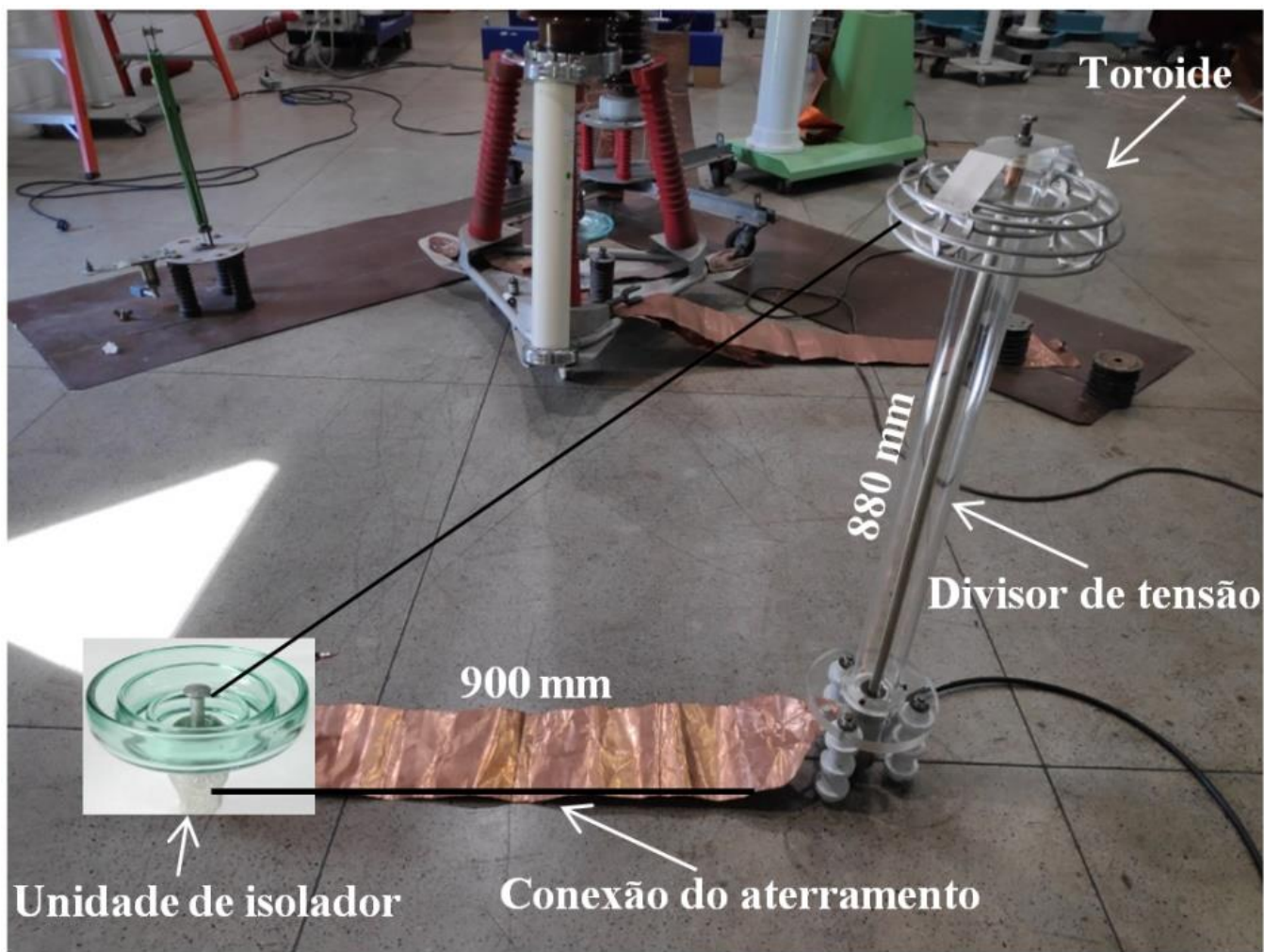

Figura 92: Arranjo da avaliação do desempenho do divisor de tensão. 


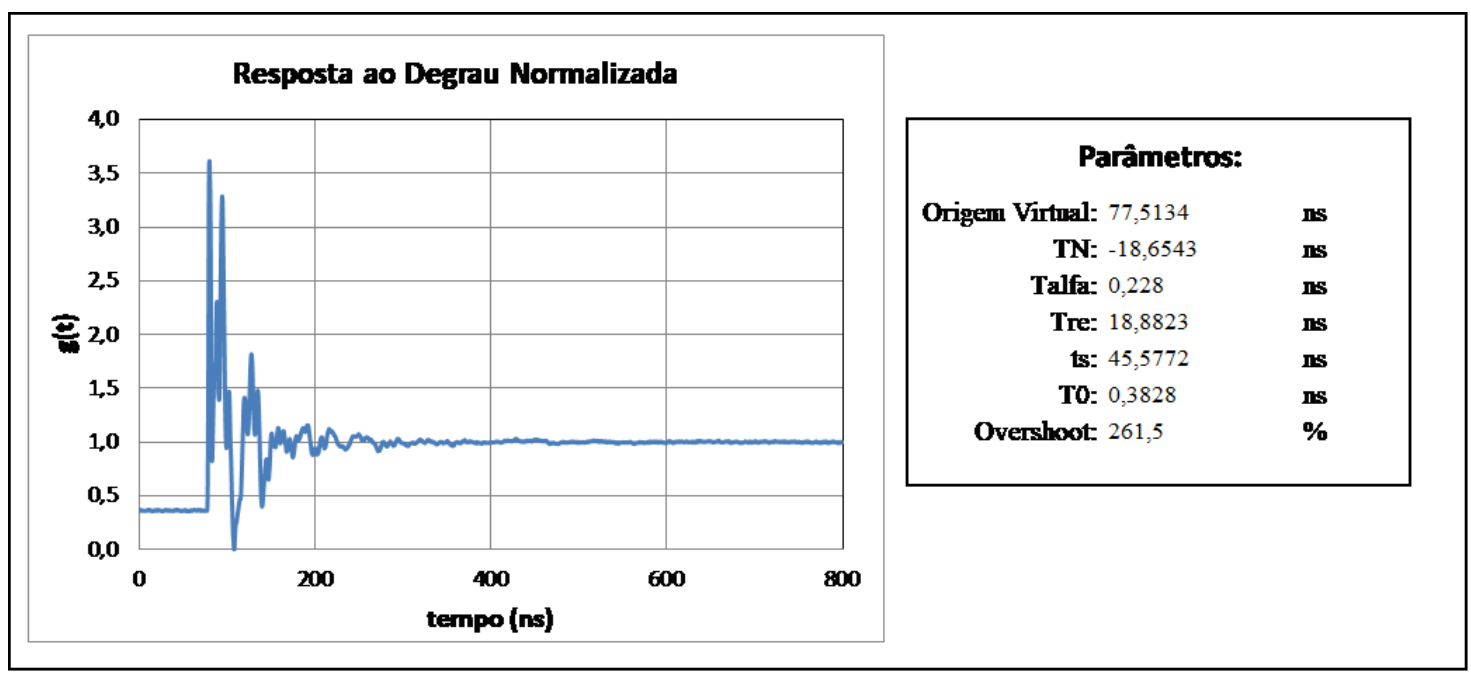

Figura 93: Resultado da resposta ao degrau do divisor de tensão.

A realização da resposta ao degrau também foi realizada no atenuador resistivo e é apresentado na Figura 94 e na Figura 95.

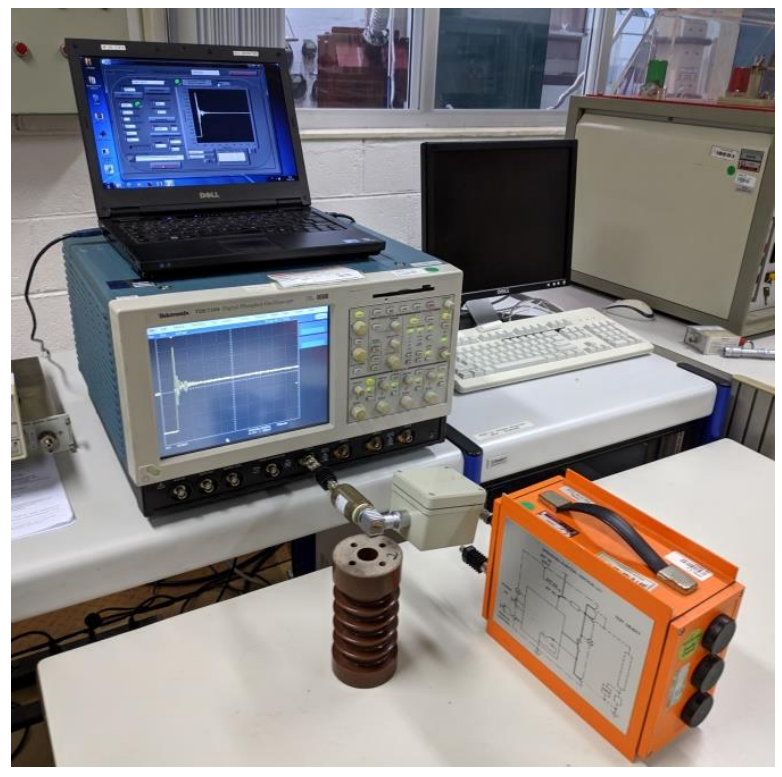

Figura 94: Arranjo da avaliação do desempenho do atenuador resistivo. 


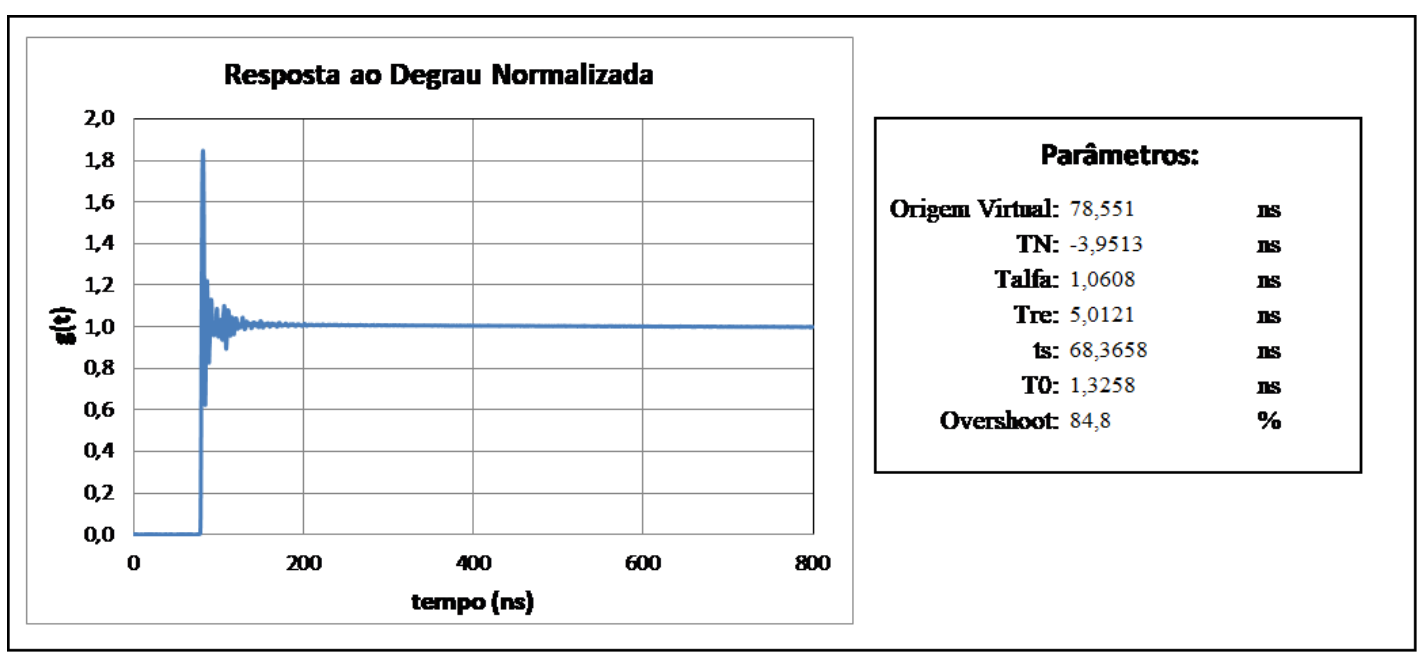

Figura 95: Resultado da resposta ao degrau do atenuador resistivo.

Pelo fato do divisor desenvolvido ser bastante compacto, sua utilização pode ser versátil. Com base na experiência de utilização de divisores de perfuração, como, por exemplo, no VTT Finland, o divisor de tensão foi avaliado uma segunda vez variando o seu ângulo em relação ao terra. Da Figura 96 à Figura 99 são apresentadas as respostas ao degrau do divisor na posição diagonal e na horizontal.

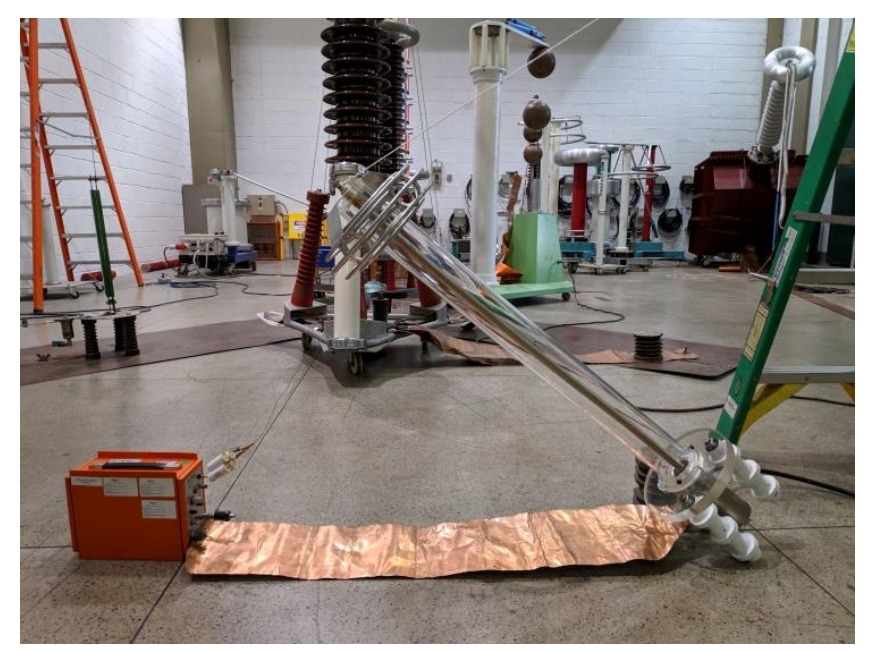

Figura 96: Avaliação do desempenho do divisor de tensão na diagonal. 


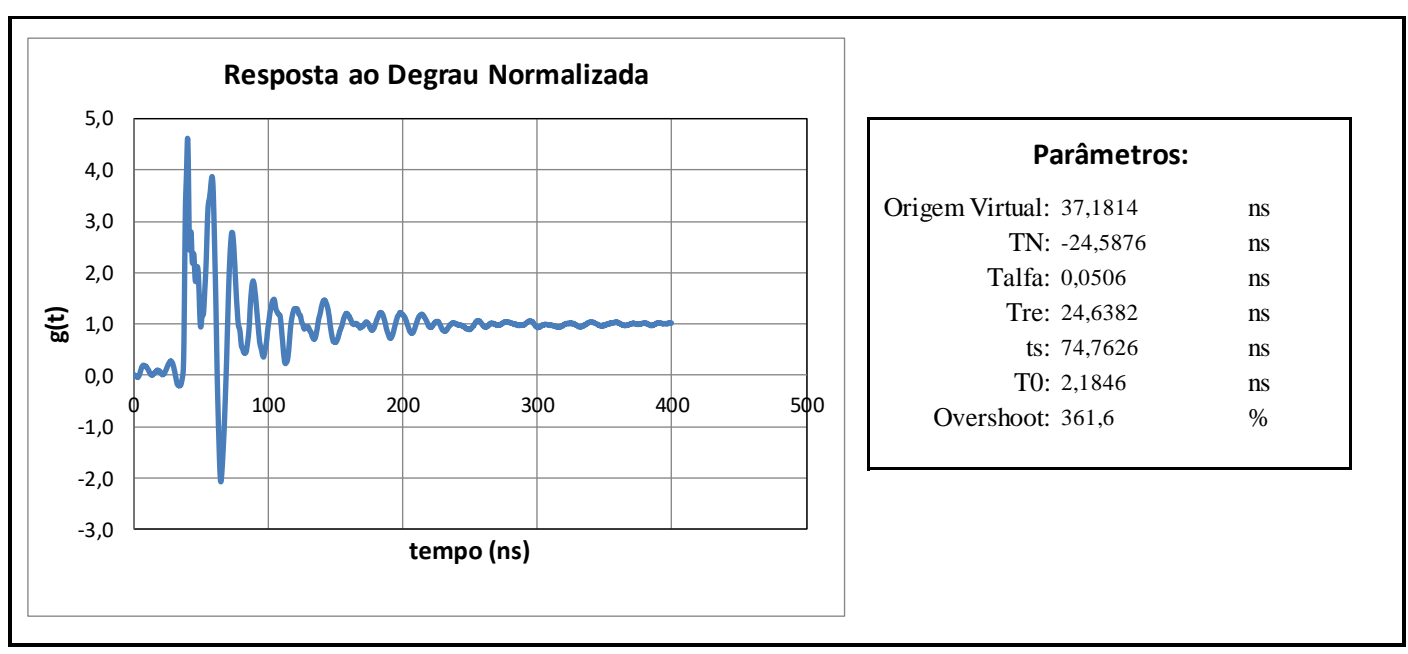

Figura 97: Resposta ao degrau do divisor de tensão na diagonal.

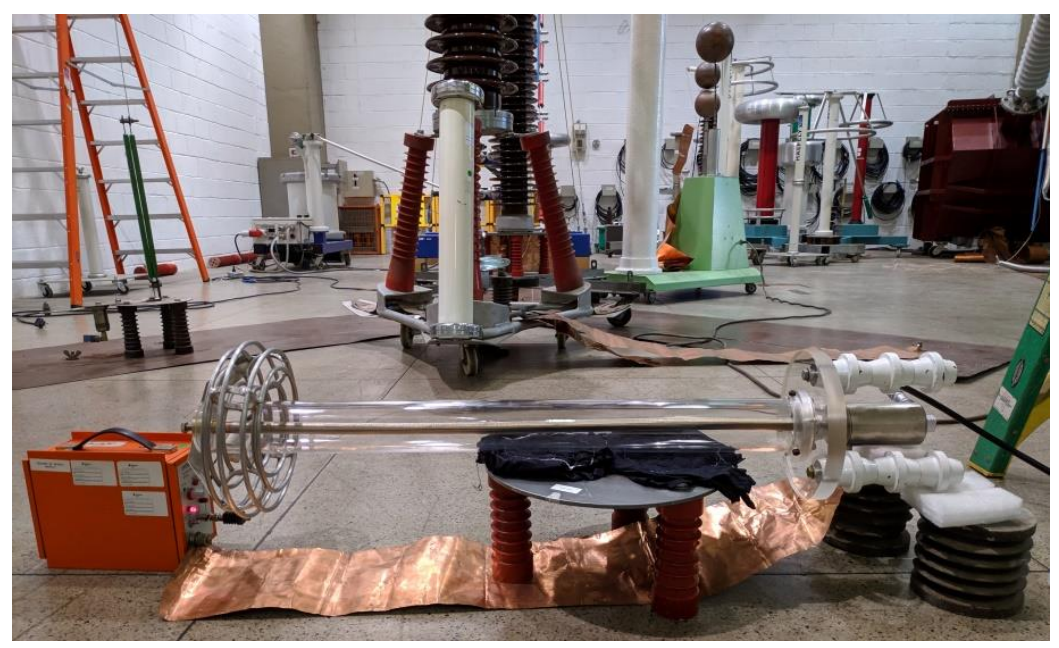

Figura 98: Avaliação do desempenho do divisor de tensão na horizontal.

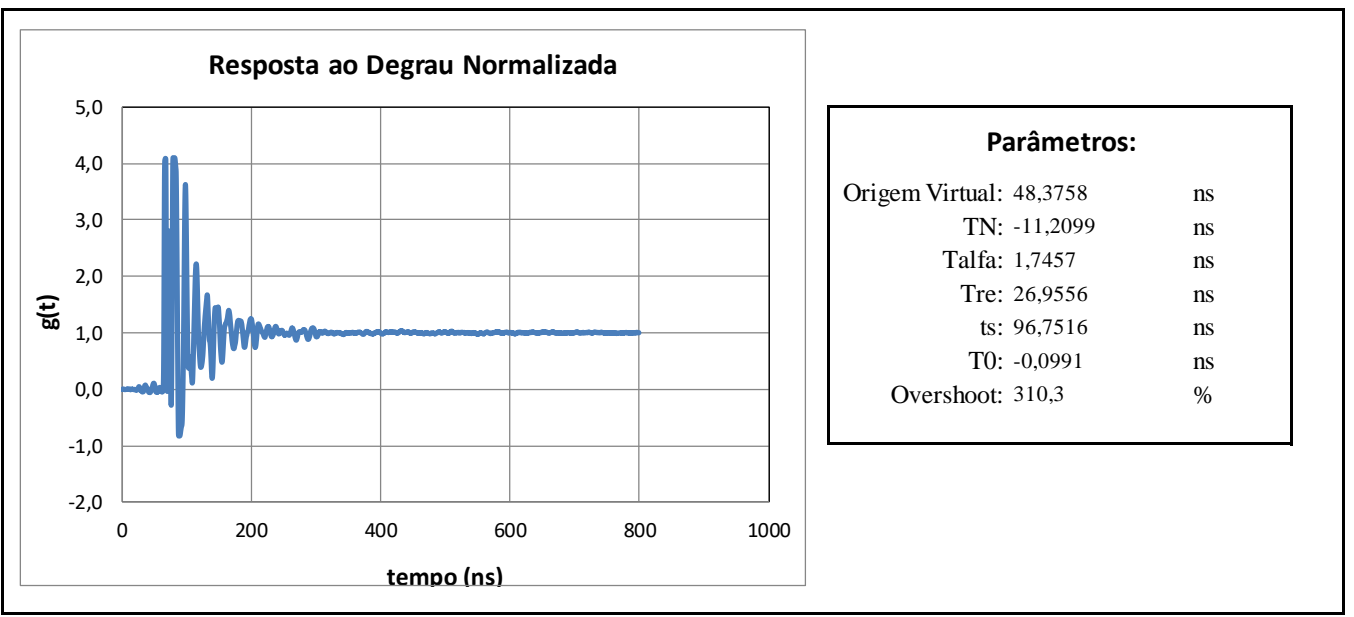

Figura 99: Resposta ao degrau do divisor de tensão na horizontal.

Após a análise dos resultados da reposta ao degrau, observou-se que, instalando-se o divisor tanto na posição diagonal quanto na posição horizontal, 
este se manteve dentro do requisito permitido pela norma IEC 61211:2004 [5]. Porém, é importante uma visão holística do sistema e enxergar que o tempo de estabilização $t_{s}$, ou settling time, contribui para o desempenho do sistema de medição, já que o sistema de medição deve estar estabilizado no momento em que ocorre a medição do impulso de perfuração que é um impulso muito rápido.

\subsection{3.}

\section{Avaliação e análise da resposta em frequência}

A análise do sistema de medição no domínio da frequência foi realizada por meio da resposta em frequência medida no Laboratório de Diagnóstico em Equipamentos e Instalações Elétricas (Labdig), utilizando um sistema denominado SCAn e o Virtualbench da National Instruments como instrumento único de geração e medição.

Esta análise foi realizada no sistema de medição nas configurações de ensaio de acordo com a Tabela 5, pois a norma IEC 61211:2004 [5] não define uma configuração específica para este ensaio, e também até o momento ainda não era conhecido o desempenho dos divisores de tensão desenvolvidos pelo Cepel em diferentes posições. Isso se fez necessário devido a não existir uma padronização da configuração de ensaio de perfuração em isoladores de diferentes laboratórios de ensaio e calibração e também em relação aos fatores informados na medição da resposta ao degrau.

Tabela 5: Descrição de cada tipo de configuração de ensaio avaliada.

\begin{tabular}{|c|c|}
\hline Configuração & Descrição \\
\hline A1 & Divisor na posição vertical com o toroide \\
\hline A2 & Divisor na posição vertical sem o toroide \\
\hline B1 & Divisor na posição $45^{\circ}$ com o toroide \\
\hline B2 & Divisor na posição $45^{\circ}$ sem o toroide \\
\hline C1 & Divisor na posição horizontal com o toroide \\
\hline C2 & Divisor na posição horizontal sem o toroide \\
\hline
\end{tabular}

Com estas configurações foram realizados dois tipos de medição, com varredura de frequência entre $100 \mathrm{kHz}$ e $20 \mathrm{MHz}$. Primeiramente, a de transferência de tensão, na qual foi aplicada uma tensão $\mathrm{V}_{\mathrm{pp}}=20 \mathrm{~V}$ entre o topo do divisor e o terra e obtida uma tensão na unidade de baixa tensão em função da 
frequência, com isso calculando o ganho em $\mathrm{dB}$ e consequentemente o ganho em tensão, que determina o fator de escala do sistema. Os resultados destas medições através da transferência de tensão são apresentados da Figura 100 até a Figura 105.

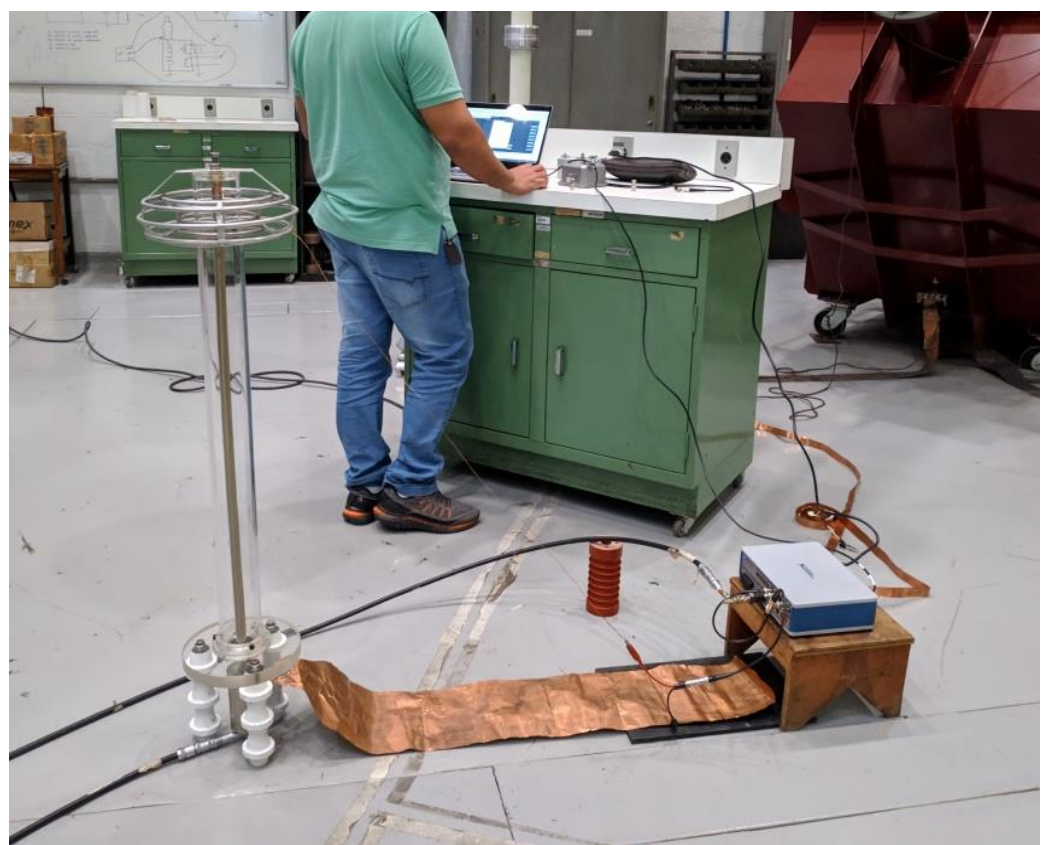

Figura 100: Transferência de tensão com toroide e na vertical.
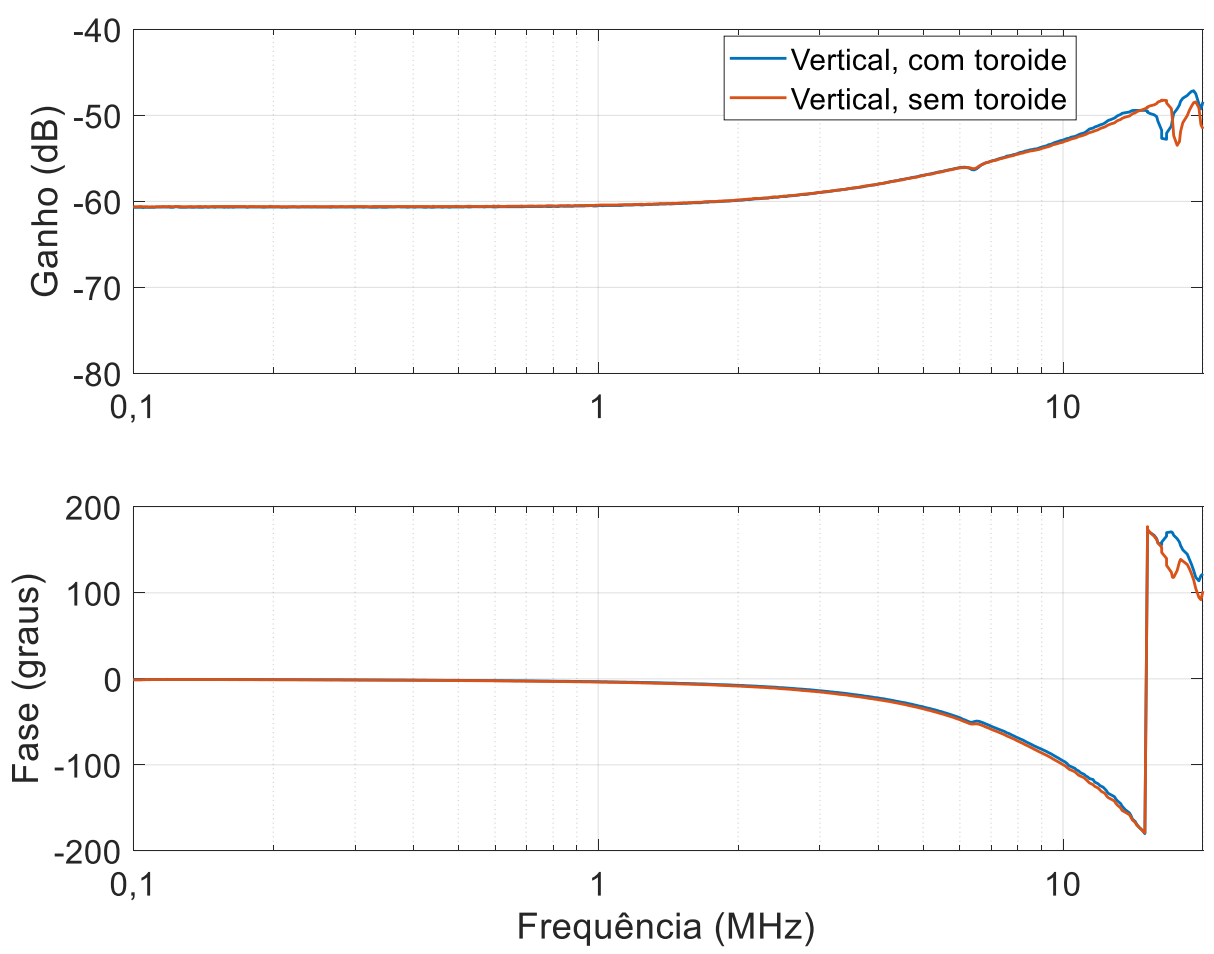

Figura 101: Transferência de tensão com e sem toroide e na vertical. 


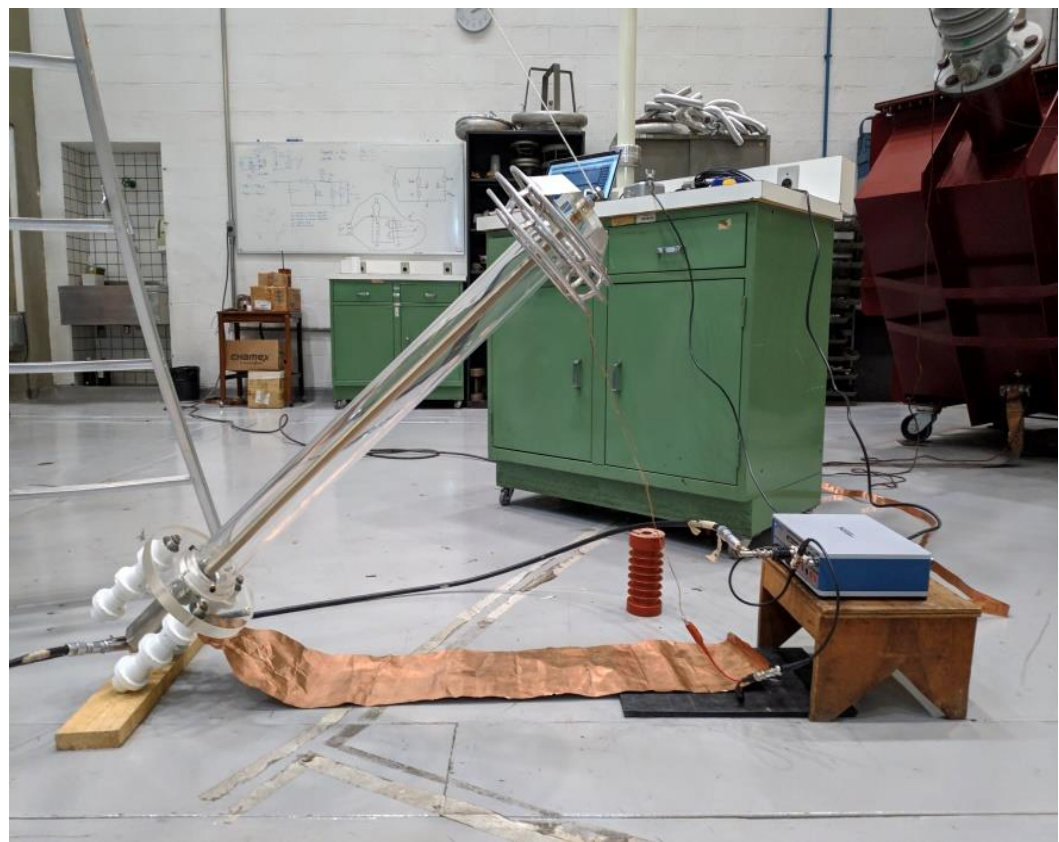

Figura 102: Transferência de tensão com toroide e na diagonal.
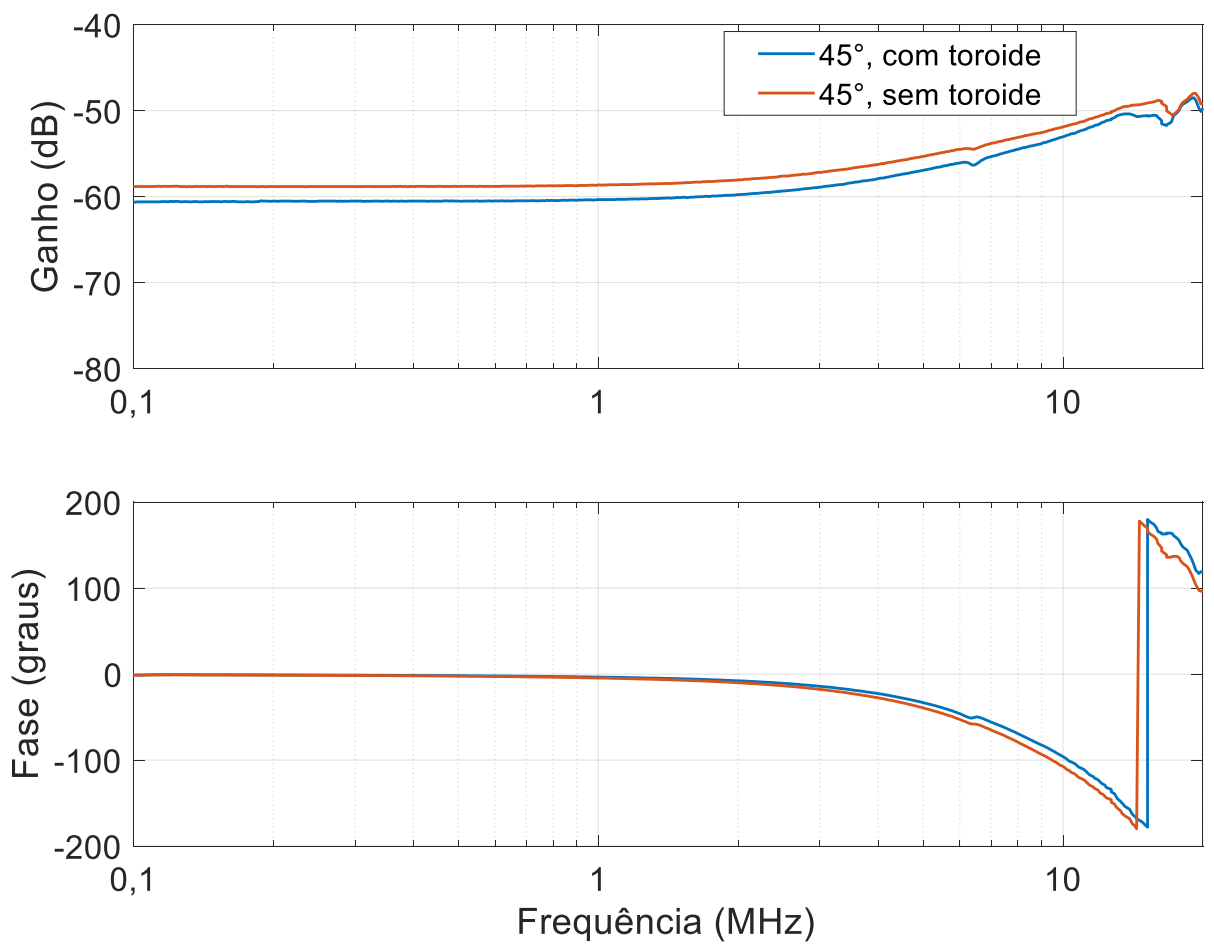

Figura 103: Transferência de tensão com e sem toroide e na diagonal. 


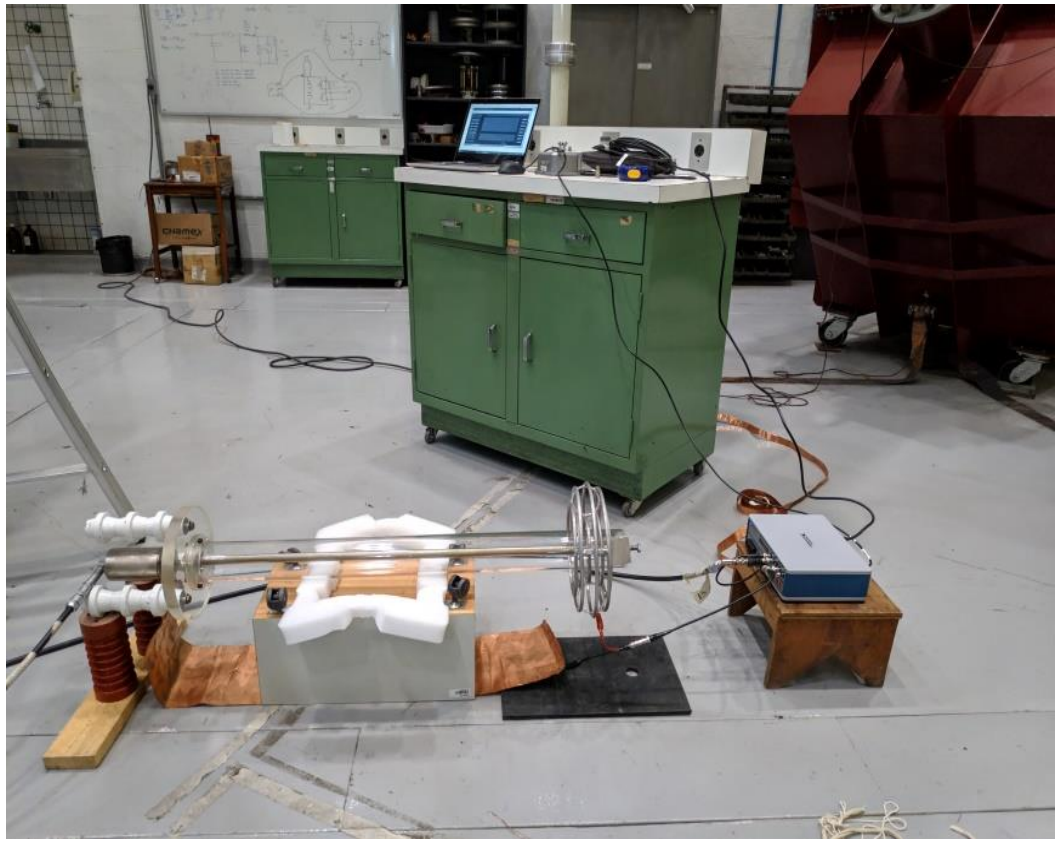

Figura 104: Transferência de tensão com toroide e na horizontal.
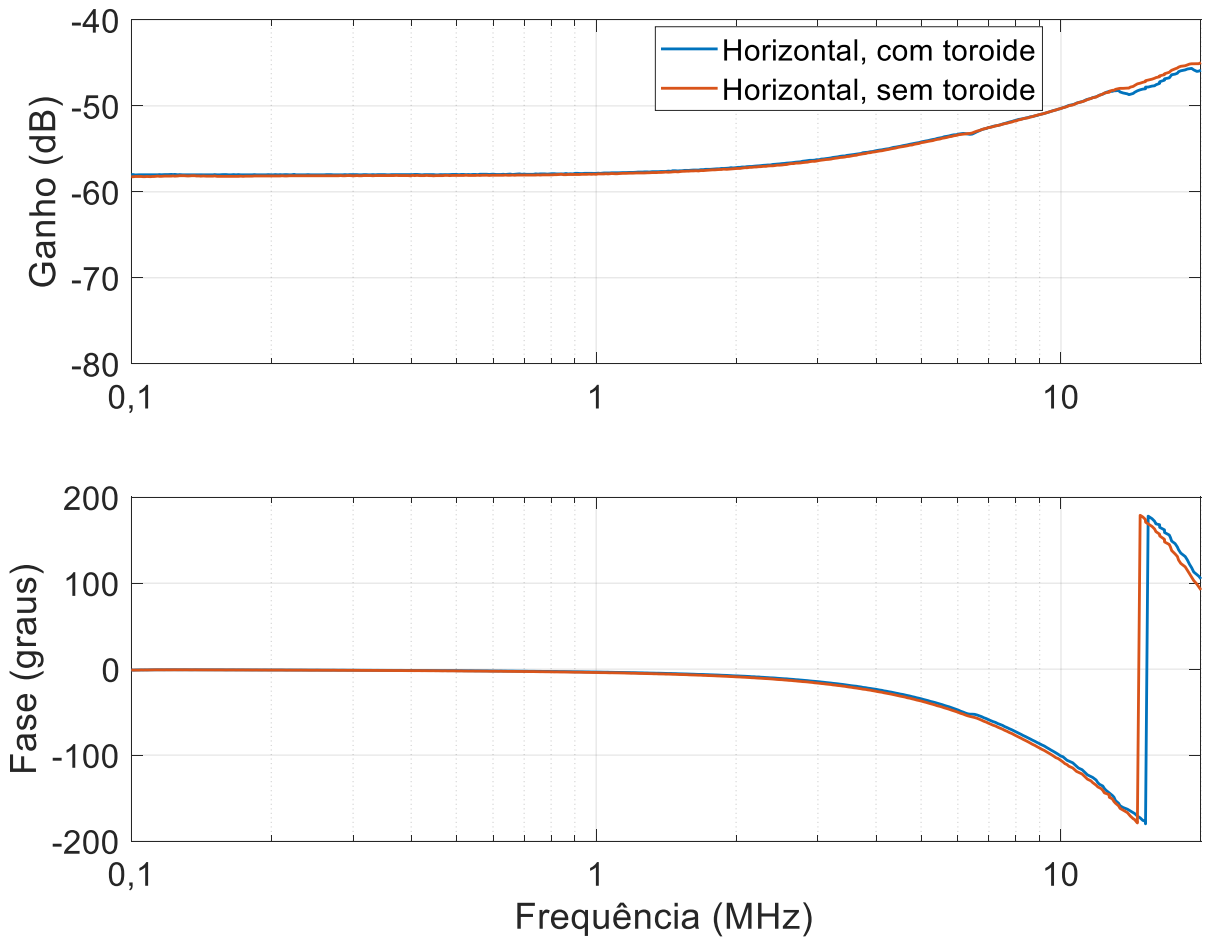

Figura 105: Transferência de tensão com e sem toroide e na horizontal.

Na sequência, foi realizada a medição da impedância do sistema em função da frequência de varredura. Em todas as configurações anteriores são apresentados os resultados com e sem o cabo a partir da Figura 106 até a Figura 111. 

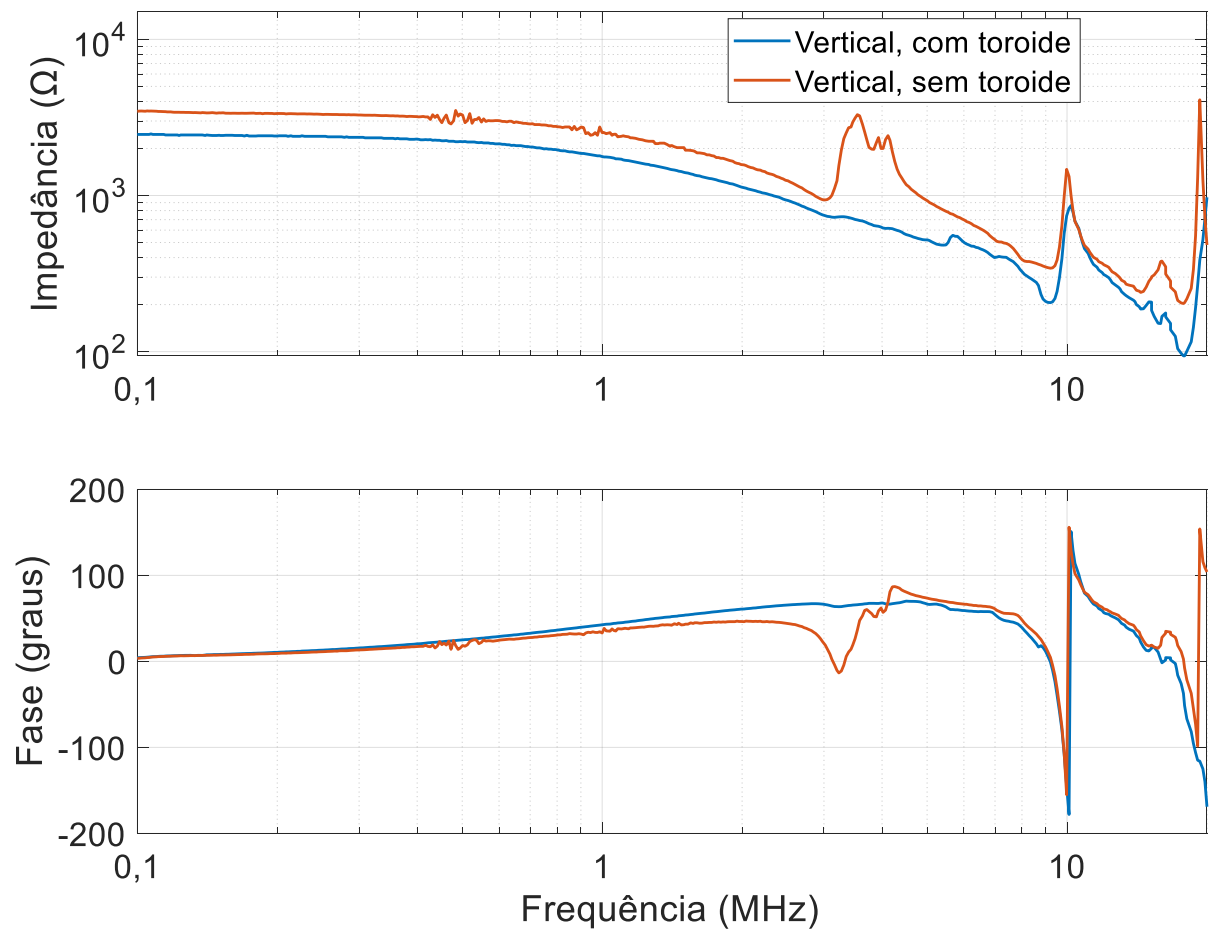

Uू

Figura 106: Medição da impedância, com cabo e na posição vertical.
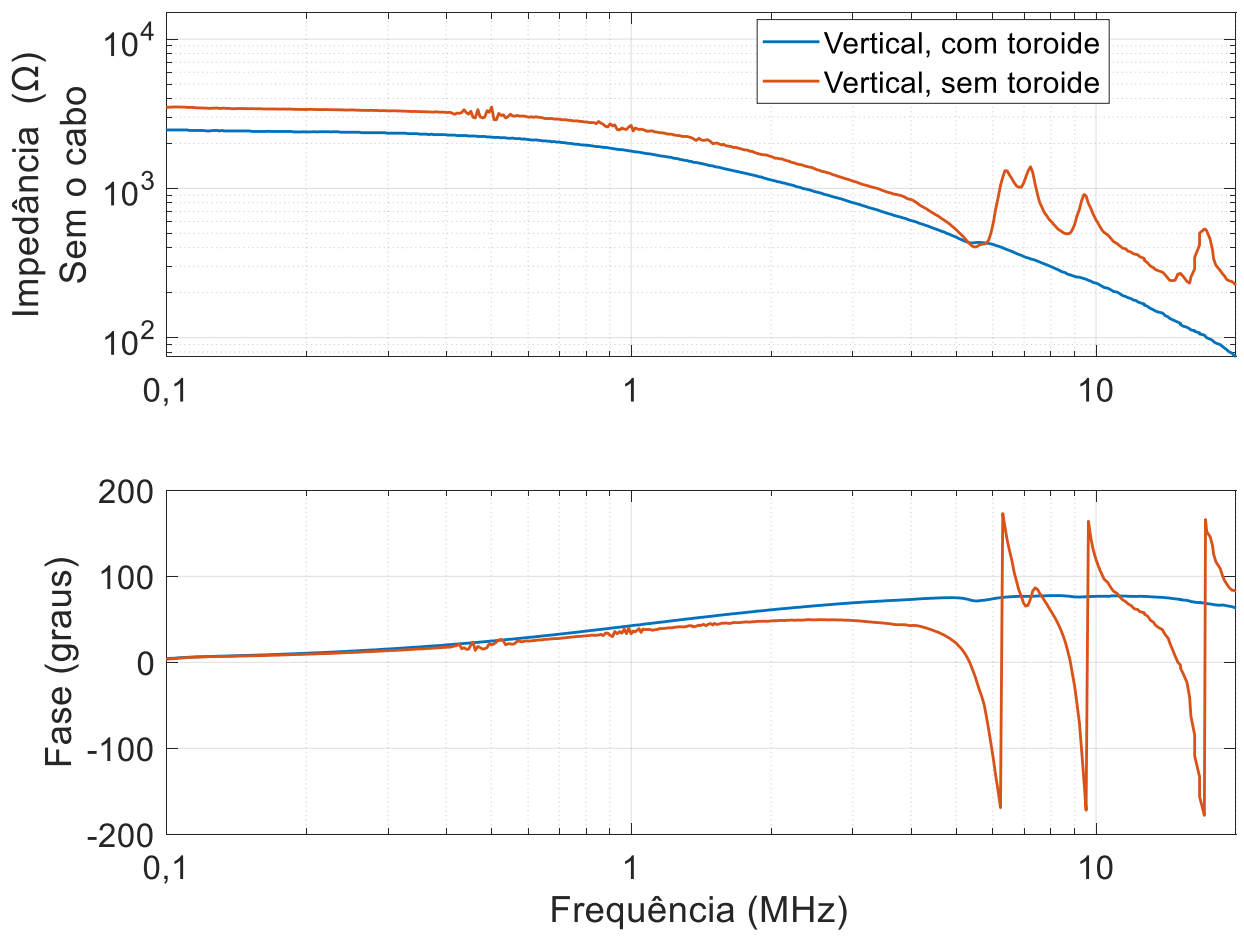

Figura 107: Medição da impedância, sem cabo e na posição vertical. 

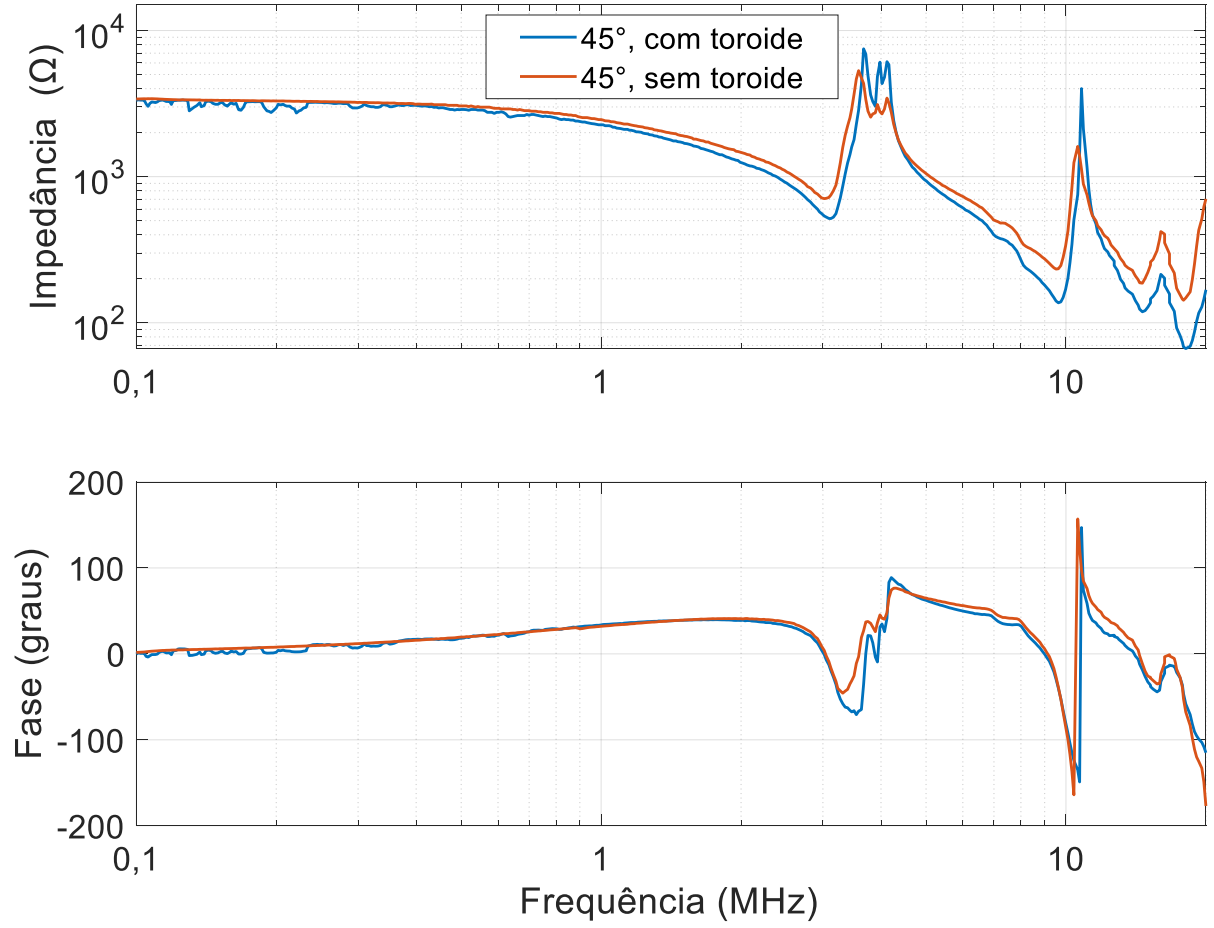

Figura 108: Medição da impedância, com cabo e na posição diagonal.
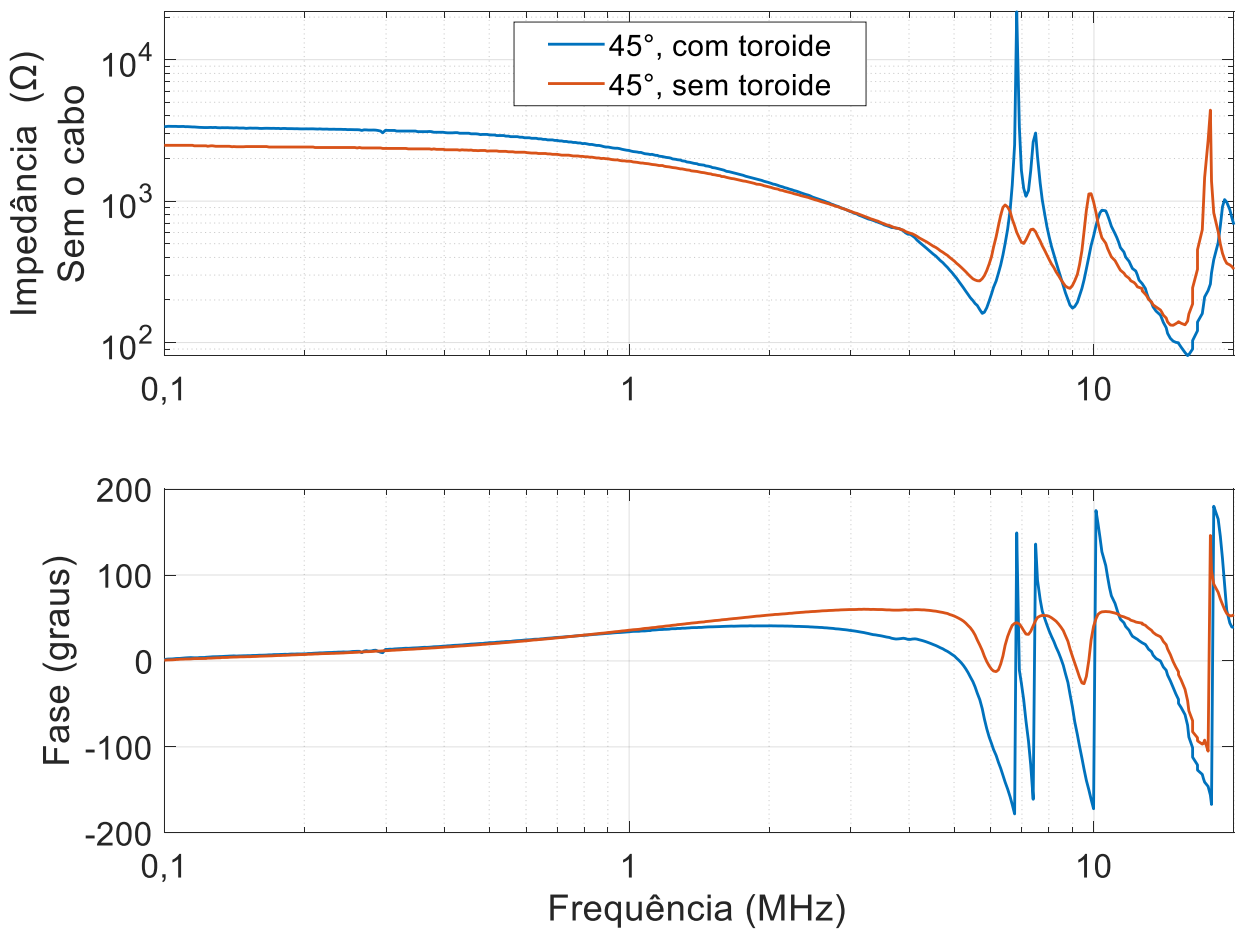

Figura 109: Medição da impedância, sem cabo e na posição diagonal. 

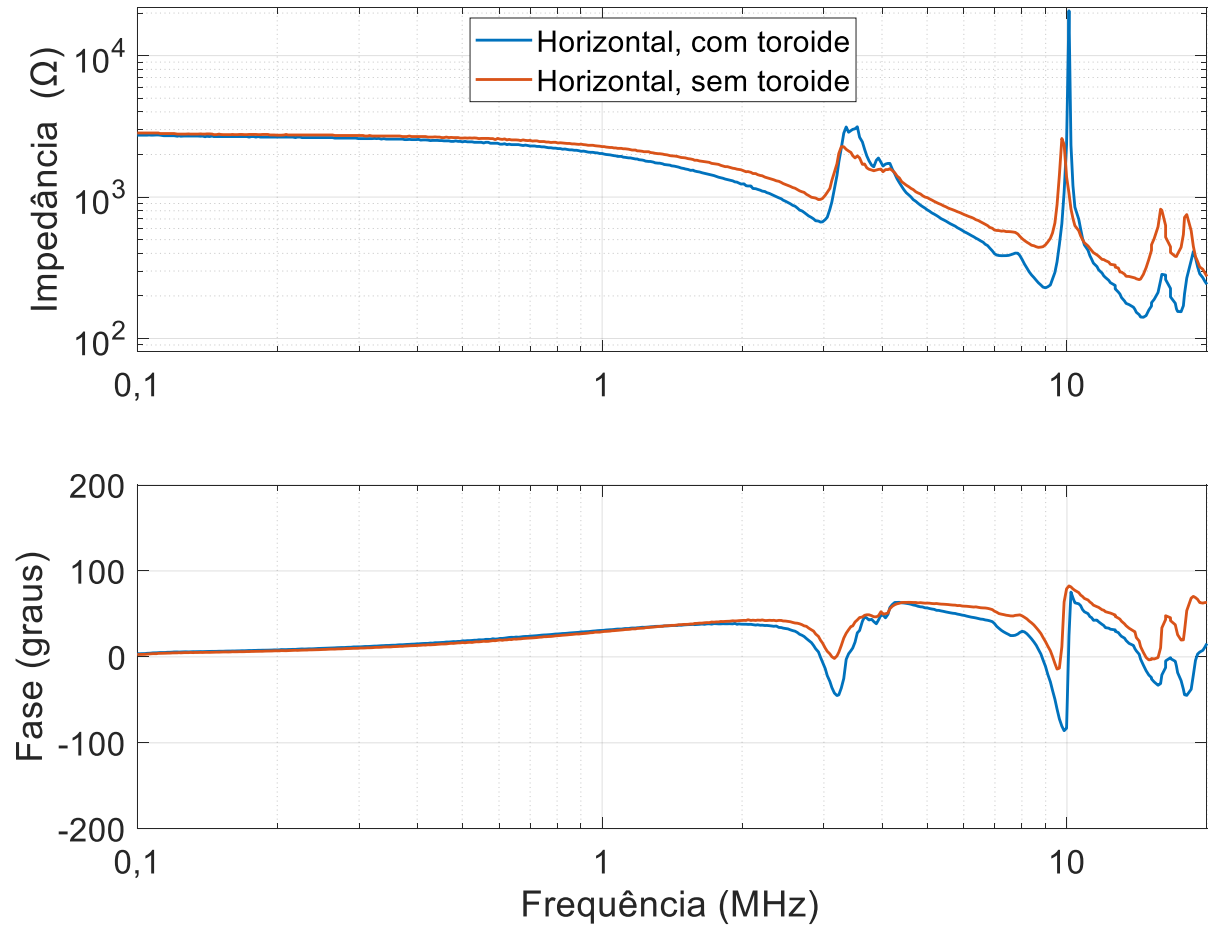

Figura 110: Medição da impedância, com cabo e na posição horizontal.
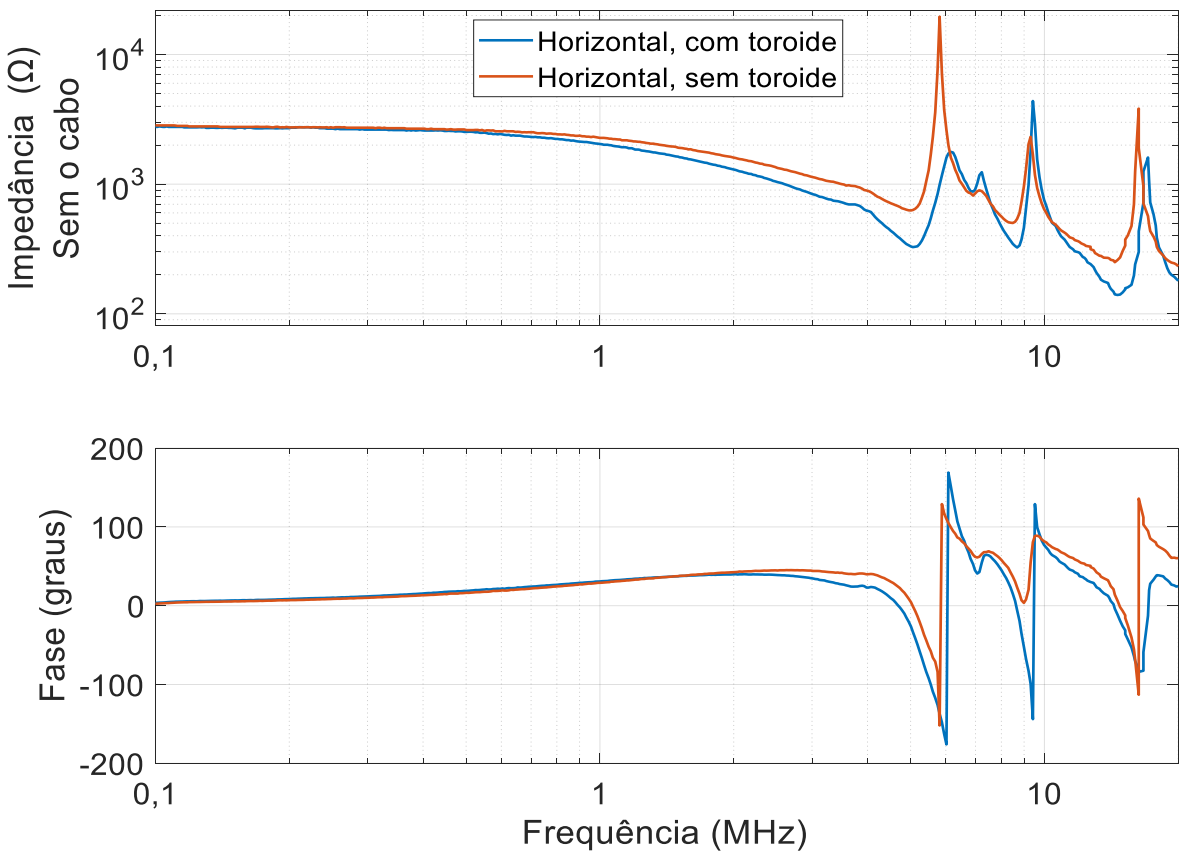

Figura 111: Medição da impedância, sem cabo e na posição horizontal.

A Tabela 6 apresenta os resultados destas medições para cada configuração de ensaio. 
Tabela 6: Resultados obtidos por meio da resposta em frequência do sistema de medição.

\begin{tabular}{|c|c|c|c|c|c|}
\hline Posição & Configuração & $\begin{array}{c}\text { Ganho } \\
(\mathbf{d B})\end{array}$ & $\begin{array}{c}\text { Fator de } \\
\text { escala }\end{array}$ & $|\mathbf{Z}|$ com cabo & $|\mathbf{Z}|$ sem cabo \\
\hline \multirow{2}{*}{$\mathrm{V}$} & $\mathrm{A} 1$ & $-60,63$ & 1075,23 & $2,461 \mathrm{k} \Omega$ & $2,461 \mathrm{k} \Omega$ \\
\cline { 2 - 6 } & $\mathrm{A} 2$ & $-60,63$ & 1075,23 & $3,462 \mathrm{k} \Omega$ & $3,488 \mathrm{k} \Omega$ \\
\hline \multirow{2}{*}{$45^{\circ}$} & $\mathrm{B} 1$ & $-60,63$ & 1075,23 & $3,326 \mathrm{k} \Omega$ & $3,355 \mathrm{k} \Omega$ \\
\cline { 2 - 6 } & $\mathrm{B} 2$ & $-58,86$ & 877,00 & $3,402 \mathrm{k} \Omega$ & $2,480 \mathrm{k} \Omega$ \\
\hline \multirow{2}{*}{$\mathrm{H}$} & $\mathrm{C} 1$ & $-58,02$ & 796,15 & $2,838 \mathrm{k} \Omega$ & $2,838 \mathrm{k} \Omega$ \\
\cline { 2 - 6 } & $\mathrm{C} 2$ & $-58,02$ & 796,15 & $2,838 \mathrm{k} \Omega$ & $2,838 \mathrm{k} \Omega$ \\
\hline
\end{tabular}

A partir dos resultados pode-se observar que os valores que mais se adequaram ao valor medido na caracterização foram os obtidos na configuração vertical para o divisor de tensão com o toroide, configuração A1. A utilização do divisor em qualquer outra posição influencia no fator de escala ou na impedância projetada.

$\mathrm{Na}$ transferência de tensão, todas as medições apresentaram uma banda de frequência com variação menor que $3 \mathrm{db}$ até a frequência de 4,36 MHz. Isso satisfaz o sistema de medição, visto que a faixa de frequências de interesse do ensaio em questão vai até $4 \mathrm{MHz}$. É importante notar e ressaltar que o condutor acrescentado ao arranjo de ensaio influencia bastante no comportamento do sistema para frequências na ordem de $1 \mathrm{MHz}$ no caso de medições de impedâncias, diferentemente da transferência de tensão. Além disso, no caso desse tipo de condutor nu, sem nenhum tipo de blindagem, é difícil executar uma boa reprodutibilidade do arranjo quanto maior for a frequência de interesse do sinal.

É importante observar também que uma simples alteração do sistema de medição, como a remoção do toroide, modifica a relação do divisor em resultados em baixa tensão e também a impedância resultante medida.

\section{2. \\ Calibração do sistema de medição para ensaios de impulso de perfuração em isoladores}

A calibração do novo sistema de medição para ensaios de impulso de perfuração em isoladores do Cepel, que será chamado de SM CA2, foi realizada 
por comparação, adotando como referência o divisor de tensão já então existente e apresentado no Capitulo 4, que foi comparado em alta tensão na Finlândia e será chamado de SM ELN. A primeira etapa para a calibração do sistema de medição é a determinação do fator de escala do sistema em alta tensão.

\subsection{1.}

\section{Determinação do fator de escala}

A determinação do fator de escala foi realizada por comparação dos sistemas de medição conectados em paralelo, conforme Figura 112 e Figura 113.

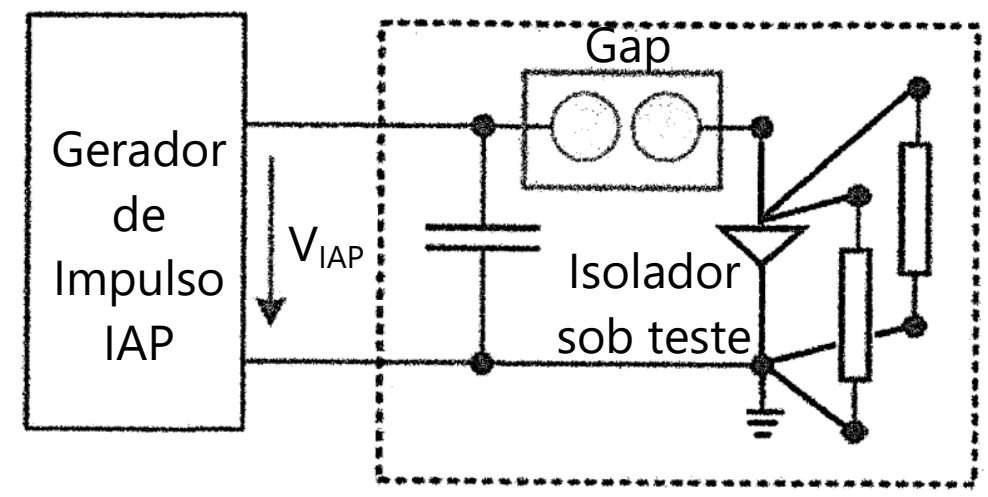

Figura 112: Diagrama simplificado para calibração de SMIP.

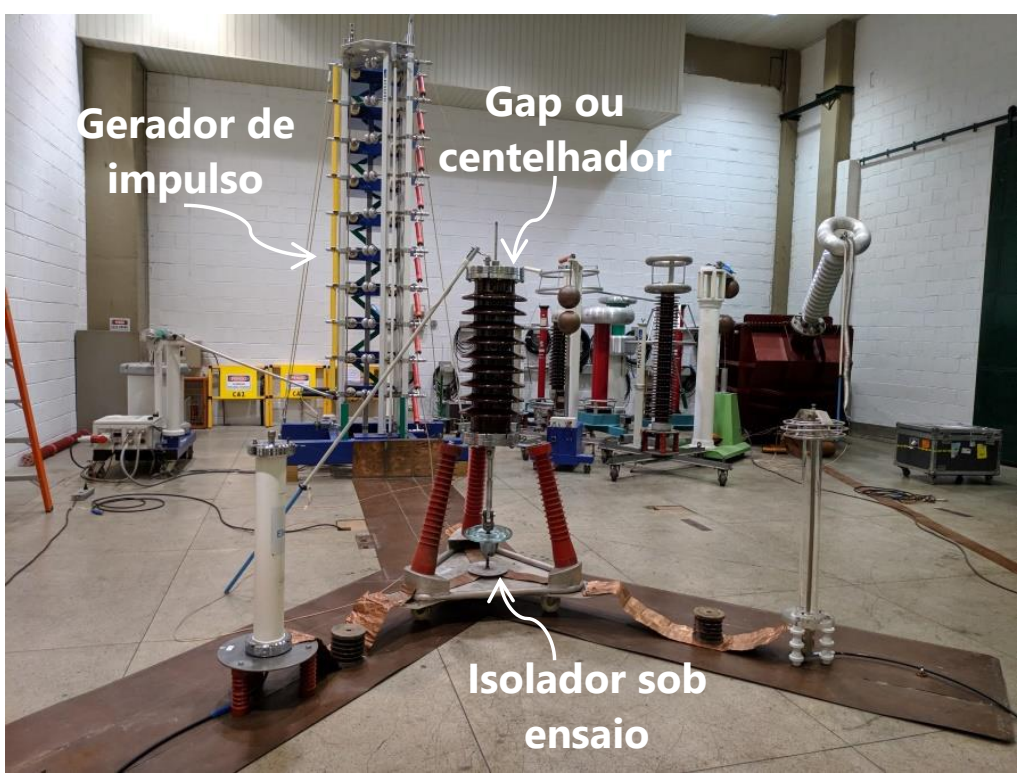

Figura 113: Arranjo para calibração de SMIP em alta tensão.

Para geração do impulso de perfuração primeiro é preciso ajustar o gerador de impulso para aplicar um impulso atmosférico pleno com forma de onda normalizada IAP $(1,2 / 50 \mu \mathrm{s})$. O gerador de impulso ajustado para esta configuração é apresentado na Figura 114. 


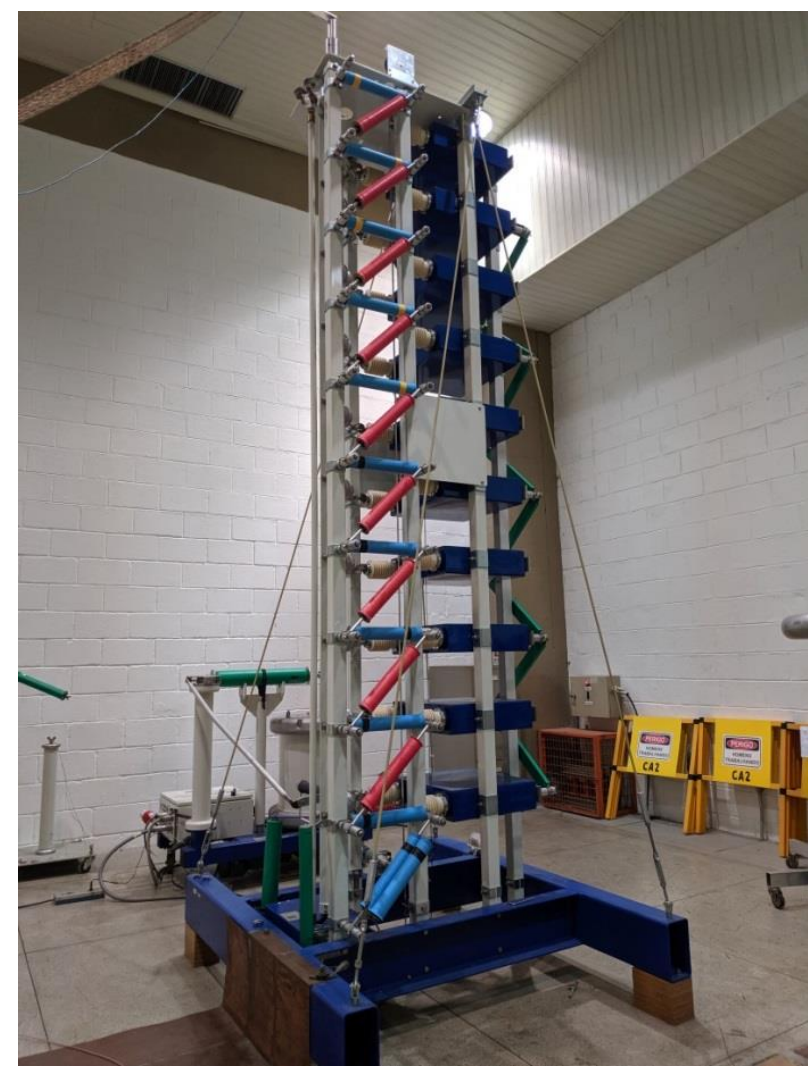

Figura 114: Gerador de impulso ajustado para IAP (1,2/50 $\mu \mathrm{s})$.

Vale ressaltar que, além da dificuldade na medição de impulsos muito rápidos, como de perfuração em isoladores, também é um grande desafio a geração de forma correta. A norma IEC 61211:2004 [5] faz pequenas recomendações para a geração do impulso, como o uso do gap/centelhador, para ser possível a frente de onda muito rápida. Como parte do arranjo, tendo sido verificado que o seu uso melhora a forma de onda, foi utilizado um capacitor de frente no circuito com tensão suportável de $500 \mathrm{kV}$.

Estudos e investigações foram e ainda estão sendo realizados no Laboratório de Referência em Medição de Alta Tensão (CA2) para definir o melhor circuito e configuração de geração deste impulso. Foi observado que, além do ajuste correto do gerador de impulso, uma variação também no gap/centelhador, como o tipo de material ou o diâmetro da esfera que o compõem, interfere na geração do impulso de perfuração.

Com o circuito todo ajustado foi realizada a primeira aplicação para testar o sistema de medição. A Figura 115 apresenta o resultado desse primeiro teste. 


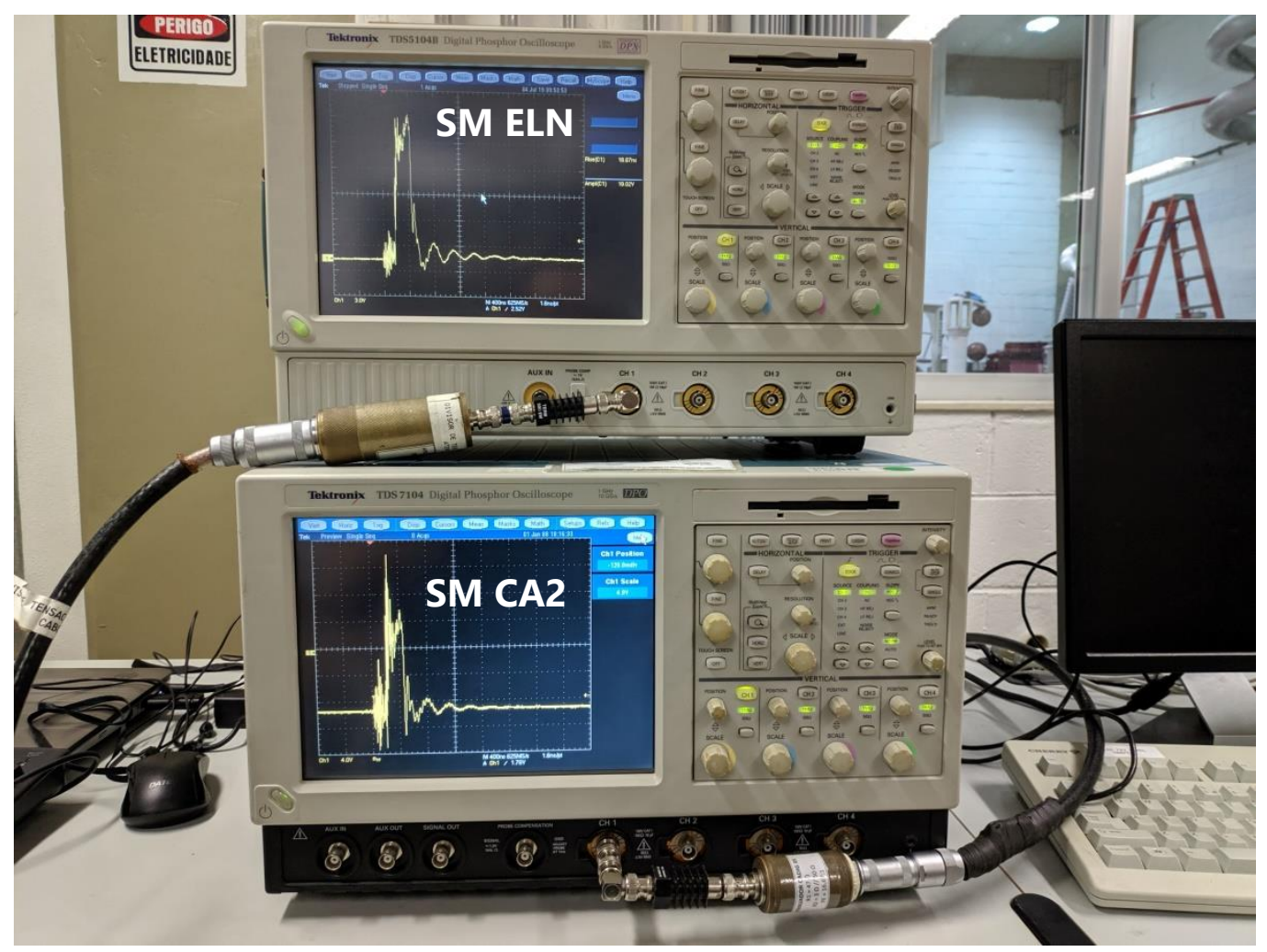

Figura 115: Resultado da primeira medição em alta tensão.

Na Figura 115 pode-se observar que o SM CA2 teve uma maior sensibilidade a interferências do ensaio. E que, mesmo utilizando o software RAPIT para a remoção do ruído, ainda assim haveria uma grande diferença na amplitude medida. Com isso, optou-se para efetuar uma reavaliação nos cuidados para a realização da medição, por ser um ensaio com grande interferência irradiada e também na realização do ensaio de interferência para verificar se o nível de interferência está de acordo com o nível permitido pelas normas aplicáveis.

\subsubsection{1.}

\section{Cuidados na realização da medição de impulsos de perfuração}

Os cuidados adicionais tomados para tentar amenizar a interferência irradiada no sistema de medição incluíram, primeiramente, melhorar o aterramento desde o divisor até a sala de controle junto ao osciloscópio. Em seguida, foi realizada uma blindagem extra no cabeamento, envolvendo o cabo em um tubo metálico, aterrando o tubo, e roteando o mesmo por uma passagem subterrânea, conforme mostra a Figura 116 e Figura 117. 


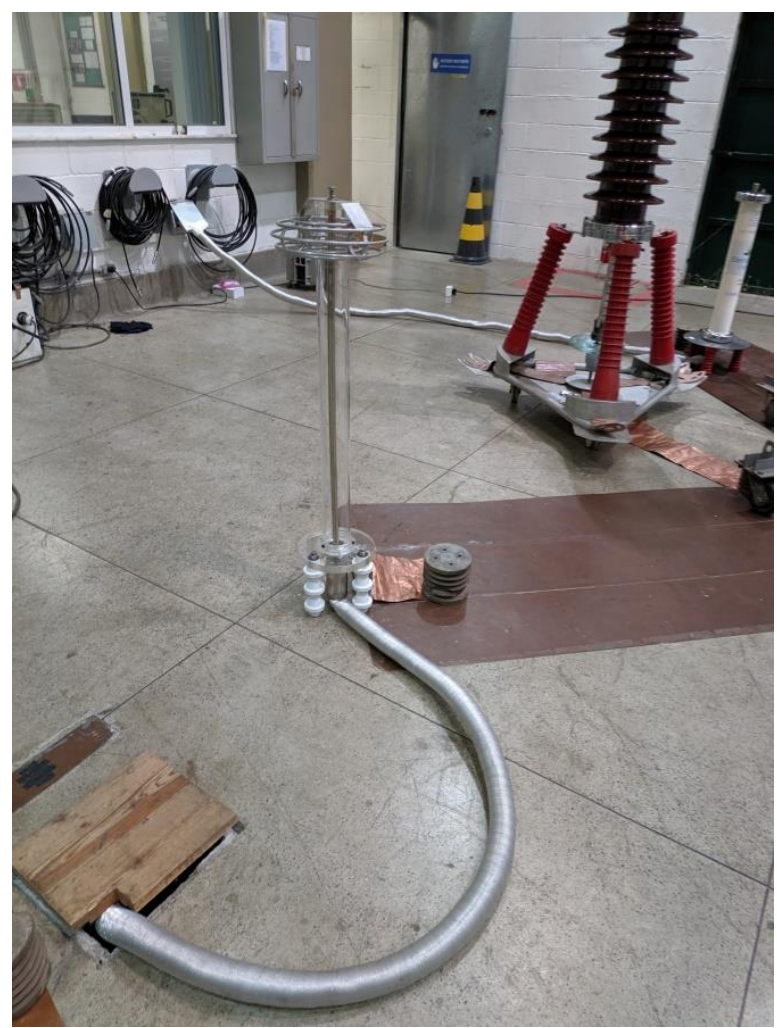

Figura 116: Blindagem extra realizada no cabo de medição.

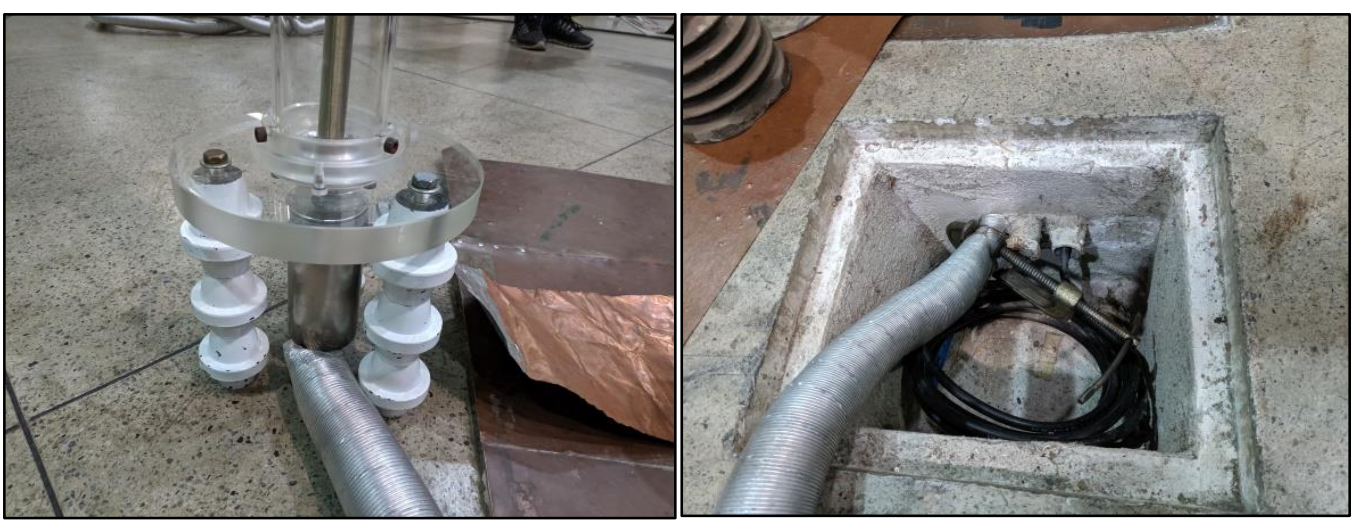

Figura 117: Blindagem extra aterrada ao divisor e passando por duto subterrâneo.

\subsubsection{2.}

\section{Verificação do nível de interferência}

O ensaio de interferência foi realizado para verificar o nível de interferência, primeiramente, registrando o impulso de perfuração e sua forma de onda. Logo após, foi desconectado o cabo do divisor e feito um curto-circuito na extremidade do cabo e conectado ao terra [28]. Essa configuração foi realizada com o auxílio da caixa de aterramento do laboratório, conforme a Figura 118. 


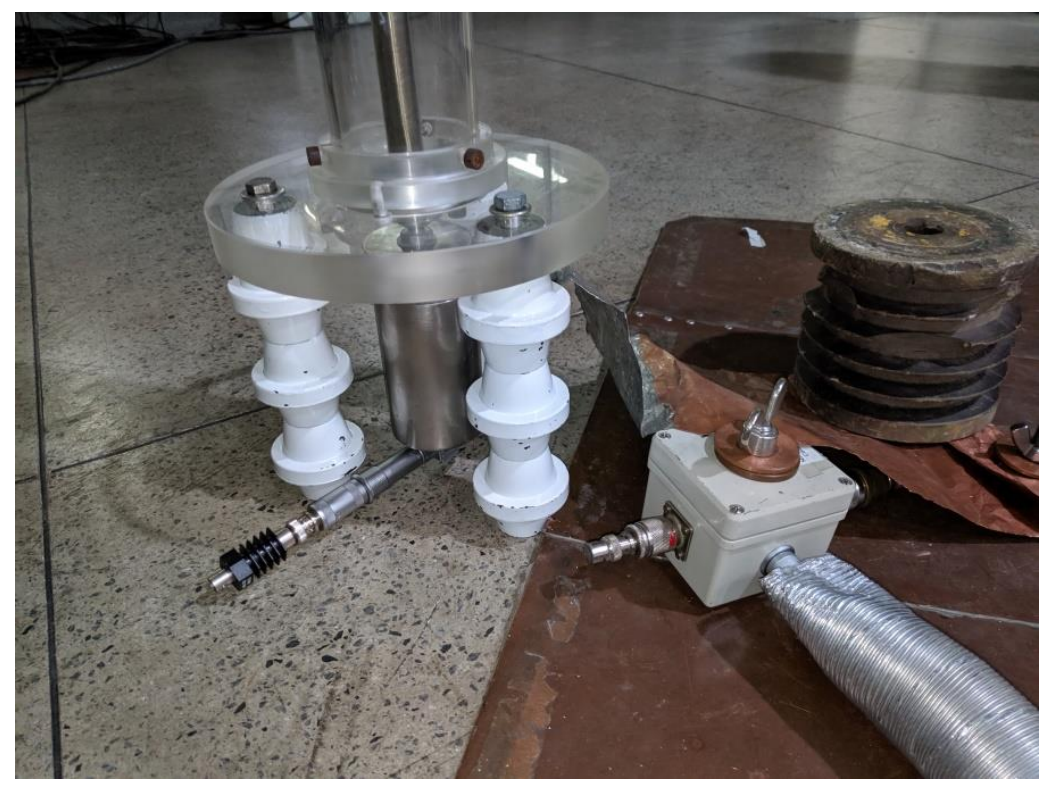

Figura 118: Caixa de curto-circuito para a realização do ensaio de interferência.

Após isso foi aplicado um novo impulso de tensão e registrada a sua forma de onda, conforme a Figura 119.

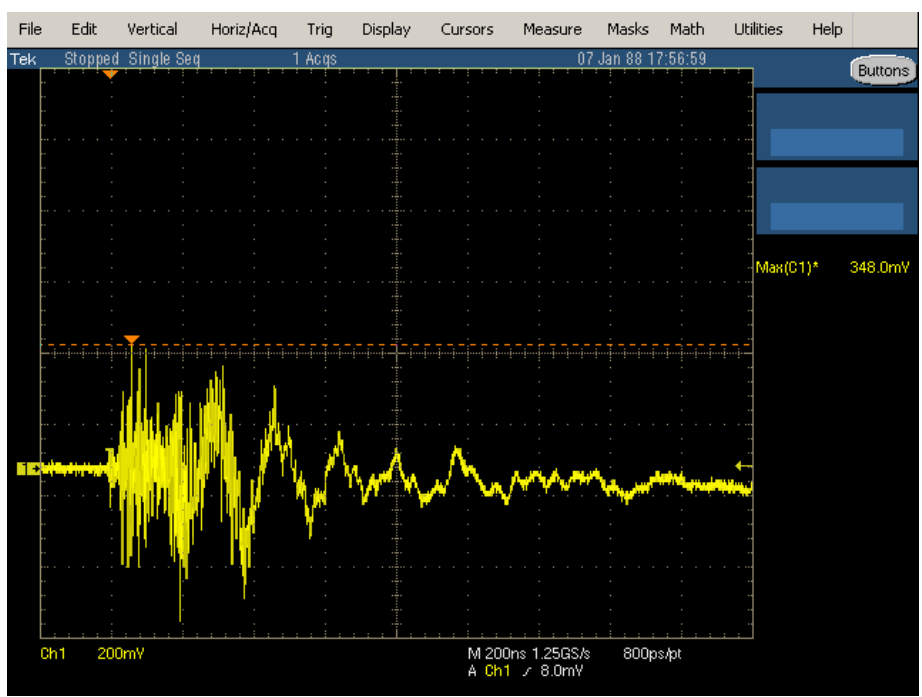

\section{Figura 119: Registro da interferência medida no osciloscópio.}

Por meio destes resultados encontrou-se um nível de interferência de aproximadamente $2 \%$. É importante considerar que anteriormente o nível de interferência estava apresentando um nível de aproximadamente $7 \%$. Visto que o nível normalizado para impulsos atmosféricos é de até $1 \%$, os devidos cuidados na medição se mostraram bastantes satisfatórios na redução deste ruído apresentado na medição. 
O fato do valor estar ainda acima do $1 \%$, limite normalizado, não é um problema, visto que não foi determinado para este tipo de impulso, mas sim para impulsos atmosféricos ou manobra e seguiu apenas de parâmetro de comparação.

O único problema é que, mesmo após a redução do nível de interferência irradiada, o SM CA2 ainda continua apresentando o mesmo ruído na crista, resultando em uma grande diferença na amplitude. Com isso surgiu a ideia de testar a outra unidade secundária, construída com resistores caddock, cujo desempenho dinâmico foi apresentado no Capitulo 3. O resultado desse teste é apresentado na Figura 120.

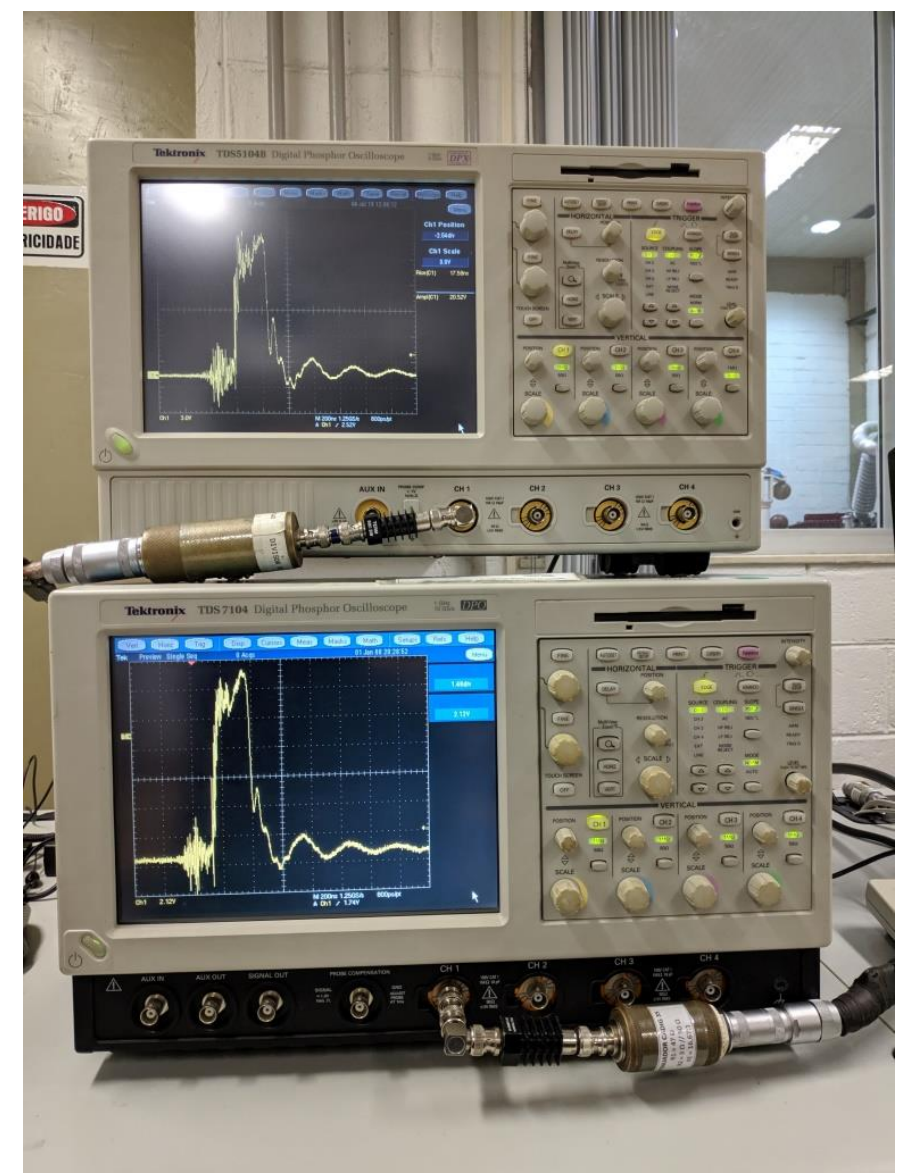

Figura 120: Medição do impulso de perfuração após troca da unidade secundária.

Após a troca da unidade secundária o SM CA2 deixou de apresentar a interferência medida e a grande diferença na amplitude.

Como o sistema com nova unidade secundária apresentou um desempenho dinâmico dentro dos limites normalizados, este foi considerado para a realização da calibração. A única diferença está no tempo de resposta parcial T $\alpha$ que mudou de 0,2 ns para 0,7 ns. Considerando que a norma IEC 61211:2004 [5] recomenda 
utilizar sistemas com empo de resposta parcial $\mathrm{T} \alpha \leq 3 \mathrm{~ns}$, o mesmo se encontra apto a ser utilizado em ensaios de perfuração em alta tensão.

Uma das razões para essa maior sensibilidade a interferências apresentada pelo sistema de medição se dá ao baixíssimo valor de T $\alpha$ pois, quanto menor esse valor, mais rápido o sistema se apresenta, porém mais sensível e susceptível a interferências. Estas constatações indicam que o sistema deve ser rápido, porém nem tanto, havendo uma região limite que deve ser estudada mais a fundo.

\subsection{2.}

\section{Comparação em alta tensão para determinação do fator de escala}

De posse da nova unidade secundária e com todos os devidos cuidados para realizar a medição, iniciou-se a aplicação do impulso de perfuração em isoladores conforme a Figura 121 a seguir.

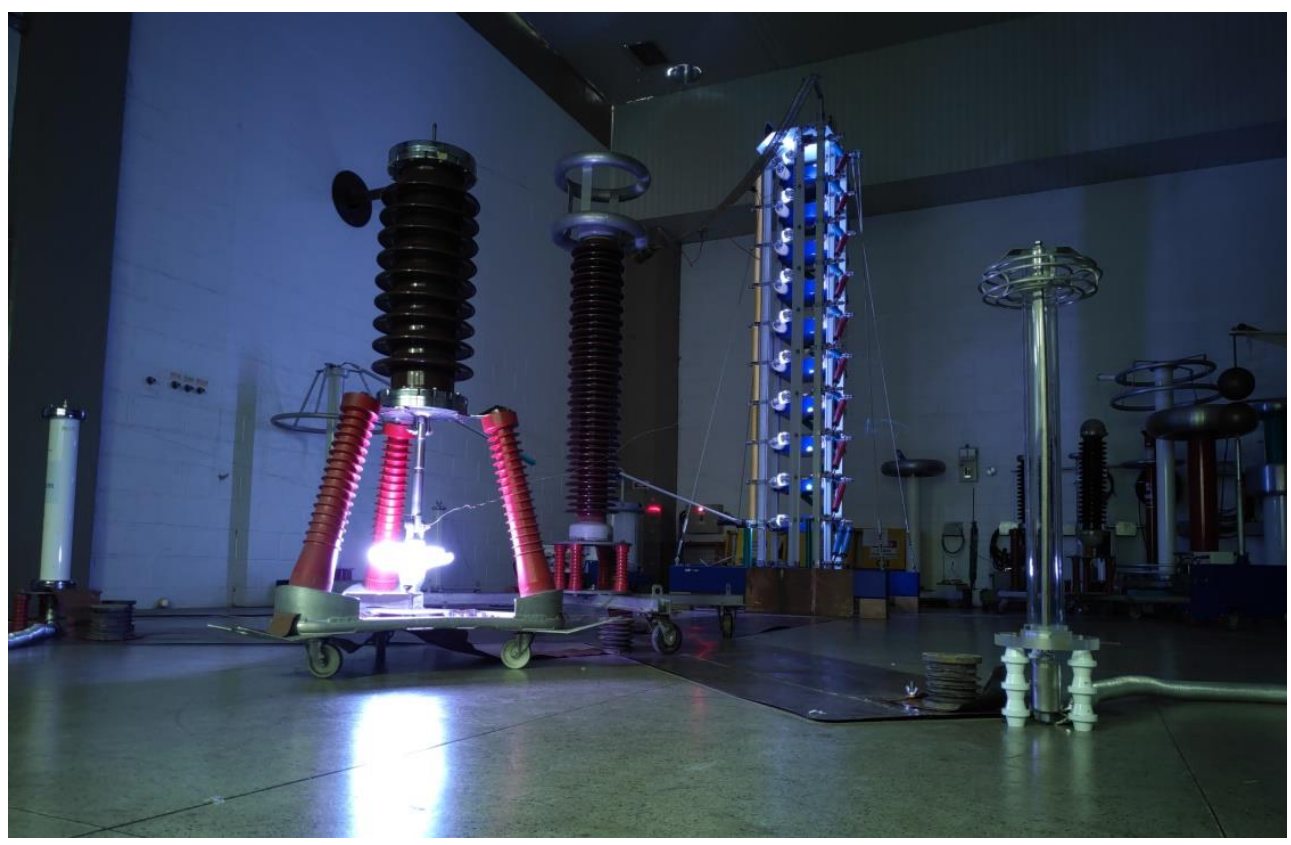

Figura 121: Aplicação do impulso de perfuração no isolador sob ensaio.

Os resultados apresentados foram adquiridos e filtrados pelo software RAPIT. A Figura 122 apresenta a tela de análise do programa realizando o condicionamento do sinal e a Figura 123 apresenta a comunicação do programa junto ao osciloscópio. 


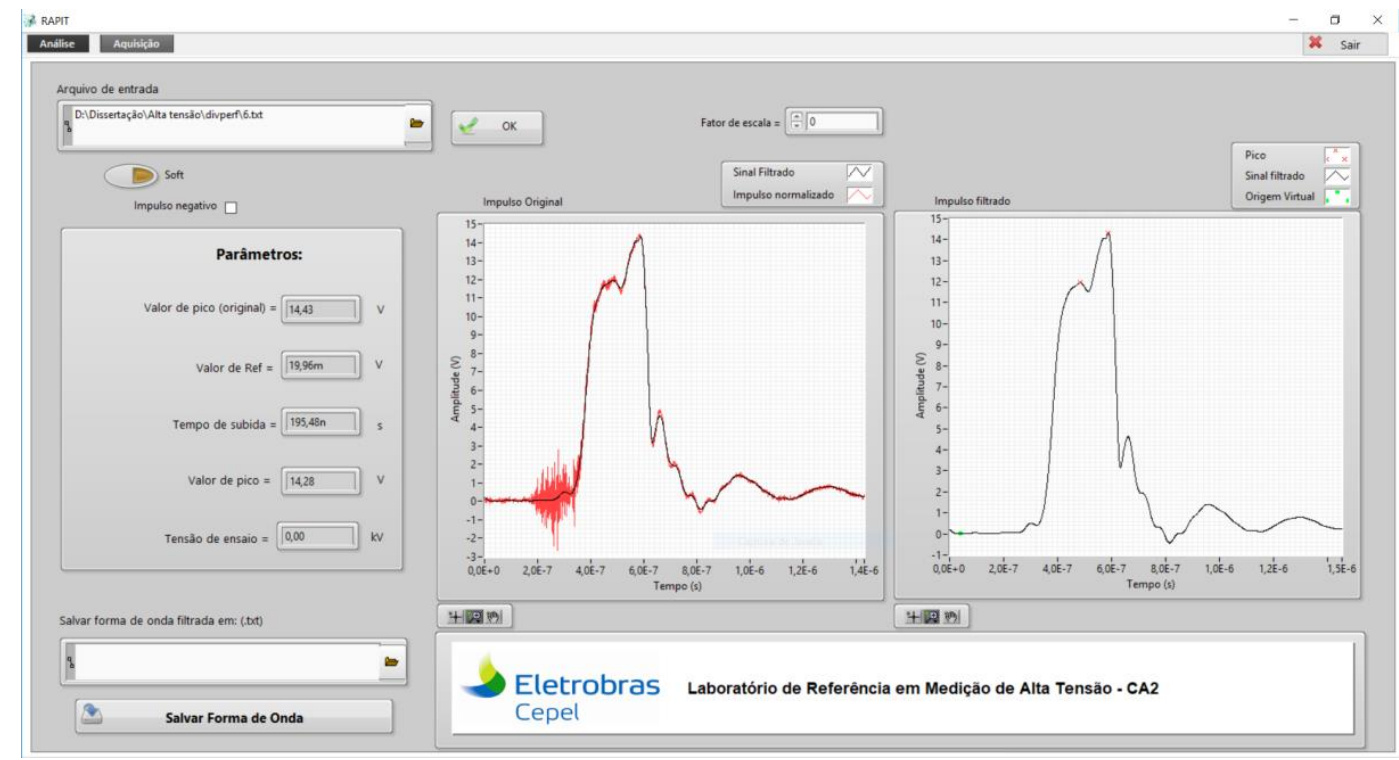

Figura 122: Tela principal de análise do programa RAPIT.

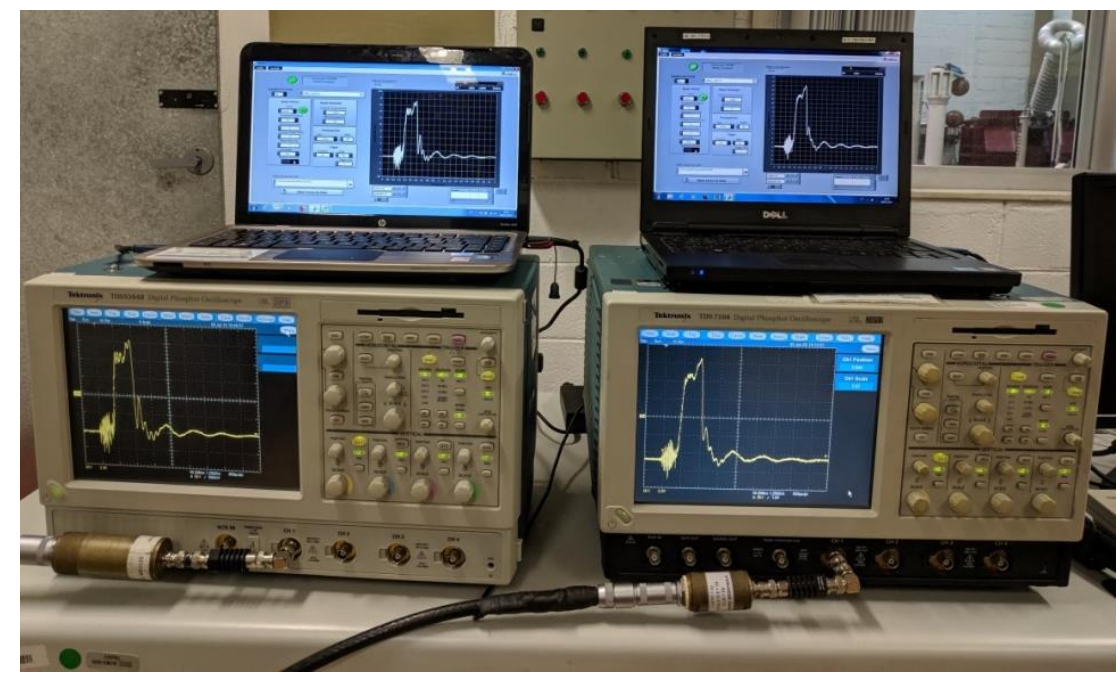

Figura 123: Comunicação realizada entre o RAPIT e os osciloscópios.

Estão apresentados na Tabela 7 todos os resultados da comparação entre o SM ELN e o SM CA2, considerando 10 aplicações em cada polaridade para o arranjo de ensaio mostrado na Figura 121. 
Tabela 7: Resultados da determinação do FE em alta tensão.

\begin{tabular}{|cc|cc|c|c|c|}
\hline \multicolumn{2}{|c|}{ ELN (Referência) } & \multicolumn{2}{|c|}{ CA2 } & \multirow{2}{*}{ Erro } & Média & $\begin{array}{c}\text { DESV. } \\
\text { PAD. }\end{array}$ \\
\cline { 1 - 4 } Up [V] & Up [kV] & Up [V] & FE (VR/VL) & & & \\
\hline 17,97 & 242,45 & 14,69 & 16499 & $1,0 \%$ & & \\
17,58 & 237,18 & 14,25 & 16641 & $1,9 \%$ & & \\
17,55 & 236,73 & 14,49 & 16341 & $0,1 \%$ & & \\
17,59 & 237,33 & 14,21 & 16704 & $2,3 \%$ & & \\
17,67 & 238,46 & 14,03 & 16996 & $4,1 \%$ & & \\
17,11 & 230,87 & 14,28 & 16168 & $-1,0 \%$ & & \\
17,24 & 232,60 & 14,47 & 16075 & $-1,6 \%$ & & \\
17,54 & 236,65 & 14,20 & 16662 & $2,0 \%$ & & \\
17,51 & 236,28 & 14,32 & 16496 & $1,0 \%$ & & \\
17,37 & 234,37 & 14,30 & 16391 & $0,4 \%$ & \multirow{2}{*}{16578} & \multirow{2}{*}{$1,25 \%$} \\
\cline { 1 - 4 }$-18,73$ & $-252,75$ & $-15,12$ & 16720 & $2,4 \%$ & & \\
$-18,49$ & $-249,48$ & $-15,12$ & 16503 & $1,1 \%$ & & \\
$-17,98$ & $-242,63$ & $-14,60$ & 16623 & $1,8 \%$ & & \\
$-18,27$ & $-246,57$ & $-14,71$ & 16766 & $2,7 \%$ & & \\
$-18,41$ & $-248,39$ & $-14,88$ & 16690 & $2,2 \%$ & & \\
$-18,27$ & $-246,51$ & $-14,74$ & 16721 & $2,4 \%$ & & \\
$-17,88$ & $-241,27$ & $-14,50$ & 16634 & $1,9 \%$ & & \\
$-18,42$ & $-248,48$ & $-15,04$ & 16523 & $1,2 \%$ & & \\
$-18,21$ & $-245,70$ & $-14,68$ & 16735 & $2,5 \%$ & & \\
$-17,99$ & $-242,77$ & $-14,57$ & 16662 & $2,0 \%$ & & \\
\hline
\end{tabular}

Um resumo dos resultados obtidos com os diferentes métodos para determinação do Fator de Escala é apresentado na Tabela 8. O FE com a medição dos componentes e com a medição CC em baixa tensão foi realizada novamente devido à substituição da unidade secundária. Observa-se na Tabela 8 uma diferença no FE inferior a $4 \%$ considerando todos os métodos para determinação do FE. Nota-se que o método que mais se aproximou da medição em alta tensão foi o de baixa tensão em corrente contínua.

Tabela 8: Resumo de diferentes métodos para determinação do FE.

\begin{tabular}{|c|c|c|c|c|}
\hline Descrição & $\begin{array}{c}\text { Componentes } \\
(\mathrm{R})\end{array}$ & $\mathrm{CC}_{\mathrm{BT}}$ & $\begin{array}{c}\mathrm{IMP} \\
\mathrm{AT}\end{array}$ & Diferença $(\%)$ \\
\hline $\mathrm{FE}_{\text {DIVISOR }}$ & 1001,00 & 1013,62 & - & $-1,24$ \\
\hline $\mathrm{FE}_{\text {ATENUADOR }}$ & 15,916 & 16,038 & - & $-0,76$ \\
\hline $\mathrm{FE}_{\text {TOTAL }}$ & 15932 & 16330 & $\mathbf{1 6 5 7 8}$ & $-1,49\left(\mathrm{CC}_{\mathrm{BT}} / \mathrm{IMP}_{\mathrm{AT}}\right)$ \\
\cline { 4 - 5 } & & & & $-3,89\left(\mathrm{R} / \mathrm{IMP}_{\mathrm{AT}}\right)$ \\
\hline
\end{tabular}




\subsection{3.}

\section{Avaliação da incerteza de medição}

São apresentadas na Tabela 9 e na

Tabela 10 as fontes individuais de incerteza identificadas e o cálculo para cada etapa da incerteza total do SMIP.

Tabela 9: Cálculo da incerteza para a calibração do FE do SMIP em corrente contínua.

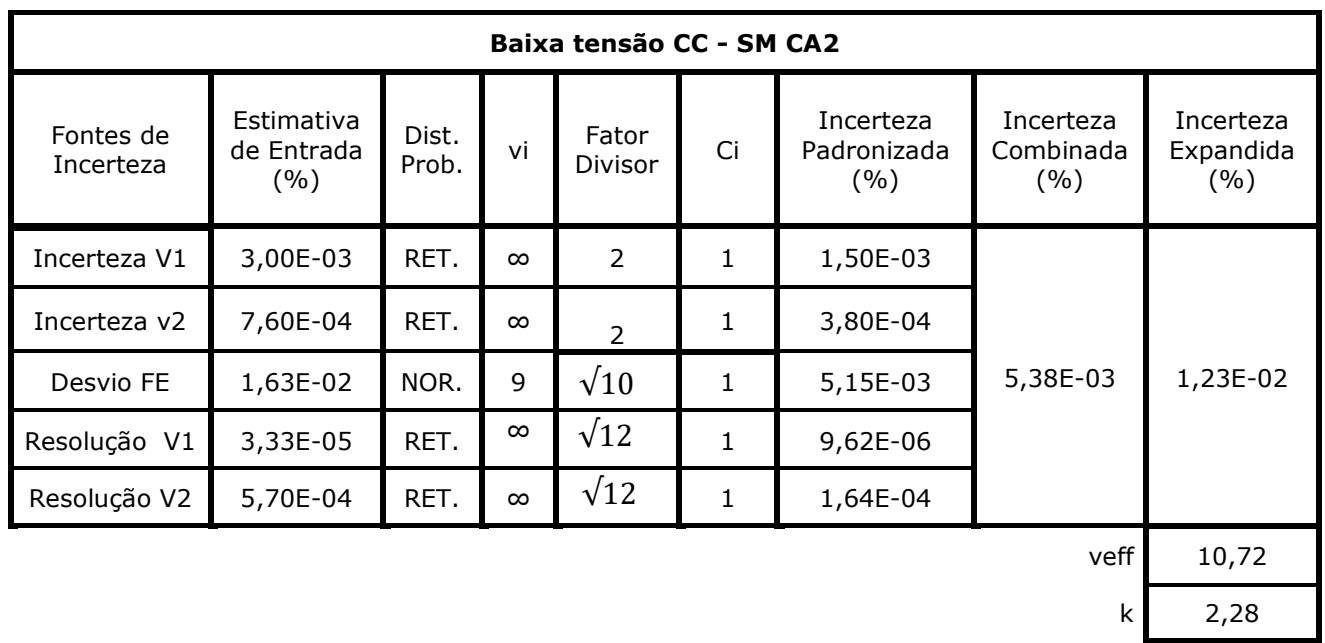

Tabela 10: Cálculo da incerteza para a calibração do FE do SMIP com impulso de perfuração em alta tensão.

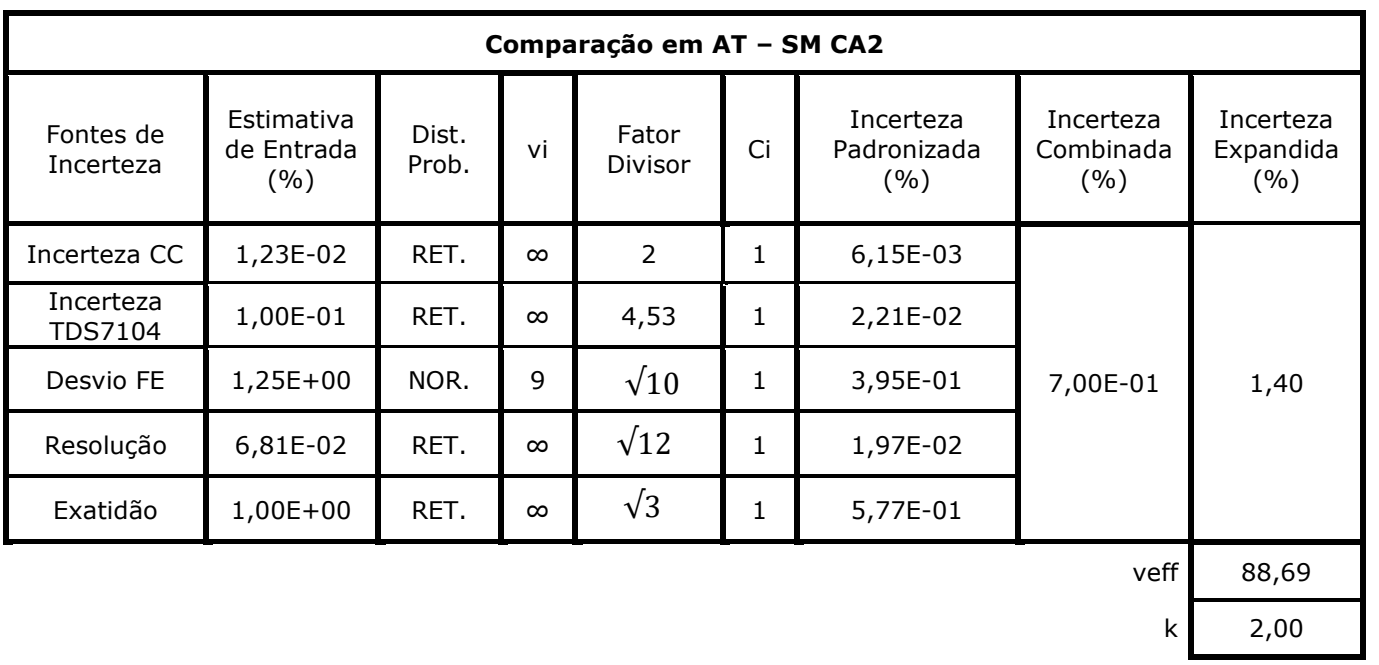

A incerteza da calibração do fator de escala do sistema de medição de impulso de perfuração foi calculada e usada para compor a incerteza do sistema de medição completo em alta tensão. 
A incerteza expandida de medição relatada é declarada como a incerteza padrão de medição multiplicada pelo fator de abrangência $k$, o qual, para uma distribuição $t$ com $\mathrm{V}_{\text {eff }}$ graus de liberdade efetivos, corresponde a uma probabilidade de abrangência de aproximadamente $95 \%$. A incerteza padrão da medição foi determinada de acordo com a publicação EA-4/02 [67]. 


\section{6 \\ Discussão e conclusão}

Com a busca pela garantia de uma maior confiabilidade e qualidade na isolação e segurança do sistema elétrico de potência, veio também a busca de ferramentas para verificar o desempenho de isoladores em condições de uso. Essa importante ferramenta é o ensaio de perfuração em isoladores, que se tornou um assunto centenário e constantemente abordado.

A realização deste ensaio é normalizada, e este deve ser executado atendendo a todos os requisitos pré-estabelecidos na norma IEC 61211:2004 [5]. Porém, além da norma especificar somente um parâmetro de desempenho dinâmico que o sistema deve possuir, ela também não especifica a utilização de um padrão de forma de onda de impulsos de ensaio de perfuração em isoladores, que são impulsos de tensão muito rápidos e que possuem grande complexidade para sua medição de forma correta. Assim, atualmente não é possível desenvolver um sistema de medição rastreável para a medição de tais impulsos.

A partir desse contexto, esta dissertação de mestrado focou especificamente no ensaio de impulso de perfuração em isoladores e toda a sistemática envolvida na sua medição, como também no desenvolvimento e construção de um sistema de medição. Tendo em vista as dificuldades encontradas na medição desse impulso muito rápido, fez-se necessário desenvolver um programa em LabVIEW para aquisição e condicionamento deste sinal. Técnicas avançadas de

processamento de sinais, como a transformada de wavelet, também foram utilizadas no desenvolvimento do filtro que compõe o programa.

Com isso, todos os conceitos teóricos que aborda o capítulo 2, como as definições do tipo de impulso, o ensaio e seus requisitos, características e aspectos construtivos dos isoladores, foram abordados com clareza para o melhor entendimento e compreensão do processo experimental envolvido no laboratório, desde as técnicas utilizadas no desenvolvimento do sistema de medição e aspectos construtivos no capítulo 3 , o desenvolvimento do filtro para ser aplicado no programa RAPIT de aquisição de impulsos de perfuração em isoladores no 
capítulo 4, e também os ensaios, validações e calibrações envolvidas no capítulo 5.

Como conclusões desta dissertação pode-se afirmar que:

- O sistema de medição de impulsos para ensaios de perfuração em isoladores desenvolvido no Cepel durante esta pesquisa de mestrado foi completamente caracterizado em baixa tensão, obtendo um valor de incerteza de 1,40\% para $k=2$ e estando de acordo com os requisitos técnicos normativos em termos de desempenho dinâmico, obtendo um parâmetro de tempo de resposta parcial $T_{\propto} \leq 3$ ns. Além disso, como foi observado que os valores da resposta em frequência que mais se adequam aos medidos na caracterização ocorreram na configuração do divisor na posição vertical, os ensaios futuros realizados neste divisor deverão ser executados somente nesta configuração. A variação da posição do divisor afeta a impedância do sistema e, consequentemente, seu fator de escala, modificando todas as suas características de projeto.

- O software RAPIT para a aquisição e condicionamento de sinais de impulso de perfuração em isoladores foi desenvolvido e validado no instituto nacional de metrologia da Finlândia VTT-Mikes, sendo que seu filtro baseado em wavelets mostrou-se eficaz, reduzindo a diferença entre os sistemas calibrados de $13 \%$ para menos de $0,5 \%$.

- A análise da resposta em frequência verificou também que o divisor de tensão responde bem e se mantém estável, com variação menor que $3 \mathrm{~dB}$, para frequências até $4,4 \mathrm{MHz}$, o que se mostra adequado em relação às componentes de frequência presentes no ensaio de impulso de perfuração.

- Nessa perspectiva, o novo sistema de medição desenvolvido no Cepel para ensaios de perfuração em isoladores durante esta pesquisa de mestrado, além de estar de acordo com a norma IEC 61211:2004 [5], foi projetado e avaliado para fornecer o maior desempenho possível na realização dos ensaios em alta tensão, contribuindo assim e estando adequado para uma possível rastreabilidade metrológica para sistemas de medição em ensaios de perfuração. 
Como sugestões de trabalhos futuros, pode-se indicar:

- Em relação a aspectos construtivos e de projeto do sistema de medição, é válido considerar outros materiais e métodos para a construção do divisor, bem como outros meios de transmissão de dados.

- Um foco adicional em meios para a transmissão de dados se faz importante, visto que o sinal envolvido é bastante sensível a qualquer variação do processo.

- Revisar projetos da malha de aterramento de laboratórios para a realização de ensaios de impulso de perfuração em isoladores, algo que interfere totalmente no produto final medido.

- E por fim, tão importante quanto a medição, o circuito de geração para impulsos de perfuração deve ser estudado de forma minuciosa. Configurações do gerador de impulso, utilização ou não de capacitores de frente, altura e diâmetro das esferas centelhadoras (gap) devem ser avaliadas, bem como cada estrutura e capacitâncias parasitas envolvidas no sistema. 


\section{Referências bibliográficas}

1. SILVA, M. T. F. Projeto e desenvolvimento de padrão para alta tensão em corrente contínua na faixa de $1 \mathrm{kV}$ a $50 \mathrm{kV}$. 2011. 85 f. Dissertação (Mestrado) - Metrologia, Pontifícia Universidade Católica do Rio de Janeiro, Rio de Janeiro, 2011.

2. OLIVEIRA, Y. R. Desenvolvimento de Algoritmos para Estimativa de Parâmetros de Ensaios em Alta Tensão em Corrente Alternada e Contínua de Acordo com a Norma ABNT NBR IEC 60060-1:2013. 2017. $169 f$. Dissertação (Mestrado) - Metrologia, Pontifícia Universidade Católica do Rio de Janeiro, Rio de Janeiro, 2017.

3. ASSOCIAÇÃO BRASILEIRA DE NORMAS TÉCNICAS. ABNT NBR ISO/IEC 17025: 2017-requisitos gerais para a competência de laboratórios de ensaio e calibração. General requirements for the competence of testing and calibration laboratories. ABNT, 2017.

4. DE PESQUISA ENERGÉTICA, Empresa. Projeção da demanda de energia elétrica: para os próximos 10 anos (2017-2026). Rio de Janeiro, p. 83, 2017.

5. IEC Standard 61211. Second edition, 2004-11. Insulators of ceramic material or glass for overhead lines with a nominal voltage greater than $1000 \mathrm{~V}-$ Impulse puncture testing in air.

6. Martti Aro (FINLAND) and Robert C. Hughes (UNITED KINGDOM) on behalf of Cigré Working Group 33.03, TF 33.03.01, "Puncture testing of ceramic and glass insulators", Electra 136, 1991.

7. Orsino Borges Filho, M. T. Fernandes, Azevedo L. C. and Oliveira Y. R., "Comparison of measuring systems used in impulse puncture withstand test", CIGRÉ Winnipeg 2017 Colloquium; Winnipeg, Canada, 2017.

8. Aro, Martti. Feasibility of Impulse Voltage Puncture Test on Insulators in Air. PhD Thesis, ACTA Polytechnica Scandinavica, Electrical Engineering Series No. 91, Helsinki University of Technology, Espoo, Finland, 1998. 
9. STANDARD, I. E. C. 60060-1: High voltage test techniques-Part 1: general definitions and test requirements. 2010.

10. CO-ORDINATION-PART, Insulation. 1: Definitions, principles and rules. International Electrotechnical Commission Standard IEC, p. 60071-1, 2006.

11. KLÜSS, Joni. Lectures from course of High Voltage Engineering S-18.3150. Aalto University, Finland. 2014.

12. FRIZK, Farouk AM; TRINH, Giao N. High voltage engineering. CRC Press, Edition 1, April 2014.

13. IEC Standard 60038. Edition 7.0, 2009-06. IEC standard voltages.

14. IEC Standard 60383-1. Fourth edition, 1993-04. Insulators for overhead lines with a nominal voltage above $1000 \mathrm{~V}$. Part 1: Ceramic or glass insulator units for a.c. systems - Definitions, test methods and acceptance criteria.

15. SCHWALM, A. E. Insulators 101. In: Transmission and Distribution Conference and Exposition, 2010 IEEE PES. IEEE, 2010. p. 1-2.

16. CAPELINI, Renato Massoni. Inspeção Remota de Isoladores em Linhas de Transmissão a Partir de Sinais de Descargas Parciais Externas. 2015.

17. NAIDU, Motukuru S. High voltage engineering. Tata McGraw-Hill Education, 2013.

18. Lucas, J.R., High Voltage Engineering, Revised Edition, Department of Electrical Engineering, University of Moratuwa, Sri Lanka, 2001, pp.128-130.

19. ARINOS, J. T. J. Divisor resistivo para ensaios de frente de onda em isoladores. 1994. 149p. Dissertação (Mestrado) - Física, Setor de Ciências Exatas da Universidade Federal do Paraná, Curitiba.

20. KAZMI, Syed et al. Measurement Techniques for Impulse Puncture Testing in Air. M.Sc. Thesis, Aalto University, 2016.

21. IEC Sub-Committee 36B: Insulators for overhead lines: WG 6 Puncture testing of insulators, 1978-1992.

22. ARO, Martti., Huhdanmäki J. K. Results of tests for checking the reproducibility of power frequency puncture test on insulators in oil. CIGRE 33-88 (WG 07) 5 IWD, Aug 1988, pg 6.

23. CIGRE SC 33. Over-voltages and insulation co-ordination, 1983.

24. ARO, Martti., PUNKKA K. Steep front impulse voltage tests on cap and pin insulators of porcelain. CIGRE 33-85 (WG 07) 14 IWD, pg 12. 
25. CIGRE WG 33.07: Dielectric strength of external insulation under transient voltages, 1985.

26. HÄLLSTRÖM, Jari. A Calculable Impulse Voltage Calibrator. PhD Thesis, ACTA Polytechnica Scandinavica, Electrical Engineering Series No. 109, Helsinki University of Technology, Espoo, Finland, 2002.

27. HAUSCHILD, Wolfgang., LEMKE, Eberhard. High-Voltage Test and Measuring Techniques, Springer, Edition 1, 2013.

28. IEC 60060-2. High voltage test technique, Part 2: Measuring systems. Edition, v. 3, 2010.

29. KUFFEL, E., ZAENGL, W.S., KUFFEL, J. High Voltage Engineering Fundamentals, Newnes, Second Edition, 2000.

30. SCHON, Klaus. High Impulse Voltage and Current Measurement Techniques - Fundamentals, Measuring Instruments, Measuring Methods, Springer, Edition 1, 2013.

31. IEC 61083-1: 2001, Instruments and software used for measurement in highvoltage impulse tests - Part 1: Requirements for instruments, 2001.

32. ARO, Martti., et al. Puncture testing of ceramic and glass insulators. Final report of CIGRE Task Force 33.07.01, ELECTRA N 136, June 1991.

33. Creed, F. C., Collins, M. M. C. The Measurement of Short-Duration Impulse Voltages. Transactions of the American Institute of Electrical Engineers, Part I: Communication and Electronics. Nov 1963, Volume: 82, Issue: 5, pg. 621630.

34. KÜCHLER, Andreas. High Voltage Engineering: Fundamentals-TechnologyApplications. Springer, 2017.

35. FERMAM, Ricardo Kropf Santos; DE SOUZA ANTUNES, Adelaide Maria. A cadeia de avaliação da conformidade brasileira para o setor de defensivos agrícolas: ferramenta para o desenvolvimento sustentável. Revista IberoAmericana de Ciências Ambientais, v. 3, n. 1, p. 112-130, 2012.

36. ISO/IEC 17025: 2017. General Requirements for the Competence of Testing and Calibration Laboratories. 2017.

37. OLIVEIRA, Orsino; SILVA, Márcio T. Fernandes da. Técnicas de medição em ensaios de alta tensão. (Relatório técnico), Cepel, Rio de Janeiro, 1996.

38. BOWDLER, G. W. Measurements in High-voltage Test Circuits. Volume 5. Pergamon Press. Germany, 1973. 
39. CAVALLIUS, N. H. The Measurements of High Impulse Voltages and Currents. SP Swedish National Testing and Research Institute. Sweden, 2004.

40. OLIVEIRA, O. B. CHAGAS, F. A. CERQUEIRA, W. R. and ALVARENGA, E. Dynamic Behavior of Non-Inductive Resistor for $\mathrm{HV}$ Impulse Applications. 9th ISH, Graz, Austria, 1995.

41. OLIVIERI, Marta Maria de Almeida; OLIVEIRA FILHO, Orsino Borges de; VITÓRIO, Patrícia Cals de Oliveira. Steral-programa computacional para cálculo dos parâmetros de resposta ao degrau para avaliação de sistemas de medição em alta tensão. 1998.

42. FARIA, L. C. et al. Automated Evaluation of Dynamic Performance of Impulse Voltage Measurement Systems. In: Journal of Physics: Conference Series. IOP Publishing, 2015.

43. CADDOCK ELECTRONICS, Inc. Disponível em: http://www.caddock.com/Online_catalog/Mrktg_Lit/TypeMV.pdf.

44. ISABELLENHÜTTE HEUSLER GmbH \& Co. KG Disponível em: https://www.isabellenhuette.de/fileadmin/Daten/Praezisionslegierungen/Daten blaetter_Widerstand/Englisch/ISAOHM.pdf.

45. Avoiding \& Testing for Dielectric Puncture, Available: http://www.inmr.com/avoiding-testing-dielectric-puncture/, Feb. 2019.

46. ONAL, Emel; KALENDERLI, Ozcan; SEKER, Serhat. Multi-resolution wavelet analysis for chopped impulse voltage measurements and feature extraction. IEEE Transactions on Dielectrics and Electrical Insulation, v. 15, n. 3, p. 893-900, 2008.

47. ALTAY, Özkan; KALENDERLI, Özcan. Interference removal on impulse voltage \& current measurements with wavelet analysis. In: 2012 International Conference on High Voltage Engineering and Application. IEEE, 2012. p. 447-450.

48. FONT, A.; ATALAY, A. K.; KALENDERLI, O. Analyzing and denoising of impulse voltage waveforms using multi-resolution wavelet analysis (MRA). In: 2014 ICHVE International Conference on High Voltage Engineering and Application. IEEE, 2014. p. 1-4.

49. PINCHES, D. S.; AL-TAI, M. A. Very fast transient overvoltages generated by gas insulated substations. In: 2008 43rd International Universities Power Engineering Conference. IEEE, 2008. p. 1-5. 
50. IEC STANDARd 60071-1:2006 Insulation co-ordination. Definitions, principles and rules, 2006.

51. OLIVERIA, V. R.; MIRANDA, G. C. Application of digital filter to lightning impulse parameters evaluation. In: 10th International Symposium on High Voltage Engineering. 1997. p. 25-29.

52. NETTO, P. S. R., SILVA, S. L., EDUARDO, A. B. D. Digital Signal Processing System Analysis and Design. 2 ed. New York, Cambridge, 2001.

53. GARBOR, D. Theory of Ccommunication, Journal of the Institute of Electrical Engineering, v. 93, pp. 429-457, 1946.

54. SHIM, I., SORAGHAN, J., SIEW, W. "Detection of PD Utilizing Digital Signal Processing Methods. Part 3: Open-loop Noise Reduction”, Electrical Insulation Magazine, IEEE, v. 17, n. 1, pp. 6-13, Jan.-Feb. 2001.

55. KIM, Chul Hwan; AGGARWAL, Raj. Wavelet transforms in power systems. Part 1: General introduction to the wavelet transforms. Power Engineering Journal, v. 14, n. 2, p. 81-87, 2000.

56. MALLAT, Stéphane. A wavelet tour of signal processing. Elsevier, 1999.

57. MALLAT, Stephane G. Multiresolution approximations and wavelet orthonormal bases of $L^{2}(R)$. Transactions of the American mathematical society, v. 315, n. 1, p. 69-87, 1989.

58. ZHOU, X.; ZHOU, C.; KEMP, I. J. An improved methodology for application of wavelet transform to partial discharge measurement denoising. IEEE transactions on dielectrics and electrical insulation, v. 12, n. 3, p. 586-594, 2005.

59. DONOHO, David L.; JOHNSTONE, Iain M. Adapting to unknown smoothness via wavelet shrinkage. Journal of the american statistical association, v. 90, n. 432, p. 1200-1224, 1995.

60. CHANG, S. Grace; YU, Bin; VETTERLI, Martin. Adaptive wavelet thresholding for image denoising and compression. IEEE transactions on image processing, v. 9, n. 9, p. 1532-1546, 2000.

61. MIHCAK, M. Kivanc et al. Low-complexity image denoising based on statistical modeling of wavelet coefficients. IEEE Signal Processing Letters, v. 6, n. 12, p. 300-303, 1999.

62. DONOHO, David L.; JOHNSTONE, Jain M. Ideal spatial adaptation by wavelet shrinkage. biometrika, v. 81, n. 3, p. 425-455, 1994. 
63. LI, Jian et al. Scale dependent wavelet selection for de-noising of partial discharge detection. IEEE Transactions on Dielectrics and electrical insulation, v. 17, n. 6, p. 1705-1714, 2010.

64. MORTAZAVI, S. H.; SHAHRTASH, S. M. Comparing denoising performance of DWT, WPT, SWT and DT-CWT for partial discharge signals. In: 2008 43rd International Universities Power Engineering Conference. IEEE, 2008. p. 1-6.

65. SATISH, L.; NAZNEEN, B. Wavelet-based denoising of partial discharge signals buried in excessive noise and interference. IEEE Transactions on Dielectrics and Electrical Insulation, v. 10, n. 2, p. 354-367, 2003.

66. MA, X.; ZHOU, Chengke; KEMP, I. J. Automated wavelet selection and thresholding for PD detection. IEEE Electrical Insulation Magazine, v. 18, n. 2, p. 37-45, 2002.

67. EA-04/02 Guia "Expression of the Uncertainty of Measurement in Calibration”, 1999. 


\section{Anexo 1 -Artigo XXV SNPTEE SEMINÁRIO NACIONAL DE PRODUÇÃO E TRANSMISSÃO DE ENERGIA ELÉTRICA}

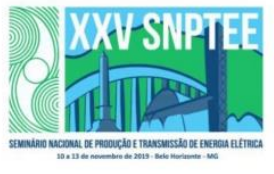

XXV SNPTEE

SEMINÁRIO NACIONAL DE PRODUÇÃO E

TRANSMISSÃO DE ENERGIA ELÉTRICA

10 a 13 de novembro de 2019

Belo Horizonte - MG

Grupo de Estudo de Transformadores, Reatores, Materiais e Tecnologias Emergentes-GTM

SISTEMA DE MEDIÇÃO PARA ENSAIOS DE PERFURAÇÃO EM ISOLADORES

MÁRCIO THELIO FERNANDES DA SILVA(1); IGHOR SOUZA DOS SANTOS(2); LUIZ CARLOS DE AZEVEDO(1); VALDIR REMILSON SANTOS(1); MARCUS VINICIUS BARROS LOPES(1); CEPEL(1);PUC-Rio(2);

RESUMO

Quantificar a amplitude de um impulso de perfuração, com todas as garantias metrológicas, não é uma tarefa trivial, por se tratar de um sinal impulsivo com centenas de $\mathrm{kV}$ e frentes rápidas entre $100 \mathrm{~ns}$ e $200 \mathrm{~ns}$. Embora o ensaio de perfuração seja normatizado pela IEC 61211 ainda não existem na maioria dos Institutos Nacionais de Metrologia (INM), inclusive no Brasil, padröes para rastrear sistemas de medição utilizados nesses ensaios. Além disso, divisores de tensão com alto desempenho dinâmico para essa aplicação năo estão disponiveis comercialmente são objetos de pesquisa dos próprios INM e ou instituiçő̃es de P\&D+1.

PALAVRAS-CHAVE

Caracterização, Ensaio, Perfuração em Isoladores, Alta Tensão, Comparação Interlaboratorial

1.0 - INTRODUÇÃO

O ensaio de impulso de perfuração em isoladores é descrito na IEC 61211:2004 "Insulators of ceramic material or glass for overhead lines with a nominal voltage greater than $1000 \mathrm{~V}$-Impulse puncture testing in air", e é fundamental para verificar, em laboratório, a qualidade do projeto, o processo de fabricaçäo, e os materiais utilizados em isoladores de vidro ou porcelana para linhas de transmissão e distribuição de energia. Em função da especificidade da medição de tensão neste ensaio os requisitos para incerteza no valor de crista do impulso e para o desempenho dinâmico do SMIP, também estão descritos na IEC $61211 \mathrm{com}$ a recomendação de que o SMIP deve ser calibrado e aprovado de acordo com a IEC 60060-2/2010: "High-voltage test techniques, Part 2: Measuring deve ser
systems"

Estudos e considerações sobre particularidades no desempenho de um SMIP, especificamente para características de desempenho dinâmico dos divisores de tensão, têm sido realizados há décadas. Atualmente, o Cigré WG D1.60 - "Traceable measurement techniques for very fast transients", tem realizado atividades com objetivo de prover metodologias para garantir a rastreabilidade desses SMIP. Pesquisas recentes realizadas no Cepel mostraram que o parâmetro de tempo de resposta parcial T $\alpha$ é um dos principais requisitos para adequação desses divisores de tensão e que a calibração de um SMIP por comparação é tecnicamente adequada para fins de rastreabilidade.

Este trabalho descreve um Sistema de Medição desenvolvido para ensaio de Impulso Perfurante - SMIP e os métodos utilizados para sua calibração, incluindo resultados de uma comparação interlaboratorial pioneira entre o SMIP do Cepel e o VTT-Mikes, que é o INM da Finlândia. Um software para aquisição e análise dos parâmetros do impulso de perfuração foi desenvolvido com base na transformada de wavelet multi-resolução e faz parte do SMIP do Cepel. 
2.0 - OBJETIVO

Caracterizar todos os componentes do SMIP principalmente em relação ao desempenho dinâmico e Fator de Escala - FE do sistema de medição completo, com objetivo de comprovar a adequação do SMIP do Cepel para ensaios de perfuração em isoladores. Essa caracterização foi realizada pela calibração em baixa tensão dos componentes individuais, por determinação do $\mathrm{FE}$ em baixa tensão corrente contínua e utilizando também calibradores de impulsos de baixa tensăo. A incerteza do FE do divisor de tensão e do sistema de medição calibradores de impulsos de baixa tensão. A incerteza do FE do

3.0 - REQUISITOS NORMATIZADOS

A norma IEC 61211/2004 estabelece quais os requisitos técnicos para adequação de um SMIP ser utilizado em ensaios de perfuração em isoladores. Alguns dos principais requisitos estão apresentados a seguir. Na Figura 1 e apresentada uma comparação gráfica entre a forma de onda do ensaio de perfuração e um ensaio de impulso tmosférico pleno para mostrar a diferença entre estes eventos na escala de tempo o quão mais rápido é um impulso utilizado em ensaios de perfuração, exigindo assim do SMIP um alto desempenho dinâmico.

Principais requisitos:

O SMIP deve ser calibrado e aprovado de acordo com a IEC 60060-2 (preferencialmente por comparação);

> Osciloscópio/registrador digital deve estar de acordo com a norma IEC 61083-1;

- É geralmente necessário utilizar divisores de tensão especiais rápidos e compactos

Incerteza total do SMIP $\leq 5 \%(\mathrm{k}=2)$

Incerteza do FE do Divisor de Tensão $\leq 2 \%$ ( $k=2$ )

Desempenho dinâmico do SMIP sem instrumento

$\checkmark$ Para resposta ao degrau com oscilação: Tempo de resposta parcial, T $\alpha \leq 3 \mathrm{~ns}$

$\checkmark$ Para resposta ao degrau sem oscilação: Tempo de resposta, $T \leq 5 \mathrm{~ns}$ :

$\checkmark$ A Resposta é avaliada com o SMIP na mesma posiçăo do arranjo de ensaio, mas sem o isolador.

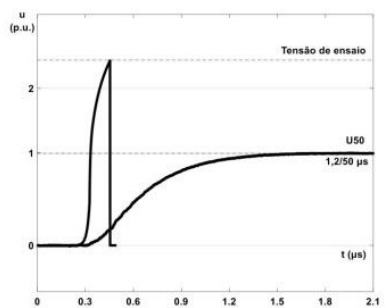

FIGURA 1 - Comparação de uma forma de onda típica para ensaio de perfuração em isoladores e a frente de um impulso atmosférico pleno padronizado.

4.0 - CARACTERIZAÇÃO DO SMIP

4.1 - Componentes

Os componentes das unidades de alta e baixa tensão do divisor de tensão e do atenuador, ambos resistivos com baixa impedância e minima indutância, foram medidos utilizando o método a quatro terminais. E apresentado na Figura 2 o circuito elétrico básico destes componentes do SMIP, incluindo o cabo coaxial, atenuador e casador de impedância. Na Tabela 1 estão os resultados medidos utilizando instrumentos de alta resolução com 8 1/2 dígitos.
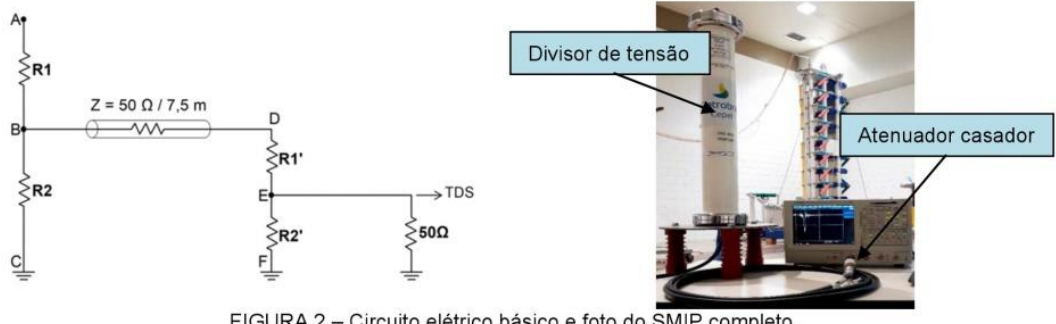

FIGURA 2 - Circuito elétrico básico e foto do SMIP completo. 
Tabela 1 - Valores medidos dos componentes resistivos indicados na Figura 2 (Tabela 1a) e determinação do FE

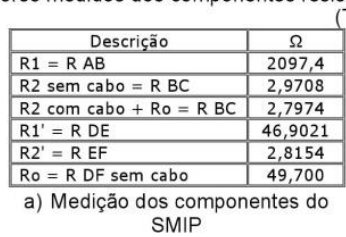

Tabela $1 \mathrm{~b}$ ).
\begin{tabular}{|l|c|}
\hline \multicolumn{1}{|c|}{ Descrição } & Adimensional \\
\hline FE - Divisor de tensão & $\mathbf{7 5 0 , 7 7}$ \\
\hline FE - Atenuador & $\mathbf{1 7 , 6 5 9}$ \\
\hline FE - SMIP & $\mathbf{1 3 2 5 8}$ \\
\hline
\end{tabular}

FE - SMIP

$E_{D i N}=\left(R_{1} / R_{2}\right)+1$

$\mathrm{FE} \mathrm{SMIP}=\mathrm{FE}$ Div $\times \mathrm{FE}$

b) Determinação do Fator de Escala

4.2 - Desempenho dinâmico

A avaliação do desempenho dinâmico foi realizada pela análise da resposta ao degrau unitário. $O$ gerador foi posicionado no lugar do isolador sob ensaio. Um osciloscópio com largura de banda (BW) plena (FULL), que para este osciloscópio é $1,0 \mathrm{GHz}$, foi utilizado na aquisição e o software do Cepel STERAL foi utilizado na análise e quantificação dos parâmetros da resposta. Estão apresentadas na Figura 3 as respostas do divisor e atenuador e o parâmetro tempo de resposta parcial $(T \alpha)$ calculado. O tempo de resposta parcial é um dos requisitos específicos previstos na IEC 61211/2004 para SMIP.

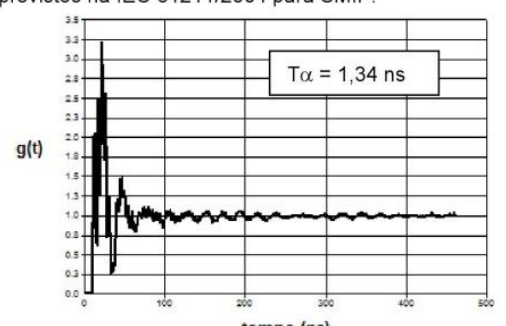

tempo (ns)

a) Resposta do divisor de tensão

FIGURA 3 - Resposta ao degrau do divisor e do atenuador.

4.3 - Fator de escala em BT

Os fatores de escala foram determinados separadamente considerando o divisor, atenuador e o sistema de medição completo. Foram utilizados dois multimetros de alta resolução com $81 \frac{1}{2}$ dígitos, um medindo o sinal aplicado e outro a saida para cada caso. Um calibrador de baixa tensão foi utilizado para gerar a tensão de ensaio. São apresentados na Tabela 2 os resultados dos fatores de escala obtidos com esta metodologia.

Tabela 2 - Fatores de escala determinados em baixa tensão corrente contínua

\begin{tabular}{|c|c|c|c|c|c|c|c|c|}
\hline \multicolumn{3}{|c|}{ Divisor de tensão } & \multicolumn{3}{|c|}{ Atenuador } & \multicolumn{3}{|c|}{ SMIP } \\
\hline$V_{1}(V)$ & $\mathrm{V}_{2}(\mathrm{mV})$ & $\mathrm{FE}\left(\mathrm{V}_{1} / \mathrm{V}_{2}\right)$ & $V_{1}(\mathrm{~V})$ & $\mathrm{V}_{2}(\mathrm{mV})$ & $\mathrm{FE}\left(\mathrm{V}_{1} / \mathrm{V}_{2}\right)$ & $V_{1}(\mathrm{~V})$ & $V_{2}(m V)$ & $\mathrm{FE}\left(\mathrm{V}_{1} / \mathrm{V}_{2}\right.$ \\
\hline \multirow{10}{*}{30,00000} & 39,63172 & 756,97 & \multirow{10}{*}{1,00000} & 56,34486 & 17,748 & \multirow{10}{*}{30,00000} & 2,23553 & 13420 \\
\hline & 39,63152 & 756,97 & & 56,34498 & 17,748 & & 2,23506 & 13422 \\
\hline & 39,63147 & 756,97 & & 56,34515 & 17,748 & & 2,23513 & 13422 \\
\hline & 39,63137 & 756,98 & & 56,34513 & 17,748 & & 2,23502 & 13423 \\
\hline & 39,63130 & 756,98 & & 56,34554 & 17,748 & & 2,23500 & 13423 \\
\hline & 39,63132 & 756,98 & & 56,34534 & 17,748 & & 2,23498 & 13423 \\
\hline & 39,63118 & 756,98 & & 56,34562 & 17,748 & & 2,23502 & 13423 \\
\hline & 39,63101 & 756,98 & & 56,34600 & 17,747 & & 2,23493 & 13423 \\
\hline & 39,63103 & 756,98 & & 56,34613 & 17,747 & & 2,23491 & 13423 \\
\hline & 39,63087 & 756,99 & & 56,34590 & 17,748 & & 2,23492 & 13423 \\
\hline \multicolumn{2}{|c|}{ Média } & 756,98 & \multicolumn{2}{|c|}{ Média } & 17,748 & \multicolumn{2}{|c|}{ Média } & 13423 \\
\hline
\end{tabular}

4.4 - Fator de escala com impulsos em BT

Antes de determinar o fator de escala do SMIP com impulsos em baixa tensão foi necessário calibrar o FE de uma ponta de prova modelo P2220 e verificar o desempenho dinâmico referente ao parâmetro T $\alpha$. Está apresentada na Figura 4 a resposta ao degrau da ponta de prova e seu respectivo parâmetro T $\alpha$ calculado. 


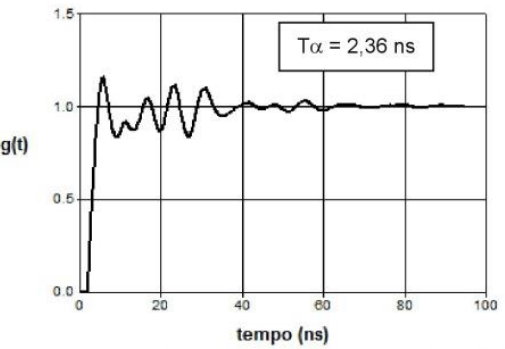

FIGURA 4 - Resposta ao degrau da ponta de prova P2220 (BW em Full).

$\mathrm{Na}$ análise e quantificação dos parâmetros de impulso para a calibração da ponta de prova foi utilizado um calibrador de impulsos de baixa tensão e um osciloscópio modelo TDS 540 com BW em FULL. Estão apresentados na Tabela 3 e Figura 5 os resultados do fator de escala e a foto do arranjo de ensaio para calibração da ponta de prova. As condições ambientais foram mantidas em torno de $23^{\circ} \mathrm{C}$ e $80 \%$ de umidade relativa.

Tabela 3 - Fator de escala e o erro no tempo de frente $T_{1}$ determinado em baixa tensão com impulso atmosférico

\begin{tabular}{|c|c|c|c|c|c|}
\hline \multicolumn{2}{|c|}{ Calibrador } & \multicolumn{2}{|c|}{ Ponta } & \multirow{2}{*}{$\begin{array}{c}\mathrm{FE} \\
\mathrm{V}_{1} \mathrm{~N}_{2}\end{array}$} & \multirow{2}{*}{$\begin{array}{c}\text { Delta } T_{1} \\
\left(\left(T_{1 L}-T_{1 R}\right) / T_{1 R}\right)^{*} 100 \\
\end{array}$} \\
\hline$V_{1}(V)$ & $T_{1 R}(\mu s)$ & $V_{2}(V)$ & $T_{1 L}(\mu s)$ & & \\
\hline 250,0 & 0,84 & 24,96 & 0,835 & 10,02 & $-0,60$ \\
\hline 250,0 & 0,84 & 24,96 & 0,840 & 10,02 & 0,00 \\
\hline 250,0 & 0,84 & 24,96 & 0,835 & 10,02 & $-0,60$ \\
\hline 250,0 & 0,84 & 24,96 & 0,835 & 10,02 & $-0,60$ \\
\hline 250,0 & 0,84 & 24,96 & 0,835 & 10,02 & $-0,60$ \\
\hline 250,0 & 0,84 & 24,96 & 0,840 & 10,02 & 0,00 \\
\hline 250,0 & 0,84 & 24,96 & 0,835 & 10,02 & $-0,60$ \\
\hline 250,0 & 0,84 & 24,96 & 0,835 & 10,02 & $-0,60$ \\
\hline 250,0 & 0,84 & 24,96 & 0,840 & 10,02 & 0,00 \\
\hline 250,0 & 0,84 & 24,96 & 0,840 & 10,02 & 0,00 \\
\hline \multicolumn{4}{|c|}{ Média } & 10,02 & $-0,36$ \\
\hline \multicolumn{4}{|c|}{ Desvio padrão \% } & 0 & 0,31 \\
\hline
\end{tabular}

A calibração do SMIP completo foi realizada aplicando-se um impulso de baixa tensão com forma de onda a mais próxima possível daquela utilizada em ensaios de perfuração em isoladores. Este impulso foi obtido por meio de um gerador de impulsos de baixa tensão. Para analise e quantificação dos parametros de impulso nessa calibração foi utilizado o osciloscópio TDS 540 com BW em FULL, com a ponta de prova medindo o sinal de entrada. Estão apresentados na Tabela 4 os resultados dos fatores de escala medidos na calibração do SMIP com impulsos de BT.

Tabela 4 - Fator de escala e erro no tempo de frente $T_{1}$ determinados com impulso simulado de perfuração em BT.

\begin{tabular}{|c|c|c|c|c|c|}
\hline \multicolumn{2}{|c|}{ Ponta } & \multicolumn{2}{|c|}{ SMIP } & \multirow{2}{*}{$\begin{array}{c}F E \\
V_{1} / N_{2}\end{array}$} & \multirow{2}{*}{$\begin{array}{c}\text { Delta } T_{1} \\
\left(\left(T_{1 L}-T_{1 R}\right) / T_{1 R}\right)^{*} 100\end{array}$} \\
\hline$V_{1}(V)$ & $\mathrm{T}_{1 \mathrm{R}}(\mathrm{ns})$ & $V_{2}(m V)$ & $T_{1 L}$ (ns) & & \\
\hline 251,2 & 121,2 & 18,96 & 121,3 & 13249 & 0,08 \\
\hline 249,6 & 120,0 & 18,72 & 122,0 & 13333 & 1,67 \\
\hline 249,6 & 121,0 & 18,72 & 123,0 & 13333 & 1,65 \\
\hline 251,2 & 120,0 & 18,92 & 121,0 & 13277 & 0,83 \\
\hline 249,6 & 120,8 & 18,96 & 122,9 & 13165 & 1,74 \\
\hline 249,6 & 120,4 & 18,96 & 121,0 & 13165 & 0,50 \\
\hline 251,2 & 122,0 & 18,96 & 123,0 & 13249 & 0,82 \\
\hline 251,2 & 120,0 & 18,96 & 121,0 & 13249 & 0,83 \\
\hline 249,6 & 121.0 & 18,96 & 1220 & 13165 & 0,83 \\
\hline 249,6 & 120,0 & 18,96 & 121,0 & 13165 & 0,83 \\
\hline \multicolumn{4}{|c|}{ Média } & 13235 & 0,98 \\
\hline & Desv & Irão \% & & 0,51 & 0,54 \\
\hline
\end{tabular}


4.5 - Software para filtragem, aquisição e análise do impulso

Para o ensaio real de impulso de perfuração foi necessário o desenvolvimento de um filtro para minimizar os efeitos de interferências nos sinais de impulso. O conceito para esse desenvolvimento está baseado no processamento digital com foco na localização do sinal no tempo e a duração das interferências. Isso é de grande importância em situações mais críticas e complexas como impulsos de perfuração em isoladores. Com isso, o processamento do sinal a ser utilizado levou em conta as informaçöes do sinal tanto no domínio da frequência quanto no domínio do tempo. E para isso se torna necessária e fundamental uma ferramenta específica.

A transformada de wavelet é uma ferramenta poderosa no processamento de sinal para representação de sinais digitais na frequência e no tempo. E e o melhor método para análise de sinais não estacionários, que são boa parte dos sinais relacionados a fenômenos fisicos. A transformada continua de wavelet (CWT) de $x(t)$ é dada por (1),
onde a transformação divide o sinal em versôes deslocadas e escaladas de uma wavelet mãe $\psi(t)$.

$$
\operatorname{CWT}(\tau, a)=\frac{1}{\sqrt{|a|}} \int_{-\infty}^{+\infty} x(t) \Psi^{*}\left(\frac{t-\tau}{a}\right) d t \quad(1)
$$

Onde:

$\tau$ e $a$ são parâmetros de escala e translação, respectivamente.

É de conhecimento amplo e consolidado na literatura um algoritmo eficiente para executar a transformada de wavelet que é chamado de análise de multi-resolução (MRA) e foi introduzido por Mallat. A MRA substitui a transformada de wavelet discreta que é usada na transformação de sinais no domínio do tempo, digitalizados transformada de wavelet discreta que e usada na transformaçâa

Na prática, a técnica de análise de multi-resolução baseia-se na filtragem de um sinal por meio de filtros passa baixa e passa alta cujos coeficientes são diretamente relacionados à wavelet-mãe, fornecendo representaçốes do sinal final em relação aos coeficientes de funçöes wavelet e funções de escala.

Após uma série de métodos deterministicos utilizados na seleção da wavelet mãe foi determinada a wavelet ótima aplicada especificamente ao filtro para remoção de ruidos em impulsos de perfuração em isoladores. Para torna prática a utilização do filtro em medições realizadas no laboratório foi desenvolvido em LabVIEW um software específico denominado RAPIT. O software desenvolvido para aquisição e condicionamento do sinal tem por objetivo garantir uma maior confiabilidade na medição do valor de pico do impulso de perfuração e minimizar o efeito de interferências comumente presentes no sinal a ser medido neste tipo de ensaio. Na Figura 5 é apresentado a tela principal do software com um impulso real de perfuração sem e com filtro.

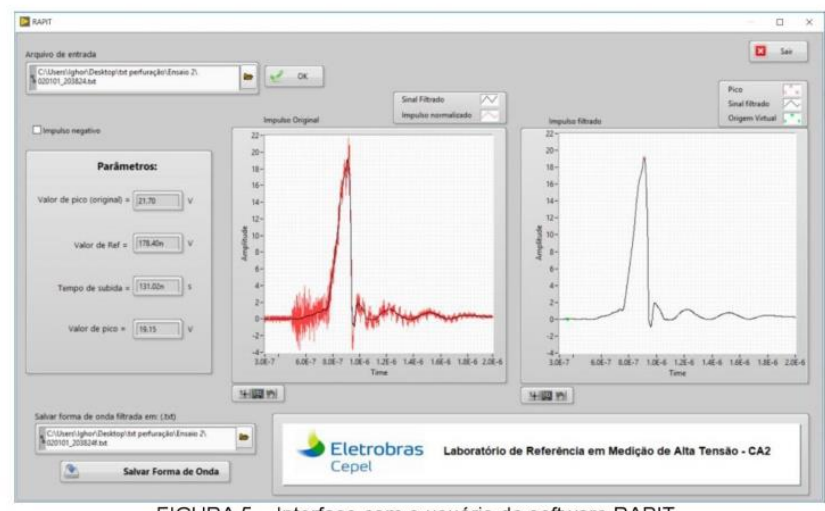

FIGURA 5 - Interface com o usuário do software RAPIT.

4.6 - Incerteza de medição

Com base no ISO GUM e em procedimentos internos foram calculadas as incertezas do divisor de tensão e do sistema de medição completo. Foram consideradas também no cálculo como fontes, as incertezas dos instrumentos, resolução, exatidäo, desvio padrăo das medidas e estabilidade. Os resultados indicaram uma incerteza de $1,7 \%(k=2)$ para o divisor de tensão, e de 4,1 \% para o SMIP. Esses valores estão dentro dos limites normatizados pela IEC 61211 
Antes da comparação interlaboratorial entre os SMIP para ensaios de perfuração em isoladores foi realizado pelo VTT - Technical Research Centre of Finland uma calibração em alta tensão com impulsos atmosféricos rápidos não normatizados com amplitude de $\cong 40 \mathrm{kV}$ e tempos $\mathrm{T}_{1} \cong 0,5 \mu \mathrm{s} \mathrm{e} \mathrm{T}_{2} \cong 30 \mu \mathrm{s}$. Foi utilizado na calibração o divisor de referência HUT400 do VTT para a determinação do fator de escala do SMIP do Cepel. O "Steeping gap" do Cepel foi utilizado no arranjo de ensaio e foi curto-circuitado mantendo os divisores do Cepel e VTT na mesma Cepel foi utilizado no arranjo de ensaio e foi curto-circuitado mâa, assim como os seus respectivos pontos de aterramento.
posio,

Foram realizadas 10 aplicação na polaridade positiva e medido o valor de crista da referência e a saída do SMIP do Cepel. Os parâmetros medidos no SMIP do Cepel foram quantificados pelo software IMPREAL de acordo com a IEC 60060-1. São apresentados na Figura 6 o arranjo de ensaio e os parâmetros medidos pelo SMIP do Cepel, respectivamente. Na Tabela 5 são apresentados todos os valores medidos.

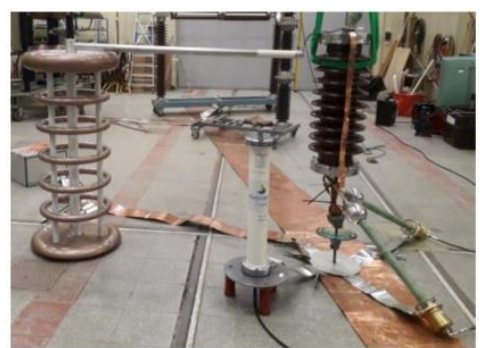

a) Arranjo de ensaio no laboratório

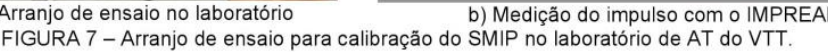

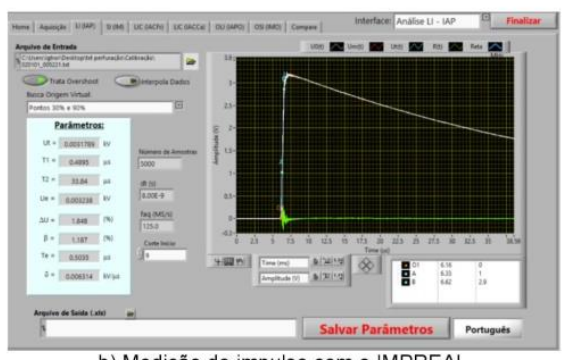

\begin{tabular}{|c|c|c|c|c|}
\hline \multicolumn{2}{|c|}{ Cepel - SMIP } & \multicolumn{2}{|c|}{ HUT 400} & \multirow{2}{*}{$\begin{array}{c}\mathrm{FE} \\
\text { Vp ref/Vp }\end{array}$} \\
\hline Arquivo (CSV) & $V p(V)$ & Arquivo (CSV) & Vp ref $(\mathrm{V})$ & \\
\hline 3924 & 3,168 & 12580 & 42731 & 13488 \\
\hline 4139 & 3,167 & 12581 & 42725 & 13491 \\
\hline 4352 & 3,167 & 12582 & 42744 & 13497 \\
\hline 4448 & 3,166 & 12583 & 42718 & 13493 \\
\hline 4540 & 3,183 & 12584 & 42932 & 13488 \\
\hline 4944 & 3,185 & 12586 & 42960 & 13488 \\
\hline 5029 & 3,181 & 12587 & 42936 & 13498 \\
\hline 5103 & 3,179 & 12588 & 42901 & 13495 \\
\hline 5141 & 3,182 & 12589 & 42923 & 13489 \\
\hline 5221 & 3,179 & 12590 & 42909 & 13498 \\
\hline \multicolumn{4}{|r|}{ Média } & 13492 \\
\hline \multirow{2}{*}{\multicolumn{4}{|c|}{$\begin{array}{l}\text { Desvio padrão } \\
\text { dräo percentual }\end{array}$}} & 4 \\
\hline & & & & $0,03 \%$ \\
\hline
\end{tabular}

\section{0 - COMPARAÇÃO INTERLABORATORIAL ENTRE SMIP}

Para essa comparação interlaboratorial, que também é uma atividade no âmbito do Cigré Working Group D1.60: Traceable measurement techniques for very fast transients, foi desenvolvido um software específico para ensaios de perfuração em isoladores para garantir uma maior confiabilidade na medição do valor de pico do impulso e minimizar o efeito de interferências inerentes ao ensaio.

O software foi desenvolvido especificamente para o processamento e análise de formas de onda de impulso de perfuração em isoladores do Cepel. O software permite quantificar os seguintes parametros. Valor de pico original do impulso, valor de referência definido na origem virtual, que e o instante em que o sinal do impulso começa aumentar acima do patamar inicial de base, o tempo de subida e o valor de pico descontado o valor de referência. Todos estes parâmetros são determinados após a remoção do ruído. 
Nesta comparação realizada nas instalações do VTT, o sistema de medição utilizado pelo Cepel foi composto pelo divisor de tensão de $600 \mathrm{kV}$ do tipo resistivo de baixa resistência e mínima indutância, um sistema de transmissão do sinal por cabo coaxial de dupla blindagem, com $7,5 \mathrm{~m}$ de comprimento e impedância de $50 \Omega$, um atenuado resistivo e o registrador digital modelo TDS 5104B. O software RAPIT utilizado no registrador para quantificar os parâmetros do ensaio também faz parte do SMIP, conforme mostrado na Figura 8.

No arranjo compacto de ensaio para a comparação o divisor do VTT, que é o Instituto Nacional de Metrologia da Finlândia, foi utilizado em posição diagonal conectado diretamente ao objeto sob ensaio, um isolador de vidro, enquanto o divisor do Cepel foi colocado na posição vertical conectado ao isolador através de um condutor de alta tensão, já que está é posição original de uso deste divicar co nual foi ciscocterizado pelo com caracteristicas similares ao do VTT também foi utiliza ro na qual foi caracterizado pelo Cepel. Un outro divisor e acordo com as recomendações da IEC 61211

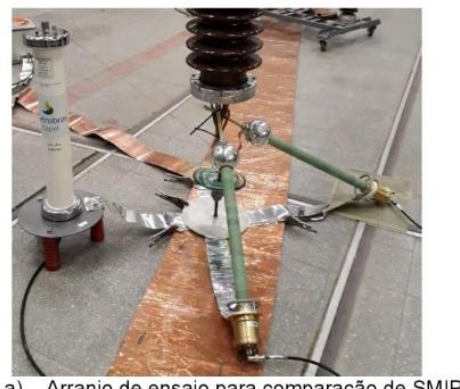

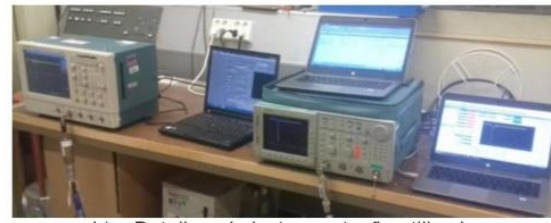

b) Detalhes da instrumentação utilizada na comparação entre SMIP.

A forma de onda filtrada pelo software RAPIT obteve uma maior correlação em termos de amplitude e forma de nda com o sinal medido pelos SMIP do VTT. São apresentados na Figura 9 dois impulsos de perfuração em isoladores, um medido pelo SMIP do VTT e outro pelo SMIP do Cepel. Embora os dois SMIP utilizem osciloscópios com 8 bits de resolução vertical os modelos são diferentes, para o VTT é utilizado o TDS 784C e para o Cepel o TDS 5104B. Nesse caso as características principais dos instrumentos utilizados são, para o VTT, uma taxa de amostragem de $1,0 \mathrm{GS} / \mathrm{s}$ e banda de passagem de $0,5 \mathrm{GHz}$, enquanto para o Cepel foi de utilizada $1,25 \mathrm{GS} / \mathrm{s}$ de taxa de amostragem e $1 \mathrm{GHz}$ de banda.

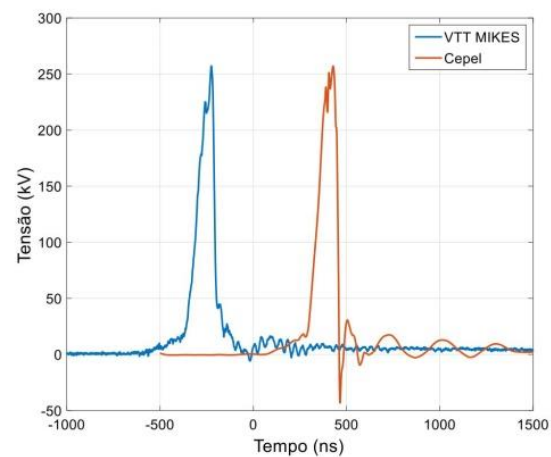

FIGURA 9 - Formas de onda medidas pelos SMIP do VTT MIKES e Cepel.

Estão apresentados na Tabela 6 todos os resultados da comparação interlaboratorial entre VTT e Cepel, considerando 10 aplicaçöes em cada polaridade para o arranjo de ensaio mostrado na Figura 8 . São apresentadas também informaçöes do Fator de Escala (SF) do SMIP do Cepel, os arquivos e o desempenho do SMIP com e sem filtro. Nesse sentido, observa-se uma redução significativa do erro médio entre os dois SMIP, assim como o desvio padrão máximo de $2 \%$. 
Tabela 6 - Resultados da comparação interlaboratorial para SMIP entre VTT MIKES e Cepel.

\begin{tabular}{|c|c|c|c|c|c|c|c|c|c|c|c|c|}
\hline \multicolumn{2}{|c|}{ MIKES } & \multirow{2}{*}{$\begin{array}{c}\text { CEPEL } \\
\text { Arquive } \\
\text { (CSV) }\end{array}$} & \multirow{2}{*}{$\begin{array}{c}\text { SF: } \\
\begin{array}{c}\text { Vpk, TEK } \\
\text { (V) }\end{array}\end{array}$} & \multicolumn{4}{|c|}{13492} & \multirow{2}{*}{\begin{tabular}{c|}
\multicolumn{1}{|c|}{ SF: } \\
Vpk, TEK \\
(V) \\
Filtered
\end{tabular}} & \multicolumn{4}{|c|}{13492} \\
\hline file & Up [V] & & & Up $[V]$ & $\begin{array}{l}\text { From } \\
\text { MIKES } \\
\text { value }\end{array}$ & avg. & stdev. & & $\begin{array}{l}\text { Up [V], } \\
\text { filtered }\end{array}$ & $\begin{array}{l}\text { From } \\
\text { MIKES } \\
\text { value }\end{array}$ & avg. & stdev. \\
\hline LIcal_12txt.txt & 260936 & 11528 & 21.60 & 291437 & $11.7 \%$ & \multirow{10}{*}{$13 \%$} & \multirow{10}{*}{$3 \%$} & 20.03 & 270253 & $3.6 \%$ & \multirow{10}{*}{$-0.4 \%$} & \multirow{10}{*}{$2.0 \%$} \\
\hline LIcal_13txt.txt & 252665 & 11930 & 21.70 & 292786 & $15.9 \%$ & & & 19.02 & 256626 & $1.6 \%$ & & \\
\hline LIcal_14txt.txt & 262415 & 12503 & 22.10 & 298183 & $13.6 \%$ & & & 19.08 & 257436 & $-1.9 \%$ & & \\
\hline LIcal_15txt.txt & 259069 & 12724 & 21.70 & 292786 & $13.0 \%$ & & & 19.00 & 256356 & $-1.0 \%$ & & \\
\hline LIcal_16txt.txt & 257435 & 12816 & 22.80 & 307627 & $19.5 \%$ & & & 19.56 & 263912 & $2.5 \%$ & & \\
\hline LIcal_17txt.txt & 256983 & 12924 & 21.60 & 291437 & $13.4 \%$ & & & 18.84 & 254197 & $-1.1 \%$ & & \\
\hline LIcal_18txt.txt & 259445 & 13014 & 20.70 & 279293 & $7.7 \%$ & & & 18.99 & 256221 & $-1.2 \%$ & & \\
\hline LIcal_19txt.txt & 264369 & 13055 & 22.20 & 299532 & $13.3 \%$ & & & 19.28 & 260134 & $-1.6 \%$ & & \\
\hline LIcal_20txt.txt & 266051 & 13137 & 22.40 & 302230 & $13.6 \%$ & & & 19.29 & 260269 & $-2.2 \%$ & & \\
\hline Llcal_21txt.txt & 263471 & 13205 & 21.70 & 292786 & $11.1 \%$ & & & 19.05 & 257031 & $-2.4 \%$ & & \\
\hline LIcal_26txt.txt & -268338 & 21047 & 22.50 & -303580 & $13.1 \%$ & \multirow{10}{*}{$12 \%$} & \multirow{10}{*}{$5 \%$} & 19.73 & -266206 & $-0.8 \%$ & \multirow{10}{*}{$0.2 \%$} & \multirow{10}{*}{$0.7 \%$} \\
\hline LIcal_27txt.txt & -271300 & 21240 & 22.50 & -303580 & $11.9 \%$ & & & 20.12 & -271468 & $0.1 \%$ & & \\
\hline LICal_28txt.txt & -265264 & 21322 & 21.20 & -286040 & $7.8 \%$ & & & 19.90 & -268499 & $1.2 \%$ & & \\
\hline LIcal_29txt.txt & -273851 & 21405 & 22.10 & -298183 & $8.9 \%$ & & & 20.38 & -274976 & $0.4 \%$ & & \\
\hline LIcal_30txt.txt & .270739 & 21445 & 20.90 & -281992 & $4.2 \%$ & & & 20.14 & -271738 & $0.4 \%$ & & \\
\hline LIcal_31txt.txt & $\begin{array}{l}-272709 \\
\end{array}$ & 21542 & 24.10 & -325168 & $19.2 \%$ & & & 20.18 & -272277 & $-0.2 \%$ & & \\
\hline LIcal_32txt.txt & .271823 & 21628 & 22.80 & -307627 & $13.2 \%$ & & & 20.04 & -270388 & $-0.5 \%$ & & \\
\hline LIcal_33txt.txt & -269876 & 21744 & 24.30 & -327866 & $21.5 \%$ & & & 20.16 & -272007 & $0.8 \%$ & & \\
\hline LIcal_34txt.txt & -272825 & 21850 & 22.10 & -298183 & $9.3 \%$ & & & 20.48 & -276325 & $1.3 \%$ & & \\
\hline Llcal_35txt.txt & .271852 & 21956 & 23.00 & -310326 & $14.2 \%$ & & & 19.97 & .269444 & $-0.9 \%$ & & \\
\hline
\end{tabular}

7.0 - ANÁLISE DOS RESULTADOS

Um resumo dos resultados obtidos com os diferentes métodos para determinação do Fator de Escala é apresentado na Tabela 7. O FE com impulsos em AT foi determinado no nivel de $+42 \mathrm{kV}$ e utilizando um impulso atmosférico näo normalizado com tempo de frente em torno de $0,5 \mu \mathrm{s}$. Observa-se na Tabela 7 uma diferença no FE inferior a $2 \%$ considerando todos os métodos para determinação do FE. Utilizando o FE determinado em AT pelo VTT para a comparação interlaboratorial entre SMIP, a diferença na amplitude do ensaio foi inferior a $0,5 \%$ pelo VTT para a comparação inter

Tabela 7 - Resumo de diferentes métodos para determinação do FE

\begin{tabular}{|c|c|c|c|c|c|}
\hline Descrição & Componentes (R) & $\mathrm{CC}_{\mathrm{BT}}$ & IMP ${ }_{B T}$ & $I M P_{A T}$ & Diferença (\%) \\
\hline FE DIVISOR & 750,77 & 756,98 & - & - & $-0,82$ \\
\hline FE ATENUADOR & 17,659 & 17,748 & - & - & $-0,50$ \\
\hline \multirow[b]{2}{*}{ FE TOTAL } & \multirow[b]{2}{*}{13258} & \multirow[b]{2}{*}{13423} & \multirow[b]{2}{*}{13235} & \multirow[b]{2}{*}{13492} & $-1,7$ (R/IMP AT) \\
\hline & & & & & $-0,51$ (CC $\left.{ }_{\text {BT }} / \mathrm{IMP} \mathrm{AT}_{\mathrm{AT}}\right)$ \\
\hline
\end{tabular}

\section{0 - OBSERVAÇÃO, COMENTÁRIOS E CONCLUSÃO}

O SMIP do Cepel foi todo caracterizado em BT e comparado em AT e está de acordo com os requisitos normatizados, tanto em termos de desempenho dinâmico ( $T \alpha<3 \mathrm{~ns}$ ) como nas incertezas calculadas do divisor ( $<$ $2 \%)$ e para o sistema de medição completo $(<5 \%)$ e, portanto, está adequado para calibração de outros SMIP.

Em relação à estabilidade do $\mathrm{FE}$ pode-se observar uma diferença inferior a $0,3 \%$ entre os $\mathrm{FE}$ determinados em 2015 (13458) e o atual (13423). O método comparativo para determinar o FE do SMIP que apresentou resultados com a menor diferença foi o método de calibração do FE utilizando baixa tensão em CC. A incerteza calculada do SMIP para ensaios de perfuração é de 4,1\% (k=2) para um FE de 13492.

Com base nos resultados da caracterização do SMIP em BT e complementado com a comparação interlaboratorial entre Cepel e VTT-Mikes, pode-se comprovar a confiabilidade dos resultados de ensaios de perfuração em entre Cepel e VTT-Mikes, pode-se comprovar a confiabilidade dos resultados de ensaios de perfuração em isoladores realizados nos laboratórios do Cepel, e que o 600 RAPIT Ne RAPIT. Nesse sentido, todo o SMIP do Cepel, incluindo o software, está rastreado a referência de um INM do 
9.0 - REFERÊNCIAS BIBLIOGRÁFICAS

(1) IEC 61211:2004 "Insulators of ceramic material or glass for overhead lines with a nominal voltage greater than $1000 \mathrm{~V}$ - Impulse puncture testing in air".

(2) IEC 60060-1:2010 "High voltage test technique, Part 1: General definitions and test requirements".

(3) IEC 60060-2:2010 "High voltage test technique, Part 2: Measuring systems".

(4) IEC 61083-1: 2001 "Instruments and software used for measurements in high-voltage impulse tests, Part 1 : Requirements for instruments

(5) Martti Aro (FINLAND) and Robert C. Hughes (UNITED KINGDOM) on behalf of Cigré Working Group 33.03, TF 33.03.01, "Puncture testing of ceramic and glass insulators", Electra 136, 1991.

(6) Orsino Borges Filho, M. T. Fernandes, Azevedo L. C. and Oliveira Y. R., "Comparison of measuring systems used in impulse puncture withstand test", CIGRÉ Winnipeg 2017 Colloquium; Winnipeg, Canada, 2017.

(7) Ighor Souza dos Santos, Carlos R. Hall Barbosa, M. T. Fernandes e Orsino Borges Filho,.,"Multi-resolution Wavelet Analysis for Noise Reduction in Impulse Puncture Voltage Measurements", artigo enviado para publicação em 2019 no IEEE "Transactions on Instrumentation and Measurement".

(8) Onal, Emel, Ozcan Kalenderli, and Serhat Seker. "Multi-resolution wavelet analysis for chopped impulse voltage measurements and feature extraction." IEEE Transactions on Dielectrics and Electrical Insulation 15.3, 2008 .

(9) S. Mallat, "A Wavelet Tour of Signal Processing", Academic Press, London, 1999

(10) ISO - GUM: "Guide to the expression of uncertainty in measurements".

10.0 - DADOS BIOGRÁFICOS

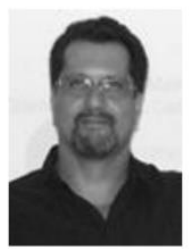

Márcio Thélio Fernandes da Silva nasceu no Rio de Janeiro, Brasil, em 1965. Graduado em Engenharia Elétrica pela Universidade Gama Filho, Rio de Janeiro, Brasil, em 1995 e titulo de Mestre em Metrologia pelo Programa de Pós-Graduação em Metrologia da Pontificia Universidade Católica do Rio de Janeiro, Brasil, em 2011. Atua no Laboratório de calibração de alta tensão do Centro de Pesquisas de Energia Elétrica (CEPEL) da Eletrobrás com pesquisas, normatização e metrologia em alta tensão, usando e desenvolvendo padrões para ensaios em equipamentos elétricos para alta tensão $\mathrm{CA}, \mathrm{CC}$ e impulsos de tensão e corrente. Trabalhando com técnicas de ensaio e calibração em alta tensão por mais de 30 anos 


\section{Anexo 2 -Artigo XIII Congresso Internacional de Metrologia Elétrica (SEMETRO)}

\section{Metrologia}

\section{Caracterização e avaliação de um sistema de medição para ensaios de perfuração em isoladores}

IS Santos ${ }^{12}$, CRH Barbosa ${ }^{1}$, MT Silva ${ }^{2}$, LC Azevedo ${ }^{2}$, LS Ferreira $^{2}$, MVB Lopes $^{2}$

'Pontificia Universidade Católica do Rio de Janeiro, Programa de Pós-graduação em Metrologia, Rio de Janeiro, Brasil; ${ }^{2}$ Centro de Pesquisas de Energia Elétrica (CEPEL), Rio de Janeiro, Brasil

E-mail: ighor.s@hotmail.com

Resumo. O isolador elétrico é um dos equipamentos de maior importância, em linhas de transmissão, pois ele é responsável por manter o isolamento elétrico entre os condutores de fase e a estrutura da torre contribuindo para a garantia e a confiabilidade no suprimento de energia elétrica. Com isso se faz necessário verificar o desempenho e a qualidade de isoladores por meio do ensaio de impulso de perfuração, descrito na norma IEC 61211:2004. Com isso, este trabalho descreve a caracterização de um Sistema de Medição para Impulso de Perfuração, desenvolvido especificamente para atender todos os requisitos técnicos desejáveis para esta aplicação.

\section{INTRODUÇÃO}

Técnicas de medição para ensaios em laboratório de alta tensão, com foco nas garantias metrológicas, requer maior atenção e pesquisas, uma vez que a grande maioria de laboratórios de pesquisa e ensaios em equipamentos para alta tensão no Brasil não possuem padrões rastreados e tampouco serviços acreditados de acordo com a norma ABNT NBR IEC 17025. Este cenário é crítico para o Brasil, pois o país carece de padrões e rastreabilidade em alguns ensaios em alta tensão, em especial os ensaios de perfuração de isoladores, conforme descrito pela norma IEC 61211:2004 "Insulators of ceramic material or glass for overhead lines with a nominal voltage greater than $1000 \mathrm{~V}$ - Impulse puncture testing in air" [1]

Sem padrões e rastreabilidade metrológica, os fabricantes nacionais de isoladores não dispõem de condições plenas para garantir a qualidade desses isoladores, fato que pode influenciar negativamente na competição desses produtos no mercado ou afetar a confiabilidade do suprimento de energia elétrica à sociedade.

Estudos especificos considerando particularidades de um sistema de medição têm sido realizados desde as últimas décadas [2-4]. Alguns Institutos Nacionais de Metrologia e Centros de pesquisas, incluindo o Cepel, estão realizando atividades no Working Group D1.60 do Cigré, denominado "Traceable measurement techniques for very fast transients", com o objetivo de prover metodologias para garantir a rastreabilidade de impulsos de tensão de frente muito íngreme, além da construção de padrões, no sentido de viabilizar a calibração de sistemas de medição de impulsos de perfuração. Além disso, divisores de tensão com alto desempenho dinâmico para essa aplicação especifica, também não estão disponíveis comercialmente. A norma IEC 61211:2004 [1] recomenda que o sistema de medição 


\section{Metrologia}

seja calibrado e aprovado de acordo com a norma IEC 60060-2/2010: "High-voltage test techniques, Part 2: Measuring systems" [5]

No ensaio de perfuração, as amplitudes do impulso com tempo de frente entre 100 a $200 \mathrm{~ns}$ devem ser medidas com incerteza total inferior a $5 \%$. Quantificar a amplitude desse impulso, com todas as garantias metrológicas, não é uma tarefa trivial, conforme apresenta a Figura 1, pois, em função das características da geração do ensaio de perfuração, é comum se observarem interferências de alta frequência sobrepostas ao sinal de impulso. No caso do sistema de medição de impulso do Cepel foi também desenvolvido um filtro integrado a um software que serve para aquisição, condicionamento do sinal, determinação e análise dos parâmetros do impulso de perfuração.

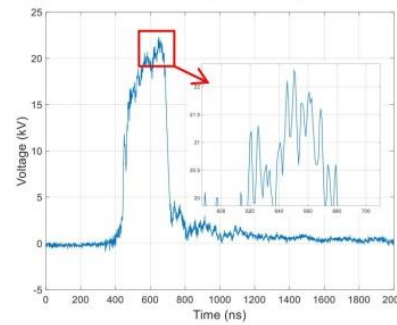

Figura 1. Impulso típico do ensaio de perfuração de isoladores

Este trabalho descreve os métodos utilizados para a caracterização de um novo sistema de medição do Cepel projetado para ensaios de perfuração em isoladores, avaliação do desempenho dinâmico por meio da análise da resposta ao degrau e da resposta em frequência. Comparações em alta tensão também foram realizadas para a determinação do fator de escala do sistema de medição e sua incerteza foi comparada com os limites normalizados.

\section{REQUISITOS NORMATIVOS PARA SISTEMAS DE MEDIÇ̃̃O USADOS EM ENSAIOS} DE PERFURAÇ̃̃O EM ISOLADORES

Os requisitos técnicos estabelecidos pela norma IEC 61211:2004 [1] devem ser utilizados em ensaios de perfuração em isoladores para garantir a conformidade do sistema de medição. Os principais requisitos são apresentados a seguir

- O sistema de medição deve ser calibrado, por comparação, e aprovado de acordo com a norma IEC 60600-2 [5];

- O osciloscópio ou registrador digital deve estar de acordo com a norma IEC 61083-1 [6];

- Recomenda-se utilizar divisores de tensão especiais para este tipo de aplicação, que sejam rápidos e compactos;

- Incerteza total do sistema de medição $\leq 5 \%(\mathrm{k}=2)$

- Incerteza do fator de escala do divisor de tensão $\leq 2 \%(\mathrm{k}=2)$

- Desempenho dinâmico do sistema de medição

- Para resposta ao degrau com oscilação: Tempo de resposta parcial $T_{\alpha} \leq 3 \mathrm{~ns}$

- Para resposta ao degrau sem oscilação: Tempo de resposta parcial $\mathrm{T} \leq 5 \mathrm{~ns}$

- A resposta é avaliada com o sistema de medição na mesma posição do arranjo de ensaio, mas sem isolador, conforme a Figura 2. 


\section{Metrologia}

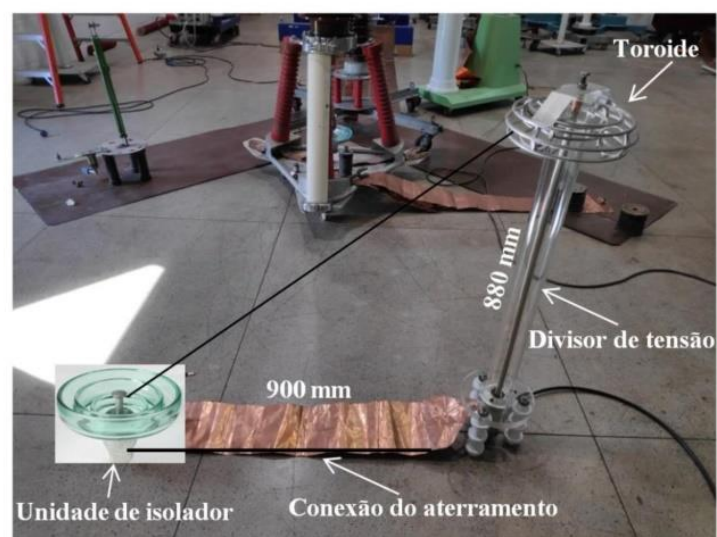

Figura 2. Exemplo da configuração recomendável para um divisor de tensão compacto de pequenas dimensões de acordo com a IEC 61211:2004.

\section{CARACTERIZAÇ̃̃o DO SISTEMA DE MEDIÇÃO USADO EM ENSAIOS DE} PERFURAÇÃO EM ISOLADORES

O sistema de medição de impulso de perfuração do Cepel é composto por um divisor de tensão resistivo com resistores de alta e baixa tensão construidos artesanalmente, com o objeto de minimizar a indutância, por um sistema de transmissão do sinal através de cabo triaxial que contém dupla blindagem, atenuador resistivo também de indutância reduzida e por um sistema de aquisição e processamento de sinais, conforme apresentado na Figura 3 (que apresenta também a configuração de medição pelo método a quatro fios)
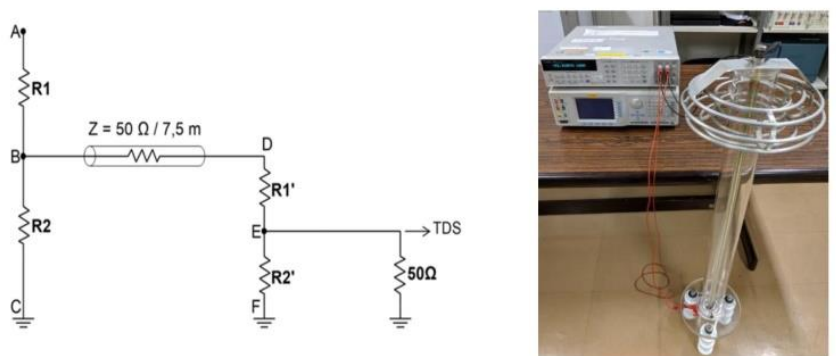

Figura 3. Diagrama elétrico do sistema de medição e configuração de medição dos componentes.

A caracterização foi realizada pela medição em baixa tensão dos componentes individuais e pela determinação do fator de escala em baixa tensão em corrente continua. 


\section{Metrologia}

3.1. Medição dos componentes

As resistências dos resistores das unidades de alta e baixa tensão do divisor de tensão e do atenuador foram medidos pelo método a quatro terminais, no qual são desprezadas as resistências dos condutores. Na Tabela 1 encontram-se os resultados da medição utilizando um multímetro digital de alta resolução, bem como o fator de escala (FE) calculado a partir destes resultados.

Tabela 1. Valores dos componentes resistivos medidos (a) e determinação do fator de escala (b)

a) \begin{tabular}{|l||c||}
\hline \multicolumn{1}{|c|}{ Descrição } & $\boldsymbol{\Omega}$ \\
\hline R1 = R AB & 2418,9 \\
\hline R2 sem cabo = R BC & 2,4165 \\
\hline R2 com cabo + Ro = R BC & 2,3045 \\
\hline \hline R1' = R DE & 47,084 \\
\hline \hline R2' = R EF & 3,1566 \\
\hline Ro = R DF & 50,262 \\
\hline
\end{tabular}

\begin{tabular}{||l||c|}
\hline \multicolumn{1}{|c|}{ Descrição } & Adimensional \\
\hline \hline FE = Divisor de tensão & 1050,6 \\
\hline \hline Atenuador & 15,916 \\
\hline \hline FE = SMIP & 16722 \\
\hline
\end{tabular}

$$
\begin{gathered}
\text { FE Divisor }=\left(R_{1 /} / R_{2}\right)+1 \\
F E_{\text {Atenuador }}=\left(R_{1}^{\prime} / R_{2^{\prime}}\right)+1 \\
F E \text { SMIP }=F E_{\text {Div }} \times F E_{\text {At }}
\end{gathered}
$$

3.2. Determinação do fator de escala em baixa tensão

Os fatores de escala também foram determinados individualmente, em baixa tensão, levando em consideração o divisor de tensão, o atenuador e o sistema de medição completo. Foi utilizado um calibrador Fluke 5720A para gerar a tensão do ensaio, e adotado o valor verdadeiro do instrumento, que é o usado para calibrar outros instrumentos no laboratório de calibração do Cepel acreditado pela RBC. Finalmente, foi utilizado um multimetro de alta resolução com 8,5 dígitos para medir o sinal

São apresentados na Tabela 2 os resultados dos fatores de escala obtidos utilizando esta

\begin{tabular}{|c|c|c|c|c|c|c|c|c|}
\hline \multicolumn{3}{|c|}{ Divisor de tensão } & \multicolumn{3}{|c|}{ Atenuador } & \multicolumn{3}{|c|}{ SMIP } \\
\hline$V_{1}(\mathrm{~V})$ & $V_{2}(\mathrm{mV})$ & $\mathrm{FE}\left(\mathrm{V}_{1} / \mathrm{V}_{2}\right)$ & $V_{1}(\mathrm{~V})$ & $V_{2}(\mathrm{mV})$ & $\mathrm{FE}\left(\mathrm{V}_{1} / \mathrm{V}_{2}\right)$ & $V_{1}(\mathrm{~V})$ & $V_{2}(m V)$ & $\mathrm{FE}\left(\mathrm{V}_{1} / \mathrm{V}_{2}\right)$ \\
\hline \multirow{10}{*}{30,0000} & 28,1611 & 1064,8 & \multirow{10}{*}{1,0000} & 62,3195 & 16,040 & \multirow{10}{*}{30,0000} & 1,75509 & 17086 \\
\hline & 28,1602 & 1064,9 & & 62,3233 & 16,039 & & 1,75505 & 17087 \\
\hline & 28,1601 & 1064,9 & & 62,3237 & 16,039 & & 1,75509 & 17086 \\
\hline & 28,1602 & 1064,9 & & 62,3239 & 16,038 & & 1,75510 & 17086 \\
\hline & 28,1602 & 1064,9 & & 62,3243 & 16,038 & & 1,75502 & 17087 \\
\hline & 28,1602 & 1064,9 & & 62,3244 & 16,038 & & 1,75501 & 17087 \\
\hline & 28,1600 & 1064,9 & & 62,3256 & 16,038 & & 1,75595 & 17078 \\
\hline & 28,1603 & 1064,9 & & 62,3258 & 16,038 & & 1,75503 & 17087 \\
\hline & 28,1603 & 1064,9 & & 62,3256 & 16,038 & & 1,75508 & 17086 \\
\hline & 28,1601 & 1064,9 & & 62,3255 & 16,038 & & 1,75501 & 17087 \\
\hline \multicolumn{2}{|c|}{ Média } & 1064,9 & & édia & 16,038 & & dia & 17086 \\
\hline
\end{tabular}
metodologia.

Tabela 2. Fatores de escala determinados em baixa tensão em corrente contínua 


\section{Metrologia}

4. AVALIAÇÃO DO DESEMPENHO DINÂMICO E RESPOSTA EM FREQUÊNCIA

Após a caracterização do sistema de medição, este foi avaliado em relação ao seu desempenho dinâmico para impulsos de perfuração, considerando que um sistema para este tipo de aplicação deve possuir desempenho dinâmico compativel com o impulso muito rápido que será medido.

4.1. Análise da resposta ao degrau

A avaliação do desempenho dinâmico foi realizada pela análise da resposta ao degrau. Um gerador de degrau com tensão $\cong 90 \mathrm{~V}$ de crista e com tempos de subida com ordem de 4 ns foi posicionado no lugar do isolador sob ensaio. Um osciloscópio com largura de banda plena de $1 \mathrm{GHz}$ foi utilizado para aquisição e o processamento do sinal foi feito pelo software STERAL, programa computacional para calculo e análise de parâmetros da resposta ao degrau. Estão apresentados na Figura 4 e Figura 5 as respostas do divisor e atenuador, respectivamente.

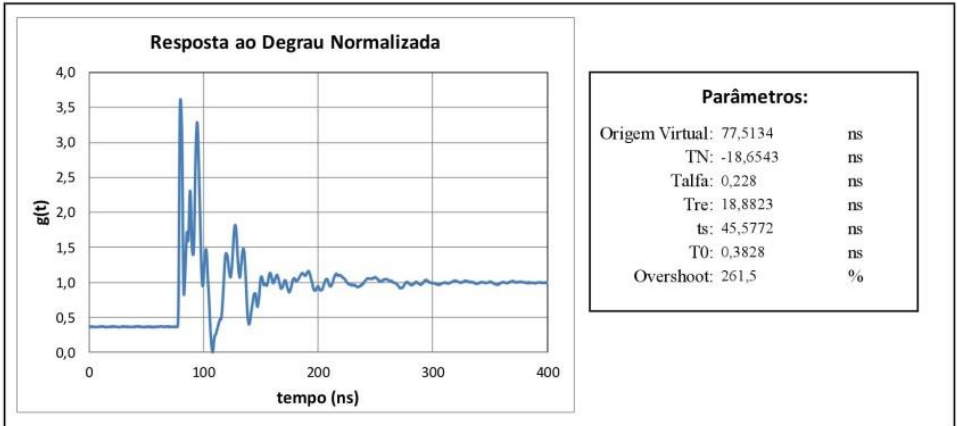

Figura 4. Resposta ao degrau do divisor de tensão.

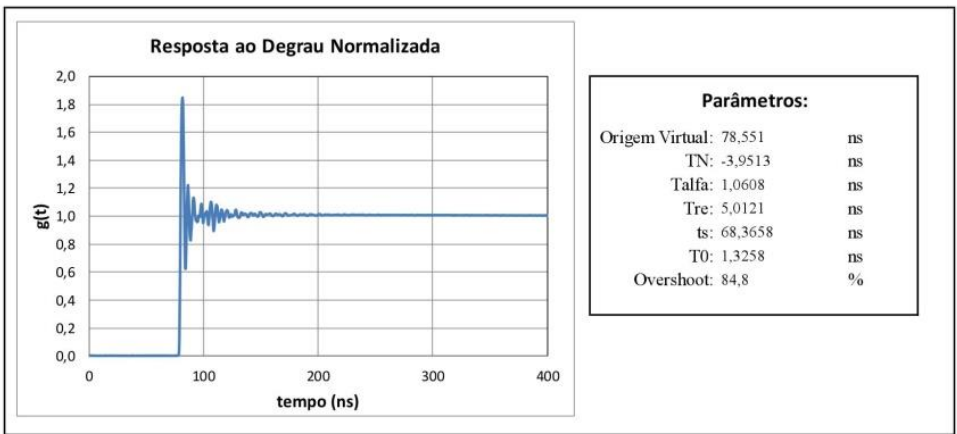

Figura 5. Resposta ao degrau do atenuador

O parâmetro de tempo de resposta parcial $\left(T_{\alpha}\right)$ calculado foi de 0.2 ns para o divisor e de aproximadamente $1 \mathrm{~ns}$ para o atenuador, o que satisfaz o requisito previsto na IEC 61211:2004 [1], que exige que o sistema de medição tenha um tempo de resposta parcial $T_{\alpha} \leq 3 \mathrm{~ns}$ 


\section{Metrologia}

4.2. Análise do sistema de medição no dominio da frequência

A análise do sistema de medição no domínio da frequência foi realizada por meio da resposta em frequência medida no laboratório de diagnóstico de equipamentos do Cepel (LABDIG), utilizando um sistema denominado SCAn e o Virtualbench da National Instruments como instrumento único de geração e medição.

Esta análise foi realizada no sistema de medição nas configurações de ensaio de acordo com a Tabela 3, pois a norma IEC 61211:2004 [1] não especifica uma configuração especifica para este ensaio, e também até o momento ainda não era conhecido o desempenho dos divisores de tensão desenvolvidos pelo Cepel em diferentes posições. Isso se fez necessário devido a não existir uma padronização da configuração de ensaio de perfuração em isoladores de diferentes laboratórios de ensaio e calibração.

Tabela 3. Descrição de cada tipo de configuração de ensaio avaliada

\begin{tabular}{||c||c||}
\hline \hline Configuração & Descrição \\
\hline \hline A1 & Divisor na posição vertical com o toroide \\
\hline \hline B1 & Divisor na posição vertical sem o toroide \\
\hline \hline B2 & Divisor na posição $45^{\circ}$ com o toroide \\
\hline \hline C1 & Divisor na posição $45^{\circ}$ sem o toroide \\
\hline \hline C2 & Divisor na posição horizontal com o toroide \\
\hline \hline
\end{tabular}

Com estas configurações foram realizados dois tipos de medição, com varredura de frequência entre $100 \mathrm{kHz}$ e $20 \mathrm{MHz}$. Primeiramente, a de transferência de tensão, na qual foi aplicada uma tensão $\mathrm{Vpp}=20 \mathrm{~V}$ entre o topo do divisor e o terra e obtida uma tensão na unidade de baixa tensão em função da frequência, com isso calculando o ganho em $\mathrm{dB}$ e consequentemente o ganho em tensão, que determina o fator de escala do sistema. Na sequência, foi realizada a medição da impedância do sistema em função da frequência de varredura. A Tabela 4 a seguir apresenta os resultados destas medições para cada configuração de ensaio.

Tabela 4. Resultados obtidos por meio da resposta em frequência do sistema de medição.
\begin{tabular}{|c|c|c|c|c|c|}
\hline Posição & Configuração & $\begin{array}{c}\text { Ganho } \\
\text { (dB) }\end{array}$ & $\begin{array}{c}\text { Fator de } \\
\text { escala }\end{array}$ & |Z | com cabo & |Z| sem cabo \\
\hline \multirow{2}{*}{ V } & A1 & $-60,63$ & 1075,23 & $2,461 \mathrm{k} \Omega$ & $2,461 \mathrm{k} \Omega$ \\
\cline { 2 - 7 } & A2 & $-60,63$ & 1075,23 & $3,462 \mathrm{k} \Omega$ & $3,488 \mathrm{k} \Omega$ \\
\hline \multirow{2}{*}{$45^{\circ}$} & B1 & $-60,63$ & 1075,23 & $3,326 \mathrm{k} \Omega$ & $3,355 \mathrm{k} \Omega$ \\
\cline { 2 - 7 } & B2 & $-58,86$ & 877,00 & $3,402 \mathrm{k} \Omega$ & $2,480 \mathrm{k} \Omega$ \\
\hline \multirow{2}{*}{ H } & C1 & $-58,02$ & 796,15 & $2,838 \mathrm{k} \Omega$ & $2,838 \mathrm{k} \Omega$ \\
\cline { 2 - 7 } & C2 & $-58,02$ & 796,15 & $2,838 \mathrm{k} \Omega$ & $2,838 \mathrm{k} \Omega$ \\
\hline
\end{tabular}

A partir dos resultados pode-se observar que os valores que mais se adequaram ao valor medido na caracterização foi o obtido na configuração vertical para o divisor de tensão com o toroide. A utilização do divisor em qualquer outra posição influencia no fator de escala ou na impedância projetada. 


\section{Metrologia}

Na transferência de tensão, todas as medições apresentaram uma banda de frequência com variação menor que $3 \mathrm{db}$ até a frequência de $4,36 \mathrm{MHz}$, conforme apresenta a Figura 6 . Isso satisfaz o sistema de medição, visto que a faixa de frequências de interesse do ensaio em questão vai até $4 \mathrm{MHz}$. É importante notar que o condutor acrescentado ao arranjo de ensaio influencia bastante no comportamento do sistema para frequências na ordem de $10^{6} \mathrm{~Hz}$ no caso de medições de impedâncias, diferentemente da transferência de tensão, conforme a Figura 7. Além disso, no caso desse tipo de condutor nu, sem nenhum tipo de blindagem, é dificil executar uma boa reprodutibilidade do arranjo quanto maior for a frequência de interesse do sinal
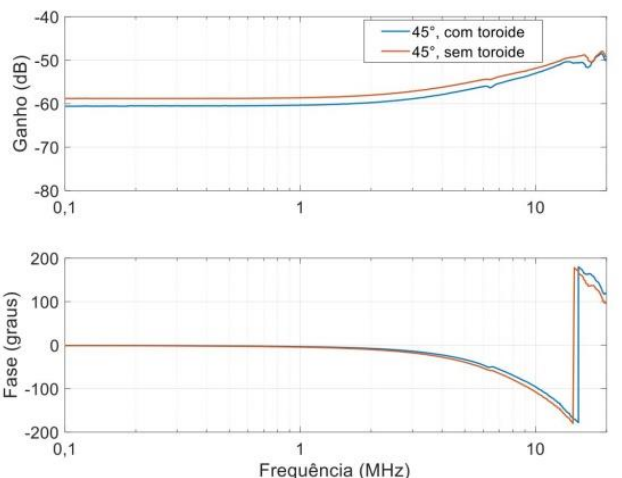

Figura 6. Resposta da transferência de tensão do divisor de tensão na posição de $45^{\circ}$.
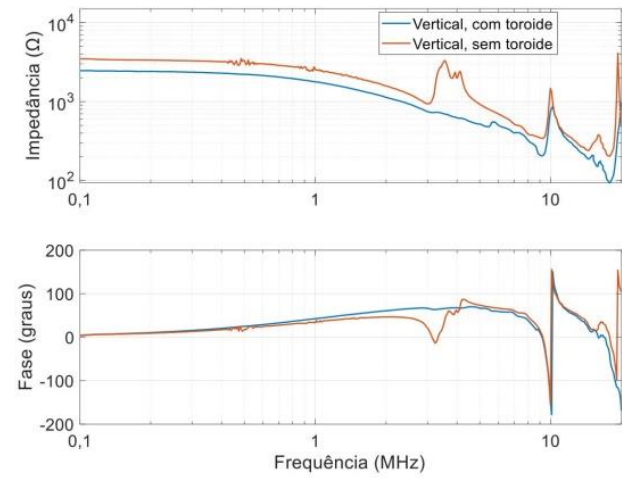

Figura 7. Resposta em frequência da impedância do divisor de tensão na posição vertical.

É importante observar também que uma simples alteração do sistema de medição, como a remoção do toroide, modifica a relação do divisor em resultados em baixa tensão e também a impedância resultante medida. 


\section{Metrologia}

\section{CONCLUSÕES}

O sistema de medição de impulsos para ensaios de perfuração em isoladores desenvolvido pelo Cepel foi completamente caracterizado em baixa tensão, obtendo um valor de incerteza de $0,01 \%$ para $\mathrm{k}=$ 2,26 e está de acordo com os requisitos técnicos normativos em termos de desempenho dinâmico, obtendo um parâmetro de tempo de resposta parcial $T_{\propto} \leq 3 \mathrm{~ns}$.

Como foi observado que os valores da resposta em frequência que mais se adequam aos medidos na caracterização ocorreram na configuração do divisor na posição vertical, os ensaios realizados neste divisor deverão ser executados somente nesta configuração. A variação da posição do divisor afeta a impedância do sistema e, consequentemente, seu fator de escala, modificando todas as suas características de projeto

A análise da resposta em frequência verificou também que o divisor de tensão responde bem e se mantém estável, com variação menor que $3 \mathrm{~dB}$, a frequências até $4,4 \mathrm{MHz}$, o que se mostra adequado em relação as componente de frequência presentes no ensaio de impulso de perfuração. Considerando que esses mesmos $3 \mathrm{db}$ resultam em um erro de aproximadamente $30 \%$ no fator de escala.

Nesse sentido, o novo sistema de medição desenvolvido pelo Cepel para ensaios de perfuração em isoladores, além de estar de acordo com a IEC 61211:2004, foi projetado e avaliado para fornecer o maior desempenho na realização dos ensaios em alta tensão, contribuindo assim e estando adequado para uma possivel rastreabilidade metrológica para sistemas de medição em ensaios de perfuração.

As próximas etapas para a avaliação do sistema de medição, que está em andamento, é a comparação em alta tensão contra o divisor e sistema de medição calibrado no instituto de nacional de metrologia da Finlândia e também a estimativa da incerteza de medição a partir destes resultados.

\section{AGRADECIMENTOS}

Os autores agradecem pelo apoio financeiro fornecido por CNPq, CAPES e Cepel.

\section{Referências}

[1] IEC 61211, Insulators of ceramic material or glass for overhead lines with a nominal voltage greater than $1000 \mathrm{~V}$ - Impulse puncture testing in air.

[2] Park, J.H. and Cones, H.N.: "Puncture Tests on Porcelain Distribution Insulators Using SteepFront Voltage Surges [includes discussion]." Power Apparatus and Systems, Part III Transactions of the American Institute of Electrical Engineers, vol. 72, nr. 2, Jan 1953

[3] Martti Aro (FINLAND) and Robert C. Hughes (UNITED KINGDOM) on behalf of Cigré Working Group 33.03, TF 33.03.01, "Puncture testing of ceramic and glass insulators", Electra 136, 1991.

[4] Martti Aro. "Feasibility of impulse voltage puncture test on insulators in air". Acta Polytechnica Scandinavica, Electrical Engineering Series No. 91, Thesis for the degree of Doctor of Technology, Espoo: Finnish Academy of Technology. 1998.

[5] IEC 60060-2. "High voltage test technique, Part 2: Measuring systems." Edition 3 (1994): 201009.

[6] IEC 61083-1: 2001, Instruments and software used for measurement in high-voltage impulse tests - Part 1: Requirements for instruments. 


\title{
Anexo 3 -Artigo Submetido à Measurement - Journal of the International Measurement Confederation (IMEKO)
}

\author{
Multi-resolution Wavelet Analysis for Noise Reduction in \\ Impulse Puncture Voltage Measurements \\ Ighor Souza dos Santos and Carlos R. Hall Barbosa \\ Postgraduate Program in Metrology, Pontifical Catholic University of Rio de Janeiro \\ Rua Marquês de São Vicente, 225 \\ Rio de Janeiro, RJ 22451-900, Brazil \\ Márcio Thelio F. da Silva and Orsino Borges Filho \\ Centro de Pesquisas de Energia Elétrica (CEPEL) \\ Avenida Olinda, 5800 \\ Nova Iguaçu, RJ 26053-121, Brazil
}

\section{ABSTRACT}

This work describes an approach for digital processing of voltage impulse signals in puncture tests of insulators on high voltage laboratories, using wavelet transform based multi-resolution analysis. Quantifying the amplitude of such impulses is not a trivial task because they have typical magnitudes of hundreds of kilovolts and rise times of $100 \mathrm{~ns}$ to $200 \mathrm{~ns}$. The processing is mainly necessary due to high frequency electromagnetic interferences, caused by the impulse generation system, which may electromagnetic interferences, caused by the impulse generation system, which may
strongly affect the measurement accuracy and, consequently, the test result. This manuscript presents qualitative and quantitative results for different types of wavelets studied, as well as the best performance obtained by the filter. Software for signal processing and analysis was also developed for this application. Results are also presented using the wavelet filter for a pioneering inter-laboratory comparison between high voltage measuring systems used in impulse puncture tests of insulators.

Index Terms - high-voltage techniques, insulator testing, impulse testing, digital filters, signal processing, wavelets.

\section{INTRODUCTION}

VOLTAGE impulses used in puncture tests of high voltage insulators are classified as Very Fast Transient (VFT) impulses. This type of test is standardized and described in IEC 61211:2004, "Insulators of ceramic material or glass for overhead lines with a nominal voltage greater than $1000 \mathrm{~V}$ Impulse puncture testing in air" [1]. Such test is recognized as one way to evaluate the integrity of the dielectric and it has been very usefult to assess, in laboratory, the quality of design, manufacture and materials used in glass or porcelain insulators for power transmission and distribution lines [2] However, depending on the characteristics of the punctur testing set up, it is common to have high frequency interferences superimposed on the acquired impulse signal. The reliability of the test results is dependent of the measurement uncertainty of the parameters of the voltage impulses, which have very steep wave fronts with rise times of $100 \mathrm{~ns}$ to $200 \mathrm{~ns}$ and peak values in the range of hundreds of kilovolts.

The voltage impulses used in insulation puncture tests are quantified by digitizing the waveforms, which can be distorted compared to the actual applied waveform, depending on the dynamic performance of the measuring system and on external factors, due to contributions from different sources of electromagnetic interference. Thus, a major challenge is to ensure an accurate and traceable measuring system, so that other high voltage test laboratories can obtain comparable results.

In this case, in order to improve the accuracy of the measuring system and satisfy the requirements of IEC 61211:2004, it is necessary to develop a filter capable of minimizing the effects of electromagnetic interference on the voltage impulse signals. This development consists on digital processing focusing on the location of the signal in time and on the dur fion of the interference. This is of great importance proce puncture tests (IPT) of insulators. Thus, the signal processing to be used must take into account the signal information in both domains: frequency and time

Some previous works have already investigated the removal of typical noises in high voltage lightning impulse tests, full and front chopped, using mult-resolution andysis based on he wavelet transform, which has demonstrated to be a powerful digital signal processing tool [3-5]

Considering that the impulses used in puncture tests of insulators are about 10 times faster than the conventional lightning impulses investigated in previous works, new studies and developments are necessary for this specific application. 
The next section discusses VFT waveforms, presenting experimental data and computational simulations. Next, there is a brief introduction to wavelets and a detailed description of the multi-resolution analysis method in sections 3 and 4 , respectively. Section 5 presents the application of the method to waveforms acquired in actual high voltage impulse puncture tests, including the selection of wavelets based on simulated signals and application in real cases. Finally, section 6 presents the conclusions of the manuscript.

\section{VERY FAST TRANSIENTS}

Very Fast Transient (VFT) voltages are normally unidirectional voltage impulses with rise times in the order of $100 \mathrm{~ns}$, with or without overlapping oscillations in the frequency range of $30 \mathrm{kHz}$ to $100 \mathrm{MHz}[6,7]$. Considering the waveform of the impulse applied in puncture test of insulators, described in section 2.1, it can be characterized as VFT

Although the insulation puncture test is standardized by IEC 61211:2004 [1], there are still no references in mo National Metrology Institutes (NMI) to provide traceability for its measuring systems. In addition, voltage dividers with high dynamic performance are not commercially available for this application and are generally developed by the high voltage metrology reference laboratories themselves, or even by the test laboratories. Therefore, it is necessary to employ specific measuring techniques in order to ensure the traceability of the measuring systems for puncture tests on insulators [8]

\section{EXPERIMENTAL WAVEFORM}

Figure 1 shows the typical impulse used in an actual puncture test for insulators in a high voltage laboratory. According to the present IEC standard, this impulse is characterized by its peak value, which is usually extremely corrupted by electromagnetic interferences that affect the measurement uncertainty.

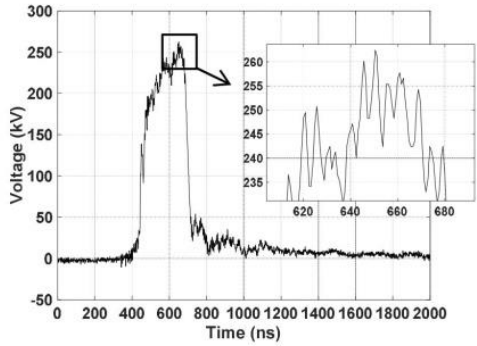

Figure 1. Typical impulse measured during insulator puncture test.

Figure 2 shows the characterization of this signal in the frequency domain, where it can be seen that there is no significant component above $20 \mathrm{MHz}$. Oscillations in the test circuit rarely have frequencies above $500 \mathrm{kHz}$, and so electromagnetic interference is often characterized in frequencies between $500 \mathrm{kHz}$ and $10 \mathrm{MHz}$. Digitizer noise in the high-voltage measurement configurations have frequencies clearly higher than $10 \mathrm{MHz}[9]$

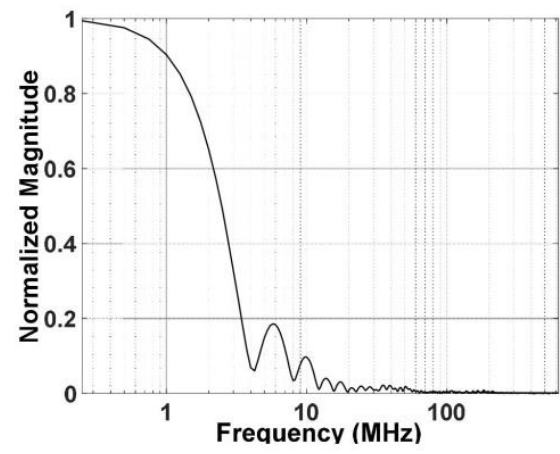

Figure 2. Frequency domain characterization of the impulse shown in

\subsection{SIMULATED WAVEFORM}

A unit exponential waveform with rise time of approximately $200 \mathrm{~ns}$ was used, for reference purpose, as a typical impulse applied in puncture tests, shown in Figure 3a. A real interference signal, measured according to the interference test described in IEC 60060-2.2010 [10], was ded to the orign sim in dede to the originl sime reference corrupted waveform, as shown in Figures $3 b$ to $3 d$
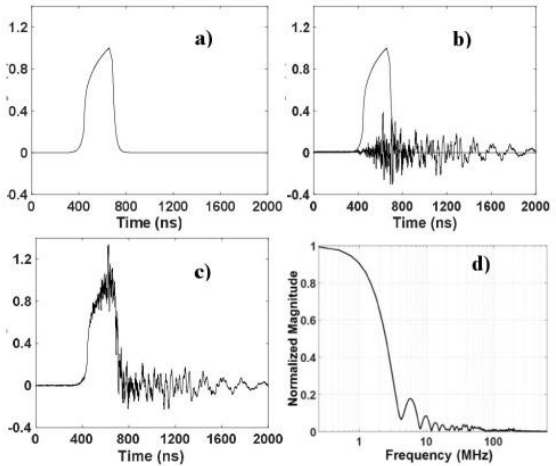
Figure 3. Simulated waveforms used as references; (a) original waveform,
(b) original waveform and real interference signal, (c) waveform corrupted by the interference and (d) corrupted waveform in frequency domain.

It can be seen, by comparing Figure $3 \mathrm{c}$ with Figure 1 and Figure $3 \mathrm{~d}$ with Figure 2, that the impulse puncture simulation obtained resembles qualitatively and quantitatively the
experimental signal, both in time and frequency domains. For experimental signal, both in time and frequency domains. For purpose of developing the filtering algorithms, the signal of
Figure $3 \mathrm{a}$ can then be considered as the ideal reference signal, starting from the signal corrupted by noise shown in Figure $3 \mathrm{c}$. 


\section{WAVELETS}

The wavelet transform is a powerful signal processing too used to analyze digital signals in frequency and time. It i considered the best method for analyzing non-stationary signals, which are a good part of the signals related to physical phenomena. In contrast with the Fourier transform, which relies on functions with infinite support (sinusoids or complex exponentials), the wavelet transform is based on finite-suppor functions $\psi(t)$, called mother wavelets, as the one shown in Figure 4 [11]

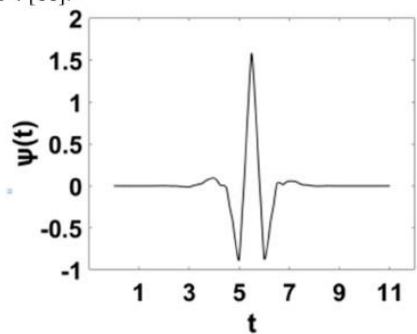

Figure 4. Example of mother wavelet $\psi(t)$, of the family known as "coiflet"

Similarly to the frequency scaling used in the Fourie transform, the wavelet transform employs a scaling of the mother wavelet, as well as time shifts.

The two main transformations in wavelet analysis are the continuous and discrete wavelet transforms. These transforms differ in how the wavelets are scaled and shifted. The continuous wavelet transform (CWT) of $x(t)$, which divides the signal into shifted and scaled versions of a mother wavelet $\psi(t)[11]$, is defined by

$$
C W T(a, b)=\frac{1}{\sqrt{|a|}} \int_{-\infty}^{+\infty} x(t) \Psi^{*}\left(\frac{t-b}{a}\right) d t,
$$

where $a$ and $b$ are the scale and translation parameters, respectively. The discrete wavelet transform is given by

$$
\operatorname{DWT}(j, k)=2^{-j / 2} \int_{-\infty}^{+\infty} x(t) \Psi^{*}\left(2^{-j} t-k\right) d t,
$$

where $j$ and $k$ are discrete versions of $a$ and $b$, respectively Finally, in the case of discrete sequences, as in the processing of digitalized signals, the transform is defined as $T W D(j, k)=2^{-j / 2} \sum_{n=0}^{N-1} x[n] \Psi^{*}\left(2^{-j} n-k\right)$.

With these two parameters $j$ and $k$, the two importan concepts of the wavelet transform can be analyzed. The scale parameter $j$ refers to the process of stretching or shrinking the signal in time, while the translation parameter $k$ refers to the displacement of the wavelet along the entire signal of interest. Thus, also similarly to the Fourier transform, an arbitrary signal $x(t)$ or $x[n]$ can be written as the combination of shifted and scaled base functions. However, unlike Fourier, the wavelet transform allows observing different aspects of the signal and its non-stationary behavior.

\section{MULTI-RESOLUTION ANALYSIS}

There is an efficient algorithm to execute the Discrete Wavelet Transform of discrete sequences called multiresolution analysis (MRA), introduced by Mallat [11]. The MRA is used in the transformation of signals from the time domain, digitized during an impulse test, to the wavelet transform domain. In practice, MRA is based on the filtering of the signal through low-pass and high-pass filters whose coefficients are directly related to the mother wavelet, providing representations of the signal in relation to the coefficients of wavelet functions and scale functions

Considering the wavelet transform, it is common to use the terms approximations and high scales, that is, the low frequency compoxe igh scalcs, that is, signal. The details are the lower scales, which represent the high-frequency components of the signal. The simplified filtering process is shown in Figure 5.

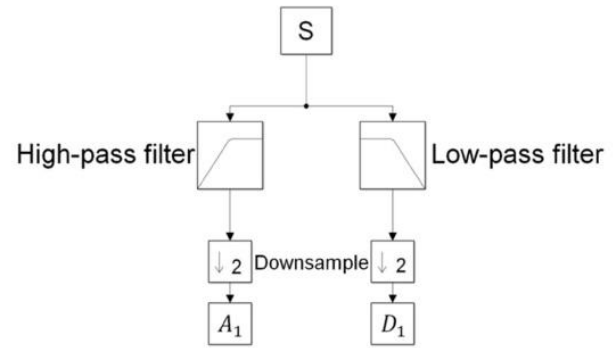

Figure 5. First level of the MRA decomposition based on QMF filters.

In this process the signal $\mathrm{S}$ is applied to two complementary parallel filters, low-pass and high-pass, called quadrature mirror filters (QMF). A downsample operator is used to decrease the number of samples. Without this operator, twice as many samples would exist compared with the initial data. If the signal $\mathrm{S}$ has a number of samples equal to 2000 , the approximation coefficients $\left(A_{1}\right)$ and the detail coefficients $\left(D_{1}\right)$ will have 1000 samples each, totaling the number of samples of the original signal. With this first decomposition, the high frequency information concentrates on the detail coefficients, typically including much of the noise to be removed, and the low frequency information is concentrated on the approximation coefficients.

By repeating the signal decomposition process, acting always on the subsequent approximation components, subbands are obtained. From the decomposition of the wavelet in sub-bands, the decomposition tree shown in Figure 6 is obtained, considering down to level 3 .

The level of decomposition determines the frequency bands that can be observed in each approximation and detail components. Figure 7 schematically shows the division of the components. Figure 7 schematically shows the division of the
frequency bands for the decomposition down to level $p=3$ shown in Figure 6 


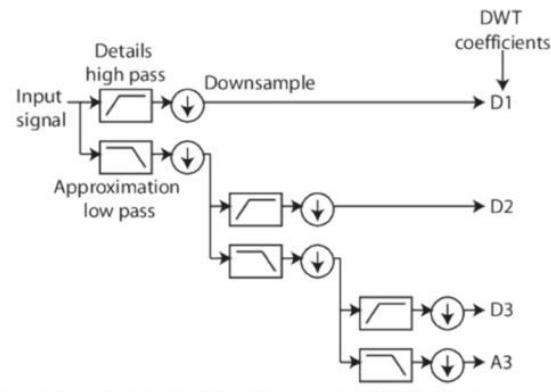

Figure 6. Multiple levels of MRA decomposition, down to level 3

The maximum frequency in the original signal, corresponding to the level 0 approximation shown in Figure 7 , is considered to be the Nyquist frequency, equal to half of the sampling frequency $f_{s}$ used in the scanning process. The decomposition by the Mallat pyramidal algorithm down to level $p$ generates 1 set of approximation coefficients $A_{p}$ and $p$ sets of detail coefficients, $D_{1}, D_{2} \ldots, D$

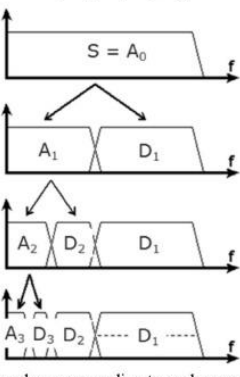

Figure 7. Frequency bands corresponding to each approximation and detail coefficient according to the level of decomposition.

Thus, the highest frequency that can be observed in the approximation coefficients $A_{p}$, for a given level of decomposition $p$ and sampling frequency $f_{s}$, is

$$
f_{\max }, A_{p}=\frac{f_{s}}{2^{p+1}} \text {. }
$$

There is no specific deterministic method to choose the optimum level of signal decomposition. In principle, all decompositions must be thoroughly tested, since the required level depends on what is to be achieved after decomposition However, in a noise removal application, as in the case of this manuscript, one can choose the level of decomposition based on the knowledge of the typical frequency spectrum of the signal under processing.

Considering the sampling frequency of $1.25 \mathrm{GHz}$ and the decomposition level $p=5$, the maximum frequency of the approximation component $A_{5}$ is $19.5 \mathrm{MHz}$, as indicated in Figure 8 together with the spectrum of an impulse puncture signal previously shown in Figure 2

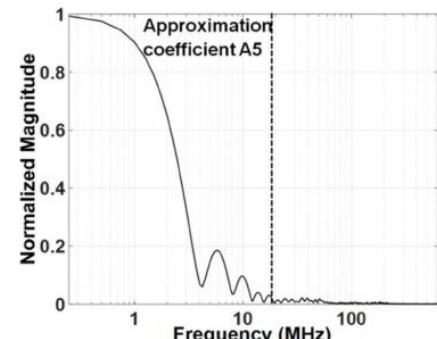

Figure 8. Puncture test frequency spectrum (solid line) and upper limit of the frequency band for approximation coefficients $A_{5}$ (dashed line).

This level of decomposition seems adequate for the type of signal and sampling frequency used, preserving the content of interest at the low frequencies of the signal.

The use of the wavelet transform for noise removal is based on the concept that the energy of a signal of interest often concentrates on few coefficients in the wavelet domain, while the noise energy spreads along all the coefficients in the wavelet domain. In this way, setting a minimum energy threshold will tend to maintain the higher energy coefficients that represent the signal of interest.

Thus, the process of noise removal by wavelets consists of the following steps:

- using Mallat's pyramidal algorithm, decompose the signal down to a certain level $p$

fully preserve the $A_{p}$ approximation components;

- define a noise threshold that will be used on the detail coefficients $D_{1}, D_{2} \ldots, D_{p}$; and

- eliminate (zero) the detail coefficients that are below the predefined threshold

This threshold determination step is important because improper selection can result in significant signal loss Although there is no single rule to determine the threshold level, it is quite common to use statistical estimators for this purpose, such as the methods presented in [12-14]

Using a less conservative threshold may preserve impulse Signals whose coefficients are very close to the noise gise chosen [15], using a fixed noise level estimator given by

$$
\lambda_{u}=\sigma \sqrt{2 \log (N)},
$$

where $\mathrm{N}$ is the sample size, 2500 in this case, and $\sigma$ is the standard deviation of the noise level that, if not known, can be estimated by the smallest scale $\left(D_{p}\right)$ wavelet coefficients. In the present work, $\sigma$ was estimated based on the noise shown in Figure $3 b$, as 0.0675 . The threshold value $\lambda_{u}$ obtained was 0.1759

After several simulations with different mother wavelets available in Matlab, it was verified that the optimal value of $p$ is 5. In fact, it can be noticed that a smaller level of decomposition $(2,3$ or even 4$)$ of the signal by the wavelet method is not enough to reduce the present noise level. For values above 5 , a large loss of signal characteristics is noted. 
To guide this empirical observation, there is a level selection method called EBWS - Energy Based Wavelet Select [16], being a selection based on the energy distribution between the coefficients of the composition subbands for each level $(j=1,2, \ldots, p)$. The equation for the percent energy in the approximation band is defined by

$$
E_{a, p}=\frac{\sum_{k}\left(a_{p, k}\right)^{2}}{\sum_{k}\left(a_{p, k}\right)^{2}+\sum_{j=1}^{p} \Sigma_{k}\left(d_{j, k}\right)^{2}} \times 100,
$$

where $a$ and $d$ are, respectively, the approximation and detail coefficients for each level $(j=1,2, \ldots, p)$.

For each level the signal is decomposed using each available wavelet function, and the level that has the approximation coefficient $a$ with the highest energy percentage will be the optimum level. The method is based on the fact that, when the detail coefficients $d$ are attenuated by the thresholding process, the filtered signal will lose power and will suffer abrupt distortions. Thus, by choosing the optimal level of decomposition and approximations with higher percentage of energy, the signal will lose less energy a will have les coefficients $d$ undergo the thresholding proces

Figure 9 presents the energy percent of the approximation coefficients for each level $(p=1 \ldots 12)$ for the 36 available wavelets that were evaluated

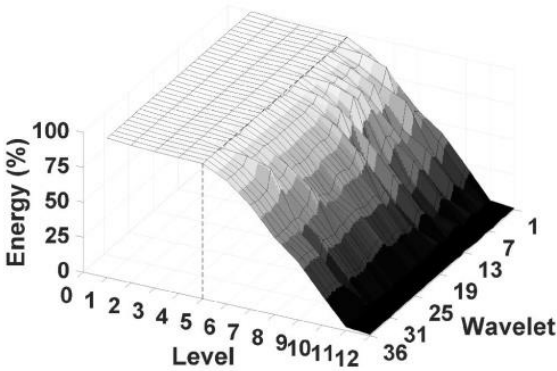

Figure 9. Energy percent of the approximation coefficients for each decomposition level and for each mother wavelet tested.

It can be seen in Figure 9 that, regardless of the mothe wavelet, the level $p=5$ is the one with the highest energy percentage in the approximation coefficients, which is $A_{5}$ in this case.

Finally, the approximation coefficients $A_{2}, A_{5}$ and $A_{7}$ are shown in Figure 10, using as an example the Daubechies 2 mother wavelet, and it is possible to see an increasing loss of signal characteristics for levels $p$ larger than 5 .

Once the decomposition level and the detail cancellation Once the decomposition level and the detail cancellation
threshold have been set, it remains to select the mother wavelet, which will be done based on the target of the impulse puncture signal processing, which is to obtain the real impulse waveform

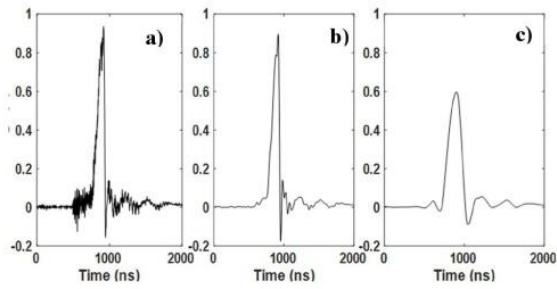

Figure 10. Approximation coefficients $A_{1}, A_{2}$ and $A_{3}$ using Daubechie

\section{RESULTS}

5.1 SELECTION OF THE MOTHER WAVELET

As described in Section 1, the impulse parameter to be measured during a puncture test of insulators is its peak value. Thus, the choice of the mother wavelet was made based on the analysis of the error in determining this value

The amplitude error, as a criterion proposed in [17-19], provides a measure of the percentage difference between the peak value $V_{1}$ of the ideal simulated reference waveform (Figure $3 \mathrm{a}$ ) and the peak value $V_{2}$ of the waveform resulting from the wavelet filtering process of the noise corrupted signal (Figure 3c), i.e.,

$$
A E=\left|\frac{V_{1}-V_{2}}{V_{1}}\right| \times 100 \%
$$

Considering the ideal and corrupted waveforms without filtering, an amplitude error of $34 \%$ is obtained. The values of the amplitude errors after filtering, for all 36 tested wavelets, are shown in Figure 11

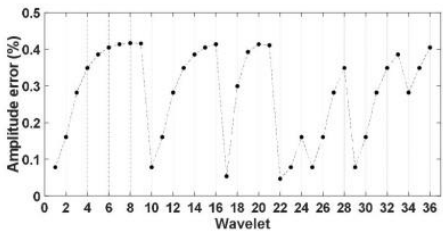

Figure 11. Amplitude error between the peak values of the ideal simulated waveform and the filtered waveform for each mother wavelet tested.

Based on Figure 11, wavelet 22, of the family Biorthogonal 1.1 , presented the lowest amplitude error of $0.05 \%$. The qualitative result of the filtering is presented in Figure 12.

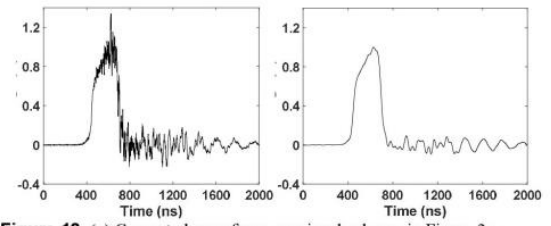

Figure 12. (a) Corrupted waveform. previously shown in Figure 3 a Figure 12. (a) Corrupted waveform, previously shown in Fig
(b) filtered waveform using biorthogonal 1.1 mother wavelet. 
Figure 13 shows the noise that was added to the ideal simulated signal and the noise that was removed by the filter, obtained by subtracting the filtered signal (Figure 12b) from the noise-corrupted signal (Figure 12a). It can be noticed a large similarity between these noises. The residual noise shown in Figure $13 \mathrm{c}$ is mainly a low frequency signal that has no influence in the peak region of the waveform.

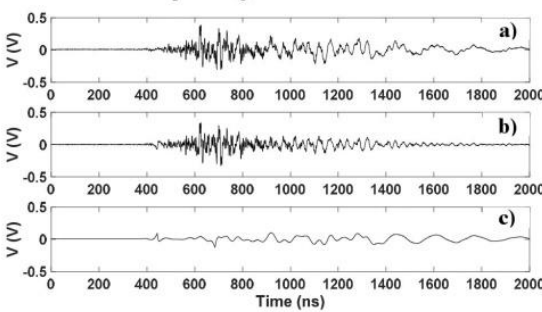

Figure 13. (a) Interference added to the ideal signal. (b) Noise removed by the wavelet filtering. (c) Difference between signals (a) and (b).

The time and frequency domain comparison between the filtered and the reference impulses are shown in Figure 14.
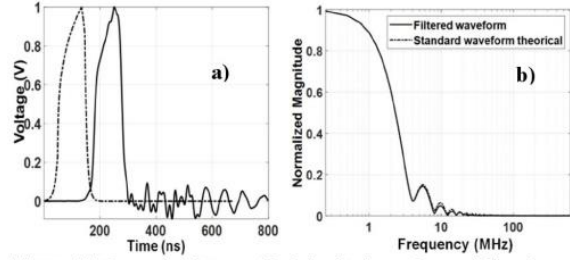

Figure 14. Comparison between ideal simulated waveform and filtere waveform in the time domain (a) and in the frequency domain (b).

5.2 APPLICATION IN REAL PUNCTURE TESTING

In order to make practical the use of the filter in laboratory measurements, specific software called RAPIT was develope in LabVIEW, based on the concepts of the wavelet filter previously described. The software developed for acquiring and conditioning the signal is intended to guarantee a greater reliability in the measurement of the peak value of the impulse puncture and to minimize the effect of interferences commonly present in the signal to be measured in this type of test. A typical test result displayed by the developed software is shown in Figure 15

The software was developed for acquiring, processing and analyzing impulse puncture signals, allowing to determine the following parameters: peak value of the raw signal, calculated as the difference between the base level and the peak level; peak value and rise time of the filtered signal, being rise time the time elapsed between $10 \%$ and $90 \%$ of the peak value

The effectiveness of the developed software RAPIT was also practically evaluated by comparing CEPEL's Impulse Puncture Test Measuring system (IPTMS) with one considered as reference, measured by the Technical Research Center of Finland (VTT- MIKES) [20]

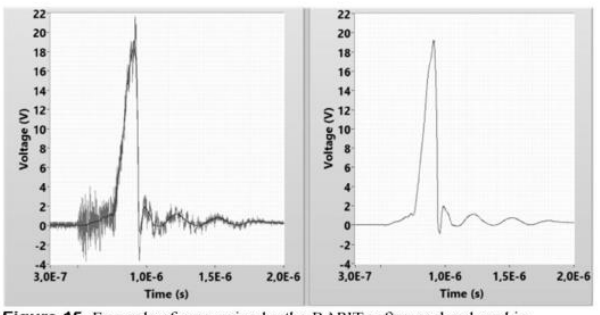

Figure 15. Example of processing by the RAPIT software developed in LabVIEW.

CEPEL's IPTMS is basically composed of a resistive voltage divider with low resistance and very low inductance; a transmission system comprising a short coaxial, double shielded cable with $50 \Omega$ matching impedance; a resistive attenuator and an 8-bit digital oscilloscope with $1.25 \mathrm{GHz}$ acquisition frequency in conjunction with the RAPIT software, as schematically shown in Figure 16

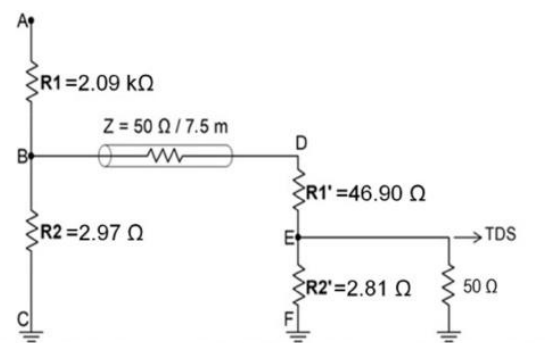

Figure 16. Basic circuit of the IPTMS including resistive voltage divider,

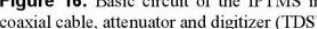

This comparison work was performed in VTT-MIKES laboratory site. An example of insulator impulse puncture waveform obtained by CEPEL IPTMS in the comparison work, before and after filtering high frequency interferences, is shown in Figure 17.
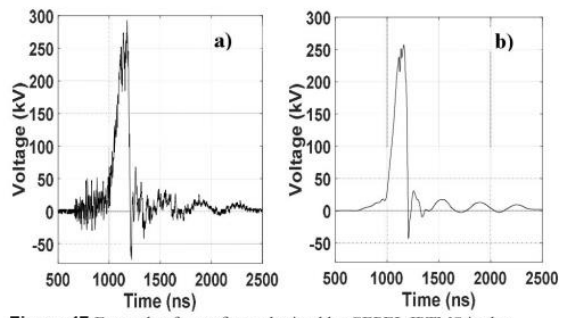

Figure 17. Example of wa form obtained by CEPEL IPTMS in the comparison work (a) before and (b) after filtering high frequency interferences. 
Tables 1 and 2 present the results for peak value measuremts obtained in the comparison, which is the parameter of interest in insulator impulse punctrure tests, considering 10 impulses in each polarity. Table 1 shows the original results without the wavelet filtering and Table 2 shows the effects of the noise removal by the wavelet filter. By comparing Table 2 with Table 1 , it can be noticed a significant reduction in the average diference between the two IPTMS, from $13 \%$ to $-0.4 \%$, as well as a reduction on the standard deviation of the diferences, from $3 \%$ to $2 \%$.

Table 1. Results of the IPT interlaboratory comparison between VTT MIKES and CEPEL prior to the wavelet filtering [20].

\begin{tabular}{ccccc}
\hline \hline $\begin{array}{c}\text { Reference } \\
\text { VTT } \\
(\mathrm{kV})\end{array}$ & $\begin{array}{c}\text { CEPEL } \\
(\mathrm{kV})\end{array}$ & Difference & Average & $\begin{array}{c}\text { Standard } \\
\text { Deviation }\end{array}$ \\
\hline 260.936 & 291.437 & $11.7 \%$ & & \\
252.665 & 292.786 & $15.9 \%$ & & \\
262.415 & 298.183 & $13.6 \%$ & & \\
259.069 & 292.786 & $13.0 \%$ & & \\
257.435 & 307.627 & $19.5 \%$ & $13 \%$ & $3.0 \%$ \\
256.983 & 291.437 & $13.4 \%$ & & \\
259.445 & 279.293 & $7.7 \%$ & & \\
264.369 & 299.532 & $13.3 \%$ & & \\
266.051 & 302.230 & $13.6 \%$ & & \\
263.471 & 292.786 & $11.1 \%$ & \\
\hline
\end{tabular}

Table 2. Results of the IPT interlaboratory comparison betwee VTT MIKES and CEPEL after the wavelet filtering [20

\begin{tabular}{ccccc}
\hline \hline $\begin{array}{c}\text { Reference } \\
\text { VTT } \\
(\mathrm{kV})\end{array}$ & $\begin{array}{c}\text { Voltage } \\
(\mathrm{kV})\end{array}$ & Difference & Average & $\begin{array}{c}\text { Standard } \\
\text { Deviation }\end{array}$ \\
\hline 260.936 & 270.253 & $3.6 \%$ & & \\
252.665 & 256.626 & $1.6 \%$ & & \\
262.415 & 257.436 & $-1.9 \%$ & & \\
259.069 & 256.356 & $-1.0 \%$ & $-0.4 \%$ & $2.0 \%$ \\
257.435 & 263.912 & $2.5 \%$ & \\
256.983 & 254.197 & $-1.1 \%$ & & \\
259.445 & 256.221 & $-1.2 \%$ & & \\
264.369 & 260.134 & $-1.6 \%$ & & \\
266.051 & 260.269 & $-2.2 \%$ & & \\
263.471 & 257.031 & $-2.4 \%$ & & \\
\hline
\end{tabular}

\section{CONCLUSIONS}

This manuscript presented a noise reduction algorithm based on wavelet multi-resolution analysis, particularly tuned for impulse puncture tests (IPT) signals. The most appropriated mother wavelet was selected by evaluating 36 different types of them, using a simulated IPT signal characterized as reference. The Biorthogonal 1.1 mother wavelet was then selected based on the criterion of the smallest amplitude error. Specific software was developed for acquiring, filtering an analyzing IPT signals. The use of the wavelet filter allowed to remove practically all high frequency interference from the signal, without distorting the actual waveforms.

The effectiveness of the developed filtering software wa also evaluated during a comparison work, under actual high voltage test conditions, between IPTMS of two different laboratories. The original average difference between the compared IPT measuring systems was $13 \%$. With the noise removal performed by the wavelet filter, this average diference was reduced to less than $0.5 \%$.

\section{ACKNOWLEDGMENT}

The authors acknowledge the financial support provided by the Brazilian funding agencies CNPq, CAPES, FINEP and FAPERJ, as well as the Centre for Metrology MIKES from VTT Technical Research Centre of Finland for having provided and allowed the use of the HV data presented in tables 1 and 2 of this manuscript.

\section{REFERENCES}

[1] Insulators of ceramic material or glass for overhead lines with a nominal voltage greater than $1000 \mathrm{~V}$ - Impulse puncture testing in air, IEC Standard 61211:2004

[2] Avoiding \& Testing for Dielectric Puncture, Available: http://www.inmr.com/avoiding-testing-dielectric-puncture, Feb. 2019.

3] E. Onal, Ö. Kalenderli and S. Seker, "Multi-resolution wavelet analysis for chopped impulse voltage measurements and feature extraction, IEEE Trans. Dielectr. Electr. Insul., vol. 15, no. 3, pp. 893.900 , Jun

4] Ö. Altay, and Ö. Kalenderli, "Interference removal on impulse voltage \& current measurements with wavelet analysis," in Proc. IFEE
High Voltage Eng and Appl. (ICHVE), 2012, pp. 447-450.

5] A. Font, A. K. Atalay, and O O. Kalenderli, "Analyzing and denoising of impulse voltage waveforms using multi-resolution wavelet analysis (MRA)," in Proc. IEEE Int. Conf. High Voltage Eng. and Appl. (ICHVE), 2014, pp. 1-4

[6] D. S. Pinches, and M. A. Al-Tai, "Very fast transient overvoltages generated by gas insulated substations," in Proc. $43^{\text {td }}$ IEEE Universities Power Engineering Conference (UPEC), 2008, pp. 1-s

, inciples and rules, IEC

measurement techniques for very fast transients, Available orguserfiles files/News/2018/TOR WG Dl 60 Trac eable measurement techniques for very fast transients.pdf

[9] V. R. Oliveria, and G. C. Miranda, "Application of digital filter to lightning impulse parameters evaluation," in Proc. $10^{4}$ International Symposium on High Voltage Engineering (ISH), 1997, pp. 431-434. 10] High Voltage Test Techniques, Part 2: Measuring Systems, IEC Standard 60060-2:2010

[11] S. Mallat, A Wavelet Tour of Signal Processing, Academic Press, 1999. D.L. Donoho, and J. M. Johnstone, Adapting to unknown smoothnes via wavelet shrinkage," Journal of
vol 90 , no 432 , pp. 1200-1224, 1995 .

[13] S. G. Chang, B. Yu, and M. Vetterli, "Adaptive wavelet thresholding for image denoising and compression," IEEE Transactions on Image Processing, vol. 9, no. 9, pp. 1532-1546, Sept. 2000

[14] M. K. Mihcak, I. Kozintsev, K. Ramchandran, and P. Moulin, "Lowcomplexity image denoising based on statistical modeling of wavelet coefficients," IEEE Signal Processing Letters, vol. 6, no. 12, pp. 300303, Dec. 1999

[15] D. L. Donoho, and J. M. Johnstone, "Ideal spatial adaptation by wavelet

16] J. Li, T. Jiang, S. Grzybowski, and C. Cheng, "Scale dependent wavelet selection for de-noising of partial discharge detection," IEEE Trans.

[17] S. H. Mortazavi, and S. M. Shahrtash, "Comparing denoising performance of DWT,WPT, SWT and DT-CWT for Partial Discharge signals," In Proc. $43^{\text {th }}$ International Universities Power Engineering

[18] L. Satish, and B. Nazneen, "Wavelet-based denoising of partial discharge signals buried in excessive noise and interference," IEEE Trans. Dielectr.

[19] X. Ma, C. Zhou, and I. J. Kemp, "Automated wavelet selection and thresholding for PD detection," IEEE Electrical Insulation Magazine,

J. Hälström, J. Havunen, W. Yan, Y. Li, M. T. F. Silva, M. V. B. Lopes,
O. Borges Filho, M. Laiho, "Comparison of Measuring Systems for Puncture Test According to IEC 61211", Submitted to "The 21st International Symposium on High Voltage Engineering, Budapest, Hungary, August 26-30, 2019 